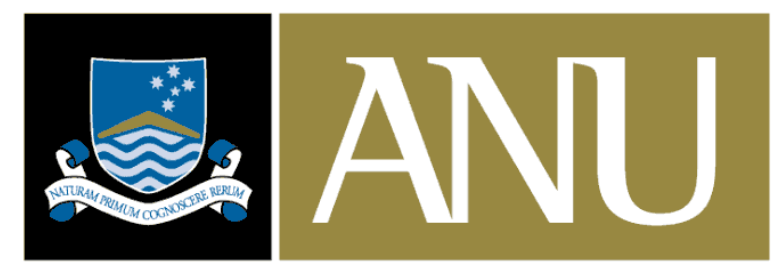

THE AUSTRALIAN NATIONAL UNIVERSITY

\title{
Trading of Takeover Target Shares
}

Jan Drienko

April 2017

A thesis submitted for the degree of Doctor of Philosophy in Finance at

The Australian National University

(C) Copyright by Jan Drienko 2017 


\section{DECLARATION}

I hereby certify that this thesis contains no material which has been accepted for the award of any other degree or diploma in any University, and, to the best of my knowledge and belief, contains no material published or written by another person, except where due reference is made.

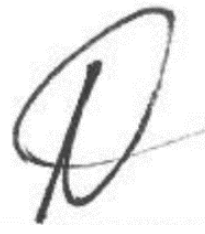

Jan Drienko

17 April 2017 


\section{ACKNOWLEDGEMENTS}

First and foremost, I would like to convey a special thanks to my primary supervisor, Associate Professor Steve Sault. Your patience and resolve allowed me to complete this piece of research to the best of my abilities. I will always be indebted to you for all your help and support.

Many thanks also go to Professor Tom Smith. Tom, this thesis would not have been possible without your support and advice. His ability to continually provide insightful advice has significantly enhanced the quality of this dissertation. Finally, I would like to thank Dr Borek Puza for all his help and advice.

I would also like to thank Dr Jenni Bettman, Dr Flavio Nardi and Dr Lingbing Feng their valuable support throughout the years.

I would also like to thank Professor Talis Putnins and Mr Henry Brun for their inspiration and encouragement.

Last but certainly not least, I would like to thank Dr Jozef Drienko, our parents and Dr Anna von Reibnitz for your patience and support.

Thank you everyone.

This thesis was edited according to Australian Editing Standards for thesis editing by Elite Editing. 
For Henry

We miss you. 


\section{ABSTRACT}

In this study, we confirm the validity of Cornelli and Li (2002) theoretical model that posits takeover traders affect the outcome of takeover activity. This study uses Australian and United States of America intraday microstructure data for the period 2008 to 2013. Analysing this trading data allows us to improve the identification of informed trading conducted by takeover traders immediately after a takeover is announced. We show that takeover traders play an active role in the takeover process, actively increasing the probability of successful takeover activity outcomes. We show that an increased presence of informed trading in target shares has a positive impact on the cumulative abnormal returns of those shares. We find that a $1 \%$ increase in informed trading immediately after a takeover is announced will increase the likelihood of takeover success by $7.42 \%$ in Australia and by $12.21 \%$ in United States. The same increase in informed trading leads to an increase in target CAR of $2.76 \%$ in Australia and $2.59 \%$ in United States. In successful takeovers, a $1 \%$ increase in informed trading is accompanied by an increase in CAR of $2.64 \%$ in United States and $1.21 \%$ in Australia. We employ United States data to conduct an out of sample test of our model and find that our model predicts the outcome of a takeover $75.89 \%$ accurately.

To confirm our main result, we conduct the same tests using three alternative measures of informed trading established in extant literature: PIN, AdjPIN and VPIN. We find that our main results are robust to the use of these alternative measures of informed trading. These results, however, suffer more from small samples estimation problems than our main results. 


\section{TABLE OF CONTENTS}

Declaration i

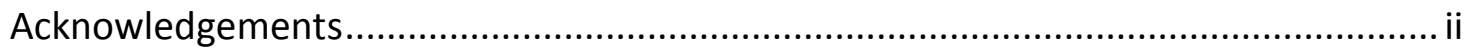

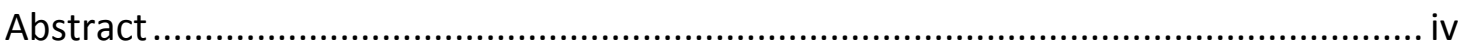

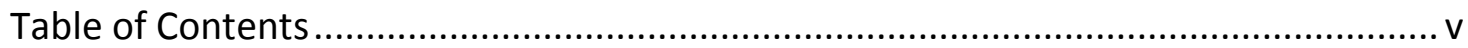

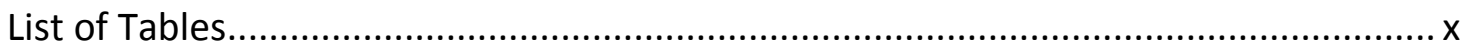

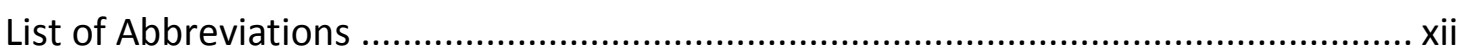

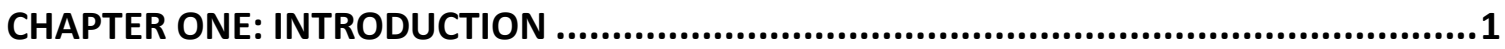

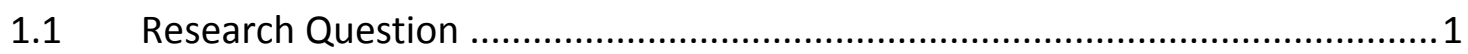

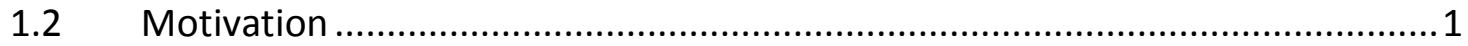

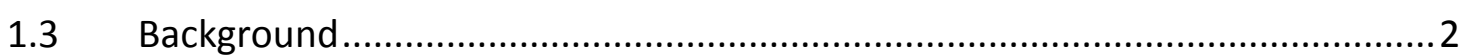

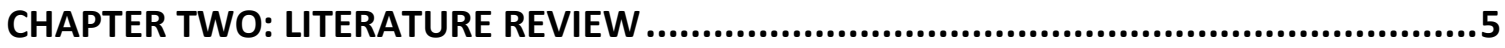

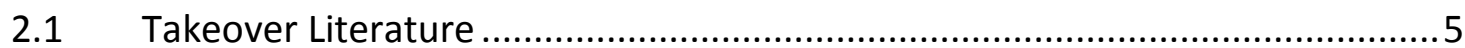

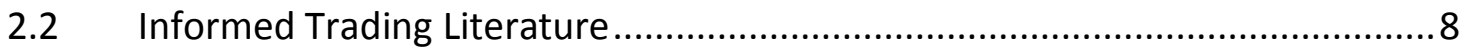

2.3 Market Microstructure Literature ..................................................................

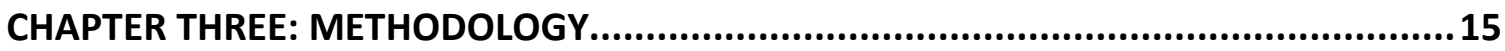

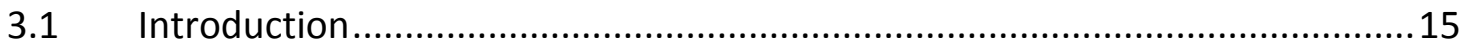

3.2 Theoretical Framework and Hypothesis Development ................................17

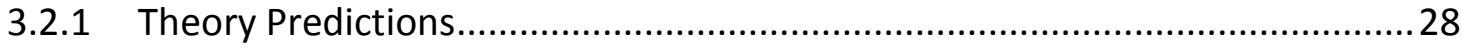

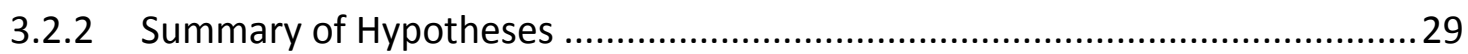

3.3 Probability of Informed Trading Model....................................................... 30

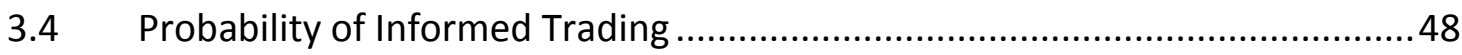

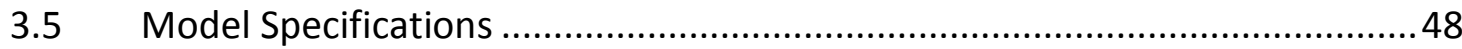

3.5.1 Impact of Probability of Informed Trading on Takeover Success ....................48

3.5.2 Impact of Probability of Informed Trading on Cumulative Abnormal Return..52 
3.5.3 Impact of Takeover Success on Probability of Informed Trading 54

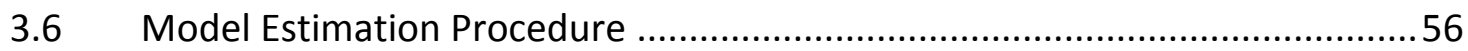

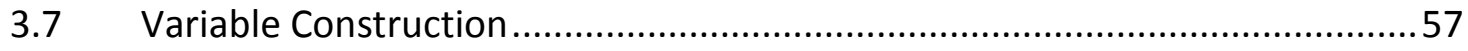

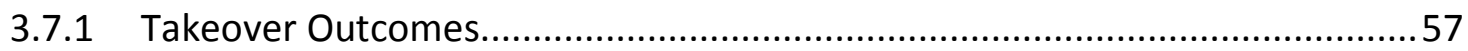

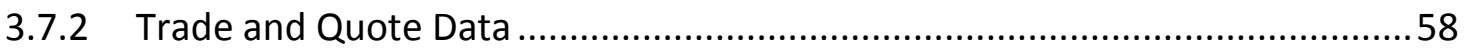

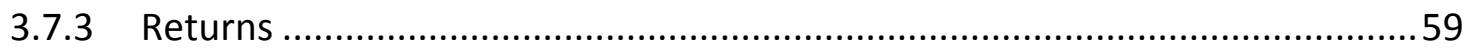

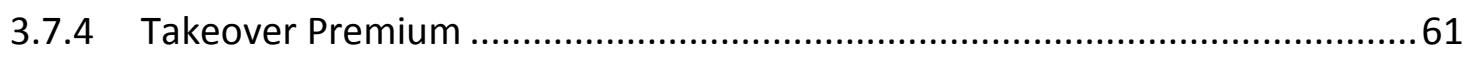

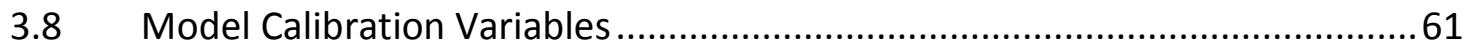

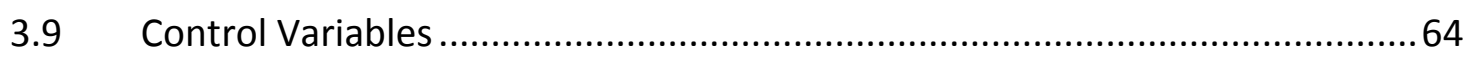

3.10 Estimation procedure using Generalised Method of Moments .....................73

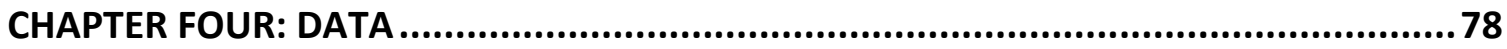

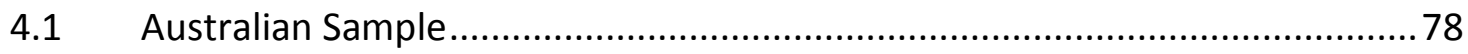

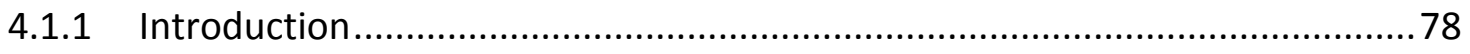

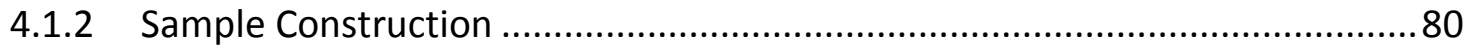

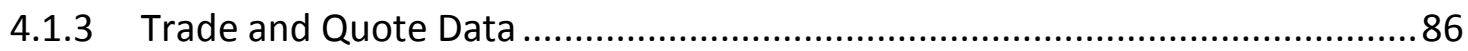

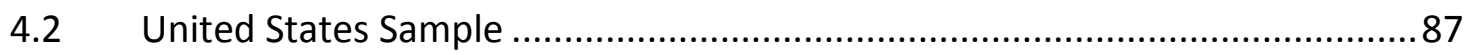

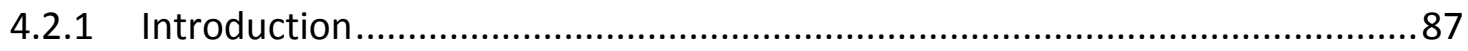

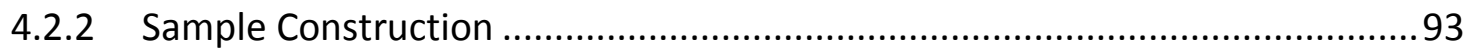

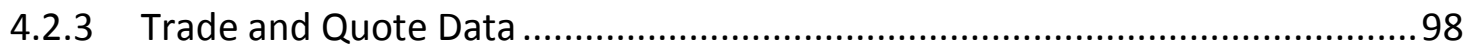

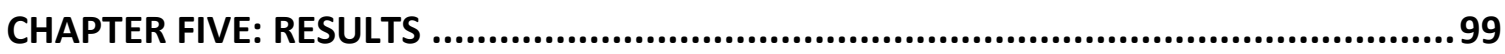

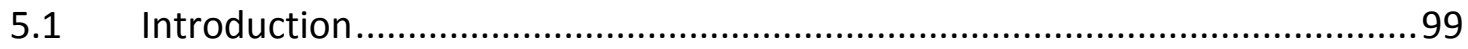

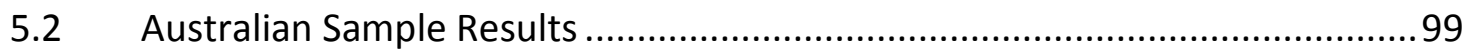

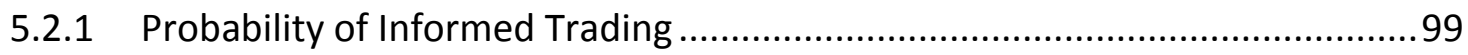

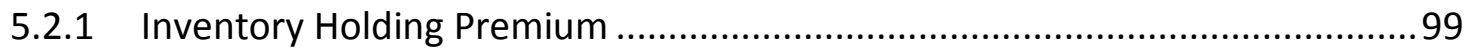

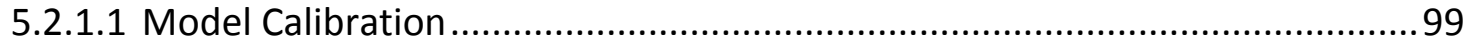


5.2.1.2 Model Estimation Results

5.2.2 Impact of Probability of Informed Trading on Takeover Success ..................105

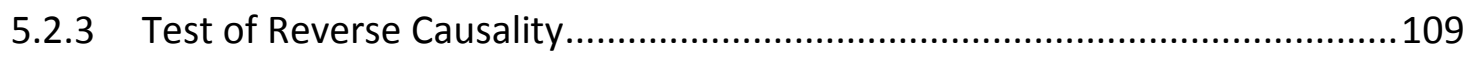

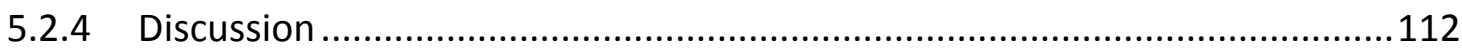

5.2.5 Impact of Probability of Informed Trading on Cummulative Abnormal Returns.

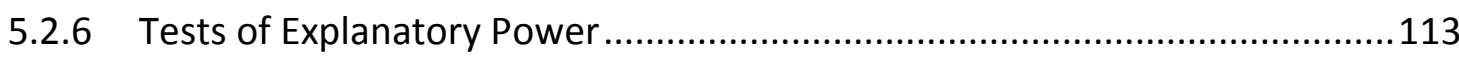

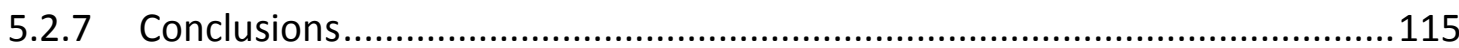

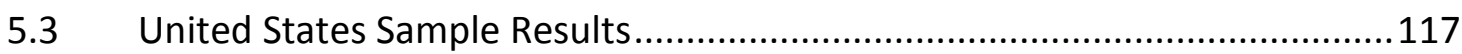

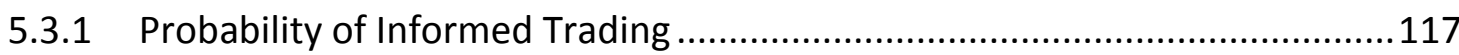

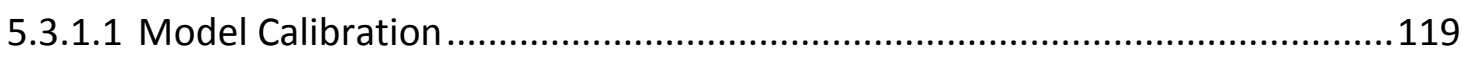

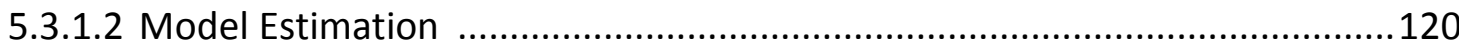

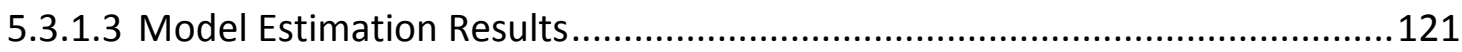

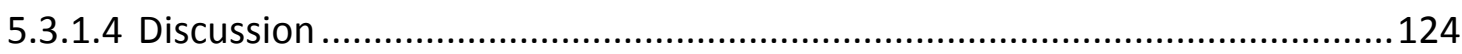

5.3.2 Impact of Probability of Informed Trading on Takeover Success ..................124

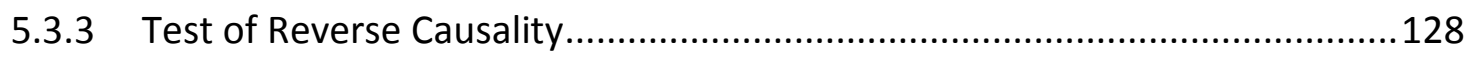

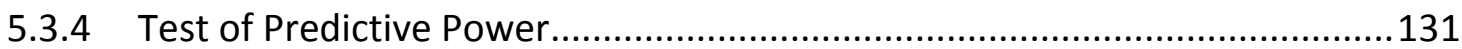

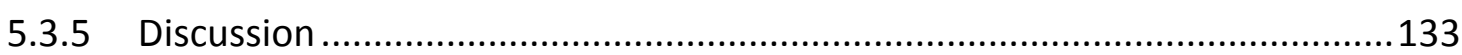

5.3.6 Impact of Probability of Informed Trading on Cumulative Abnormal

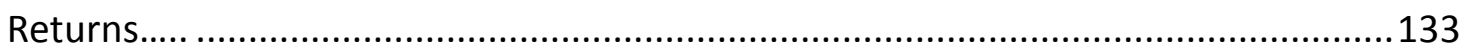

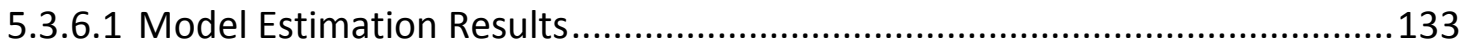

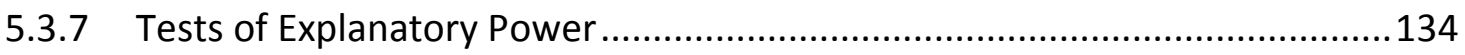

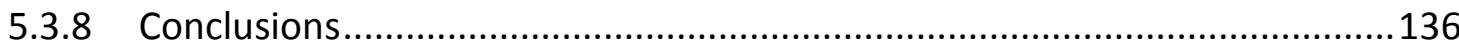

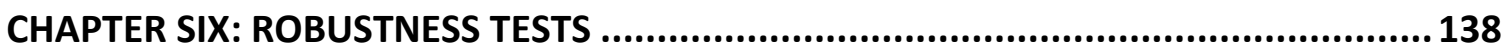

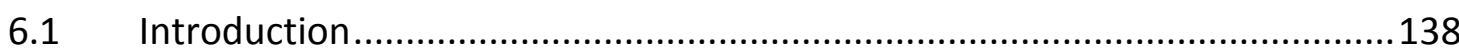


6.2 Probability of Informed Trading Models

6.2.1 The Probability of Informed Trading Model..............................................139

6.2.2 The Adjusted Probability of Informed Trading Model .................................141

6.2.3 The Volume Synchronised Probability of Informed Trading Model...............145

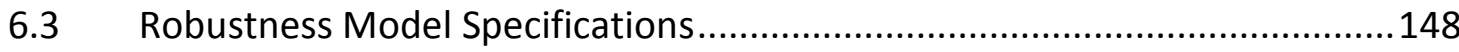

6.3.1 Impact of Probability of Informed Trading on Takeover Success .................148

6.3.2 Impact of Probability of Informed Trading on Cumulative Abnormal

Returns. 151

6.3.3 Impact of Takeover Success on Probability of Informed Trading ..................153

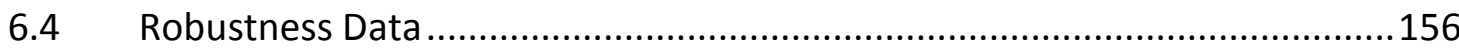

6.5 Robustness Models Estimation Procedure .................................................159

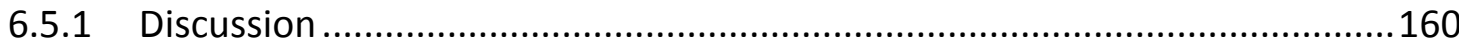

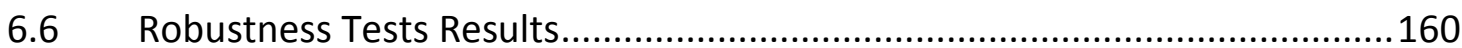

6.6.1 Australian Sample Robustness Tests Results ...........................................161

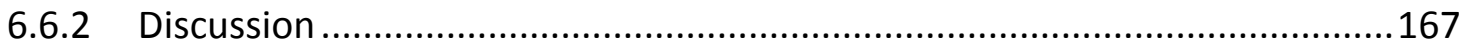

6.6.3 United States Sample Robustness Tests Results .......................................168

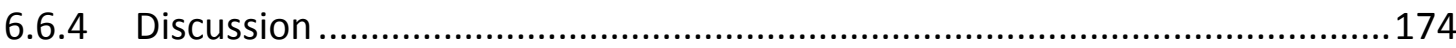

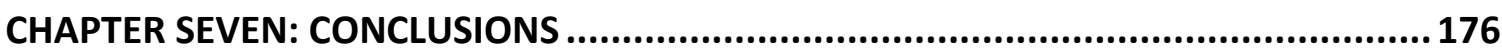

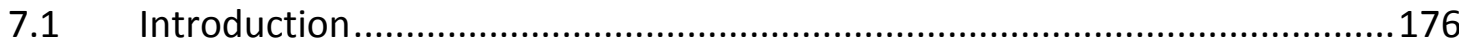

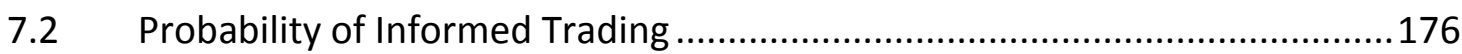

7.3 Impact of Informed Trading on Takeover Success .....................................177

7.4 Impact of Informed Trading on Cumulative Abnormal Returns ...................177

7.5 Impact of Informed Trading Using Alternative Measures...........................178

CHAPTER EIGHT: LIMITATIONS AND FUTURE RESEARCH DIRECTIONS ......................180

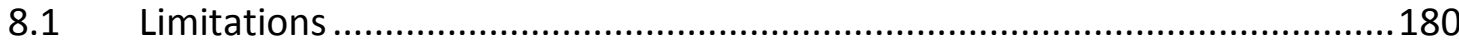




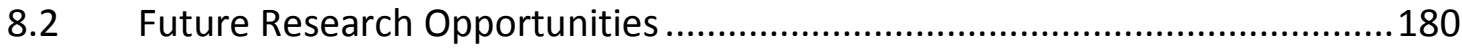

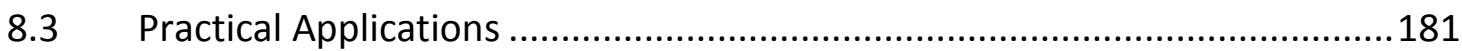

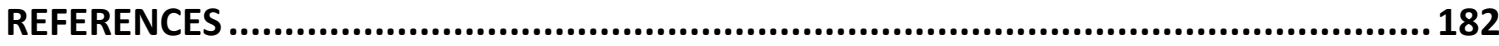

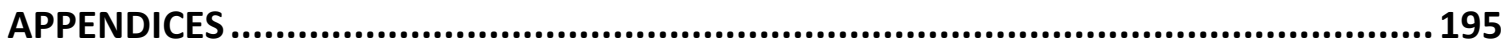




\section{LIST OF TABLES}

Table 4.1 - Australian Sample: Data Selection Australia ................................................. 84

Table 4.2 - Australian Sample: Data Summary Statistics ........................................... 85

Table 4.3 - United States Sample: Data Selection United States ...................................96

Table 4.4 - United States Sample: Data Summary Statistics ........................................97

Table 5.1 - Australian Sample: Inventory Holding Premium Estimates .........................101

Table 5.2 - Australian Sample: Probability of Informed Trading Estimates ...................104

Table 5.3 - Australian Sample: Impact of Probability of Informed Trading on Takeover

Success 107

Table 5.4 - Australian Sample: Impact of Takeover Success on Probability of Informed

Trading

Table 5.5 - Australian Sample: Impact of Probability of Informed Trading on Target Firm

Cumulative Abnormal Returns....

Table 5.6 - United States Sample: Inventory Holding Premium Estimates

Table 5.7 - United States Sample: Probability of Informed Trading Estimates 123

Table 5.8 - United States Sample: Impact of Probability of Informed Trading on

Takeover Success 126

Table 5.9 - United States Sample: Impact of Takeover Success on Probability of Informed Trading

Table 5.10 - United States Sample: Impact of Probability of Informed Trading on

Takeover Success Random Sub-sample

Table 5.11 - United States Sample: Impact of Probability of Informed Trading on Target

Firm Cumulative Abnormal Returns 135

Table 6.1 - Australian Sample: Data Selection Australia 157

Table 6.2 - United States Sample: Data Selection United States 158 
Table 6.3 - Australian Sample: Impact of Probability of Informed Trading on Takeover

Success

Table 6.4 - Australian Sample: Impact of Probability of Informed Trading on Target Firm Cumulative Abnormal Returns..... 165

Table 6.5 - Australian Sample: Impact of Takeover Success on Probability of Informed

Trading 166

Table 6.6 - United States Sample: Impact of Probability of Informed Trading on Takeover Success 169

Table 6.7 - United States Sample: Impact of Probability of Informed Trading on Target Firm Cumulative Abnormal Returns 172

Table 6.8 - United States Sample: Impact of Takeover Success on Probability of Informed Trading 173

Table A.1 - Australian Sample: Impact of Probability of Informed Trading on Takeover Success 195

Table A.2 - Australian Sample: Impact of Takeover Success on Probability of Informed Trading 196

Table A.3 - Australian Sample: Impact of Probability of Informed Trading on Target Firm Cumulative Abnormal Returns 197

Table A.4 - Australian Sample: Impact of Probability of Informed Trading on Takeover Success One Week Prior to Announcement 198

Table A.5 - Australian Sample: Impact of Probability of Informed Trading One Week prior to Announcement on Target Firm Cumulative Abnormal Returns 199

Table A.6 - Australian Sample: Impact of Takeover Success on Probability of Informed Trading One Week Prior to Announcement 200 


\section{LIST OF ABBREVIATIONS}

\begin{tabular}{|c|c|}
\hline AdjPIN & Adjusted PIN \\
\hline ASX & Australian Securities Exchange \\
\hline CAR & Cumulative Abnormal Return \\
\hline CFIUS & Committee on Foreign Investment in the United States \\
\hline EMH & Efficient Market Hypothesis \\
\hline FIRB & Foreign Investment Review Board \\
\hline GMM & Generalised Methods of Moments \\
\hline NASDAQ & National Association of Securities Dealers Automated Quotations \\
\hline NYSE & New York Stock Exchange \\
\hline$P I$ & Probability of Informed Trading using Bollen, Smith and Whaley (2004) \\
\hline PIN & Probability of Informed Trading \\
\hline SDC & Security Data Corporation \\
\hline SEC & Securities and Exchange Commission \\
\hline SIC & Standard Industry Classification \\
\hline SIRCA & Securities Industry Research Centre of Asia-Pacific \\
\hline US & United States of America \\
\hline$V P I N$ & Volume Synchronised Probability of Informed Trading \\
\hline
\end{tabular}




\section{CHAPTER ONE: INTRODUCTION}

\subsection{Research Question}

We empirically investigate the Cornelli and Li (2002) proposition that informed traders trade shares of the target firm after the takeover is announced. More specifically, we investigate the impact of takeover traders on takeover success, where takeover traders buy shares to become large shareholders in the target firm directly influencing the outcome of the takeover by tendering their shares to the bidder. The incentives of takeover traders to participate in the process include the profit generated by participating in successful takeovers. In addition to the propositions of Cornelli and Li (2002) we also examine the impact of informed trading on takeover premiums and the returns to target shareholders as well.

\subsection{Motivation}

The announcement of a takeover represents a significant corporate event revealing previously unknown or private information to market participants. Further, takeover activities, unlike an ordinary corporate event that occurs at regular intervals (such as dividends and earnings announcements), are announced at random and in an exogenous fashion allowing a more in depth examination of market participants' reaction to new information releases. In order to more closely investigate the Cornelli and Li (2002) propositions regarding the impact that informed traders have on the takeover process, we test their impact on the success or failure of the takeover after announcement. This gap in the literature is due to the difficulty associated with reliably estimating the probability of informed trading due to computational power required when using 
intraday trade by trade microstructure data in order to obtain daily estimates. Further, we investigate the performance of the target firm shares after the announcement of a takeover to better understand the impact that takeover traders have on returns of target firms. We enrich the existing literature in trading of takeover shares by using trade by trade empirical data microstructure data and a robust methodology of estimation of informed trading to study Cornelli and Li (2002) propositions.

\subsection{Background}

The takeover literature is largely devoted to the study of the impact of takeover announcements on the abnormal returns of target shares. Jensen and Ruback (1983), Desai and Kim (1988) and Bruner (2002) report strong evidence that shareholders of target firms earn substantial excess returns after the takeover is announced. Jarrell and Poulsen (1989) report adjusted abnormal returns of $15.3 \%$ for United States targets and 9\% for bidders, while Walter (1984) reports returns of $27.5 \%$ for Canadian targets. For Australian targets, Bishop, Dodd and Officer (1987) find abnormal returns of $22.3 \%$, and Anderson, Heaney and Hayes (1994) report abnormal returns of $18 \%$. Such high abnormal returns create profit incentives for traders to participate in trading these shares. More specifically, empirical studies of Murray (1991) and Ascioglu, Mclnish and Wood (2002) consider the impacts on the trading volume of target shares after takeovers are announced. Both studies report increases in trading of target shares after the announcement, providing evidence of trader participation in these fundamental corporate events. Finally, Jennings (1994) employ changes in share prices, bid-ask spreads and order sizes around takeover announcement, using intraday data to investigate effects of takeover announcement on trading of target shares. The study reports widening bidask spreads, and increased trade sizes immediately after the announcement is made 
returning back to normal over the next few days providing anecdotal evidence that using microstructure data may be used to uncover the impact of takeover traders on takeovers.

A possible impact of takeover traders on the takeover outcome has been studied more directly in Larker and Lys (1987). The study argues that takeover traders possess superior information about the outcome of the takeover and therefore can better predict if a takeover will be successful. The authors test this assertion through examining the investments of takeover traders in targets of successful takeover activities. The study reports that takeover trader participation in the deal, by purchasing target shares, increases the success rate of takeovers over average success rate for the sample. The paper further finds that takeover traders generate an average return of $5.3 \%$ on their positions between the announcement and the completion dates when they trade on takeover events.

Cornelli and Li (2002), in their theoretical work, formalise the incentives that lead to takeover trader participation in trading target shares. The study establishes the theory that takeover traders have an active role to play in the takeover process. Cornelli and $\mathrm{Li}$ (2002) argue that active trading of shares during the takeover period directly influence the outcome of the takeover by the traders' acquisitions of block holdings of target shares which are then sold to the bidder on or before the completion day at the previously announced offer price. This is significantly different from Larker and Lys (1987) conclusion that takeover traders have the ability to more accurately predict takeover outcomes. Unlike the Larker and Lys (1987) model, the takeover traders in Cornelli and Li (2002) model, derive their information from the knowledge of their own positions and expected profits of their investment in target shares. Due to the fact that the offer price is known 
in advance, but the likelihood of takeover success is not, the takeover traders' ability to profit on their holdings dictates whether or not they will participate in the trading of takeover shares. Trading of takeover traders based on their own information allows their activity to be classified as informed trading and, as such, open to being detected by established measures of informed trading. The Cornelli and Li (2002) model predicts that the active trading of target shares by takeover traders not only increases the probability of takeover success but also leads to higher takeover share premiums.

The remainder of the study is organised as follows. In chapter two, we review the extant literature. In chapter three, we outline the methology for testing the theoretical model of Cornelli and Li (2002). In chapter four, we describe the data used in empirical testing. Chapter five contains a summary of our results and in chapter six confirms our results by presenting results of robustness tests. Chapter seven concludes and chapter eight outlines limitations and future research directions. 
CHAPTER TWO: LITERATURE REVIEW

\subsection{Takeover Literature}

The seminal work of Manne (1965) first identified the market for corporate control as the primary mechanism for aligning the motivations of companies, shareholders and managers. In this model, the managers are incentivised to maximise the value of the firm given available resources or face their removal with an acquisition by a competitor and replacement by a more efficient management team. Most importantly Manne (1965) offers a general insight as to the impact of acquisition on share prices. Prices of target shares increase after a takeover is announced due to the expected improvement of resource management by the new management team. Dodd and Ruback (1977) further this research by establishing the timeframe, around the takeover date, in which these effects on share prices should be studied. Jensen and Ruback (1983) provide a survey of literature confirming theoretical work of Manne (1965) that shareholders of target firms gain from acquisitions but were not able to clearly specify the sources of these gains. Further, the survey confirms that in the event of an unsuccessful takeover bid, the share price gains to targets reverse as soon as the market participants realise that the offer has failed. Following this review, empirical results have since been confirmed in Bishop, Dodd and Officer (1987), Bhagat, Brickley and Loewenstein (1987), Jarrell, Brickley and Netter (1988), Anderson and Heaney (1994) and more recently in Bruner (2002) and Campa and Hernando (2004). Betton, Eckbo, and Thorburn (2008) offer an updated review in the takeover literature also providing more details with regard to takeover traders. The summary of recent literature suggests that incentives for takeover traders to purchase target shares remain persistent also in current times. 
Jensen (1986) first focused on the role that takeover traders play during merger and acquisition activity, by identifying the specific services that they provide and therefore should be compensated for. First, takeover traders evaluate the offer made by the bidder. They also offer the counterparty for target shareholders who do not want to face the risk of uncertainty of the takeover outcome, and finally, they help in solving the free rider problem that small shareholders face by not being able to negotiate directly with the bidder on the price for their shares. Moeller, Schlingemann and Stulz (2005) suggest that the presence of large blockholders of shares who have an incentive to sell their shares to the bidder has a significant impact of the outcome of the takeover process. Cornelli and Li (2002) propose that takeover traders will assume a block holder role and facilitate the takeover transaction which further explains Brown and Raymond (1986) and Larcker and Lys (1987) empirical findings that a higher trading volume immediately after a takeover announcement has a positive impact on the probability of takeover success, due to the actions of takeover traders.

Cornelli and Li (2002) apply the Kyle (1985) model based on the Grossman and Stiglitz (1976) informed trading system in the context of corporate takeovers with postannouncement investors in the target firm (takeover traders) identified as informed traders and all other traders as uninformed. By proposing this in the context of takeovers, Cornelli and Li (2002) present a theoretical model that offers clear explanations of empirically observed reactions to takeover announcements as documented in literature surveys by Jensen and Ruback (1983), as well as Desai and Kim (1988). Both of these surveys report that the share prices and trading volumes of takeover target firms significantly increase immediately after a takeover is announced, relative to levels prior to the announcement. Mitchell, Pulvino and Stafford (2004) also document significant 
activity on the part of takeover traders by taking risk positions immediately after the announcement as a response to the anticipated result of the takeover outcome.

Cornelli and Li (2002) explain this outcome by deriving two separate equilibria under which informed traders either trade or do not trade shares under the takeover offer, based on their expectations of takeover success or failure. The incentive for takeover traders to trade shares under offer stems from the opportunity cost of not participating in a successful takeover. This motive is further enhanced during times of high takeover activity, when competition between takeover traders is reduced, leading to higher profits for each participant. Cornelli and Li (2002) further extend their model to ensure it is valid under generally observed market conditions. The authors consider the effects of an increased liquidity that allows takeover traders to derive higher profits even in the presence of lower offer premiums. Traders are able to do this by better concealing their trading strategies from uninformed liquidity traders similar to the participants in the Kyle (1985) model. Cornelli and Li (2002) propose several extensions of their base model, including short selling. This strategy enables takeover traders to derive further profits when they believe the takeover has no chance of succeeding, by selling shares at a higher share price immediately after the takeover is announced, and re-purchasing the target shares when they return to the original level after it becomes clear that the takeover has failed. Further extension allows takeover traders to act in groups to achieve the same outcome. Working as a group is more optimal than acting alone, as the takeover traders share the costs of information gathering and the benefits of knowledge sharing. In addition, they leverage the groups' financial power, which allows a faster resolution of takeover outcome uncertainty. Finally, Cornelli and Li (2002) propose that in the presence of legal disclosure requirements, such as reporting material shareholdings greater than 
5\% (according to the Section 13D of the Securities and Exchange Act in the US), takeover traders may not be able to conceal their trading effectively. In theory, this conjecture is reasonable; however, in practice a trader can wait up to ten days after acquiring material holdings of $5 \%$ or more of the target's shares. This time is more than sufficient to enter into their desired positions without being required to report their holdings to market participants. In Australia, this threshold is the same, at 5\% for all block holders, with a reporting requirement of two days after the acquisition threshold has been reached.

\subsection{Informed Trading Literature}

Roll (1988) proposes that firm-specific stock price movements are generally associated with identifiable information releases. The study postulates that private information plays an important role in explaining the stock-specific price movements that individual shares exhibit. In light of this theory, Morck, Yeung and Yu (2000), Durnev, Morck and Yeung (2004) and Chen, Lesmond and Wei (2007) employ firm-specific share return variation as a proxy for new information inclusion in stock price to investigate a variety of issues relating to the impact of private information on asset market prices, including price formation based on corporate earnings announcements and changes in company investment policies. Hasbrouck (1991) reports that the price effect of information on traded shares is dependent on the proportion of informed traders, the precision of private information that informed traders possess, and the probability of a private information signal, all contained within trading data. Kim and Verrecchia (1991) theoretical model proposes an incentive for gathering private information around the time of scheduled corporate announcements. In their model, private information gathering increases the information asymmetry among traders around such announcements. 
Further, Chae (2005) specifically investigates trading around scheduled and unscheduled corporate announcements. Chae finds that trading around unscheduled corporate announcements is consistent with theories of asymmetric information, by identifying that liquidity (uninformed) traders reduce their participation in trading during times when they expect higher adverse selection costs. Finally, Graham, Konski and Loewenstein (2006) focus on unexpected corporate events, reporting that information processing by traders is particularly affected by the unanticipated nature of merger and acquisition activity. Their paper concludes that unexpected corporate events, such as takeovers, are associated with asymmetric information and adverse selection costs decrease over a short period following the initial announcement.

Barclay and Warner (1993) test the occurrence of trading around takeover announcements. The authors generalise their findings by testing firms not associated with any takeover activity; they report that informed traders are more likely to submit medium-sized trade orders by observing the price impact of their trades. The study focuses on stealth trading of target shares prior to takeover announcement where traders have an incentive to trade specific sizes of share parcels prior to announcements in order to hide their trades more than after the takeover is announced. The incentive to hide trades more before the takeover announcement is of course to due to the potential revelation of the private information to market participants. This effect is studied from a volume perspective in Chakravaty (2001) by sorting trades into different volume categories and subsequently counting the number of trades in each category. Easley, Kiefer and O'Hara (1997) findings suggest that larger trade sizes have more information content. Sequential trading models in Easley, Kiefer, O'Hara and Paperman (1996) and Handa, Schwartz and Tiwari (2003) describe the trading process in detail, focusing on 
detecting the probability of informed trading and the impact of information trading on share prices. Easley, Hvidkjaer and O'Hara (2010) and Duarte and Young (2009) present two main methodologies to estimate the probability of informed trading.

A second stream of literature in the area (commencing with Bagehot [1971]), employs the bid-ask spread as a proxy measure for information asymmetry. This suggests that bidask spreads may reflect the adverse selection problem of the market maker with respect to other market participants. Mclnish and Wood (1992), Foster and Viswanathan (1990, 1993), Glosten (1987), Glosten and Harris (1988), Bollen, Smith and Whaley (2004) and Sidhu, Smith, Whaley and Willis (2008) focus on separating the components of bid-ask spreads. Alexander and Peterson (2007) attempt to link the two literature streams by extending idea of Chakravaty (2001) to sort trades based on volume but also include information content of trades contained in effective bid-ask spread and price impact. This idea is very similar to the approach in Bollen, Smith and Whaley (2004) where the authors estimate adverse selection components contained in spreads, which can also be used to evaluate the probability of informed trading.

Mitchell and Pulvino (2001) were first to propose a contingent claim framework to study the risk and return from trading takeover target shares. Their study suggests that purchasing the shares of a target firm after the takeover has been announced is analogous to a long position in the stock, and a free long position in a put-option on the target shares, with the exercise price equal to the announced offer price and the takeover offer expiration maturity date. Such synthetic options can be valued using Black and Scholes (1973) and Merton (1973) traditional option-pricing framework. Bollen, Smith and Whaley (2004) establish an empirical model that enables decomposition of the bidask spread, including the inventory holding premium, which may be estimated as a call- 
option on the target shares. This is equivalent to a portfolio target share and a put-option, as outlined in Mitchell and Pulvino (2001). They employ the put-call parity formula of Nelson (1904), provided that the present value of the exercise price is set to the target offer price. Arguably, this adjustment is reasonable if the trader has the amount equal to the present value of the exercise price readily available and has already internalised the opportunity costs (in terms of expected profits) of participating in such a strategy. With takeover trading, which is not riskless, this part of opportunity cost can be assumed to be the same for all traders. Even if it is included in the call-option side of the put-call parity formula, it becomes a sunk cost for all traders after they decide to participate in target share trading.

To investigate the Cornelli and Li (2002) propositions, we consider the probability of informed trading measure, as introduced by Bollen, Smith and Whaley (2004), by estimating the measure from bid-ask spread data directly. This model does not suffer from the shortcomings in estimating informed trading probabilities found in Easley, Kiefer, O’Hara and Paperman (1996) framework.

\subsection{Market Microstructure Literature}

The market microstructure literature offers a detailed theoretical and empirical analysis of market participants' trading behaviour by allowing private information about future firm performance to be incorporated into current share prices. Seminal trading theories have been formalised in the Kyle (1985) discrete time trading model, which allows each trader to use a different information set. By transacting with one another, traders reach asset equilibrium prices. At each point in time, the equilibrium only partially reflects traders' private information. Traders have an incentive to retain the private information 
in their information set for as long as possible, to maintain an advantage over less informed traders. The model allows a close empirical investigation of different trader classes, based on the Kreps and Wilson (1982) sequential auctions model. This model specifies three agents in the market: informed (fundamental) traders, uninformed (liquidity) traders and the market maker. These agents trade with each other; the market maker sets the prices at which trades occur, based on an efficiency condition. The uninformed traders in this model submit orders to the market maker for liquidity reasons, so their orders are independent of any past or future prices, or trading volumes. The informed traders are unable to predict the level of liquidity trading by the uninformed traders, or influence the price set by the market maker. However, informed traders do have knowledge about private information that neither the uninformed traders nor the market makers are aware. Kyle (1985) suggests that the private information possessed by informed traders is eventually revealed to the remaining market participants through those traders' behaviour. However, these informed traders need uninformed traders to provide the required liquidity for two reasons: first to provide the counterparty to their trades; and second to obscure their trading behaviour. Kyle (1985) and Admanti and Pfleiderer (1988) specify it is in the interest of informed traders to behave as much as possible like uninformed traders. Informed traders should spread their desired trading strategy evenly over the time they expect the information they possess to remain private. Further, informed traders have an incentive not to introduce any additional variation in their orders. Doing so would adjust their trades away from optimally efficient levels. This incentive drives the gradual, rather than immediate, inclusion of private information in market prices, thereby creating an enduring abnormal volume in trading. It is this strategy of gradually including private information that distinguishes informed traders from 
uninformed liquidity traders, and allows informed traders to be identified and studied separately from other market participants.

Glosten and Milgrom (1985) present a similar model to that of Kyle (1985), developing their model under continuous time assumptions. The authors focus on informed traders' behaviour under a slight generalisation resembling the empirical observations of bid and ask quotes set by a risk-neutral market maker. Glosten and Milgrom (1985) further extend the base model to include the existence of multiple market makers who remain riskneutral, displaying their bid and ask prices and order sizes publicly while remaining in competition with other market makers. Glosten and Milgrom (1985) show that other market participants will still reach equilibrium, where informed traders can follow a mixed strategy of trading only if the asset's liquidation value is known. The equilibrium derived by Glosten and Milgrom (1985) is equivalent as Kyle (1985) equilibrium as shown in Back and Baruch (2004). This result validates the discrete time in Kyle (1985) model. It shows that Kyle model is relevant to continuous time situations. It is also consistent with the empirically observed conditions of bid and ask prices and the trading volumes publicly reported by trading venues. Back and Baruch (2007) extend Kyle (1985) model by focusing on traders who mostly trade in significantly different trade volumes. The authors find that the equilibrium conditions require at least a partial pooling of large-volume traders with small-volume traders, as the market maker does not know if the same trader will place more orders under the same strategy in the future. This finding further validates the relevance of Kyle (1985) model to the more contemporary setting of dynamic trading equilibria observed under current market conditions. 
The proportion of informed traders is difficult to measure empirically. Kyle (1985) highlights a number of implications stemming from informed traders' behaviour that create this difficulty. Informed traders attempt to hide their trading from uninformed traders, making it inherently difficult to determine whether or not a trader is informed based on their trading behaviour. Thus, the proportion of informed trading of the total trading for each period is not observable directly and must be estimated from observable trade data such as quotes, prices and trade volumes. Studies in this area can be split into three areas: estimating the impact of private information on prices, considering information asymmetry and investigating insider trading.

We add to the current literature by empirically testing the theoretical model of Cornelli and Li (2002), the application of the Kyle (1985) and Glosten and Milgrom (1985) models to merger and acquisition literature. We employ microstructure trade level data by using the Bollen, Smith and Whaley (2004) bid-ask spread decomposition model to estimate the probability of informed trading that we then use it to test the Cornelli and Li (2002) theory predictions. 


\section{CHAPTER THREE: METHODOLOGY}

\subsection{Introduction}

Prior to takeover bid announcement, the bidder may approach the target firm shareholders in an attempt to purchase shares directly from the target's large shareholders and establish a position large enough to force a sale of the remaining shares. These types of successful takeovers are not included in our sample, as they are private transactions for which no trading dynamics can be observed. However, when the target shareholders do not accept the private offer and the bidder still wishes to attempt firm acquisition, a public takeover bid is announced. In this process, all current shareholders are approached collectively and publicly by the bidder with an offer to purchase their shares. Target shareholders then decide from several options. They may accept the current market price and sell their shares to the takeover traders at the current market price; they may hold out for a higher offer price; or they may wait until the end of the offer period to sell their shares directly to the bidder at the offer price. Each action carries specific risks. First, if the target shareholders can sell their shares to the takeover traders, this decision depends on the share market price. A price sufficiently close to the offer price may motivate target shareholders to sell their shares to the takeover trader and lock in a profit immediately, even though the takeover may not be successful. Unfortunately, this will mean that target shareholders forgo any benefits of possible future increases in the offer price during the takeover activity period, but they also do not face the risk of holding target shares in the event that the takeover is not successful. Second, if the takeover traders can amass a sufficient number of shares in the target, they can then tender these shares to the bidder as a block, which increases their (the takeover traders') bargaining power and potentially increase the final offer price. Takeover traders will begin and keep purchasing shares of the target firm from existing shareholders as 
long as a positive profit (after transaction costs) remains, and if a sufficient number of shares are available for purchase in the market. In this way, the takeover traders' collective block holding can force the takeover to succeed simply through selling target shares to the bidder. If the takeover traders do not acquire a sufficient amount of shares to force the takeover's success, they can still sell their positions to the bidder before the offer expires, or to the other market participants after the takeover is deemed a failure. The former action may still generate a small profit, while the latter may generate losses for the takeover traders, as market prices return to their pre-takeover announcement levels.

According to the Cornelli and Li (2002) model, if the takeover bid succeeds and the target is acquired, the takeover traders derive a profit: this is the difference between the purchase price and the offer price of the target shares. If the takeover fails, the target continues to operate independently, the share price returns to pre-bid levels, and the takeover trader position may result in a loss. In this situation, takeover traders are not engaging in arbitrage, or risk-free profits (in the strictest sense) as they face possible transaction risks. The risk of such an investment strategy may be reduced significantly by takeover traders entering into the right positions, depending on the method of takeover payment. For cash-only takeovers, the strategy involves a long position for the bidder, with cash paid to the holder of target shares at the time the takeover is completed. If successful, the profit for a cash-only takeover offer is simply derived from tendering target shares to the bidder and receiving the offer price. For a takeover paid for in shares, the strategy involves taking a long position in target shares and a short position in bidder shares. Once the takeover is completed, the long position in target shares is converted into a long position in bidder shares. This perfectly offsets the short position in the bidder 
shares. For share-only transactions, the profit is derived by tendering target shares and using the bidder shares received to cover the short position in bidder shares entered into previously. Finally, for the mixture of cash and stock takeover payment methods, the same strategies are employed proportionally. Thus, if the takeover traders anticipate that the takeover will be successful, a profit incentive exists for them. However, if the traders do not expect that the takeover will succeed, they will be very unlikely to participate in target share trading. Mitchell and Pulvino (2001) document the limits to profitability of trading on takeover announcements due to trading transactions costs and limitations on short positions in bidder shares. Further, trading in cash-only transactions is not a selffinancing strategy and requires outside capital to enter the target share long position. By extension, this also applies to mixed payment transactions, as at least part of the offer payment in these transactions is in cash.

The announcement of a takeover bid represents a significant corporate event for both takeover target and bidder. The announcement communicates a large amount of private information about the target firm to the market, as well as the bidder firm's valuation of the target. Further, the announcement also contains information on the bidder's strategic intentions, as revealed in its valuation.

\subsection{Theoretical Framework and Hypothesis Development}

Cornelli and Li (2002) show the solutions of their theoretical model by tracking back the symmetric equilibrium outcomes to the initial proportion of target shares that takeover traders acquire. More specifically, the authors solve this condition by first determining the optimal proportion of shares to be sold to the bidder for takeover success. Cornelli and Li (2002) identify the positions taken by the takeover traders, in terms of the 
proportion of target shares owned by them. This proportion is directly dependent on number of takeover traders who decide to purchase target firm shares, and their individual holdings in the target firm. To derive the proportion of shares that takeover traders sell to the bidder, Cornelli and Li (2002) assume rational expectations of takeover traders regarding the likelihood of takeover success, where takeover traders only take positions in target shares if they expect the takeover activity to be successful. Traders evaluate their expectations of takeover success probability as between zero and one; they purchase shares based on this expectation. If the observed acquisition of takeover traders is zero, the traders do not purchase any target shares, the probability of takeover success equals zero, and the offer fails. Conversely, if the observed traded proportion of target shares is positive, some takeover traders believe that the takeover may succeed. However, the successful outcome is not certain and depends on the number of traders who believe the takeover will succeed. If a sufficient number of takeover traders operate according to their belief that the takeover will succeed, they can force a successful takeover outcome. This solution provides for testing of this outcome in an empirical setting establishing the hypothesis:

$H_{1}$ : Takeover traders increase the likelihood of the successful outcome of takeover offer by buying shares and becoming large shareholders in the target firm.

More generally, in the Cornelli and Li (2002) theoretical model, with regard to of presence of block-holders prior to the takeover announcement has impact on the conditional likelihood of takeover success. It depends on the evaluation of the takeover traders and their subsequent decision to purchase or not purchase the shares of the target based on this condition. If block-holders already negotiated with the bidder to tender in their 
shares and this is sufficient to complete the offer there is no need for takeover traders to enter as the market price jumps immediately to the offer price because the probability of success is equal to one. If however, there exist block-holders that do wish to tender their shares and instead want to wait for a better offer (for example), the probability of success rests with the reactions of the takeover traders. If the traders believe they can, collectively, amass sufficient number of shares through their trading activities and by tendering these shares derive a net profit, they will enter into the market buy orders for the target shares. If any of these conditions are not met, however, they will not enter.

The Cornelli and Li (2002) model allows the above solutions to operate as mixed pooling equilibria, where larger shareholders have incentives to trade with smaller shareholders to increase their holdings over the takeover ownership threshold of $50 \%$ in the target firm. This ensures that the takeover is successful. If the overall trading volume is below $50 \%$ of target shares, a resulting equilibrium solution, where the takeover traders purchase no shares and the takeover fails. The takeover will also fail if the takeover traders observe that the overall supply of shares at prices at levels of positive amount of profit is below 50\%. Thus, according to Cornelli and Li (2002) model, the takeover has a possibility of succeeding only if sufficient shares are available to be purchased at prices that allow the takeover traders to derive positive profits while their overall holding reaches $50 \%$ of target shares. The decision to purchase shares for each takeover trader is discrete: either they purchase the maximum amount of shares they can or they do not engage in trading at all. Finally, the authors account for the role of a bidder premium in the takeover offer price in deriving the equilibrium solutions. The takeover premium, which is set by the bidder in excess of the current market price at the time of a takeover announcement, is also the key to determining takeover trader participation. This is because its size impacts the motivations of takeover trader participation directly by 
representing profitability in the risky strategy of takeover traders purchasing takeover shares.

Cornelli and Li (2002) specify their theoretical model using Grossman and Hart (1980) assumption that small diverse shareholders hold all shares of a firm. This assumption represents an extreme case of the complete absence of block holders, which-under the classical takeover theory described above-creates significant difficulties for the bidder to complete a takeover. This situation allows small shareholders to 'free ride' on information revealed in the takeover offer (more than when larger shareholders are present), as long as the probability of takeover success at announcement is less than one. To demonstrate this, Cornelli and Li (2002) set up a multi-period multi-agent system to solve the equilibrium of this type of system analytically. This model assumes that the bidder has no initial holdings in the target and allows the outcome to emerge over four trading periods among three agent groups. Agents are categorised into small shareholders, takeover traders or noise traders. Small shareholders are assumed as riskneutral agents in the model; the result is expected to be reinforced if these shareholders emerge as risk-averse. This category of agents believes that selling shares will not affect the trading price or the probability of takeover success in any way. The takeover traders are also assumed to be risk-neutral and rational in their trading decisions. The model assumes that $\mathrm{N}$ potential traders take positions in the target firm shares after the takeover is announced, with each trader $A_{i}$ facing a cost. This could be the cost of gathering information about the target, the opportunity cost of investing in target shares (as traders do not have unlimited financial resources and receive no interest on invested funds, as described in Shleifer and Vishny [1997]), or just the basic cost of trading into the desired position. If trader $A_{i}$ decides to enter trading of takeover trades, they take a long 
position of $\delta_{i}$ a proportion of the overall number of outstanding shares in the target firm. If traders acquire more than $\bar{\delta}$ of shares, they may incur a further cost of reporting their intentions to the regulator. This cost and information provision is examined closely by Collin-Dufresne and Fos (2014), but has a limited effect on the overall outcome of trading. All takeover traders determine to enter endogenously, dependent on their own assessment of takeover conditions, and form a set of takeover traders $n \subset N$. Each trader learns about the position of other traders after the trading period closes and then decides what proportion of shares $\gamma_{i}$ he or she will sell to the bidder. Noise traders represent a category of investors that continues to buy and sell target shares randomly after the takeover is announced, independently of market prices. They do not trade shares to sell to the bidder; rather, they do so for other reasons, including liquidity or diversification. The aggregate random trades are expressed as $\omega$ in the total trading volume equation:

$$
y=\omega+\sum_{i=1}^{n} \delta_{i}
$$

Where:

$y$ is the total trading volume

$\omega$ is the total trading by noise traders

$\delta_{i}$ is the position of each takeover trader $i$.

Cornelli and Li (2002) develop their model to cover the model four distinct periods after the takeover announcement takes place to study the takeover process in a theoretical setting. During the different periods, target shareholders decide to continue to hold or sell their shares to the takeover traders. The strategies of takeover traders depend on the incentives available to them in each period. At time $t=0$, bidder announces the offer set at price $P_{T}$ per share of the target. The market price of target shares at this time is $P_{0}$ and 
the offer price must be at least equal to it so that at least indifferent shareholders will sell their shares to the traders. However, the traders should provide a premium since they need to induce more target shareholders to sell their shares. In order to obtain a probability of success greater than zero $P_{T}$ must be set as:

$$
P_{0}+\Delta P \geq P_{T} \geq P_{0}
$$

Where:

$P_{0}$ is the current market price of target firm shares $P_{T}$ is the bidder offer price in the offer $\Delta P$ is the per share value improvement the bidder expects to obtain once the takeover is successful.

In the next period, at time $t=1$, takeover traders decide to purchase or not purchase shares of the target firm at the prevailing market price $P_{1}$. During the trading period, $t=$ 2 , takeover traders establish their positions in target shares $\delta_{i}$ by trading among noise traders as outlined in Kyle (1985). Finally, in the tendering period, $t=3$, traders decide what proportion of their position $\gamma$ they sell to the bidder at the predetermined offer price $P_{T}$. The proportion of overall shares purchased by the traders $\delta$ and the amount sold to the bidder $\gamma$ given $P_{T}$ dictates the takeover attempt outcome. In general, the bidder requires more than $50 \%$ of the total outstanding shares in the target firm for the takeover to be deemed successful. If the takeover is successful, all remaining shares are acquired at the offer price $P_{T}$. If the bidder does not secure this critical amount of shares, the takeover is unsuccessful and the shares are sold back to diverse shareholders at 
market prices. The outcome remains unchanged if takeover traders purchase their shares prior to the takeover announcement.

The solution, to the equilibrium suggests that takeover is a success if:

$$
\frac{1}{2} \leq \omega+n \bar{\delta} \leq 1
$$

Where:

$\omega$ is the proportion of traded volume traded by noise traders

$\bar{\delta}$ is the proportional position traded by each takeover trader

$n$ is the number of takeover traders that decide to trade.

Trading equilibria leading to takeover success are bounded on the lower side by the last equilibrium, under which $\frac{1}{2}=\omega+n \bar{\delta}$. Under this solution, some takeover traders only purchase their position $\bar{\delta}$ as long as the market price is:

$$
P_{t}<\left(P_{0}+\tau_{i} \Delta P\right)
$$

Where:

$P_{t}$ is the market price of target shares at time $t$

$P_{0}$ is the market price of target shares at takeover announcement

$\tau_{i}$ is the probability of takeover success proposed by each trader $i$.

Cornelli and Li (2002) first present a symmetric model of actions for each takeover trader and later relax this assumption by deriving a pooling equilibrium in which different takeover traders are allowed to act differently or together dependent on their individual assessment of the takeover outcome. In the symmetric model, with all traders acting in the same way, each purchases up to $\delta_{i}>\frac{1}{2}$ of target shares. This is optimal for all traders 
if they intend to tender the minimum amount of shares that achieves takeover success, $\frac{1}{2}$. Each trader receives $P_{T}$ on all his shares up to $\frac{1}{2}$ and receives $P_{0}+\Delta P$ for all other shares $\left(\delta_{i}>\frac{1}{2}\right)$. The expected profit is therefore:

$$
E\left(\pi_{i}\right)=\frac{1}{2} P_{T}+\left(\delta_{i}-\frac{1}{2}\right)\left(P_{0}+\Delta P\right)-\delta_{i} P_{1}
$$

Where:

$E\left(\pi_{i}\right)$ is the expected profit of each trader $i$

$P_{0}$ is the current market price of target firm shares

$P_{T}$ is the bidder offer price in the offer document

$\Delta P$ is the per share value improvement the bidder expects to obtain once the takeover is successful

$P_{1}$ is the prevailing market price of target shares during the traders' decision period $\delta_{i}$ is the position of each takeover trader $i$ in terms of shares of the target.

Next the takeover traders trade into their desired positions $\delta_{i}$ following the Kyle (1989) framework. The market maker observes the order flow and sets bid and ask prices based on the value of the shares conditional on the order flow. The model assumes that each trader either purchases $\delta_{i}$ shares or 0 shares and that the probability that the trader purchases $\delta_{i}$ shares is $q_{i}$. This can be observed in the order flow since if the trades decide to buy $\delta_{i}$ shares, with probability $q_{i}$, the market maker sets the price at $P_{0}+q_{i} \Delta P$ and the takeover succeeds. If the order flow is significantly larger, at $2 \delta_{i}$ for instance, each trader clearly purchased $\delta_{i}$ shares, the market maker sets a price of $P_{0}+\Delta P$ and the offer succeeds. If on the other hand, the order flow would remain at 0 shares, takeover traders do not buy any target shares, the market maker would reset the price of the target back to $P_{0}$ and the takeover attempt fails with a probability $\left(1-q_{i}\right)$. In this equilibrium each 
trader expects to pay $P_{1}=\frac{1}{2}\left(P_{0}+q_{i} \Delta P\right)+\frac{1}{2}\left(P_{0}+\Delta P\right)$ for shares of the target and so if the traders believe in takeover success their profits are derived as:

$$
\pi_{i}=\frac{1}{2}\left(P_{T}-P_{0}-\Delta P\right)+\frac{1}{2}\left(1-q_{i}\right) \delta_{i} \Delta P
$$

Where:

$\pi_{i}$ is the profit of each trader $i$

$P_{0}$ is the current market price of target firm shares

$P_{T}$ is the bidder offer price in the offer document

$\Delta P$ is the per share value improvement the bidder expects to obtain once the takeover is successful $q_{i}$ is the probability that trader $i$ purchased zero shares $\delta_{i}$ is the position of each takeover trader $i$ in terms of shares of the target.

The greater the risk of takeover offer failing, the larger must be the profit for takeover traders to motivate their participation by offering higher profits by increasing the bid premium. This prediction can be tested in empirical data in the following related hypotheses:

$\mathrm{H}_{2}$ : The takeover traders participate more in takeovers with higher offer premiums.

$H_{3}$ : The trading of takeover traders in successful takeovers increases target shares' abnormal returns.

The expected profit for the bidder once the firm decides to submit a bid can be derived as:

$$
E\left(\pi_{b}\right)=\frac{1}{2} q^{*}\left(P_{T}\right)\left(P_{0}+\Delta P-P_{T}\right)
$$




$$
q^{*}\left(P_{T}\right)=\frac{1}{2} \frac{\left(P_{T}-P_{0}-\Delta P\right)}{\delta_{i} \Delta P}+\frac{1}{2}
$$

Where:

$\pi_{b}$ is the profit of bidder

$q^{*}\left(P_{T}\right)$ is the probability of success when the takeover price is set at $P_{T}$

$P_{0}$ is the current market price of target firm shares

$P_{T}$ is the bidder offer price in the offer

$\Delta P$ is the bidder premium

$\delta_{i}$ is the position of each takeover trader $i$ in terms of target shares.

The optimal bid premium from the bidder in terms of price of target shares is therefore:

$$
\begin{gathered}
P_{T}^{*}=P_{0}+\left(1-\frac{1}{2} \delta\right) \Delta P \\
P_{T}^{*} \leq P_{0}+\Delta P
\end{gathered}
$$

$P_{T}^{*}$ is the optimal price of target shares

$P_{0}$ is the current market price of target firm shares

$\Delta P$ is the bidder premium

$\delta$ is the overall position held by the takeover traders.

Cornelli and Li (2002) theoretical model reveals a bound regarding the optimal price for target shares in equilibrium. This price is not observed in the market after an initial takeover announcement, but emerges nevertheless as an artefact of trading in target shares. The emergence of the equilibrium price and the speed with which an equilibrium 
is reached depends solely on the ability and willingness of takeover traders to buy target shares and later sell them to the bidder during the takeover process. The likelihood of entering into such positions depends on two factors. First, takeover traders require the bidder premium over the share price just before a takeover announcement $\Delta P$ to be large enough so they can purchase their positions from current shareholders of the target at cost of $P_{T}^{*}$. When the outcome of the takeover is still uncertain this price will be lower than the sum of the market price just before an announcement and the bidder premium contained in the takeover announcement $\left(P_{0}+\Delta P\right)$. The difference between the two prices $\left(P_{T}-P_{T}^{*}\right)$ is the profit that the takeover traders could receive if they held all the shares of the firm. However, this is not required in the model; as it is only necessary for the takeover traders to own a sufficient amount of the target shares so that the overall bidder position after the tendering process is larger than half of the total target shares required for takeover success. The takeover fails in two instances outside the range. When $0.5>\omega+n \bar{\delta}$, the trading volume of target shares in the market is too low for takeover traders to acquire sufficiently large positions; thus, they choose not to participate. When $\omega+n \bar{\delta}>1$, the supply of target shares to satisfy the bidder demand by aggregate noise traders ensures it is impossible for takeover traders to generate positive profits.

The extension of this model suggests that in the presence of more than one takeover trader, it is the sum of all the traders' positions that dictates the takeover process outcome. If a sufficient number of shares is freely available for purchase by a number of takeover traders, and the profit remains large enough to mitigate the cost of information collection, trading and coordination, takeover traders will enter the trading of target shares and mitigate the takeover's uncertainty. This will result in takeover success. For 
these evaluation activities and risk-taking, we can classify the takeover traders as informed traders and apply methods to measure their trading activities accordingly.

This theoretical prediction may be studied by considering empirical tests based on the following hypothesis:

$H_{4}$ : The takeover traders participate more in successful takeovers.

Cornelli and Li (2002) do not strictly rely on takeover traders collecting their own private information to assess participation in target share trading. According to their model, it is sufficient for takeover traders to determine if they wish to buy target firm shares, and to have knowledge of their own position in the target shares to derive private information about their trading. This condition originates from the Noe (2001) specification, where shareholders are not endowed with any information, but produce their own private information, and knowledge of their own positions and trading decisions. In Cornelli and Li (2002) model, under the rational expectation assumption for all takeover traders, if the motivation to hold takeover shares is satisfied by one takeover trader, it is also satisfied for all. As such, traders can expect that if they wish to acquire $\delta$ proportion of target shares, others will do the same; this ensures the takeover will succeed after all shares are sold to the bidder.

\subsubsection{Theory Predictions}

Cornelli and Li (2002) established a theoretical model, building on Larcker and Lys (1987) empirical observations, and offering a formal explanation for why informed traders who 
participate in target share trading increase the probability of takeover success. The predictions this model draws from its specifications include that traders have an incentive to purchase shares of the target firm although they have no information on the likelihood of takeover success. According to the model, the fact that a trader has purchased shares is a sufficient condition to increase the likelihood of takeover success. However, the model also specifies that it is advantageous for takeover traders to cooperate with each other, allowing them to increase their informational advantage. In turn, this increases information content and improves the precision of traders' expectations regarding whether the takeover will be successful or unsuccessful and motivates their trading behaviour. Here, trading on information is more precise and intensive, leading to a quicker resolution of uncertainty around the likelihood of takeover success. Whatever the situation, if takeover traders act independently or in a group, the model predicts a greater amount of informed trading, leading to a greater probability that the takeover bid will be resolved successfully.

\subsubsection{Summary of Hypotheses}

In this study, we examine the Cornelli and Li (2002) hypothesis that takeover traders influence the success of takeovers by specifically testing the hypothesis:

$H_{1}$ : Takeover traders increase the likelihood of the successful outcome of takeover offer by buying shares and becoming large shareholders in the target firm.

In addition, we examine the following testable hypotheses based on the Cornell and Li (2002) theoretical model by testing the following hypotheses:

$\mathrm{H}_{2}$ : The takeover traders participate more in takeovers with higher offer premiums. 
$\mathrm{H}_{3}$ : The trading of takeover traders in successful takeovers increases target shares' abnormal returns.

$H_{4}$ : The takeover traders participate more in successful takeovers.

\subsection{Probability of Informed Trading Model}

In order for us to be able to reliably measure the informational content of trades we follow Cornelli and Li (2002) use of the Kyle (1989) framework, where the market maker observes the order flow and sets bid and ask prices based on the value of the shares conditional on the order flow. If the market maker believes that the trader he is trading with is trading for the purposes of liquidity provision, there is not incentive to increase the bid-ask spread. If however, the market maker believes that he is trading with a more informed trader, he will widen the spread to be compensated for adverse selection costs likely to eventuate in such trades. Therefore, we can use the bid- ask spread to separate trading with informed and uniformed traders. For this purpose, we employ Bollen, Smith and Whaley (2004) bid-ask spread decomposition methodology, using data at intraday frequency. The synthetic options are calculated according to previous trade data at 5, 10, 15 and 30 minute intervals of trading to estimate the proportion of informed trading at a daily level. Employing smaller sample sizes enables the removal of any timing effects, particularly in the shorter time window samples. Varied sample sizes increase the robustness of our results and allow us to investigate the effects of informed trading during the day using several different time windows. Bollen, Smith and Whaley (2004) propose a model of bid-ask spread decomposition based on the financial market microstructure theory, whereby any submitted orders in the market are accompanied implicitly by a free-call-option for any counterparty trader who wishes to take the 
opposite side to each trade. This specification is further supported in a study by Mitchell and Pulvino (2001). Here, the authors specify-in the context of takeover trading - that a position in a target stock after a takeover announcement is equivalent to a position in the share, plus a put-option with an exercise price equal to the takeover offer price. According to the arbitrage rules of put-call parity and the assumption that any present value of the exercise price is internalised by each trader (and is the same for all traders), the value of the call option equals the value of a portfolio comprised of a stock and putoption.

The value of such a call-option is included in the cost of placing such a trade which is, in microstructure terms, expressed as portion of the bid-ask spread. The proposed model is more formally based on Stoll (1989) theory, building on the informational content contained in bid-ask spread data. Stoll (1989) model decomposes the bid-ask spread into order processing costs, competition in trading and the inventory holding premium, together with the spread's information asymmetry components. Bollen, Smith and Whaley (2004) attempt to model each part of the bid-ask spread, separating out each component. They add a minimum tick size measure to Stoll (1989) theoretical model and specify their model as:

$$
S P R D_{i}=\alpha_{0}+\alpha_{1} \operatorname{InvTV}_{i}+\alpha_{2} N H I_{i}+\alpha_{3} I H P_{i}+\varepsilon_{i}
$$

Where:

$S P R D_{i}$ is the bid/ask spread for each firm $i$

$\alpha_{0}$ is the minimum tick size for the market maker

$\operatorname{InvTV} V_{i}$ is the inverse of trading volume for each firm $i$ 
$N H I_{i}$ is the normalised Herfindahl Index for each firm $i$.

The normalised Herfindahl Index is calculated as:

$$
N H I_{i}=\frac{H I_{i}-1 / N M_{i}}{1-1 / N M_{i}}
$$

Where:

$H I_{i}$ is the Herfindahl Index measure of Hirschman (1964) calculated as:

$H I_{i}=\sum s_{j}^{2}$ where $s_{j}$ is the market share of each market maker $j$ the measure is estimated for each firm $i$

$N M_{i}$ is the number of market makers offering to facilitate trading securities of firm $i$ $I H P_{i}$ is the inventory holding premium for each firm $i$.

The minimum tick size corresponds to the smallest price movement allowed by the market maker and serves as the theoretical lower bound of the bid-ask spread. Order processing costs reflect the actual costs of processing and the matching orders conducted by the market maker, including fixed costs such as equipment expenses, labour and rent, as well as opportunity costs to the market maker of providing trading services. In this context, such fixed costs could be minimised by trading higher volumes and by diversifying trading operations over large amount of assets traded. This would lead to a fixed trading cost per trade submitted being charged to each client. Further, in the presence of many other market makers trading the same securities, the order processing costs may be very small, due to high competition levels. Bid-ask spread components are approximated by inverse trading volumes and the normalised Herfindahl index, 
respectively. The inverse trading volume approximates the effects of trading costs, as highlighted in Foster and Viswanathan (1993) and Admanti and Pfleiderer (1988) studies, whereby higher trading volumes reduce the per order trading costs. The normalised Herfindahl index is employed to model the competition level among market makers and accounts for competition intensity contained in the bid-ask spread offered. The Herfindahl index is traditionally used in the financial literature. For example, Lang and Stulz (1994) and Kelly (1981) use it to estimate competition intensity within specific industries. In the context of equity trading, the measure takes values in the range of small values of $1 / N M_{i}$ under perfect market competition to 1 under a single market maker, where $N M_{i}$ is the number of market makers. Bollen, Smith and Whaley (2004) modify this measure by removing $1 / N M_{i}$ from the traditional Herfindahl index measure and dividing the measure under perfect competition with the measure under monopoly. This transformation ensures that the resulting measure lies between 0 and 1.

Finally, the inventory holding premium is the premium demanded by any trader and the market maker to cover any expected holding costs of shares, including any price movements that generate a loss for the trader. In practice, market makers (as providers of liquidity) commonly hold sub-optimally low levels of share inventories, especially shares traded in lower quantities and less frequently. This is due to the possibility of adverse price movements during the period between offsetting trades, which could result in substantial losses for the market maker. This risk increases when a market maker expects shares to be held for longer periods, or faces larger price movements during the holding period, or both. These risks are reflected by a higher risk premium required by the market maker, widening the bid-ask spread charged to traders to compensate for 
bearing it. Bollen, Smith and Whaley (2004) derive the inventory holding premium for all market participants, such that the risk of a loss is minimised by:

$$
\min E\left(\Delta S_{i}+I H P_{i} \mid \Delta S_{i}<0\right)^{2}
$$

Where:

$\Delta S_{i}$ is the change in price of share in firm $i$

$I H P_{i}$ is the inventory holding premium of share in firm $i$.

Solving the first order condition to minimise the loss function and rearranging it to express it as a function of the inventory holding premium yields:

$$
I H P_{i}=-E\left(\Delta S_{i} \mid \Delta S_{i}<0\right) \operatorname{Pr}\left(\Delta S_{i}<0\right)
$$

Where:

$I H P_{i}$ is the inventory holding premium of share in firm $i$

$\Delta S_{i}$ is the change in price of share in firm $i$.

The minimum inventory holding premium is therefore the amount that traders, market makers and liquidity traders must invest in to prevent losses on each trade position over its holding period. Bollen, Smith and Whaley (2004) propose that this hedging position is equal to an at-the-money option position for the holding period duration for the shares of each firm traded. For a trader in the long position of shares, the offsetting instrument insuring against any loss would be an at-the-money European put-option. For a trader in the short position, an at-the-money European call-option would insure against any losses. 
Thus, Black and Scholes (1973) and Merton (1973) option valuation models for the European call-option can be employed as follows:

$$
I H P_{i}=S_{i} N\left(\frac{\ln \left(\frac{S_{i}}{X_{i}}\right)}{\sigma_{i} \sqrt{t_{i}}}+\frac{1}{2} \sigma_{i} \sqrt{t_{i}}\right)-X_{i} N\left(\frac{\ln \left(\frac{S_{i}}{X_{i}}\right)}{\sigma_{i} \sqrt{t_{i}}}-\frac{1}{2} \sigma_{i} \sqrt{t_{i}}\right)
$$

Where:

$I H P_{i}$ is the inventory holding premium of share in firm $i$

$S_{i}$ is the midpoint of quoted market price of a share in firm $i$.

The midpoint of the quoted market price is calculated as follows:

$$
S_{i}=\frac{S_{B i d}+S_{A s k}}{2}
$$

Where:

$S_{B i d}$ is the quoted bid price

$S_{A s k}$ is the quoted ask price

$X_{i}$ is the synthetic option exercise price at maturity $t_{i m}$ for a share in firm $i$

$\sigma_{i}$ is the standard deviation of return for share in firm $i$

$t_{i}$ is the time until offsetting trade in share of firm $i$ can occur, this is the minimum inventory holding period for share in firm $i$

$N[$.$] is the cumulative normal density function.$ 
Bollen, Smith and Whaley (2004) suggest that the holding period is relatively small and, as such, the effects of interest rate term may be ignored. Along with the at-the-money specification of the option, the formula for IPH for each trade may be rewritten as:

$$
I H P_{i}=S_{i}\left(2 N\left[\frac{1}{2} \sigma_{i} \sqrt{t_{i}}\right]-1\right)
$$

Where:

$I H P_{i}$ is the inventory holding premium of share in firm $i$

$S_{i}$ is the midpoint of quoted market price of a share in firm $i$

$\sigma_{i}$ is the standard deviation of return for share in firm $i$

$t_{i}$ is the time until the share in firm $i$ can be traded, the inventory holding period for share in firm $i$

$N[$.$] is the cumulative normal density function.$

The main issue with estimating the inventory holding premium in this model is that every trader will have an individual holding period for the shares they own. However, the model may be rewritten in expectation to simplify this complication as:

$$
E\left(I H P_{i}\right)=S_{i}\left(2 N\left[\frac{1}{2} \sigma_{i} E\left(\sqrt{t_{i}}\right)\right]-1\right)
$$

Where:

$E\left(I H P_{i}\right)$ is the expected inventory holding premium of share in firm $i$

$S_{i}$ is the midpoint of quoted market price of a share in firm $i$

$\sigma_{i}$ is the standard deviation of return for share in firm $i$ 
$t_{i}$ is the time until the share in firm $i$ can be traded, the inventory holding period for share in firm $i$

$N[$.$] is the cumulative normal density function$

$E\left(\sqrt{t_{i}}\right)$ is the expected value of square root of time until the offsetting trades become available.

It is possible to use empirical data to estimate the time until offsetting trades become available and recover it from the average expected inventory holding premium by observing the trading frequency of shares prior to the commencement of the inventory holding premium.

Market makers supply immediacy to the market and are generally unaware if a trader with whom they are transacting is better informed (or not) about the true value of the shares they are trading. Easley and O'Hara (1992) investigate this uncertainty regarding trading with an informed or uninformed trader; they conclude that the market maker or any other trader will lose out whenever a trade with a more informed trader occurs. This risk of buying above and selling below the true value of shares is known in the literature as the risk of adverse selection. The first analytical model that relates the costs of adverse selection to the bid-ask spread is provided in Glosten and Milgrom (1985). In this theoretical model, an asset can only assume one of two possible values: a high value $v^{H}$ or low value $v^{L}$, with equal probability of occurrence for the uninformed trader. The informed trader is the only participant that knows the true value of the share. The model also specifies the probability of the market maker trading with an informed investor as $\pi$ and expresses the bid ask spread as: 


$$
S_{\text {Ask }}-S_{\text {Bid }}=\pi\left(v^{H}-v^{L}\right)
$$

Where:

$S_{B i d}$ is the quoted bid price

$S_{A s k}$ is the quoted ask price

$\pi$ is the probability of trading with an informed trader

$v^{H}$ is the high value of a share

$v^{L}$ is the low value of a share.

This model shows that, as the probability of trading with an informed trader increases, the market maker will set higher ask and lower bid prices to compensate for the losses realised when trading with a better-informed trader.

In the context of Bollen, Smith and Whaley (2004) framework, when the market maker receives a buy order from an informed trader, the true value of the shares is assumed to lie above the current ask price. Here, the model predicts that the cost of the adverse selection component of the inventory holding premium $I H P_{i}$ (for a trade with an informed trader) can be measured as a slightly in-the-money call-option, where the exercise price is set at the ask price. As this option is now in-the-money, it has a positive value. The cost of such an option is thus the amount the market maker should charge in addition to the ask price, achieved through widening the bid-ask spread by its value. Conversely, if the trader is uninformed, the true value of the share for this trader is below the ask price and the market maker requires a slightly out-of-the-money call-option to hedge this exposure. The inventory holding premium is different for the informed and 
uninformed trader, and the overall $I H P_{i}$ is just a combination of inventory holding costs and adverse selection costs for each trader type. Inventory holding costs remain at similar levels for both informed and uninformed traders, but the costs of adverse selection vary depending on the trader being identified by the market maker as informed or uninformed. These two effects are not separable, and market makers base their decisions on past order flow information about the levels of bid and ask prices quoted to each trader. This problem of inventory holding and adverse selection cost inseparability does not prevent decomposition of the overall inventory holding premium. The bid and ask price differences are based only on the material difference in individual trader adverse selection costs, as the inventory holding costs of the same shares are assumed to be the same for the market maker. Finally, as only two kinds of traders exist (informed and uninformed), the overall inventory holding premium may be decomposed to uncover each type separately:

$$
I H P_{i}=\left(1-p_{I}\right) I H P_{U i}+p_{I} I H P_{I i}
$$

Or:

$$
I H P_{i}=I H P_{U i}+p_{I}\left(I H P_{I i}-I H P_{U i}\right)
$$

Where:

$I H P_{i}$ is the inventory holding premium of share in firm $i$

$p_{I}$ is the probability that the trader is informed

$I H P_{U i}$ is the inventory holding premium for uninformed trader of share in firm $i$

$I H P_{I i}$ is the inventory holding premium for informed trader of share in firm $i$ 
$p_{I}$ is the constant multiplier on the $\left(I H P_{I i}-I H P_{U i}\right)$ term and represents the probability of informed trading directly from the inventory holding premium part of the bid-ask spread.

To estimate the specified inventory holding premium, Bollen, Smith and Whaley (2004) first estimate the at-the-money option values for true share prices $S_{i}$ and the time between offsetting trades $t_{i}$. As the true share price is obscured by bid and ask prices and is thus unobservable, it can be calculated in two ways. First is a simulation method, where the share prices are selected at small increments of one to ten per cent increases over the synthetic option exercise price $X_{i}$ while the time to offsetting trade is also allowed to vary between 1 second and 30 minutes. This specification leads to a set of inventory holding premium $I H P_{i}$ estimates that are conditional on the amount of information, the degree to which the synthetic option is in-the-money, and the time to offsetting trade. If the true price is just slightly above the ask price, and the option is slightly in-the-money, the probability of informed trade is high. Conversely, if the true price exceeds the exercise price by a large amount, the probability of informed trade is low. Sidhu, Smith, Whaley and Willis (2008) document this process in detail. They argue that for a determined time between offsetting trades, the uninformed component of inventory holding premium $I H P_{U i}$ remains constant. Therefore, for a constant level of bid-ask spread, the probability of informed trade must vary inversely with the informed component of inventory holding premium $I H P_{I i}$. Sidhu, Smith, Whaley and Willis (2008) also specify an alternative methodology of calculating the true share prices that is well-established in the microstructure literature. The approximation of true share prices can be obtained by calculating the midpoint of bid and ask prices, assuming that the market makers set the bid and ask prices symmetrically. Further, to the time between offsetting trades, when 
the trading of a particular share is very liquid, it is possible that $I H P_{i}$ will be very close to zero as the time between offsetting trades approaches zero. However, the expected inventory holding premium does not reach zero as the time between offsetting trades approaches zero. To understand this Sidhu, Smith, Whaley and Willis (2008) consider that the market maker requires compensation from two types of traders, the informed and the uninformed. The market maker does not require any compensation in the form of inventory holding premium from uninformed traders $I H P_{U i}$, as dealing with these traders takes place in order to provide market liquidity. The $I H P_{U i}$ can be zero as time between offsetting trades $t_{i}$ approaches zero due to their synthetic option being out-of-themoney. With informed traders, the inventory holding premium $I H P_{I i}$ approaches the amount that the option is in-the-money, as the time to offsetting trade approaches zero. In this situation, the market maker faces the full cost of providing liquidity to an informed trader. The $I H P_{I i}$ is therefore the difference between the true price and the ask price when informed traders buy and the difference between bid price and the true price when informed traders sell their shares. Therefore, when considering a liquid stock with very small time to offsetting trade, the compensation required by the market maker will become:

$$
I H P_{i}=p_{I}\left(I H P_{I i}\right)
$$

Where:

$I H P_{i}$ is the inventory holding premium of share in firm $i$

$p_{I}$ is the probability that the trader is informed

$I H P_{I i}$ is the inventory holding premium for informed trader of share in firm $i$. 
A further concern relating to the reliable estimation of inventory holding premium $I H P_{i}$ in the Bollen, Smith and Whaley (2004) model is the order arrival process. In previous literature of static models of market participant behaviour, such as that in Kyle (1985) and Glosten and Milgrom (1985), the trade arrival process is assumed constant. While the role of trade arrival times has been considered previously in Garman (1976) and Diamond and Verrecchia (1987) theoretical models, adjustments have not yet been formalised in empirical studies.

Toke (2011) offers an empirical observation that the rate of limit orders arrival is strongly and linearly correlated with the rate of market orders arrivals. Market orders lead and limit orders react to them, and not vice versa. This observation is best explained in a theoretical setting with liquidity traders and market makers reacting to the observed increase in demand for liquidity by increasing the supply of liquidity while charging the appropriate cost of the increase. Depending on the market framework, in general, when a market order is received and executed, and this information is published to market participants, market makers or liquidity providers react to this information by sending limit orders to replace the liquidity depleted by the market order. These new limit orders may contain a price update. This depends on the market maker's or liquidity trader's beliefs regarding whether or not the final trade contains new information not yet included in the market price. The replacement limit order is placed in the order book. Thus, it replaces the liquidity consumed by the previous market order ready for the next market order to be received. The reaction and replacement time from market order execution to liquidity replenishment can vary widely, but depending on the construction of the market order placement engine, it may take between 5 and 15 milliseconds. This is typically the reaction time for a single trade. However, during ordinary trading, many 
trades occur within fewer milliseconds, compounding the impact on price of multiple trades between quotes.

Hasbrouck (1991) first identified that changes in prices also depend on the characteristics of trades placed in the market in past trading periods. This theoretical model proposes that past trade sizes, as well as trade prices, are informative and relevant to predictions of future price levels. These are modelled by empirical tests, for example in Dufour and Engle (2000). This study extends Hasbrouck (1991) theoretical model to empirical applications of trading frequency to generalise models of price and trade dynamics. It relaxes the assumption of constant trade arrivals and considers an autoregressive conditional duration model to capture clustering and over-dispersion of trades. Easley, Engle, O'Hara and Wu (2008) employ the generalised autoregressive model to investigate market liquidity, order book depth and order flow. The authors find that both informed and uninformed trading exhibits significant persistence in arrival rates, with uninformed rates responding negatively to increases in the rate of informed trade arrivals. This result is consistent with previous theories, including that of Cornelli and Li (2002). However, we do not pre-specify the rate of trade arrival and its impact on the bid-ask spread in any way. Instead, we employ an average time between offsetting trades from immediately preceding trading periods in our sample as the closest approximation of time between trades in the following period. This respects the autoregressive nature of trade arrival rates and thus the expected amount of time between offsetting trades at the time of trade submission, as identified in previous studies by Engle and Russell (1998) and Zhang, Russell and Tsay (2001).

Next we consider price variation at increased trade arrival frequencies, examining the impact of this effect on the bid-ask spread data. Mandelbrot and Taylor (1967) commence 
their investigation into the effect of trading frequency on price through the concept of subordination by trading time, which cumulates the number of trades to physical time. This theoretical framework is more formally explained by Blume and Stambaugh (1983), who suggest that a large proportion of observed price variance is due to the bid-ask effect in trading data reported using physical time. Empirically, Dacorogna, Gencay, Müller, Olsen and Pictet (2001) observe that seasonal fluctuations simply reflect the variations in trading activity during physical time, while this observation is irrelevant regarding the way in which market prices vary in event time. Wyart, Bouchaud, Kockelkoren, Potters and Vettorazzo (2008) show that order book depletion during periods of increased trading is the source of variance in trading bid and ask prices and should be considered separately. This is in contrast to the traditionally reported variance in trading prices that employ either the midpoint of quoted bid and ask prices or the last traded price. In the first case, the variance captures half of the bid-ask effect and in the second case the variance captures the full amount of the variance if the opening price is for a trade at-bid and the closing trade is at-ask or vice versa. From this perspective, using a constructed effective spread, rather than the reported quoted spread is a more reliable measure of true share price. A quoted spread can overstate or understate the execution costs for liquidity, demanding trades when trades can be executed outside the best prevailing quotes. Trades can be executed within the quoted spread for a number of reasons, including execution against hidden orders, market makers giving orders for price improvement relative to the prevailing limit order book quotes (internalising client orders), and in trades negotiated between two counterparties off-market that are only reported to the market. Trades can also execute at prices beyond the best prevailing quotes for a number of reasons. These include large market orders exhausting all the available volume at the best price level, which then continue 'walking' through the limit order book and executing 
limit orders at the next tick or ticks. The effective spread accounts for the fact that liquidity demanding trades do not always execute at the best quotes by comparing the trade-execution price to the prevailing mid-quote price. An effective spread is frequently as a proxy for the fundamental value of shares.In order to estimate the probability of informed trading, Bollen, Smith and Whaley (2004) employ the following restricted calibration model using the effective spread:

$$
\operatorname{ESPRD}_{i}=\alpha_{0}+\alpha_{1} \operatorname{InvTV}_{i}+\alpha_{2} N H I_{i}+I H P_{i}\left(t_{i}\right)+\varepsilon_{i}
$$

Where:

$E S P R D_{i}$ is the effective bid-ask spread for each firm $i$, calculated as:

$$
\operatorname{ESPRD}_{i}=2\left|P_{i}-M_{i}\right| / M_{i}
$$

Where:

$P_{i}$ is the trade price for the trade, either an ask price $S_{A s k}$ or a bid price $S_{B i d}$ depending on the desired position of the trader

$M_{i}$ is the midpoint of quoted market price of a share in firm $i$ calculated as:

$$
M_{i}=\left(S_{\text {Bid }}-S_{\text {Ask }}\right) / 2
$$

Where:

$S_{B i d}$ is the quoted bid price

$S_{A s k}$ is the quoted ask price

$\alpha_{0}$ is the minimum tick size for the market maker

$\operatorname{InvTV} V_{i}$ is the inverse of trading volume for each firm $i$ 
$N H I_{i}$ is the normalised Herfindahl Index for each firm $i$

$I H P_{i}$ is the inventory holding premium for each firm $i$.

The model is calibrated through scaling it by a constant factor of $\tau_{i}=t_{i} / \sqrt{\widehat{t}_{l}}$ for each firm $i$ separately, where $\widehat{t}_{l}$ is the historical average time between trades recorded by the market maker in the previous trading period. This restriction forces the coefficient on the $I H P_{i}$ factor to be equal to 1 , which enables substitution of the informed and uninformed model into the estimation, and allows the final model specification:

$\operatorname{ESPRD}_{i}=\alpha_{0}+\alpha_{1} \operatorname{InvTV}_{i}+\alpha_{2} N H I_{i}+\alpha_{3} I H P_{U i}\left(\tau_{i}\right)+\alpha_{4}\left(I H P_{I i}\left(\tau_{i}\right)-I H P_{U i}\left(\tau_{i}\right)\right)+\varepsilon_{i}$

Where:

$E S P R D_{i}$ is the effective bid-ask spread for each firm $i$

$\alpha_{0}$ is the minimum tick size for the market maker

$\operatorname{InvTV} V_{i}$ is the inverse of trading volume for each firm $i$

$N H I_{i}$ is the normalised Herfindahl Index for each firm $i$

$I H P_{U i}$ is the inventory holding premium for uninformed trader of share in firm $i$

$I H P_{I i}$ is the inventory holding premium for informed trader of share in firm $i$.

In the above model, coefficient $\alpha_{4}$ estimates the probability of informed trade $P I_{i}$ and is the main variable of interest when testing the presence of informed trading, $\alpha_{0}$ captures the effect of tick size, $\operatorname{InvTV}_{i}$ proxies the order costs, and $N H I_{i}$ accounts for market maker competition. 
The calculation of the inventory holding premium for informed trader, $I H P_{I i}$, according to Bollen, Smith and Whaley (2004) uses a slightly in-the-money European call option while inventory holding premium for uninformed trader, $I H P_{I U}$, using a slightly out-ofthe money European call option. We calculate the values for each using Black and Scholes (1973) and Merton (1973) option valuation model can be employed as follows:

$$
\begin{aligned}
& I H P_{I i}=S_{i} N\left(\frac{\ln \left(\frac{S_{i}}{S_{A s k}}\right)}{\sigma_{i} \sqrt{\tau_{i}}}+\frac{1}{2} \sigma_{i} \sqrt{\tau_{i}}\right)-S_{A s k} N\left(\frac{\ln \left(\frac{S_{i}}{S_{A s k}}\right)}{\sigma_{i} \sqrt{\tau_{i}}}-\frac{1}{2} \sigma_{i} \sqrt{\tau_{i}}\right) \\
& I H P_{U i}=S_{i} N\left(\frac{\ln \left(\frac{S_{i}}{S_{B i d}}\right)}{\sigma_{i} \sqrt{\tau_{i}}}+\frac{1}{2} \sigma_{i} \sqrt{\tau_{i}}\right)-S_{B i d} N\left(\frac{\ln \left(\frac{S_{i}}{S_{B i d}}\right)}{\sigma_{i} \sqrt{\tau_{i}}}-\frac{1}{2} \sigma_{i} \sqrt{\tau_{i}}\right)
\end{aligned}
$$

Where:

$I H P_{I i}$ is the inventory holding premium for informed trader of share in firm $i$

$S_{i}$ is the midpoint of quoted market price of a share in firm $i$

$S_{A s k}$ is the quoted ask price

$S_{B i d}$ is the quoted bid price

$\sigma_{i}$ is the standard deviation of return for share in firm $i$

$\tau_{i}$ is the time until offsetting trade in share of firm $i$ can occur calibrated from the first pass of the model

$N[$.$] is the cumulative normal density function.$ 


\subsection{Probability of Informed Trading}

Model estimations undertaken using Bollen, Smith and Whaley (2004) linear model framework of bid-ask spread decomposition (which uses the three separate components of inverse trading volume, normalised Herfindahl-Hirshmann index of trading intensity and the inventory holding premium for informed and uninformed trading) require a calibration and an estimation stage to produce the desired decomposition results. The calibration stage yields variables of the amount of time between offsetting trades $\tau_{i}$ and annualised standard deviation of firm returns $\sigma_{i}$ which are then used in the estimation phase of the full model.

\subsection{Model Specifications}

3.5.1. Impact of Probability of Informed Trading on Takeover Success

The Bollen, Smith and Whaley (2004) methodology removes colinearity problems that are likely to exist between $I H P_{I i}$ and $I H P_{U i}$ as well as allowing the test for the presence of informed trading in takeovers as proposed in Cornelli and Li (2002). To test this theory we use the following model using the Palepu (1986) and Powell (1997) nominal logistic regression framework across all daily estimates to estimate for all firms $i$ and days $t$ :

$$
\operatorname{Pr}_{i}=E\left(\operatorname{SUCCESS}_{i}=1 \mid Z_{i}\right)=\frac{1}{1+e^{-Z_{i}}}
$$

$$
\ln \left(\frac{P r_{i}}{1-P r_{i}}\right)=Z_{i}=\beta_{0}+\beta_{1} \ln \left(S I Z E_{i}\right)+\beta_{2} P R E M I U M 1 D_{i}+\beta_{3} D P A Y C A S H_{i}
$$




$$
\begin{gathered}
+\beta_{4} \text { DHOSTILE }_{i}+\beta_{5} \text { DBIDDERS }_{i}+\beta_{6} \text { DTOEHOLD }_{i}+\beta_{7} \text { BLOCKHOLDING }_{i}+\beta_{8} \text { PI }_{i} \\
+\beta_{9} \text { ROA }_{i}+\beta_{10} \text { ROE }_{i}+\beta_{11} \text { EPS }_{i}+\beta_{12} \text { B } / M_{i}+\beta_{13} \text { DINDUSTRY }_{i}+\beta_{14} \text { DYEAR }_{i} \\
+\beta_{15} \text { IMR }_{i}+\varepsilon_{i}
\end{gathered}
$$

Where:

$P r_{i}$ is the probability of success of a takeover expected in the logistic model conditional on the set of parameters $Z_{i}$

$\operatorname{SUCCESS}_{i}$ is an indicator variable for the takeover outcome, it takes value of 1 when the takeover is successful and 0 otherwise for each firm $i$

$\ln \left(S I Z E_{i}\right)$ is the natural logarithm transformation of market capitalisation of each firm $i$ on the day of announcement

PREMIUM $1 D_{i}$ is the premium offered by the bidder compared to last observed market price for each firm $i$ before the announcement

$D P A Y C A S H_{i}$ is an indicator variable equal 1 when the announced takeover payment method is in cash and 0 otherwise for each firm $i$

DHOSTILE $_{i}$ is an indicator variable equal 1 when the takeover can be characterised as hostile and 0 otherwise for each firm $i$

$D B I D D E R S_{i}$ is an indicator variable equal 1 when the takeover has more than one bidder and 0 otherwise for each firm $i$ 
DTOEHOLD $D_{i}$ is an indicator variable equal 1 when bidder owns an amount of $5 \%$ or more of the target shares when the takeover is announced and 0 otherwise for each firm $i$

BLOCKHOLDING $_{i}$ is the proportion of shares of each firm $i$ held by blockholders (individual holdings greater than $5 \%$ of shares of each firm $i$ )

$P I_{i}$ is the estimated probability of informed trading from the Bollen, Smith and Whaley (2004) model for each firm $i$ on the day of announcement for different estimation time intervals of 5, 10, 15 and 30 minute aggregation windows over each trading day

$R O A_{i}$ is the most recently reported return on assets prior to the takeover announcement day for each firm $i$

$R O E_{i}$ is the most recently reported return on equity prior to the takeover announcement day for each firm $i$

$E P S_{i}$ is the most recently reported earnings per share for each firm $i$

$B / M_{i}$ is the book to market ratio for each firm $i$

$\operatorname{DINDUSTR} Y_{i}$ is an indicator variable which equals 1 when the target firm is in the primary industry of operation, the same as defined industry for each firm $i$ $D Y E A R_{i}$ is an indicator variable equal to 1 when the takeover is announced that year $I M R_{i}$ is the Inverse Mills Ratio estimated in the second step of Heckman (1976) model, correcting for the sample selection bias which could be present in the model estimates.

The model estimates the probability of discrete outcomes regarding success, or the lack of it, for each takeover. The logistic model is estimated using a set of quantitative 
variables represented collectively by the vector $Z_{i}$ for each takeover event, as a discriminator between successful and unsuccessful takeover attempts. Using a logistic regression has advantages. Unlike the linear probability model, the logistic model allows for a linear relationship of log odds of takeover success and explanatory variables, rather than suggesting a non-linear relationship of probability of takeover success and explanatory variables. This model allows us to estimate the probability of takeover success for each takeover event. The logistic estimation method further allows application of out-of-sample explanatory variable sets in a similar way to a linear regression model. This estimates the success probabilities for out-of-sample predictions on takeover announcements. The partial derivative is specified as:

$$
\frac{\partial P r_{i}}{\partial Z_{i}}=\gamma P r_{i}\left(1-P r_{i}\right)
$$

Where:

$P r_{i}$ is the probability of success of a takeover expected in the logistic model conditional on the set of parameters $Z_{i}$

$Z_{i}$ is the linear model of all factors

This partial derivative allows us to measure the impact of explanatory variable changes on the likelihood of takeover success. At high and low success probabilities, the effects of explanatory variables are reduced. This is because the probability odds measured by $\operatorname{Pr}_{i}\left(1-P r_{i}\right)$ are much lower than the baseline case, where the probability of success is equal to the probability of no success; $P r_{i}=0.5$. Therefore, if a firm is defined clearly as the target of a successful or unsuccessful takeover attempt, and has a very high or very 
low $P r_{i}$, significant changes in the explanatory variables are required to change the takeover outcome.

3.5.2. Impact of Probability of Informed Trading on Cumulative Abnormal Returns

To test the effects of informed trading on the abnormal returns of target firms we specify the following model. The model uses a cross sectional regression framework across all daily estimates to estimate for firms $i$ :

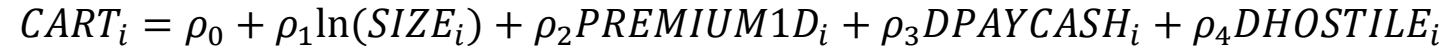

$$
\begin{aligned}
& +\rho_{5} \text { DTOEHOLD }_{i}+\rho_{6} \text { DBIDDERS }_{i}+\rho_{7} \text { DBLOCKHOLDING } i+\rho_{8} \text { DSUCCESS }_{i}+\rho_{9} \text { PI }_{i} \\
& +\rho_{10} \text { DSUCCESS }_{i} \times P I_{i}+\rho_{11} R O A_{i}+\rho_{12} R O E_{i}+\rho_{13} E P S_{i}+\rho_{14} B / M_{i} \\
& +\rho_{15} D_{I N D U S T R} Y_{i}+\rho_{16} D Y E A R_{i}+\rho_{17} I M R_{i}+\varepsilon_{i}
\end{aligned}
$$

Where:

$C A R T_{i}$ is the cumulative abnormal return of target firm at different event windows of $1,5,10$ and 30 days from the takeover announcement day

$\ln \left(S I Z E_{i}\right)$ is the natural logarithm transformation of market capitalisation of each firm $i$ on the day of announcement

PREMIUM $1 D_{i}$ is the premium offered by the bidder compared to last observed market price for each firm $i$ before the announcement

$D_{P A Y C A S H}$ is an indicator variable equal 1 when the takeover announced is in cash and 0 otherwise for each firm $i$ 
$\operatorname{DHOSTILE}_{i}$ is an indicator variable equal 1 when the takeover can be characterised as hostile and 0 otherwise for each firm $i$

$D B I D D E R S_{i}$ is an indicator variable equal 1 when the takeover has more than one bidder and 0 otherwise for each firm $i$

DTOEHOLD $D_{i}$ is an indicator variable equal 1 when bidder owns an amount of $5 \%$ or more of the target shares when the takeover is announced and 0 otherwise for each firm $i$ before the day of announcement

$B L O C K H O L D I N G_{i}$ is the proportion of shares of each firm $i$ held by blockholders (individual holdings greater than $5 \%$ of shares of each firm $i$ )

$\operatorname{DSUCCESS}_{i}$ is an indicator variable for the takeover outcome, it takes value of 1 when the takeover is successful and 0 otherwise for each firm $i$

$\operatorname{DSUCCESS}_{i} \times P I_{i}$ is a variable equal to $P I_{i}$ when the takeover is successful and 0 otherwise

$P I_{i}$ is the estimated probability of informed trading from the Bollen, Smith and Whaley (2004) model for each firm $i$ on the day of announcement for different estimation time intervals of 5, 10, 15 and 30 minute aggregation windows over each trading day

$R O A_{i}$ is the most recently reported return on assets prior to the takeover announcement day for each firm $i$

$R O E_{i}$ is the most recently reported return on equity prior to the takeover announcement day for each firm $i$

$E P S_{i}$ is the most recently reported earnings per share for each firm $i$ $B / M_{i}$ is the book to market ratio for each firm $i$ 
$\operatorname{DINDUSTR} Y_{i}$ is an indicator variable which equals 1 when the target firm is in the primary industry of operation same as defined industry for each firm $i$

$D Y E A R_{i}$ is an indicator variable equal to 1 when the takeover is announced that year

$I M R_{i}$ is the Inverse Mills Ratio estimated in the second step of Heckman (1979) model correcting for the sample selection bias which could be present in the model estimates.

\subsubsection{Impact of Takeover Success on Probability of Informed Trading}

To conduct a more comprehensive examination of Cornelli and Li (2002) theory, we consider the possibility that informed traders evaluate the takeover announcement exante and form expectations about the likelihood of takeover success trading accordingly. To test this possibility we employ the theory of Larcker and Lys (1987) that informed traders, who exhibit higher probability of informed trading, possess perfect foresight as to the future success or failure of the takeover. The model establishes a further dimension of investigation whereby we study the degree to which variance in $P I$ is explained by variances in the success indicator variable, while controlling for takeover announcement characteristics and firm characteristics.

To test the effects of takeover success on the probability of informed trading we specify the following model using a cross sectional regression framework across all daily estimates to estimate for each firm $i$ : 


$$
\begin{gathered}
\text { PI }_{i}=\gamma_{0}+\gamma_{1} \ln \left(\text { SIZE }_{i}\right)+\gamma_{2} \text { ROA }_{i}+\gamma_{3}{\text { PREMIUM } 1 D_{i}+\gamma_{4} \text { DPAYCASH }_{i}}_{+\gamma_{5} \text { DHOSTILE }_{i}+\gamma_{6} \text { DBIDDERS }_{i}+\gamma_{7} \text { DTOEHOLD }_{i}+\gamma_{8} \text { BLOCKHOLDING }_{i}} \\
+\gamma_{9} \text { DSUCCESS }_{i}+\gamma_{10} \text { ROE }_{i}+\gamma_{11} \text { EPS }_{i}+\gamma_{12} B / M_{i}+\gamma_{13} \text { DINDUSTRY }_{i} \\
+\gamma_{14} \text { DYEAR }_{i}+\gamma_{15} \text { IMR }_{i}+\varepsilon_{i}
\end{gathered}
$$

Where:

$P I_{i}$ is the estimated probability of informed trading from the Bollen, Smith and Whaley (2004) model for each firm $i$ on the day of announcement for different estimation time intervals of 5, 10, 15 and 30 minute aggregation windows over each trading day

$\ln \left(S I Z E_{i}\right)$ is the natural logarithm transformation of market capitalisation of each firm $i$ on the day of announcement

$R O A_{i}$ is the most recently reported return on assets of each firm $i$ before the day of announcement

PREMIUM $1 D_{i}$ is the premium offered by the bidder compared to last observed market price for each firm $i$ before the announcement

$D P A Y C A S H_{i}$ is an indicator variable equal 1 when the takeover announced is in cash and 0 otherwise for each firm $i$

$D_{\text {HOSTILE }}$ is an indicator variable equal 1 when the takeover can be characterised as hostile and 0 otherwise for each firm $i$ 
$D B I D D E R S_{i}$ is an indicator variable equal 1 when the takeover has more than one bidder and 0 otherwise for each firm $i$

DTOEHOLD $D_{i}$ is an indicator variable equal 1 when bidder owns an amount of $5 \%$ or more of the target shares when the takeover is announced and 0 otherwise for each firm $i$

$B L O C K H O L D I N G_{i}$ is the proportion of shares of each firm $i$ held by blockholders (individual holdings greater than $5 \%$ of shares of each firm $i$ )

$\operatorname{DSUCCESS}_{i}$ is an indicator variable for the takeover outcome, it takes value of 1 when the takeover is successful and 0 otherwise for each firm $i$

$R O E_{i}$ is the most recently reported return on equity prior to the takeover announcement day for each firm $i$

$E P S_{i}$ is the most recently reported earnings per share for each firm $i$

$B / M_{i}$ is the book to market ratio for each firm $i$

$\operatorname{DINDUSTR} Y_{i}$ is an indicator variable which equals 1 when the target firm is in the primary industry of operation same as defined industry for each firm $i$

$D Y E A R_{i}$ is an indicator variable equal to 1 when the takeover is announced that year $I M R_{i}$ is the Inverse Mills Ratio estimated in the second step of Heckman (1979) model correcting for the sample selection bias which could be present in the model estimates.

\subsection{Model Estimation Procedure}

For statistical testing, we employ the Hansen (1982) Generalised Methods of Moments (GMM) estimation framework to ensure consistency of our estimates. Skoulakis (2008) and Petersen (2008) study the validity of the Fama and MacBeth (1973) cross-sectional 
modelling approach and identify concerns regarding the bias of standard errors and the presence of cross-sectional and time series correlation when using time coefficients of time-series regressions in place of variables. This practice may result in underestimating the standard errors under ordinary least squares estimates. These issues are likely to be resolved under the Hansen (1982) methodology where the standard errors of estimates are adjusted.

\subsection{Variable Construction}

\subsubsection{Takeover Outcomes}

Takeover activity outcomes are captured from the Thomson Reuters security data corporation (SDC) platinum takeover status field. This can take several different values: completed, intended, partly completed, withdrawn and unknown. All status outcomes (apart from completed) present a failure to complete the takeover under the original offer. Therefore, they represent a failure to acquire the target as expected under the announced proposal. The unknown status is reported whenever the bidder does not engage in any additional corporate actions-subject to an exhaustive search of corporate records-after the takeover is announced, for a period of 12 months. This effectively deems the offer as lapsed and therefore as not successful. The indicator variable for the takeover outcome:

$$
\operatorname{SUCCESS}_{i}=\left\{\begin{array}{cc}
1 & \text { if the outcome is reported a "Completed" } \\
0 & \text { Otherwise }
\end{array}\right.
$$

Where:

$\operatorname{SUCCESS}_{i}$ is an indicator variable for the takeover outcome, it takes value of 1 when the takeover is successful and 0 otherwise for each firm $i$. 


\subsubsection{Trade and Quote Data}

The intraday trade prices and market bid and ask quotes were obtained from Thomson Reuters Tick History trade and quote data for each target firm in the range of ten days before to ten days after the takeover announcement date. The trade and quote data has been filtered to include only trades realised over the course of ordinary market trading, excluding the opening and closing auctions, as well as any after-hours trading.

Quotes were filled with the trades to which they apply. This was conducted by matching the prevailing quote of bid and ask prices to each trade, correcting for the contemporaneous occurrence of trades and quotes. Chordia, Roll and Subrahmanyam (2001) methodology further instructs for the removal of trades at times of noncontinuous trading. This is indicated by crossed spreads and trades executed outside the spread where the trade is more than $25 \%$ of the price outside the quoted spread. This filter adjusts for any trades that occur outside ordinary market trading venues of, such as privately negotiated transactions. We employ Lee and Ready (1991) algorithm to assign trade directions by categorising the trade as a buy (sell) trade if a transaction occurs above (below) the prevailing mid-quote; it is accordingly regarded as buy (sell) order. If the transaction occurs exactly at the mid-quote, the order is assigned using the previous transaction price according to the tick test. The tick test consists of categorising a buy (sell) if the last non-zero price movement is positive (negative). The trade data are then transformed from transaction time to ordinary time for aggregation purposes at different time intervals and calibration variables' calculations. Time intervals of 5, 10, 15 and 30 minutes were selected to study the effects of informed trading over different time intervals, comparing the results across different time aggregations during the trading day. 
We select the mid-quote of the last ordinary trade of the day to act as a closing share price for each trading day for every firm:

$$
S_{\text {id }}=\frac{S_{\text {Last Bid }}+S_{\text {Last Ask }}}{2}
$$

Where:

$S_{i d}$ is the midquote of the last trade of day $d$ and is used as the closing share price for each firm $i$

$S_{\text {Last Bid }}$ is the quoted bid price of the last trade for day $d$

$S_{\text {Last Ask }}$ is the quoted ask price of the last trade for day $d$.

\subsubsection{Returns}

We calculate the daily return for each firm $i$ on day $d$ as:

$$
R_{i d}=\ln \left(\frac{S_{i d}}{S_{i d-1}}\right)
$$

Where:

$R_{i d}$ is the return for each day $d$ for each firm $i$

$S_{i d}$ is the midquote of the last trade of day $d$ and is used as the closing share price for each firm $i$.

We calculate abnormal return using Fama and French (1993) three factors in the two step process. First we estimate monthly time series factor loadings by estimating the Fama and French (1993) equation: 


$$
A R_{i}=\alpha_{i}=\left(R_{i m}-R_{f m}\right)-\beta_{i}\left(R_{M m}-R_{f m}\right)-s_{i} S M B_{m}-h_{i} H M L_{m}
$$

Where:

$A R_{i}$ is the abnormal return for each share $i$

$R_{i m}$ is the return on share $i$ in month $m$

$R_{f m}$ is the return on risk-free asset in month $m$

$R_{M m}$ is the return on the market in month $m$

$S M B_{m}$ is the difference in returns of small and big stocks in month $m$

$H M L_{m}$ is the difference in returns of high and low book to market stocks in month $m$.

For Australian sample we use Fama and French (1993) factors for Asia ex Japan while for United States sample we use United States factors sourced from Kenneth French's website ${ }^{1}$

We calculate the cumulative abnormal returns (CARs) as the sum of the cumulative difference between return on the asset and expected return on the asset approximated by previous month's return on the asset calculated by the formula:

$$
C A R_{i}(h)=\sum_{d=0}^{h} R_{i m}-E\left[R_{i m}\right]
$$

Where:

$C A R_{i}(h)$ is the cumulative abnormal return on share $i$ for the period 0 to $h$

$R_{i m}$ is the return on share $i$ in month $m$

$E\left[R_{i m}\right]$ is the expected return on share $i$ in month $m$ equal to previous return $R_{i m-1}$.

\footnotetext{
${ }^{1}$ http://mba.tuck.dartmouth.edu/pages/faculty/ken.french/
} 


\subsubsection{Takeover Premium}

Finally, we calculate the takeover premium on the takeover announcement day. Premium 1 day is the difference between the closing share price on one day prior to takeover announcement and the offer price of the target firm contained in the takeover announcement.

$$
\text { PREMIUM } 1 D_{i}=\ln \left(\frac{O P_{i}}{S_{i d-1}}\right)
$$

Where:

PREMIUM $1 D_{i}$ is the premium offered by the bidder compared to last observed market price for each firm $i$ before the announcement

$O P_{i}$ is the offer price of share $i$

$S_{i d-1}$ is the midquote of the last trade one day before the announcement date $d-1$ for each firm $i$.

\subsection{Model Calibration Variables}

Bollen, Smith and Whaley (2004) bid-ask spread decomposition model employs four variables in order to estimate the probability of informed trading. One of the control variables in this model includes the normalised Herfindahl index adjusting the decomposition for the size of market orders and the availability of trading counterparties. As Australia has a very open and transparent equity trading infrastructure with many trading venues and large amount of brokers, the estimates on the normalised Herfindahl index variable are very small and statistically insignificant. This result confirms the competitive nature in the provision of market making services and trading outcomes in competitive markets as outlined in Dennert (1993). The relationship of an inverse volume 
of orders to a bid-ask spread is negative and small. This suggests that large orders do not reduce the size of bid-ask spreads. Small trades have a more significant negative impact on the size of the bid-ask spread, decreasing the spread. This result is consistent with Lin, Sanger and Booth (1995) theoretical model and empirical testing. Finally, the intercept offers an additional form of verification regarding the model's appropriateness, in that Bollen, Smith and Whaley (2004) suggest this value should be close to the average tick size for traded shares.

For the inverse trading volume, we calculate the number of shares traded in each time period given by:

$$
\operatorname{InvTV} V_{i}=\frac{1}{\sum V_{i}}
$$

Where:

$\operatorname{InvTV}_{i}$ is the inverse of trading volume for each firm $i$

$\sum V_{i}$ is the sum of the volume of shares traded for each firm $i$ during the time period

We calculate the normalised Herfindahl index for each firm trading day as follows:

$$
N H I_{i}=\frac{H I_{i}-1 / N M_{i}}{1-1 / N M_{i}}
$$

Where:

$N H I_{i}$ is the normalised Herfindahl Index measure for each firm $i$

$H I_{i}$ is the Herfindahl Index measure of Hirschman (1964) calculated as: 


$$
H I_{i}=\sum s_{j}^{2}
$$

Where:

$s_{j}$ is the market share of each market maker $j$ the measure is estimated for each firm $i$

$N M_{i}$ is the number of market makers offering to facilitate trading securities of firm $i$.

Finally, the inventory holding premium is calculated using the Black and Scholes (1973) formula for at the money call option:

$$
I H P_{i t}=S_{i}\left(2 N\left(\frac{1}{2} \sigma_{i t} E \sqrt{\widehat{t}_{l}}\right)-1\right)
$$

Where:

$I H P_{i t}$ is the inventory holding premium for time aggregation period $t$ for each firm $i$

$S_{i}$ is the midquote is used as the reference price of each trade for each firm $i$

$N(\cdot)$ is the cumulative standard normal density function

$\sigma_{i t}$ is the standard deviation of returns for time aggregation period $t$ for each firm $i$

$E \sqrt{\widehat{t}_{l}}$ is the expected time between offsetting trades for each firm $i$.

We calculate the standard deviation of returns employing the standard statistical formula to employ in the model estimation procedure: 


$$
\sigma_{i t}=\sqrt{\frac{\sum_{n=1}^{n}\left(r_{i t}-\overline{r_{l t}}\right)^{2}}{(n-1)}}
$$

Where:

$\sigma_{i t}$ is the standard deviation of returns for time aggregation period $t$ for each firm $i$ $r_{i t}$ is the return for time aggregation period $t$ for each firm $i$ $\overline{r_{l t}}$ is the average return for time aggregation period $t$ for each firm $i$ $n$ is the number of observations for each time aggregation period.

We calculate the average time between offsetting trades by summing the number of shares traded during each aggregation period, and then dividing by number of milliseconds in the aggregation periods. We calculate the time to offsetting trade for each trade by applying the following formula:

$$
\widehat{t_{l}}=\frac{v_{i}}{\frac{\sum V_{i}}{m}}
$$

Where:

$\widehat{t}_{l}$ is the time between offsetting trades for each firm $i$

$\sum V_{i}$ is the amount for all traded shares of firm $i$ within each aggregation period $m$ is the number of milliseconds for each aggregation period $v_{i}$ is the number of shares of firm $i$ traded for each trade.

\subsection{Control Variables}

The prior literature on corporate takeovers suggests that takeover firm characteristics can influence the bid price at takeover announcement significantly, and therefore affect the takeover outcome, as well as the size of abnormal returns. 
Anderson, Haynes and Heaney (1994) examine the relationship between the size of target firms and market reactions to the announcement of a takeover offer. They find that smaller targets earn significantly higher abnormal returns. This effect is driven by the lower amount of publicly available information for smaller firms than for larger firms. Zeghal (1984) also documents this phenomenon, highlighting that investors require higher returns in takeovers of small target firms, due to the increased information asymmetry risk. Further, Klein and Bawa (1977) find that due to large amounts of information released in takeover announcements about the valuation of small target firms, those firms are more likely to earn higher abnormal returns. Further, smaller firms are less widely held; according to Lakonishok and Smidt (1986), the owners of smaller firms require a higher premium to induce them to sell their company shares. According to Bradley (1980), this liquidity premium is what drives the positive relationship of size takeover premiums with returns to smaller target shares.

We employ the following size variable to control for these effects:

$$
\ln \left(\operatorname{size}_{i}\right)=\ln \left(S_{i d-1} \times N_{i}\right)
$$

Where:

$\ln \left(\operatorname{size}_{i}\right)$ is the natural logarithm of market capitalisation of firm $i$

$S_{i d-1}$ is the mid-quote of the last trade one day before the announcement date $d-$ 1 for each firm $i$

$N_{i}$ is the number of outstanding shares for each firm $i$.

Further, the previous takeover literature reveals firm-specific information relating to the takeover offer characteristics. The variable relevant to takeover offer selected most frequently is payment method. Travlos (1987), Berkovitch and Narayanan (1990), and Loughran and Vijh (1997) confirm that both bidder and target abnormal returns are 
higher when a takeover is completed with a cash offer. Thus, we select this variable and set it as equal to 1 when the takeover is completed with cash and 0 when the offer is a mix of cash and equity, or when the offer is a pure stock offer. Travlos (1987) explores the method of payment when financing takeover bids. Travlos (1987) finds that equityonly bids experience significant losses, while cash-only bids earn positive returns; this is consistent with the signalling hypothesis that states bidder firm shares are overpriced in all equity offers (Rhodes-Kropf, Robinson \& Viswanthan, 2005). Jensen (1986) offers an alternative view in that when takeover offer payments are in shares, target shareholders take a premium to mitigate the risks associated with holding bidder shares; as a result, the overall value created in all equity transactions is lower. In contrast, Davidson and Cheng (1997) argue that all-cash acquisitions are associated with even larger premiums for target shareholders, and these are what generate large abnormal returns. Therefore, we construct the indicator variable on the basis of payment, as proposed by Bradley and Sundaram (2006):

$$
D_{P A Y C A S H}=\left\{\begin{array}{cc}
1 & \text { if the offer payment is only in cash } \\
0 & \text { if the offer is in any other payment method }
\end{array}\right.
$$

Where:

$D P A Y C A S H_{i}$ is an indicator variable equal 1 when the takeover announced is in cash and 0 otherwise for each firm $i$.

Harris and Raviv (1988) study takeover proxy contests and tender offers in the context of takeovers, as such activities constitute a hostile takeover rather than a friendly one. The dynamics of hostile takeovers may differ significantly, as the target firm may employ 
resistance strategies to deter the bidder's actions. To control for this type of takeover, we employ an indicator variable to identify hostile takeovers:

DHOSTILE $_{i}$

$=\left\{\begin{array}{lc}1 & \text { if the offer is accompanied by proxy contest or tender offer of both } \\ 0 & \text { if the offer is not accompanied by proxy contest or tender offer }\end{array}\right.$

Where:

DHOSTILE $i$ is an indicator variable equal 1 when the takeover can be characterised as hostile and 0 otherwise for each firm $i$.

We also control for the existence of multiple bidders; this may affect the outcome and dynamics of the takeover process, as studied by Tenorio (1997) and Kremer and Nyborg (2004). These authors' theoretical models suggest that multiple bids increase the amount of private information available to market participants, and therefore decrease the likelihood of takeover success. To adjust for this conjecture, we form an indicator variable as follows:

D MULTIPLE BIDDERS

$$
=\left\{\begin{array}{cc}
1 & \text { if the offer is followed by bids from new takeover bidders } \\
0 & \text { if the offer is not followed by any other bids }
\end{array}\right.
$$

Where:

$D$ MULTIPLE BIDDERS $S_{i}$ is an indicator variable equal 1 when the takeover has more than one bidder and 0 otherwise for each firm $i$.

A further takeover-specific variable is related to Officer (2003) study. Officer suggests that bidders pay less for targets if the bidder already owns shares in the target prior to takeover; this is known as a toehold. We adopt this variable equal to 1 if the bidder has 
owned $5 \%$ or more of the target shares prior to the takeover announcement and 0 otherwise. We establish the indicator variable based on the findings of Officer (2003) as:

DTOEHOLD

$= \begin{cases}1 & \text { if the bidder owns at least } 5 \% \text { of target prior to takeover annoucement } \\ 0 & \text { if the bidder }\end{cases}$

Where:

DTOEHOLD $D_{i}$ is an indicator variable equal 1 when bidder owns an amount of $5 \%$ or more of the target shares when the takeover is announced, and 0 otherwise for each firm $i$ before the day of announcement.

To test for the actions of takeover traders as block holders separate to those actions of existing block holders, we establish an indicator variable that captures the presence of block holders prior to the takeover announcement. This approach is consistent with Gorton and Kahl (2008) model of different incentives for takeover traders and block holders, allowing them to perform different functions during the capital restructuring process, including takeover activity. We construct the indicator variable for block holders as: $D B L O C K H O L D I N G_{i}= \begin{cases}1 & \text { if } B H_{n i}>5 \% \text { of target prior to takeover annoucement } \\ 0 & \text { if } B H_{n i}<5 \% \text { of target prior to takeover annoucement }\end{cases}$ Where:

$D B L O C K H O L D I N G_{i}$ is the indicator variable equal 1 when at least one block holder owns an amount of $5 \%$ or more shares of each firm $i$

$B H_{n i}$ is the proportion of shares held by each block holder $n$ (individual holdings greater than $5 \%$ of shares of each firm $i$ ). 
Ravenscraft and Scherer (1989) employ a more intuitive measure for overall takeover value in business profitability. They find that target companies tend to be more profitable prior to the bid announcement; this aligns with earlier studies on positive abnormal returns for targets. Palepu (1986) employs return on assets to proxy for profitability using accounting data. We follow this approach and calculate the return on equity according to the accounting formula:

$$
R O A_{i}=\frac{{\text { Net } \text { Income }_{i}}_{\text {Total Assets }}}{\text { Tol }}
$$

Where:

$R O A_{i}$ is the most recently reported return on assets prior to the takeover announcement day for each firm $i$

Net Income $_{i}$ is the most recently reported Net Income in the Annual Statement for each firm $i$

Total Assets $_{i}$ is the most recently reported Total Assets in the Annual Statement for each firm $i$

Walter (1984), uses return on equity to proxy for company profitability instead of the return on assets. We employ the following accounting formula to calculate the return on equity in the following manner:

$$
R O E_{i}=\frac{\text { Net } \text { Income }_{i}}{\text { Shareholder Equity }}
$$

Where:

$R O E_{i}$ is the most recently reported return on equity prior to the takeover announcement day for each firm $i$

Net Income $_{i}$ is the most recently reported net income for each firm $i$ 
Shareholder Equity is $_{i}$ the most recently reported Shareholder Equity for each firm $i$.

We employ a further profitability measure of investments traditionally considered by financial investors in companies in earnings per share. We use the following equation to calculate the proxy using the following equation:

$$
E P S_{i}=\frac{\text { Net Income }_{i}-D_{i}}{N_{i}}
$$

Where:

$E P S_{i}$ is the earnings per share for each firm $i$

Net Income $_{i}$ is the most recently reported net income for each firm $i$

$D_{i}$ is the most recently distributed dividend for each firm $i$

$N_{i}$ is the number of outstanding shares for each firm $i$.

We employ the book-to-market ratio developed in Fama and French (1993) to capture any effects of the pricing anomaly described in the study. We use the formula of Fama and French (1993) and calculate the book-to-market ratio as:

$$
B / M_{i}=\frac{\text { Book Value of Equity }}{P_{0} \times N_{i}}
$$

Where:

$B / M_{i}$ is the book to market ratio for each firm $i$

Book Value of Equity E $_{i}$ is the most recently reported book value of equity for each firm $i$

$P_{0}$ is the market share price on the day of takeover announcement for each firm $i$ 
$N_{i}$ is the number of outstanding shares for each firm $i$.

Studies examining takeover activity at the industry level are more successful in establishing patterns of takeover activity; see especially Nelson (1999) and McGowan (1971). Mitchell and Mulherin (1996), along with Andrade, Mitchell and Stafford (2001), observe clustering of takeover activity by industry suggesting that deregulation and innovation effect specific industries over time. Further, Mitchell and Mulherin (1996) note that if takeover activity is driven by industry-specific shocks, bidder performance should not necessarily be higher than the performance before the shock occurred. This explanation is consistent with previous empirical research showing no post-takeover increase in bidder returns. Finally, Andrade and Stafford (2004) confirm previous studies' outcomes by finding a strong positive relationship between industry-specific shocks, followed by within-industry takeover activity. However, they also confirm the changing nature of industry effects on takeovers across time. We capture the standard industry classification (SIC) code at the two-digit level and establish a set of indicator variables to control for industry effects. Note the following set of indicator variables:

\section{DINDUSTRY}

$=\left\{\begin{array}{cc}1 & \text { if the target firm remains in its primary industry of operation } \\ 0 & \text { if the target firm does not remain in its primary industry of operation }\end{array}\right.$ Where:

$\operatorname{DINDUSTR} Y_{i}$ is an indicator variable which equals 1 when the target firm remains in its primary industry of operation, for each firm $i$.

Jensen (1986) postulates that in times of economic growth due to more retained earnings available to management, the agency motive described above will dominate and likely 
increase takeover activity incidents. Grugler, Mueller, Yurtoglu and Zulehner (2003) show that the United States economy has experienced five clearly identifiable takeover periods: in the early 1900s, the 1920s, the 1960s, the 1980s and finally in the 1990s: all coincide with periods of strong economic growth. We establish a set of indicator variables, one for each year in the sample, to control for year effects in our tests as:

$$
D_{Y E A R_{i}}=\left\{\begin{array}{lc}
1 & \text { if the takeover announcement is in the year } \\
0 & \text { if the takeover announcement is not in the year }
\end{array}\right.
$$

Where:

$D Y E A R_{i}$ is an indicator variable equal to 1 when the takeover is announced during that year.

Finally, due to the cross-sectional nature of our analysis, this study is likely to have been affected by the sample selection bias. This is because dependent variables are only observed for a non-randomly selected sample, which is the case when we only select companies experiencing takeover activity for our sample. This issue can result in biased regression results and therefore inference as documented in Campbell, Grossman and Wang (1993) and Chan, Jegadeesh and Lakonishok (1995). Further, as our sample construction is not random, our model's inference is not reliable in the context of population distributions. The issue of sample selection bias can be corrected by applying the Heckman (1979) two-step methodology. In the first stage, we estimate a probit model with a sample of both sample firms and matched control firms not exposed to any merger and acquisition activity. Firm matching was conducted by first matching the sample firms by industry, size of firm capitalisation and year of observation in the takeover sample. The model is specified as: 


$$
D S A M P L E_{i}=\Phi\left(\gamma_{0}+\gamma_{1} \ln \left(S I Z E_{i}\right)+\gamma_{2} \operatorname{DINDUSTRY_{i}}+\gamma_{3} D Y E A R_{i}+\varepsilon_{i}\right)
$$

Where:

$D S A M P L E_{i}$ is the indicator variable equal to 1 when the firm $i$ is in the takeover sample and 0 when it is not exposed to any takeover activity

$\ln \left(S I Z E_{i}\right)$ is the natural logarithm transformation of market capitalisation of each firm $i$ on the day of announcement

$\operatorname{DINDUSTR} Y_{i}$ is an indicator variable which equals 1 when the target firm is in the primary industry of operation same as defined industry for each firm $i$

$D Y E A R_{i}$ is an indicator variable equal to 1 when the takeover is announced that year.

After estimating the first step of Heckman (1979) model, the second step allows calculation of the inverse mills ratio, estimating the unobservable relationship that influences the selection from the overall matched sample. More specifically, we capture the error term $\varepsilon_{i}$ of the first step model and use it as a control variable $I M R_{i}$ in subsequent models. The inclusion of this variable in further estimation corrects for the sample selection bias which could be present in the model estimates.

\subsection{Estimation procedure using Generalised Method of Moments}

We employ the Hansen (1982) GMM framework to test all linear models. This includes estimating the measures of informed trading according to Bollen, Smith and Whaley (2004) specifications, the tests of informed trading effects on CAR and tests of reverse causality. The same procedures are used for robustness testing informed trading effects on CAR and tests of reverse causality. Hansen (1982) GMM framework presents several 
advantages over traditional estimation methods. It is useful in particular for time-series data obtained from financial markets.

The estimation technique allows for less restrictive assumptions than more commonly employed techniques. In particular, by permitting generally more relaxed distributional assumptions, allowing us to use non-normally distributed intraday share trading data. Using such data in the GMM estimation methodology still provides parameter estimates that are consistent, asymptotically normally distributed and have a consistently estimated asymptotic covariance matrix. GMM employs no distributional assumptions in model estimation procedures, instead relying only on data stationarity conditions and the central limit theorem to deliver robust model estimates.

The methodology also corrects for autocorrelation, a common problem in time-series data. In ordinary estimation techniques for linear models, such as ordinary least squares, no built in corrections for sample reductions exist, due to autocorrelations present in the financial data series leading to overestimating the statistical significance of these models broadly, and with standard errors of estimators specifically. GMM corrects for overestimation and allows us to use customised moment conditions to test for specific relationships, without the need to specify the full model. This enables us to focus on the reliably measurable part of the model relationship, rather than distributional considerations that require fully specified theoretical model analogue variables observed in tractable data.

To conduct our proposed test, we specified a family of orthogonality conditions. These were used to construct the criterion function under the GMM framework in such a way 
that the parameter estimator was consistent, asymptotically normal and had an asymptotic variance-covariance matrix estimated consistently. The criterion function is minimised by selecting the weighting matrix to set the moment conditions equal to 0 and obtain the model parameters.

In relation to testing specific models in this context, the moment conditions are expressed as follows:

$E_{t}\left[\begin{array}{c}E S P R D_{i t}-\alpha_{0}-\alpha_{1} I n v T V_{i t}-\alpha_{2} N H I_{i}+\alpha_{3} I H P_{U i t}\left(\tau_{i t}\right)-\alpha_{4}\left(I H P_{I i t}\left(\tau_{i t}\right)-I H P_{U i t}\left(\tau_{i t}\right)\right) \\ {\left[E S P R D_{i t}-\alpha_{0}-\alpha_{1} I n v T V_{i t}-\alpha_{2} N H I_{i}+\alpha_{3} I H P_{U i t}\left(\tau_{i t}\right)-\alpha_{4}\left(I H P_{I i t}\left(\tau_{i t}\right)-I H P_{U i t}\left(\tau_{i t}\right)\right)\right] \times \operatorname{InvTV} V_{i t}} \\ {\left[E S P R D_{i t}-\alpha_{0}-\alpha_{1} I n v T V_{i t}-\alpha_{2} N H I_{i}+\alpha_{3} I H P_{U i t}\left(\tau_{i t}\right)-\alpha_{4}\left(I H P_{I i t}\left(\tau_{i t}\right)-I H P_{U i t}\left(\tau_{i t}\right)\right)\right] \times I H P_{U i t}\left(\tau_{i t}\right)} \\ {\left[E S P R D_{i t}-\alpha_{0}-\alpha_{1} I n v T V_{i t}-\alpha_{2} N H I_{i}+\alpha_{3} I H P_{U i t}\left(\tau_{i t}\right)-\alpha_{4}\left(I H P_{I i t}\left(\tau_{i t}\right)-I H P_{U i t}\left(\tau_{i t}\right)\right)\right] \times\left(I H P_{I i t}\left(\tau_{i t}\right)-I H P_{U i t}\left(\tau_{i t}\right)\right)}\end{array}\right]=0$

Where:

$E S P R D_{i}$ is the effective bid-ask spread for each firm $i$

$\alpha_{0}$ is the minimum tick size for the market maker

$\operatorname{InvTV} V_{i}$ is the inverse of trading volume for each firm $i$

$N H I_{i}$ is the normalised Herfindahl Index for each firm $i$

$I H P_{U i}$ is the inventory holding premium for uninformed trader of share in firm $i$

$I H P_{I i}$ is the inventory holding premium for informed trader of share in firm $i$.

Therefore, the vector of orthogonality conditions used to test the unrestricted model can be specified as: 
$g_{t}=\frac{1}{t} \sum_{n=1}^{t}\left[\begin{array}{c}E S P R D_{i t}-\alpha_{0}-\alpha_{1} I n v T V_{i t}-\alpha_{2} N H I_{i}+\alpha_{3} I H P_{\text {Uit }}\left(\tau_{i t}\right)-\alpha_{4}\left(I H P_{\text {IIt }}\left(\tau_{i t}\right)-I H P_{\text {Uit }}\left(\tau_{i t}\right)\right) \\ {\left[E S P R D_{i t}-\alpha_{0}-\alpha_{1} I n v T V_{i t}-\alpha_{2} N H I_{i}+\alpha_{3} I H P_{\text {Uit }}\left(\tau_{i t}\right)-\alpha_{4}\left(I H P_{I i t}\left(\tau_{i t}\right)-I H P_{\text {Uit }}\left(\tau_{i t}\right)\right)\right] \times \operatorname{InvTV}} \\ {\left[E S P R D_{i t}-\alpha_{0}-\alpha_{1} I n v T V_{i t}-\alpha_{2} N H I_{i}+\alpha_{3} I H P_{U i t}\left(\tau_{i t}\right)-\alpha_{4}\left(I H P_{\text {Iit }}\left(\tau_{i t}\right)-I H P_{\text {Uit }}\left(\tau_{i t}\right)\right)\right] \times I H P_{\text {Uit }}\left(\tau_{i t}\right)} \\ {\left[E S P R D_{i t}-\alpha_{0}-\alpha_{1} I n v T V_{i t}-\alpha_{2} N H I_{i}+\alpha_{3} I H P_{U i t}\left(\tau_{i t}\right)-\alpha_{4}\left(I H P_{\text {Iit }}\left(\tau_{i t}\right)-I H P_{\text {Uit }}\left(\tau_{i t}\right)\right)\right] \times\left(I H P_{\text {Iit }}\left(\tau_{i t}\right)-I H P_{\text {Uit }}\left(\tau_{i t}\right)\right)}\end{array}\right]$

We can test hypotheses of significance in the overall model by restricting the above model. We can remove the variables of interest and re-estimate the model to test the hypothesis $H_{0}: \alpha_{n}=0$. Hansen (1982) GMM framework flexibility also allows us to test a joint hypothesis that a specific set of estimators are significant by through a joint hypothesis $H_{0}: \alpha_{1}=\alpha_{2}=\alpha_{3}=\alpha_{4}=0$ by using the asymptotic covariance matrix to formally test if a group of estimated parameters is significantly different from zero. Hansen (1982) study provides a proof that the asymptotic distribution of estimators is:

$$
\sqrt{t}(\hat{\alpha}-\alpha) \underset{\sim}{a} N\left(0,\left[D_{0}^{\prime} S_{0}^{-1} D_{0}\right]^{-1}\right)
$$

Where:

$t$ is the number of observation

$\hat{\alpha}$ is the GMM estimator of the true parameter vector $\alpha$

$D_{0}$ is the derivative matrix equal to $\partial g_{t} / \partial \alpha$

$S_{0}$ is the sample estimate of the variance matrix of moment conditions.

Under the GMM framework, the estimator means converge to a normal distribution; sample mean squares divided by their variance converge to a $\chi^{2}$ distribution. Using the weighting of the inverse of the covariance matrix, we obtain the test statistic of over identifying restrictions, known as the $J$ test, is defined as:

$$
J_{t}=\operatorname{tg}_{t} \hat{\alpha}^{\prime} S_{0}^{-1} g_{t \sim}^{a} \chi_{j-k}^{2}
$$

Where:

$J_{t}$ is the test statistic for over identifying restrictions

$g_{t}$ is the vector of sample moment conditions used to test model significance 
$S_{0}$ is the sample estimate of the variance matrix of moment conditions

$\chi_{j-k}^{2}$ is the test statistic distributed under the chi squared distribution with degrees of freedom of number of restrictions $j$ less number of estimators $k$.

In the GMM framework, if the number of estimators, $k$, is lower than the number of restrictions, $j$, the model is said to be over-identified. This arrangement allows us to use the remaining degrees of freedom to test if the model moment conditions match the data. More formally, we are able to reject the restrictions under the null hypothesis if test statistic is higher than the $\chi^{2}$ statistic at the remaining degrees of freedom, at each level of significance. 


\section{CHAPTER FOUR: DATA}

\subsection{Australian Sample}

\subsubsection{Introduction}

In Australia, the takeover rules ${ }^{2}$ apply to all market listed entities and unlisted entities with more than 50 shareholders. The principles under which the takeover rules operate include an efficient, competitive and informed methodology with sufficient time for target shareholders to consider a bidder's proposal and the equal treatment of all target shareholders. The rules regarding takeovers are triggered once any legal entity, in this case the bidder, gains more than $20 \%$ of the voting rights in the target firm. Under the current listing rules for Australia, this equates to the acquisition of more than $20 \%$ of a target company's ordinary shares. This means that if any entity acquires more than $20 \%$ of any company's ordinary shares, they immediately become the bidder and must release an acquisition statement to inform the target firm and the market of their intentions. One exception for listed targets exists where a firm can continue to purchase shares above the $20 \%$ threshold and not become the bidder: this is accomplished by purchasing at most $3 \%$ of the target company shares every six months (this is known as a creep acquisition). For Australian listed firms, substantial shareholders must file the statement of their holdings with the Australian Stock Exchange (ASX) if they own 5\% or more in a listed firm. With $15 \%$ of shareholdings, if the block holder is not an Australian entity, the regulation requires that the Foreign Investment Review Board (FIRB) approves any further

\footnotetext{
${ }^{2}$ In Australia, the takeover process is governed by a combination of legislation and regulatory policies. The legislation governing takeovers can be found in Part 5.1 and Chapter 6 of the Corporations Act 2001, with the policy developed by Australian Securities and Investments Commission (ASIC) and administered by the takeover panel (a specialist tribunal set up to resolve any takeover disputes). Australian listed companies are also subject to the ASX listing rules and any investments by foreign entities are subject to the Foreign Acquisitions and Takeover Act 1975 and are examined by FIRB. Finally, the applicable anti-trust rules are established in Competition and Consumer Act 2010 which are administered by the Australian Competition and Consumer Commission (ACCC) with specific regulations for banking, financial, media and telecommunications, aviation, gaming and energy and resources industries governed by the relevant laws.
} 
acquisitions of a firm's shares. Beyond $25 \%$ shareholding, the shareholder can block any special resolutions and stop any other takeover attempts. With greater than $50 \%$ shareholdings, the investor can propose and pass ordinary resolutions to approve a takeover, and at $75 \%$ the investor can approve a special resolution. At a shareholding of $90 \%$, the rules force the bidder to compulsorily acquire the remaining shares.

A bidder must announce their intentions as soon as they own more than $20 \%$ of a target's shares. In this declaration, the bidder must declare the proportion of shares sought in the takeover (usually $50 \%$ or $100 \%$ ), the proportion of shares already held, the payment form for share acquisition, whether the takeover is friendly or hostile. The bidder must also satisfy all due diligence requirements. Usually, prior to such an announcement the prospective bidder approaches the prospective target informally to discuss a possible takeover. The discussion may be followed by a written, confidential, non-binding proposal that seeks due diligence access for the bidder. If the target grants due diligence access, it is on a basis of a confidentiality agreement, restricting information use, and leading to a friendly takeover. The target may also require a 'standstill' agreement, halting any further acquisition of its shares by the prospective bidder until a formal bid is made. If the target is not cooperative regarding takeover proposal, the bidder may still launch a hostile takeover in an announcement to the market and target shareholders.

The board of directors of the target firm must follow their fiduciary duties to maximise shareholder wealth when assessing the reasonableness of any takeover proposal and bid. Further, according to the ASX listing rules, the directors should not take any action without shareholder approval. The board can prepare a statement in response to a takeover bid, recommending or not recommending that the shareholders sell their 
shares. If the board concludes that the takeover is not in shareholders' best interests, it (the board) should prepare a takeover defence manual, monitor the share register closely, prepare valuation reports and study the takeover announcement and proposal documents for any inadequacies or inconsistencies. The target may also consider approaching other potential bidders and negotiate more friendly terms or ask the takeover tribunal to intervene in the process.

Once a takeover bid is made, takeover announcement rules govern the situation. The offer to all shareholders must be the same, no special deals for individual shareholders are allowed. The offer price cannot be lower than the amount the bidder paid for target shares within the last four months. The offer period must not be less than one month and no longer than one year. The bidder must complete full acquisition of the target if the shareholding reaches $90 \%$, and must complete the acquisition of all shares sought in the offer if the proportion of shares acquired reaches $75 \%$ of the amount in the offer. The target firm must also release a statement containing the board's recommendation to its shareholders if they believe this is a beneficial bid for the firm's shares.

\subsubsection{Sample Construction}

The initial sample consisted of Australian companies under takeover activity between 1 January 2007 and 1 July 2013. This information was obtained from the Thomson Reuters SDC Platinum Mergers and Acquisitions Database. To be included in the initial sample, the target firm was required to be a fully identifiable Australian incorporated company.

This requires that the company name, identifier fields and country of firm domicile contain records and that the country of incorporation for these firms was Australia. This search revealed 2,778 firms that were classified as takeover targets in merger and 
acquisition events. The sample was further filtered to include only three methods of payment proposed for the takeover event: cash, shares, and both cash and shares. Other forms of payment were excluded, such as convertible securities, preferred securities or other types of payments. This selection is consistent with Mitchell and Pulvino (2001) approach. This suggests that other, non-standard payment methods would require takeover traders to implement very complicated and more costly investment strategies to secure any profits from trading around the announcement event. Therefore, informed traders are very unlikely to participate in deals with complex payment structures. Including only clearly identifiable parties with specified payment structures of cash, shares or both resulted in 566 takeover events remaining in the sample. We further removed share repurchases and capital restructuring transactions from the sample, as these events are not considered takeover events. We also removed any records with a 'rumour' status, as these do not represent any formal takeover bids, but only takeover rumours that are never formalised.

We also removed acquisitions where the bidder already owned more than $50 \%$ of the target shares before the takeover announcement. This was done as these transactions constitute only the completion of previous takeover activity. These transactions are usually binding and do not require any market activity for their resolution, as the bidder already owns a controlling interest in the target firm. This type of transaction is by itself interesting, as it may involve the possibility for expropriation outside shareholders by the bidder, but this is not the focus of our study. This sample adjustment left 484 firms in the sample. 
Acquisition intents for ownership below $50 \%$ of total shares of the target after completion were also removed as they did not pose a direct threat (takeover attempt) to the target firm. These intents are disqualified because if the bidder proposes to own less than the controlling interest in the company, they cannot assume managerial control of the target. As such, this action may be classified as an acquisition rather than a takeover. This sample selection step resulted in 244 announcement events eligible for inclusion in the takeover sample.

Next, we restricted our sample to events where both the bidder and target firms were listed firms during the takeover process. This was done to exclude any going private transactions, which have a significantly different dynamic to traditional takeovers. Takeover traders are unlikely to participate in going private transactions, as they are unable to obtain a sufficient amount of target shares to execute their investment strategy.

Finally, target firms with capitalisation of less than 1 million Australian dollars were removed, as these represent deals concerning very small firms, so-called penny stocks. Most notably, Jegadeesh and Titman (2001) suggest that as the price movements of a single tick present a very large return relative to the small price of the shares, these shares provide exaggerated values for returns, merely due to equity market construction and not to large price changes. Typically, Australian studies (such as Aitken, Buckland, Izan and Walter [1996]) on listed firms remove penny stocks due to this issue.

This selection process yielded 175 takeovers, with 75 successful takeovers and 100 unsuccessful takeover attempts. The dataset included the following variables: company 
identifier, company name, date of takeover announcement, proportion of target shares intended for acquisition in the takeover, proportion of target acquired in the takeover, proportion of shares held by the bidder prior to the takeover announcement, the payment method (percentage paid in cash and percentage paid in shares), the offer price per share, and the company and takeover outcome.

One observation was removed, due to the extreme value of return at $185 \%$ on the takeover announcement day. This observation was uncharacteristically high where the next largest announcement day return was $100 \%$. Six target companies in the sample were included more than once, due to unsuccessful takeover outcomes followed by another takeover announcement within the sample collection period.

Table 4.1 details the selection criteria for constructing our sample. Our sample size aligns with existing literature on the Australian takeover market, using 53 to 240 events: Dodd (1976) uses 72 target firm observations; McDougall and Round (1986) study 88 Australian takeover events; Casey, Dodd and Dolan (1987) focus on 53 takeovers. Bellamy and Lewin (1992) study 210 takeovers, while Bugeja and Walter (1995) focus on 78 target firms. Brown and da Silva Rosa (1995) employ 153 firms, da Silva Rosa, Izan, Steinbeck and Walter (2000) 240 takeovers, while Bugeja and da Silva Rosa (2010) use 205 takeovers in their studies. Table 4.2 details the summary statistics for variables in the constructed sample on 172 takeover targets. The measures of informed trading across different time aggregation periods during the day show similar statistical features suggesting that trading occurs in a steady manner during the day. 
Table 4.1 Australian Sample: Data Selection Australia

Table 4.1 shows the process of Australian sample data selection. It details the extraction of observations from four databases used to obtain the data: Thomson Reuters SDC Platinum Mergers and Acquisitions Database, Thomson Reuters Tick History, Thompson Financial Datastream and Annual Reports Online, via the Aspect Huntley Database. The initial sample was collected for takeover events between 1 January 2008 and 1 July 2013 in the Australian market. The Transaction data was collected from the Thomson Reuters SDC Platinum Mergers and Acquisitions Database and filtered as described in the table below. The availability of supplementary data from Thomson Reuters Tick History, Thompson Financial Datastream, Annual Reports Online via the Aspect Huntley Database, the Securities Industry Research Centre of Asia-Pacific (SIRCA), and the Corporate Governance Database resulted in only two firms being removed from the sample. Finally. One further firm was removed due to unexplained extreme values.

Thomson Reuters Security Data Corporation (SDC) Platinum Mergers and Acquisitions Database

Observations

Total number of Mergers and Acquisitions (1 January 2008 - 1 July 2013) 112,321

Target Firms domiciled in Australia 2,778

Clearly identifiable parties to takeover activity 1,856

Clearly stated method of payment either cash, shares or both 566

The activity is not share repurchases and capital restructuring 501

Activity where bidder has less than $50 \%$ holdings in the target prior to announcement 484

Activity where bidder intends to acquire more than $50 \%$ holdings in the target 244

Activity where both bidder and target are listed firms 205

Target market capitalisation is above than 1 million dollars 175

Thomson Reuters Tick History

Trade and Quote data (10:10am-4pm) 175

Thompson Financial Datastream

\begin{tabular}{lr}
\hline \hline Earnings per share & 175 \\
\hline Book to market & 175
\end{tabular}

Annual Reports Online via Aspect Huntley Database

\begin{tabular}{lr}
\hline \hline Return on Equity & 173 \\
\hline Return on Assets & 173 \\
\hline
\end{tabular}

Securities Industry Research Centre of Asia-Pacific (SIRCA), Corporate Governance Database

Block Holdings

Extreme Values

Non extreme value observations

Takeover Sample

Successful Takeovers

Unsuccessful Takeovers 
Table 4.2 Australian Sample: Data Summary Statistics

Table 4.2 shows the summary statistics for the Australian sample data. It details the standard measures of statistical location and dispersion. The table covers the following variables: an indicator variable of takeover success, equal to 1 when the takeover announcement leads to a successful completion and 0 otherwise; $\log ($ Size), the natural logarithm transformation of market capitalisation of the firm on the day of takeover announcement, calculated as the number of ordinary shares multiplied by the opening share price; Premium 1 Day is a calculated as the difference between the takeover target offer price per share and the closing price per one day prior to the announcement. This variable is also sometimes referred to as the target share run-up; Pay cash, pay stock and shares held are reported in the Thomson Reuters SDC database. Pay cash reports the percentage of shares announced for acquisition in exchange for cash, while the pay stock variable reports the percentage of shares for acquisition paid in shares of the bidder. Shares held details the percentage of target shares held by the bidder before the acquisition is announced. Returns on assets (ROA) and returns on equity (ROE) are the most recent reported percentage values for the year before the takeover announcement date, and are captured from Annual Reports Online via the Aspect Huntley Database. The earnings per share (EPS) and book-to-market ratio (B/M) variables are captured from the Thomson Reuters Financial Datastream. EPS is the most recent dollar amount of declared earnings by the target prior to the takeover announcement data, divided by the total number of ordinary shares. The $\mathrm{B} / \mathrm{M}$ ratio is calculated as the most recently reported book value of target equity prior to the takeover date, divided by the market capitalisation of the firm one day prior to the takeover announcement. Probability of informed trading $(P I)$ estimated in the 5 minute, 10 minute, 15 minute and 30 minute aggregation periods obtained from Bollen, Smith and Whaley (2004) model of spread decomposition. This measure represent the proportion of informed trading on the day of takeover announcement estimated using different time aggregation periods of 5, 10, 15 and 30 minutes of trading activity.

\begin{tabular}{lccccc} 
& Mean & Median & $\begin{array}{c}\text { Standard } \\
\text { Deviation }\end{array}$ & $\begin{array}{c}\text { Minimum } \\
\text { Value }\end{array}$ & $\begin{array}{c}\text { Maximum } \\
\text { Value }\end{array}$ \\
\hline \hline Success & 0.4114 & 0 & 0.4935 & 0 & 1 \\
Log(Size) & 4.9007 & 4.6555 & 2.0476 & 0.4383 & 10.399 \\
Premium 1 Day & $15.972 \%$ & $5.745 \%$ & $29.262 \%$ & $-82.33 \%$ & $100 \%$ \\
Pay Cash & $23.169 \%$ & $0 \%$ & $39.864 \%$ & $0 \%$ & $100 \%$ \\
Pay Stock & $55.310 \%$ & $84.605 \%$ & $47.667 \%$ & $0 \%$ & $100 \%$ \\
Share Held & $6.142 \%$ & $0 \%$ & $15.601 \%$ & $0 \%$ & $29.1 \%$ \\
ROA & $-23.631 \%$ & $-3.459 \%$ & $174.366 \%$ & $-1874.45 \%$ & $66.194 \%$ \\
ROE & $1.755 \%$ & $-5.136 \%$ & $460.412 \%$ & $-270.90 \%$ & $4445.581 \%$ \\
EPS & $\$ 0.1413$ & $\$ 0.00$ & $\$ 0.4291$ & $\$ 0.00$ & $\$ 2.75$ \\
B/M & 0.7655 & 0.6137 & 0.7341 & -0.8265 & 5.2632 \\
Block Holders & $19.809 \%$ & $0 \%$ & $25.790 \%$ & $0 \%$ & $98.63 \%$ \\
PI 5 min & $5.555 \%$ & $6.593 \%$ & $3.424 \%$ & $0 \%$ & $12.986 \%$ \\
PI 10 min & $5.551 \%$ & $6.595 \%$ & $3.483 \%$ & $0 \%$ & $12.986 \%$ \\
PI 15 min & $5.555 \%$ & $6.592 \%$ & $3.451 \%$ & $0 \%$ & $12.986 \%$ \\
PI 30 min & $5.691 \%$ & $6.596 \%$ & $3.460 \%$ & $0 \%$ & $12.987 \%$ \\
N & 172 & 172 & 172 & 172 & 172 \\
\hline \hline
\end{tabular}




\subsubsection{Trade and Quote Data}

We capture the Australian trade and quote data from the Thomson Reuters Tick History Database. For the ASX, the hours of trading are between 9:59:45 am and 3:59:00 pm Australian eastern standard time. However, the opening auctions for alphabetical groupings of stock codes occur until at least 10:09:15 am. During this time the market is in opening phase where opening prices are calculated and no reliable bid-ask spreads are known to the traders in the market. To avoid any possibility of capturing these results of the opening auction in the data, we commence trade recording in the sample from 10:10:00 am Sydney time for every trading day, continuing to record data until 3:59:00 pm, after which a closing auction and the adjustment period were also excluded. ${ }^{3}$

In Australian data, the ASX has strict rules about the tick sizes for shares traded on the exchange. We assign tick size, the minimum amount of price updates, using the calculated mid-quote to approximate the share price for each trade by using the ASX tick size categorisation: 0.1 cent tick for shares with price smaller than 10 cents, 0.5 cent tick for shares with prices between 10 cents and 2 dollars and 1 cent tick for shares with prices greater than 2 dollars.

\footnotetext{
${ }^{3}$ In our estimation procedure we rely on market quoted bid-ask spreads to consistently estimate the Bollen, Smith and Whaley (2004) probability of informed trading PI measure and therefore require that the market be fully open and in ordinary state of trading to provide reliable data.
} 


\subsection{United States Sample}

\subsubsection{Introduction}

The United States corporation and securities laws represent a regulatory framework allowing two main methods of structuring takeover transactions. The takeover bidder may decide to announce an offer to acquire $100 \%$ of target immediately in a single-step merger, or may announce an acquisition intent only a specific amount of shares in the target. The single-step takeover announcement uses merger statutes available in every US state that require the approval of a mandatory proportion of target firm shareholders. The tender offer for a specific proportion of target shares is made directly to each shareholder individually to purchase their shares, and is typically followed by a tender offer to acquire shares of minority shareholders in an independent tender offer. In addition, both single-step takeovers and tender offers are subject to the general fiduciary duty law within each state of incorporation of each target firm. The overall framework is focused more on a takeover's disclosure aspects, rather than regulating the changes in managerial control of the target firms. This ensures that target firm shareholders are given sufficient information and time to make an informed decision on the offer provided by the bidder.

The bidder is also restricted to purchasing shares in classes under the offer, and not any other class of shares in the target firm. The bidder must treat all shareholders equally for the duration of the offer and in any amendments to the original offer. If the bidder acquires a majority stake in the target of at least 85 to $90 \%$ or more (subject to state takeover regulations), the bidder may implement a short-form merger without any further approvals of the target shareholders; here, the bidder must acquire all remaining shares in the target. 
Activities of a bidder firm incorporated outside the United States are deemed bids by foreign entities and are subject to additional regulation under the Exon-Florio Act, where the Committee on Foreign Investment in the United States (CFIUS). The CFIUS has the right to review and approve, stop and even unwind transactions involving a controlling interest of foreign bidders associated with foreign governments and any other entities that could affect US national security. Further, special attention is placed on acquisitions in the following industries: electric and gas utilities, banks, holders of broadcasting licences and airlines. Bidders are allowed to offer cash or their shares, or mix of both as consideration for acquiring target shares in the takeover tender process. When any shares are used by the bidder as a payment method, the offer must also comply with the public sale of securities legislation under the Securities Act 1934, which includes filing pro forma financial statements for the bidder.

Single-step takeovers are primarily regulated under the relevant state corporation laws but are also subject to federal securities regulation regarding proposal by the target firm's shareholders and board of directors (proxy rules). The most common method of acquisition is a friendly takeover, which includes the bidder and target firm entering into a formal agreement. They provide all details of the acquisition intent to the target shareholders, including the structure of the bidder's offer. The bidder's obligations for completing the takeover are to obtain a board recommendation from the target firm to its shareholders within ten days of the announcement, and to respect any restrictions placed on the target firm's business operations until the takeover activity is concluded. This contract may also include the target's ability to solicit competing takeover bids and can specify any termination fees, with a clause whereby the target may solicit competing 
takeover bids and specify any termination fees payable to the bidder in case third parties enter the takeover process. Single-step takeovers in the United States market, unlike other countries, may only be paid in cash. Such transactions do traditionally take longer to be approved by a target's shareholders and therefore it also takes longer to finalise the tender offers. However, if a bidder provides his or her own shares as payment, there may be significant regulatory delays in approving the takeover. Finally, the single-step takeover process will always ensure that the bidder acquires all of the outstanding shares of the target if the takeover is successful. This feature may be particularly valuable to bidders, as it ensures a full acquisition and creates only two possible outcomes for the takeover proposal. The disadvantage of engaging in single-step takeovers is that the bidder is generally prohibited from acquiring any shares of the target between the time the negotiations begin and the takeover is approved by the board of directors and shareholders. This feature creates opportunities for takeover traders to participate in trading target shares, later tendering their shares to the bidder once the takeover is approved.

If the bidder announces an unsolicited or hostile takeover, and the agreement between the bidder and target does not exist prior to making such an announcement can be classified as either a tender offer or a single-step takeover. In either case, the bidder must obtain the target shareholders' approval, as the offer was made directly to them under the tender offer rules. When no prior agreement exists between takeover parties, the bidder is allowed to purchase shares on the share market or directly from target firm shareholders. However, there are two main restrictions with respect to the amount of shares the bidder is allowed to acquire before a formal takeover announcement must be made to the market. With the first, under Section 13D of the Securities Exchange Act of 
1934 (SEA), an acquirer may purchase up to $5 \%$ of the outstanding shares of the target before being required, within ten calendar days, to publicly file a disclosure statement on Schedule 13D with the Securities and Exchange Commission (SEC). This disclosure includes a field where the bidder must declare its plans regarding any future acquisitions of target shares. With the second restriction, under the Hart-Scott-Rodino Antitrust Improvements Act 1976, an acquirer may not purchase more than $\$ 70$ million in inflationadjusted value of common target before the bidder must file their actions with United States antitrust authorities. The bidder must also notify the target company of the filing and stop all actions for at least 30 days. Once announced, the tender offer must be open for acceptance by the board of directors and target shareholders for at least 20 business days. After any adjustments to the original offer (related to either the price or amount of shares) at least 10 days must be allowed for target shareholder acceptance. There is no maximum limit on the duration of the tender offer or single-step; however, most takeovers are completed within a year.

Bidders seeking to launch a tender offer to acquire target firm shares must prepare and file a disclosure statement on Schedule TO for the Securities and Exchange Commission (SEC) and to the target on the day a takeover is announced. The bidder must comply with all rules relating to tender offers after the announcement day until the action is completed. The bidder is not required to distribute the complete Schedule TO filing documentation. Only the offer reference letter required in the Schedule TO documentation process must be sent to the target shareholders. In cash-only transactions, even though the Schedule TO must be filed with the SEC, the bidder may distribute the offer documents to the target's shareholders and commence acquiring target shares immediately. Bidders in all-cash transactions are also not required to prove 
they possess the necessary financing for the takeover, as this is assumed to be the case before the takeover is announced. However, the bidder must provide United States Generally Accepted Accounting Principles (GAAP) reconciled financial statements as part of the filing requirements and to target shareholders in all transactions.

It is important to note that if bidders have restrictions placed on their ability to acquire shares of the target they may rely on the activity of takeover traders to improve their chances of successfully completing the takeover. These traders specialise in purchasing target firm shares from existing shareholders, effectively assembling blocks of shares and later tendering their shares to the bidder receiving the offer price. This activity, as well as traders' motivations, is proposed in Cornelli and Li (2002) theoretical work. Takeover traders may also participate in purchasing target shares if there are no restrictions placed on acquisitions of the bidder itself, if they can obtain a sufficient number of shares at a sufficiently low price to derive profit from the transactions.

Unlike in the Australian regulation of takeover activity, in the US, once the takeover is announced, the bidder is allowed to individually negotiate with shareholders offering different prices to each in order to acquire their shares. In Australia, the bidder must treat all shareholders the same offering the same conditions of the offer to all of them. Further, Australian bidders are allowed to engage in slow takeovers (above $20 \%$ holdings in the target) acquiring small stakes in the target over time not triggering any formal takeover reporting requirements to ASIC (Australian Securities and Investments Commission) while in the US any increases in stakes above $5 \%$ in even a prospective target have to be publicly disclosed to the SEC (Securities and Exchange Commission) with intention of the acquisition provided. Takeover bidders in both markets must buy all shares if they 
purchase $85 \%-90 \%$ of the target shares but only in Australia they must complete the acquisition of all shares under the offer once the acquisition reaches $75 \%$ of shares under the offer. The regulation of foreign bidders is at any level has to be approved by FIRB (Foreign Investments Review Board) and CFIUS (Committee on Foreign Investments in the United States) in Australia and US respectively, however, under antitrust provisions, the DOJ (Department of Justice) approval in the US is only required for acquisitions above US\$70m level while in Australia the ACCC (Australian Competition and Consumer Commission) can independently investigate impacts of takeover activities at any level.

The most significant difference between regulations relating to takeover traders is that in the US bidders can engage with shareholders separately and negotiate prices for their shares individually. Therefore in US, we expect to see a much more concentrated impact of takeover traders on the day of bid announcement because traders are more likely to rush in to buy shares of the target in order to secure the largest possible stake in the target given the capital resources available to them. The larger their stake in the target, the better their bargaining position with regard to the bidder. Other than this difference, slightly different regulations takeover in US and Australia, may cause the traders to behave slightly differently at the margin depending on the specific features of each takeover bid. This ability to acquire significant target stakes quickly is further limited in the Australian market due to the significantly lower level of liquidity compared to the US market. However, since there are primarily only two different levels of takeovers, the full and the partial, and both of these have sufficiently similar rules to cause the reaction of takeover traders to acquire significant stakes in the target after the bid is announced to be sufficiently similar in each market even if the ability to do so may be more limited in the Australian market. 


\subsubsection{Sample Construction}

The initial sample consisted of companies in the United States market subject to takeover activity between 1 January 2007 and 1 July 2013; data were obtained from the Thomson Reuters SDC Platinum Mergers and Acquisitions Database. To be included in the initial sample, the target firm was required to be a fully identifiable incorporated company in the US. This requires that the company name, identifier fields and country of firm domicile contain records and that the country of incorporation for these firms was the US, and that it was listed on one of the United States stock exchanges. This search revealed 6,354 takeover announcements where takeover target firms could be identified in merger and acquisition events. The sample was further filtered to include only three methods of payment proposed for the takeover event: cash, shares, and both cash and shares. Other forms of payment were excluded, such as convertible securities, preferred securities or any other payment types. This selection methodology follows of Mitchell and Pulvino (2001) approach, where non-standard payment methods would require investors to implement costly investment strategies to secure any profits from trading as a result of the announcement event. Therefore, the sample includes only clearly identifiable firms with specified payment structures of cash, shares or both, resulting in 5,969 takeover events retained in the sample. We further removed share repurchases and capital restructuring transactions from the sample as these events were not considered takeover events.

We removed any acquisitions where the bidder owned more than $50 \%$ of target shares prior to the takeover announcement, due to the fact that these transactions constituted a completion of previous takeover activity. Such transactions are usually binding for the 
bidder, as well as target shareholders, and do not require any market activity for their completion as the bidder already owns a controlling interest in the target firm. This adjustment retained 1,283 events in the sample.

Acquisition announcements for ownership below $50 \%$ of total shares of the target were also removed as they did not pose a takeover attempt for a controlling interest of the target firm. This sample selection step resulted in 1,185 announcement events remaining eligible for inclusion in the sample as takeovers.

Next, we restricted our sample to events where both the bidder and target firms were publicly listed on a national stock exchange during the takeover process to enable the capture of trade and quote data required for estimating the presence of informed trading.

Finally, target firms with capitalisation of less than 1 million United States dollars were removed as representing deals concerning small firms. This is due to the fact that a 1 cent change in price represents a very large return relative to the very small share price of a penny stock. This effect, identified in Jegadeesh and Titman (2001), leads to exaggerated values for returns reported among penny stocks, due simply to equity market construction and not to large price changes.

This selection process resulted in a dataset of 522 takeovers, with 345 successful takeovers and 177 unsuccessful takeover attempts. Consistent with construction of the Australian sample, data captured from SDC Platinum included the following variables: company identifier, company name, date of takeover announcement, proportion of target shares intended for acquisition in the takeover, proportion of target acquired in 
the takeover, the proportion of shares held by the bidder prior to the takeover announcement, the payment method (percentage paid in cash and percentage paid in shares), the offer price per share, and the company and takeover outcome. The sample contains 491 announcements, including target companies counted more than once. This occurs because an unsuccessful takeover attempt may be followed by a successful takeover within the sample period.

Table 4.3 details the selection criteria for constructing the United States market sample, along with observations available at every filter applied in sample selection. Our sample size aligns with existing literature in the United States takeover market that studies the effects of takeover announcements on target firms, using 50 to 704 events. The sample size is comparable to Jarrell and Poulsen (1989) 526 tender offers. Franks, Harris and Titman (1991) separate their sample of 399 mergers and tender offers by payment method, while Berkovitch and Narayanan (1993) focus on 330 tender offers. Schwert (1996) uses 665 observations of mergers and tender offers to study different offer attributes. Muherin and Boone (2000) employ 376 takeover announcements, while Mulherin (2000) focuses on 202 incomplete acquisitions. Table 4.4 details the summary statistics for variables in the constructed sample of 491 takeover targets. The measures of informed trading show that in the 5 minute interval the trading is higher indicating higher concentration of informed trading smaller periods during the trading day. 
Table 4.3 United States Sample: Data Selection United States

Table 4.3 shows the process of United States sample data selection. It details the obtaining of observations from four databases used to obtain the data: Thomson Reuters Security Data Corporation (SDC) Platinum Mergers and Acquisitions Database, Thomson Reuters Tick History, Thompson Financial Datastream and Wharton Research Data Services CRSP and Compustat Databases and Bureau van Dijk Orbis Database. The initial sample was collected from takeover events between 1 January 2008 and 1 July 2013 in the United States takeover market, with data from Thomson Reuters Security Data Corporation (SDC) Platinum Mergers and Acquisitions Database and filtered as described in the table. The availability of supplementary data from Thomson Reuters Tick History, Thompson Financial Datastream, Wharton Research Data Services CRSP and Compustat Database and Bureau van Dijk Orbis Database resulted in no firms being removed from the sample.

Thomson Reuters Security Data Corporation (SDC) Platinum Mergers and Acquisitions Database Observations

Total number of Mergers and Acquisitions (1 January 2008 - 1 July 2013) 63,033

Target Firms domiciled in United States of America 9,429

Clearly identifiable parties to takeover activity 6,352

Clearly stated method of payment either cash, shares or both 5,969

The activity is not share repurchases and capital restructuring 1,323

Activity where bidder has less than $50 \%$ holdings in the target prior to announcement

Activity where bidder intends to acquire more than $50 \%$ holdings in the target 1,185

Activity where both bidder and target are listed firms 605

Target market capitalisation is above than 1 million dollars 491

Thomson Reuters Tick History

Trade and Quote data (9:31am-3:59pm)

Thompson Financial Datastream

Earnings per share 512

Book to market

Wharton Research Data Services CRSP and Compustat Database

\begin{tabular}{ll} 
Return on Equity & 491 \\
\hline
\end{tabular}

\begin{tabular}{ll} 
Return on Assets & 491 \\
\hline
\end{tabular}

Bureau van Dijk Orbis Database

Block Holdings

Extreme Values

Non extreme value observations

Takeover Sample

\begin{tabular}{lr}
\hline Successful Takeovers & 327 \\
\hline Unsuccessful Takeovers & 164 \\
\hline
\end{tabular}


Table 4.4. United States Sample: Data Summary Statistics

Table 4.4 shows the summary statistics for the United States sample data. It details the standard measures of statistical location and dispersion. The table covers the following variables: an indicator variable of takeover success, equal to 1 when the takeover announcement leads to a successful completion and 0 otherwise; $\log ($ Size), the natural logarithm transformation of market capitalisation of the firm on the day of takeover announcement, calculated as the number of ordinary shares multiplied by the opening share price; Premium 1 Day is a calculated as the difference between the takeover target offer price per share and the closing price per one day prior to the announcement. This variable is also sometimes referred to as the target share run-up; Pay cash, pay stock and shares held are reported in the Thomson Reuters SDC database. Pay cash reports the percentage of shares announced for acquisition in exchange for cash, while the pay stock variable reports the percentage of shares for acquisition paid in shares of the bidder. Shares held details the percentage of target shares held by the bidder before the acquisition is announced. Returns on assets (ROA) and returns on equity (ROE) are the most recent reported percentage values for the year before the takeover announcement date captured from the Wharton Research Data Services CRSP and Compustat Database. The EPS and B/M ratio are captured from the Thomson Reuters Financial Datastream. EPS is the most recent dollar amount of declared earnings prior to the takeover announcement data, divided by the total number of ordinary shares. $\mathrm{B} / \mathrm{M}$ ratio is calculated as the most recently reported book value of equity prior to the takeover date, divided by the market capitalisation of the firm immediately prior to the takeover announcement. Probability of informed trading $(P I)$ estimated in the 5 minute, 10 minute, 15 minute and 30 minute aggregation periods obtained from Bollen, Smith and Whaley (2004) model of spread decomposition. This measure represent the proportion of informed trading on the day of takeover announcement estimated using different time aggregation periods of 5, 10, 15 and 30 minutes of trading activity.

\begin{tabular}{lccccc} 
& Mean & Median & $\begin{array}{c}\text { Standard } \\
\text { Deviation }\end{array}$ & $\begin{array}{c}\text { Minimum } \\
\text { Value }\end{array}$ & $\begin{array}{c}\text { Maximum } \\
\text { Value }\end{array}$ \\
\hline \hline Success & 0.6659 & 1 & 0.4722 & 0 & 1 \\
Log(Size) & 6.2671 & 6.2680 & 1.8967 & 1.4158 & 11.0056 \\
Premium 1 Day & $24.972 \%$ & $17.650 \%$ & $40.641 \%$ & $-80.66 \%$ & $439.46 \%$ \\
Pay Cash & $29.813 \%$ & $17.420 \%$ & $34.906 \%$ & $0 \%$ & $100 \%$ \\
Pay Stock & $58.415 \%$ & $62.500 \%$ & $38.641 \%$ & $0 \%$ & $100 \%$ \\
Share Held & $3.3456 \%$ & $0 \%$ & $13.738 \%$ & $0 \%$ & $49.2 \%$ \\
& - & & & & \\
ROA & $10.230 \%$ & $-5.532 \%$ & $111.336 \%$ & $-1797.35 \%$ & $27.885 \%$ \\
ROE & $-3.379 \%$ & $-2.134 \%$ & $3.779 \%$ & $-450.599 \%$ & $219.439 \%$ \\
EPS & $\$ 1.054$ & $\$ 0.510$ & $\$ 1.544$ & $\$ 0.00$ & $\$ 11.68$ \\
B/M & 2.384 & 1.830 & 5.395 & -48.66 & 54.51 \\
Block Holders & 0.768 & 1 & 0.423 & 0 & 1 \\
PI 5min & $4.4065 \%$ & $3.9038 \%$ & $3.7795 \%$ & $0 \%$ & $46.465 \%$ \\
PI 10min & $3.9242 \%$ & $3.9037 \%$ & $3.0378 \%$ & $0 \%$ & $31.195 \%$ \\
PI 15min & $3.9176 \%$ & $3.8293 \%$ & $4.1662 \%$ & $0 \%$ & $31.254 \%$ \\
PI 30min & $3.9924 \%$ & $3.8792 \%$ & $3.2665 \%$ & $0 \%$ & $31.365 \%$ \\
N & 491 & 491 & 491 & 491 & 491 \\
\hline \hline
\end{tabular}




\subsubsection{Trade and Quote Data}

For the New York Stock Exchange (NYSE) and the electronic-trading-only New York Stock Exchange Arca (NYSE-ARCA) the hours of ordinary trading are between 9:31 am and 3:59 pm US eastern standard local time. However, the opening auctions occur at 9:30 am and the closing auctions at 4:00pm. We also excluded the opening and closing auctions as they do not provide a distinctly time-separable trade flow observed by the market maker, which Bollen, Smith and Whaley (2004) model relies on. In addition, firms listed instead on the National Association of Securities Dealers Automated Quotations (NASDAQ) have the same hours of ordinary trading between 9:31 am and 3:59 pm US eastern standard time. The opening auctions are held at 9:30 am and the closing auction at 4:00pm, similar to NYSE and NYSE-ARCA.

To avoid capturing results of the opening and closing auctions in the data, we commenced recording trades in the sample from 9:31 am US eastern standard time for every trading day until 3:59 pm, after which a closing auction and the adjustment period were also excluded.

In United States data, the exchanges included in the sample-NYSE, NYSE-ARCA and NASDAQ - have strict rules about the tick sizes for shares traded on the exchange. The tick rule for all United States exchanges after decimalisation was completed for NYSE and NYSE-ARCA exchanges on 1 February 2001 and on 12 March 2001 for NASDAQ; the minimum price update for all shares is 1 cent. 
CHAPTER FIVE: RESULTS

\subsection{Introduction}

We conduct our proposed empirical tests using data from Australian and United States markets separately as well as dividing the United States sample randomly and testing predictive power of the model in that market.

\subsection{Australian Sample Results}

\subsubsection{Inventory Holding Premium}

\subsubsection{Model Calibration}

Table 5.1 shows the estimate averages for all takeover targets for both successful and unsuccessful takeovers, together and separately, during the event period of ten days before and ten days after the announcement of a takeover. The estimated average inventory holding premium $I H P_{i}$ remains largely stable over all days in the estimation period. The variation of this estimate in the unsuccessful takeover sub-sample period is higher than in the successful takeovers sub-sample. However, this does not significantly deviate from the average sample figure on any particular day, apart from one day before the takeover is announced in the unsuccessful sub-sample, where the average inventory holding premium reduces significantly.

Table 5.1 illustrates the calibration variables of interest, presenting the results in event time perspective. The variable of time between trades, $\tau_{i}$, exhibits a significant decrease on the announcement day, which is consistent with an increase in trading volume immediately after announcement of a takeover bid. The average estimate is lower in the successful takeover sub-sample, suggesting that the shares of successful targets are 
traded with greater intensity on average compared to the shares of unsuccessful takeovers. Further, the time between trades continues to remain low for at least one day after the announcement in successful takeovers. This implies that traders are, on average, more active in trading target firms that result in successful takeovers. This result is lower for the whole successful sub-sample, suggesting that the sub-sample consists of firms with a greater number of liquidly traded shares. These firms naturally present an easier acquisition target than firms with less liquid shares and should, on average, experience higher levels of success even after controlling for levels of trading volume. 
Table 5.1 Australian Sample: Inventory Holding Premium Estimates

Table 5.1 shows the average estimates of time series linear regression results on the Australian sample data using Hansen (1982) Generalised method of moments estimator of the first stage of Bollen, Smith and Whaley (2004) model of bid-ask spread decomposition for the target firm shares. The specification on the model $S P R D_{i t}=\alpha_{0}+$ $\alpha_{1} I n v T V_{i t}+\alpha_{2} N H I_{i t}+\alpha_{3} I H P_{i t}\left(T_{i}\right)+\varepsilon_{i}$ where $I H P_{i t}$, is the expected inventory holding premium for trading period and firm, $N H I_{i t}$ is the normalised Herfindahl index and $I n v T V_{i t}$ is inverse trading volume. The bid-ask spread of target firm shares, $S P R D_{i t}$, the dependent variable, is calculated according to the standard bid ask spread model as $S P R D_{i t}=$ ask $_{\text {price }}{ }_{i t}-$ bid $_{\text {price }}$ it . The quoted bid and ask prices for each executed trade $t$ for each target firm $i$ respectively. The independent variables include the inverse of trading volume, 1 divided by number of shares per trade, for each trade as well as inventory holding premium calculated as a European at-the-money call option according to Black and Scholes (1973) model $I H P_{i}=M_{i}\left(2 N\left[\frac{1}{2} \sigma_{i} E\left(\sqrt{T_{i}}\right)\right]-1\right)$ where the mid-quote $M_{i}=\left(\frac{\left(\text { ask price }_{i}+\text { bid price }_{i}\right)}{2}\right), \sigma_{i}$ is the annualised standard deviation of 15 minutes of returns, $T_{i}$ is the calculated average time until offsetting trade in share of firm $i$ can occur. The estimator of $I H P_{i}$ is employed as a scaling factor for obtaining the length between offsetting trades such that $\tau_{i}=\sqrt{\widehat{\alpha_{2}} / T_{i}}$. Trade and Quote data is obtained from Thomson Reuters Tick History. Date of takeover announcement, is captured from Thomson Reuters SDC Platinum Database.

\begin{tabular}{|c|c|c|c|c|c|c|c|c|c|}
\hline \multirow[t]{2}{*}{$\begin{array}{l}\text { Dependent } \\
\text { variable }\end{array}$} & \multicolumn{3}{|c|}{ Bid-Ask Spread } & & & & & & \\
\hline & \multicolumn{3}{|c|}{ All Takeovers } & \multicolumn{3}{|c|}{ Successful Takeovers } & \multicolumn{3}{|c|}{ Unsuccessful Takeovers } \\
\hline variables & $I H P_{i t}$ & $\tau_{i}$ & $\sigma_{i}$ & $I H P_{i t}$ & $\tau_{i}$ & $\sigma_{i}$ & $I H P_{i t}$ & $\tau_{i}$ & $\sigma_{i}$ \\
\hline \multicolumn{10}{|c|}{$\begin{array}{c}\text { Announcement } \\
\text { Day }\end{array}$} \\
\hline-10 & 0.0249 & 0.0055 & 0.1545 & 0.0136 & 0.0013 & 0.1530 & 0.0202 & 0.0017 & 0.1508 \\
\hline-9 & 0.0141 & 0.0078 & 0.1234 & 0.0225 & 0.0100 & 0.1400 & 0.0050 & 0.0026 & 0.1093 \\
\hline-8 & 0.0064 & 0.0030 & 0.1311 & 0.0312 & 0.0023 & 0.1353 & -0.006 & 0.0110 & 0.1244 \\
\hline-7 & 0.0135 & 0.0038 & 0.1747 & 0.0279 & 0.0042 & 0.1772 & 0.0230 & 0.0022 & 0.1679 \\
\hline-6 & 0.0138 & 0.0070 & 0.2087 & 0.0252 & 0.0017 & 0.2360 & 0.0053 & 0.0050 & 0.1852 \\
\hline-5 & 0.0293 & 0.0042 & 0.2216 & 0.0023 & 0.0013 & 0.2401 & 0.0276 & 0.0103 & 0.2033 \\
\hline-4 & 0.0160 & 0.0042 & 0.2196 & 0.0267 & 0.0027 & 0.2629 & 0.0042 & 0.0050 & 0.1858 \\
\hline-3 & 0.0200 & 0.0065 & 0.2187 & 0.0306 & 0.0019 & 0.2748 & 0.0138 & 0.0055 & 0.1770 \\
\hline-2 & 0.0248 & 0.0032 & 0.1864 & 0.0341 & 0.0016 & 0.2002 & 0.0230 & 0.0093 & 0.1720 \\
\hline-1 & 0.0132 & 0.0014 & 0.2359 & 0.0290 & 0.0018 & 0.2163 & 0.0017 & 0.0040 & 0.2411 \\
\hline 0 & 0.0308 & 0.0035 & 0.4983 & 0.0266 & 0.0009 & 0.4716 & 0.0280 & 0.0017 & 0.4999 \\
\hline+1 & 0.0363 & 0.0057 & 0.2271 & 0.0309 & 0.0016 & 0.2859 & 0.0331 & 0.0046 & 0.1834 \\
\hline+2 & 0.0336 & 0.0086 & 0.2420 & 0.0336 & 0.0068 & 0.3029 & 0.0337 & 0.0049 & 0.1965 \\
\hline+3 & 0.0087 & 0.0120 & 0.2328 & 0.0397 & 0.0043 & 0.2804 & -0.007 & 0.0111 & 0.1959 \\
\hline+4 & 0.0223 & 0.0099 & 0.2448 & 0.0318 & 0.0200 & 0.2031 & 0.0182 & 0.0065 & 0.2634 \\
\hline+5 & 0.0198 & 0.0189 & 0.2639 & 0.0333 & 0.0194 & 0.3031 & 0.0212 & 0.0037 & 0.2313 \\
\hline+6 & 0.0378 & 0.0072 & 0.1989 & 0.0279 & 0.0064 & 0.2043 & 0.0436 & 0.0261 & 0.1896 \\
\hline+7 & 0.0078 & 0.0069 & 0.2616 & 0.0843 & 0.0130 & 0.2659 & 0.0331 & 0.0033 & 0.2511 \\
\hline+8 & 0.0171 & 0.0079 & 0.2798 & 0.0267 & 0.0091 & 0.1947 & 0.0020 & 0.0053 & 0.3247 \\
\hline+9 & 0.0401 & 0.0070 & 0.2867 & 0.0331 & 0.0104 & 0.2236 & 0.0435 & 0.0060 & 0.3175 \\
\hline+10 & 0.0074 & 0.0078 & 0.3178 & 0.0404 & 0.0046 & 0.2852 & -0.010 & 0.0083 & 0.3285 \\
\hline
\end{tabular}


The calibration variable of annualised standard deviation of returns $\sigma_{i}$ increases sharply on the announcement day-double the amount observed on ordinary days-and subsequently returns to ordinary levels on the next day. The variable is obtained through standard deviations of returns. As such, this result is consistent with the effect of a single large positive return of the target on takeover announcement day, as previously reported in the takeover literature. The effect does not appear to differ across successful and unsuccessful takeovers; however, the overall level of variance in return data is higher in the successful sub-sample, which may once again be linked to higher levels of liquidity in average firms in the successful takeover sub-sample. From a time-series perspective, the effect of higher overall standard deviation among the successful takeovers tends to last up to four days after the takeover announcement day. In contrast, among the unsuccessful takeover target firms, the standard deviation is significantly lower, lasting for a similar number of days after the announcement before returning to ordinary preannouncement levels.

Both calibration variables of time between trades $\tau_{i}$ representing the maturity and annualised standard deviation $\sigma_{i}$ representing the variance of returns, are used in the Black Scholes (1973) option pricing model to establish the price of a synthetic call option associated with submitting an order to trade in the market. This was outlined previously in the methodology section.

\subsubsection{Model Estimation Results}

The model estimates presented in event time in Table 5.2 suggest that, on average, the PI trading in target shares increased significantly on the takeover announcement day and remained at a higher level for around four days after the takeover was announced. 
The difference in estimates between successful and unsuccessful takeover outcomes was insignificant before the takeover was announced; however, the difference was significant on the day of announcement and for the subsequent four days. This suggests a significantly higher presence of informed traders in the market among successfully acquired targets than those not successfully acquired. This effect is most significant on the day after a takeover is announced, with the significance level and magnitude of difference decreasing over the subsequent four days, supporting the hypothesis regarding the inclusion of new information by takeover traders trading in target firm shares. This observation of informed trading for a few days after a takeover is announced is consistent with Cornelli and Li (2002) theoretical model. This indicates that takeover traders have a limited time within which to take advantage of their superior information to derive profits, due to competition from other informed or uninformed traders increasing the target share price closer to the bid offer price. The observation is also consistent with Kyle (1985) and Glosten and Milgrom (1985) theoretical models of gradual information incorporation in the market price through trading activities. In these models, informed traders effectively hide their trading strategies among uninformed traders in the market. 
Table 5.2 Australian Sample: Probability of Informed Trading Estimates

Table 5.2 shows the average estimates of time series linear regression results on the Australian sample data using Hansen (1982) Generalised method of moments estimator of the second stage of Bollen, Smith and Whaley (2004) model of bid-ask spread decomposition for the target firm shares. In the second stage, effective bid-ask spread of the target firm shares is decomposed into the expected inventory holding premium of uninformed traders $\left(I H P_{U i t}\right)$, and inventory holding premium of uninformed traders less inventory holding premium of informed traders $\left(I H P_{\text {Iit }}-I H P_{U i t}\right)$, inverse trading volume $\left(I n v T V_{i t}\right)$ and $N H I_{i t}$, the normalised Herfindahl index. The model is specified as: $E S P R D_{i t}=\alpha_{0}+\alpha_{1} I n v T V_{i t}+\alpha_{2} N H I_{i t}+\alpha_{3} I H P_{U i t}\left(\tau_{i}\right)+\alpha_{4}\left(\operatorname{IHP}_{I i t}\left(\tau_{i}\right)-I H P_{U i t}\left(\tau_{i}\right)\right)+\varepsilon_{i}$. Where the effective bid-ask spread of target firm, the dependent variable, are calculated trade level frequency according to the standard effective spread model is $E S P R D_{i t}=2 \mid$ Trade Price $_{i t}-M_{i t} \mid / M_{i t}$ where the mid-quote $M_{i t}=$ $\left(\frac{\left(\text { ask price }_{i t}+\text { bid price }_{i t}\right)}{2}\right)$ and Trade Price $_{i t}$ is the price for each executed trade $t$ for each target firm $i$, bid price $i t$ and ask $_{\text {price }}{ }_{i t}$ are the quoted bid and ask prices for each executed trade $t$ for each target firm $i$ respectively. The independent variables of the model include the inverse of trading volume, 1 divided by the number of shares per trade, for each trade as well as inventory premium calculated as a the value European call option according to Black and Scholes (1973) model IHP $i t=M_{i t} N\left(\frac{\ln \left(\frac{M_{i t}}{X_{i t}}\right)}{\sigma_{i \sqrt{\tau_{i}}}}+\frac{1}{2} \sigma_{i} \sqrt{\tau_{i}}\right)-X_{i t} N\left(\frac{\ln \left(\frac{M_{i t}}{X_{i t}}\right)}{\sigma_{i \sqrt{\tau_{i}}}}-\frac{1}{2} \sigma_{i} \sqrt{\tau_{i}}\right)$ where $X_{i t}$ is the synthetic option exercise price at maturity selected according to Bollen, Smith and Whaley (2004) at $5 \%$ above the prevailing mid-quote for the $I H P_{I t}$ and at the mid-quote for $I H P_{U t}, \sigma_{i}$ is the annualised standard deviation of 15 minutes of returns, $\tau_{i}$ is the calibrated time until offsetting trade in share of firm $i$ from the first stage of estimation. Probability of informed trading $(P I 15 \mathrm{~min})$ is captured by the model $\alpha_{4}$ regression coefficient on $\left(I H P_{I i t}-I H P_{U i t}\right)$ variable. Trade and Quote data is obtained from Thomson Reuters Tick History Database. Date of takeover announcement, is captured from Thomson Reuters SDC Platinum Database.

\begin{tabular}{|c|c|c|c|}
\hline & Average & Successfu & ccessful \\
\hline Independent variable & $P I 15 \mathrm{~min}$ & $P I 15 \mathrm{~min}$ & $p$ value \\
\hline \multicolumn{4}{|l|}{ Announcement Day } \\
\hline-10 & 0.0512 & 0.0124 & 0.1635 \\
\hline-9 & 0.0495 & 0.0050 & 0.5551 \\
\hline-8 & 0.0545 & 0.0092 & 0.1467 \\
\hline-7 & 0.0510 & 0.0067 & 0.2999 \\
\hline-6 & 0.0506 & -0.0019 & 0.7635 \\
\hline-5 & 0.0513 & 0.0038 & 0.5650 \\
\hline-4 & 0.0457 & 0.0055 & 0.4297 \\
\hline-3 & 0.0508 & 0.0038 & 0.5605 \\
\hline-2 & 0.0456 & 0.0016 & 0.8031 \\
\hline-1 & 0.0495 & 0.0014 & 0.2167 \\
\hline 0 & 0.0628 & $0.0162^{* *}$ & 0.0650 \\
\hline+1 & 0.0618 & $0.0169 * *$ & 0.0111 \\
\hline+2 & 0.0579 & $0.0081 * *$ & 0.0484 \\
\hline+3 & 0.0587 & $0.0113^{*}$ & 0.0836 \\
\hline+4 & 0.0615 & $0.0055^{*}$ & 0.0791 \\
\hline+5 & 0.0578 & 0.0069 & 0.1112 \\
\hline+6 & 0.0568 & 0.0070 & 0.1283 \\
\hline+7 & 0.0547 & $0.0149 * *$ & 0.0216 \\
\hline+8 & 0.0545 & 0.0023 & 0.3500 \\
\hline+9 & 0.0579 & 0.0003 & 0.5833 \\
\hline+10 & 0.0565 & 0.0054 & 0.4136 \\
\hline
\end{tabular}

$*$ indicates significance at $10 \%$ level; **significance at $5 \%$ level; ***significance at $1 \%$ level 
The results in Tables 5.1 and 5.2 are consistent with the previous literature on takeovers, market microstructure and trading behaviour. Table 5.1 results show that the intensity of trading in target shares on the takeover announcement day increases substantially compared to previous levels. The evidence supporting this is represented by the decrease in estimated time between trades. This is the case for both successful and unsuccessful takeover attempts. However, in the successful sub-sample the estimate is lower, suggesting a higher trading intensity on the takeover announcement day for those target firm shares. The average annualised standard deviation estimate increases on the announcement day for both sub-samples, which is consistent with the abnormal increases in returns of target firms on the announcement day, as the empirical literature documents thoroughly. In Table 5.2, the PI trading estimate increased, on average, for the whole sample on the announcement day and remained at similar levels for one day after the announcement. We report a difference in informed trading between successful and unsuccessful takeover targets, to investigate Cornelli and Li (2002) theory that more takeover traders participate in successful takeovers than unsuccessful ones. The results in Table 5.2 indicate that the presence of informed traders is significantly higher on the takeover announcement day and over the following four days for targets in successful takeovers compared to unsuccessful takeover targets.

\subsubsection{Impact of Probability of Informed Trading on Takeover Success}

Table 5.3 contains the results from the direct tests of Cornelli and Li (2002) prediction. This prediction and our $H_{1}$ states that takeover traders have a direct impact on the 
takeover process outcome, by increasing the likelihood of takeover success when they participate in trading target shares. The table presents the estimates of a logistic (logit) regression. The results of this model specification can be interpreted in two ways. Firstly, in terms of effects on the probability of success, which constitutes the inference of overall model prediction; and secondly in terms of the likelihood odds over the unsuccessful case, where the marginal effects of one variable may be used to show the effect of its changes on the odds of a successful outcome over an unsuccessful outcome. We report both techniques of inference in this logistic model.

Table 5.3 presents the results of logistic estimation using results from informed trading regressions in different time aggregation groups of 5, 10, 15 and 30 minutes separately. As the results are very close to each other, we present the inference of our model using a 15-minute PI trading estimate. The coefficient is reported at 0.3946 , and the probability of success of the mean transaction is $41.33 \%$. If the $P I$ trading estimate were to increase by $1 \%$ from its mean value, the probability of success would increase to $48.75 \%$, while all other variables remain constant. Conversely, if the $P I$ trading figure were to decrease by $1 \%$, the probability of success would fall to $38.93 \%$, with other variables remaining at original levels. If the $P I$ trading variable rose by 1 standard deviation above its mean (by $3.451 \%)$, the probability of takeover would increase to $76.86 \%$, while the same decrease in the 15-minute PI trading measure from the mean would decrease the probability of success by only $18.23 \%$, with other levels of variables held constant. 


\section{Table 5.3. Australian Sample: Impact of Probability of Informed Trading on Takeover Success}

Table 5.3 shows the estimates of binary logit regression results of takeover outcome on the $(P I)$ measure and controls. The takeover outcome indicator, the dependent variable, is equal to 1 when the takeover is a success and 0 otherwise. The independent variables include the $\log ($ Size), the natural logarithm transformation of market capitalisation of the firm on the day of takeover announcement, calculated as the number of ordinary shares multiplied by the opening share price; Premium 1 Day is a calculated as the difference between the takeover target offer price per share and the closing price per one day prior to the announcement. The indicator variable on takeover method of payment equals 1 when cash is the method of payment and 0 otherwise. The toe hold variable is an indicator of the bidder ownership greater than $5 \%$ in the bidder prior to the takeover announcement equal to 1 and 0 otherwise. The indicator variable of multiple bidders is equal to 1 when there are more than one bidder during the takeover process and 0 if there is only one. The block holding variable is the control for the existence of block holders owning more than $5 \%$ of the target shares on the announcement day equals 1 and 0 otherwise. PI is estimated using Bollen, Smith and Whaley (2004) model, aggregating trade data in 5, 10,15 and 30 minute trading intervals. The effects of individual firms are controlled by the inverse mills ratio estimated using the 2-step Heckman (1976) procedure to account for sample selection bias by using the closest propensity scored matched firm that is not engaged in any takeover activity. Matching is performed on market capitalisation and industry of operation. Firm year effects controls include a set of indicator variables for each year equal to 1 for the year in which takeover activity takes place and 0 otherwise. Firm industry effects controls include an indicator variable equal to 1 when the takeover occurs with a specific industry (based on 2-digit SIC code categorisation) and 0 otherwise.

\begin{tabular}{|c|c|c|c|c|}
\hline \multirow{2}{*}{$\begin{array}{l}\text { Dependent variable } \\
\text { Independent variables }\end{array}$} & \multicolumn{2}{|c|}{ Outcome } & \multirow[b]{2}{*}{ (3) } & \multirow[b]{2}{*}{ (4) } \\
\hline & (1) & $(2)$ & & \\
\hline \multirow[t]{2}{*}{ Intercept } & $-19.622 * * *$ & $-19.628 * * *$ & $-19.622 * * *$ & $-19.628 * * *$ \\
\hline & $(-4.828)$ & $(-4.826)$ & $(-4.827)$ & $(-4.830)$ \\
\hline \multirow[t]{2}{*}{$\log ($ Size $)$} & $-0.1884^{*}$ & $-0.1886^{*}$ & $-0.1883^{*}$ & $-0.1888^{*}$ \\
\hline & $(-1.827)$ & $(-1.722)$ & $(-1.708)$ & $(-1.768)$ \\
\hline \multirow[t]{2}{*}{ Premium 1 Day } & $-0.0142 *$ & $-0.0145^{*}$ & $-0.0143^{*}$ & $-0.0142 *$ \\
\hline & $(-1.658)$ & $(-1.763)$ & $(-1.653)$ & $(-1.643)$ \\
\hline \multirow[t]{2}{*}{ D Pay Cash } & $1.7901^{* *}$ & $1.7904 * *$ & $1.1904^{* *}$ & $1.1791 * *$ \\
\hline & $(1.964)$ & $(1.994)$ & $(1.944)$ & $(2.198)$ \\
\hline \multirow[t]{2}{*}{ D Toe Hold } & 1.3684 & 1.3684 & 1.3684 & 1.3675 \\
\hline & $(1.499)$ & $(1.488)$ & $(1.499)$ & $(1.497)$ \\
\hline \multirow[t]{2}{*}{ D Multiple Bidders } & $-1.7545^{* *}$ & $-1.7547 * *$ & $-1.7545^{* *}$ & $-1.7540 * *$ \\
\hline & $(-2.074)$ & $(-2.072)$ & $(-2.070)$ & $(-2.071)$ \\
\hline \multirow[t]{2}{*}{ D Block Holding } & -0.6829 & -0.6829 & -0.6829 & -0.6883 \\
\hline & $(-0.581)$ & $(-0.585)$ & $(-0.589)$ & $(-0.594)$ \\
\hline \multirow[t]{2}{*}{ PI $5 \mathrm{~min}$} & $0.3966 * * *$ & & & \\
\hline & $(3.540)$ & & & \\
\hline \multirow[t]{2}{*}{ PI 10min } & & $0.3945 * * *$ & & \\
\hline & & $(3.539)$ & & \\
\hline \multirow[t]{2}{*}{ PI 15min } & & & $0.3946 * * *$ & \\
\hline & & & $(3.537)$ & \\
\hline \multirow[t]{2}{*}{ PI 30min } & & & & $0.3729 * * *$ \\
\hline & & & & $(3.868)$ \\
\hline \multirow[t]{2}{*}{ PI $\times \mathrm{D}$ Block Holding } & -0.1295 & -0.1288 & -0.1296 & -0.1289 \\
\hline & $(-0.797)$ & $(-0.790)$ & $(-0.794)$ & $(-0.790)$ \\
\hline Firm Control Variables & $Y$ & $\mathrm{Y}$ & $Y$ & $\mathrm{Y}$ \\
\hline Year Effects & Y & $\mathrm{Y}$ & $Y$ & $\mathrm{Y}$ \\
\hline Industry Effects & $Y$ & $Y$ & $Y$ & $\mathrm{Y}$ \\
\hline Pseudo R squared & 0.418 & 0.419 & 0.427 & 0.415 \\
\hline $\mathrm{N}$ & 172 & 172 & 172 & 172 \\
\hline
\end{tabular}

$*$ indicates significance at $10 \%$ level; $* *$ significance at $5 \%$ level; ***significance at $1 \%$ level 
Next we consider the interpretation using the odds ratios on the same model, estimated using a 15-minute $P I$ trading. The estimate reported with a coefficient of 0.3731 is significant at a $1 \%$ level. In this case, a $1 \%$ increase in the $P I$ trading from its average level leads to an increase in the odds of success by 3.322 times over the odds of the average takeover. The same level of decrease in informed trading from the average level would lead to a decrease in the odds ratio by 2.382 times the odds of the average takeover.

The estimated coefficient on the indicator variable for block holders is insignificant, suggesting that the presence of shareholders holding more than $5 \%$ increasing their shareholding in the target company before the takeover announcement does not affect the probability of takeover success. An explanation for this finding lies in the interests of pre-existing block holders who may oppose the takeover activity; takeover traders may still participate and cause the takeover to succeed. If the block holders do not own more than $50 \%$ of all shares of the target company ${ }^{4}$, takeover traders may still be able to acquire sufficient shares that can be sold to an outside bidder, making the takeover binding for all shareholders. Conversely, if block holders do own more than $50 \%$ of the target firm shares, they would most likely already have negotiated with the bidder prior to the announcement privately, securing a private arrangement with the bidder firm on acquisition of their shares. In such a situation, if block holders oppose the takeover, informed traders will not have sufficient incentives to participate in the takeover process. This is because they cannot acquire a sufficient amount of shares to ensure the takeover offer is binding for acquiring the remaining shares. The decisions of block holders,

\footnotetext{
${ }^{4}$ We also remove any firms where blockholders hold more than $60 \%$ of shares from the sample and re-estimate the model results. These results are presented in appendix tables A.1, A.2 and A.3. The results presented show that there are no significant effects of blockholdings greater than $60 \%$ on the original results which include these observations.
} 
coupled with their initial shareholding amounts, are exogenous to the decisions of takeover traders. This information is revealed in the information gathering process immediately after a takeover announcement and is factored into the decision of takeover traders to participate in the trading of target shares. Surprisingly, the estimated coefficient on the indicator variable for toehold is insignificant suggesting that the bidder holding more than $5 \%$ in the target company before the takeover announcement has no significant impact on takeover outcome.

This test of Cornelli and Li (2002) theoretical model employs high frequency trade-bytrade intraday data to estimate the daily Bollen, Smith and Whaley (2004) measure of PI trading, as well as takeover target and takeover characteristics, to adjust for any effects these variables may have on the probability of takeover success. While the $P I$ trading estimation employs very high frequency data, the remaining variables employ a takeoverspecific set of variables or target firm variables, obtained primarily from the last financial statement released by the target firm. The significantly different frequencies of these variables are very unlikely to contain any significant relationships between variables.

\subsubsection{Test of reverse causality}

Larcker and Lys (1987) propose that takeover traders may have superior predictive ability regarding the likelihood of takeover success. We construct a relevant test, specifying a model where the $P I$ trading is the dependent variable, while the success variable is independent, and testing the reverse causality of the original model. Table 5.4 details the results of this model specification. In this case, a positive relationship exists between the PI trading and a one day premium and the likelihood of success allowing us to test $\mathrm{H}_{2}$. 
Both effects are expected, as informed traders have an incentive to participate more in takeovers with higher premiums, and in takeovers that are more likely to be successful, testing $H_{4}$. If informed traders indeed have perfect foresight regarding which takeovers are ultimately successful, then the coefficient on the success variable should be very large. The coefficient is around 2.5 and is significant at the $1 \%$ level, which means that a $2.5 \%$ increase in the $P I$ trading occurs when the takeover is successful. The $1 \%$ increase in the one day premium is only linked to a $0.03 \%$ increase in PI trading, suggesting that higher premiums have a marginal effect on inducing informed traders to participate in trading of target shares. Far more important to the informed traders' participation levels is their ability to purchase a sufficient amount of shares to successfully conclude the takeover activity.

The measures of informed trading offer indirect evidence that takeover traders react to news, rather than anticipate those takeovers. In Table 5.2, the probability of difference between informed and uninformed trading becomes significant only after the takeover is announced; it remains significant for four days after the announcement on average. This suggests that informed trading occurs only after the announcement of takeovers has been made, rather than before this day. This is when fully informed agents and insiders are most likely to engage in trading target shares that could increase the PI trading of target shares before the announcement had been made. 


\section{Table 5.4. Australian Sample: Impact of Takeover Success on Probability of Informed Trading}

Table 5.4 shows the estimates of linear regression results using Hansen (1982) GMM estimator of the PI measure on the indicator of takeover success and controls. PI is estimated using Bollen, Smith and Whaley (2004) model, aggregating trade data in 5, 10, 15 and 30 minute intervals. The independent variables include the $\log ($ Size), the natural logarithm transformation of market capitalisation of the firm on the day of takeover announcement, calculated as the number of ordinary shares multiplied by the opening share price; Premium 1 Day is a calculated as the percentage difference between the takeover target offer price per share and the closing price per one day prior to the announcement. The indicator variable on takeover method of payment equals 1 when cash is the method of payment and 0 otherwise. The toe hold variable is an indicator of the bidder ownership greater than $5 \%$ in the bidder prior to the takeover announcement equal to 1 and 0 otherwise. The indicator variable of multiple bidders is equal to 1 when there are more than one bidder during the takeover process and 0 if there is only one. The block holding variable is the control for the existence of block holders owning more than $5 \%$ of the target shares on the announcement day equals 1 and 0 otherwise. The indicator variable on hostile takeovers equals 1 when the bid is accompanied by a proxy contest or tender offer and 0 otherwise. The Firm fixed effects is the inverse mills ratio estimated using the 2-step Heckman (1976) procedure to account for sample selection bias using the closest matched firm not engaged in any takeover activity based on market capitalisation and industry of operation. Firm year effects include indicator variables for each year equal to 1 for the year in which takeover is announced and 0 otherwise. Firm industry effects include an indicator variable equal to 1 when the takeover occurs within a specific industry based on 2-digit SIC code categorisation and 0 otherwise.

\begin{tabular}{|c|c|c|c|c|}
\hline Dependent variable & $P I 5 \mathrm{~min}$ & $P I 10 \mathrm{~min}$ & $P I 15 \mathrm{~min}$ & $P I 30 \mathrm{~min}$ \\
\hline $\begin{array}{l}\text { Independent } \\
\text { variables }\end{array}$ & $(1)$ & $(2)$ & (3) & (4) \\
\hline Intercept & $\begin{array}{l}4.0028 \\
(1.462) \\
\end{array}$ & $\begin{array}{l}3.9338 \\
(1.434) \\
\end{array}$ & $\begin{array}{l}4.0023 \\
(1.462) \\
\end{array}$ & $\begin{array}{l}4.0890 \\
(1.521) \\
\end{array}$ \\
\hline Log(Size) & $\begin{array}{l}-0.1711 \\
(-0.956)\end{array}$ & $\begin{array}{l}-0.1875 \\
(-1.013) \\
\end{array}$ & $\begin{array}{l}-0.1714 \\
(-0.958)\end{array}$ & $\begin{array}{l}-0.1616 \\
(-0.917)\end{array}$ \\
\hline Premium 1 Day & $\begin{array}{l}0.0344^{* * *} \\
(5.201)\end{array}$ & $\begin{array}{l}0.0354 * * * \\
(5.491)\end{array}$ & $\begin{array}{l}0.0344^{* * *} \\
(5.204)\end{array}$ & $\begin{array}{l}0.0353 * * * \\
(5.466)\end{array}$ \\
\hline D Pay Cash & $\begin{array}{l}-0.3459 \\
(-0.576)\end{array}$ & $\begin{array}{l}-0.2817 \\
(-0.469)\end{array}$ & $\begin{array}{l}-0.3467 \\
(-0.578) \\
\end{array}$ & $\begin{array}{l}-0.3241 \\
(-0.538) \\
\end{array}$ \\
\hline D Toe Hold & $\begin{array}{l}0.2743 \\
(0.556) \\
\end{array}$ & $\begin{array}{l}0.2872 \\
(0.578) \\
\end{array}$ & $\begin{array}{l}0.2750 \\
(0.558) \\
\end{array}$ & $\begin{array}{l}0.2657 \\
(0.537) \\
\end{array}$ \\
\hline D Block Holding & $\begin{array}{l}0.0215^{* *} \\
(2.084)\end{array}$ & $\begin{array}{l}0.0205^{* *} \\
(2.051)\end{array}$ & $\begin{array}{l}0.0215^{* *} \\
(2.085)\end{array}$ & $\begin{array}{l}0.0266^{* *} \\
(2.069)\end{array}$ \\
\hline D Hostile & $\begin{array}{l}-1.7512^{* * *} \\
(-3.301)\end{array}$ & $\begin{array}{l}-1.7924 * * * \\
(-3.345)\end{array}$ & $\begin{array}{l}-1.7514 * * * \\
(-3.301)\end{array}$ & $\begin{array}{l}-1.7577^{* * *} \\
(-3.315)\end{array}$ \\
\hline D Success & $\begin{array}{l}2.5184 * * * \\
(4.793)\end{array}$ & $\begin{array}{l}2.5092 * * * \\
(4.748)\end{array}$ & $\begin{array}{l}2.5186 * * * \\
(4.793)\end{array}$ & $\begin{array}{l}2.5092 * * * \\
(4.775)\end{array}$ \\
\hline $\begin{array}{l}\text { Firm Control } \\
\text { Variables }\end{array}$ & $\mathrm{Y}$ & $Y$ & $Y$ & $Y$ \\
\hline Year Effects & $Y$ & $\mathrm{Y}$ & $Y$ & $Y$ \\
\hline Industry Effects & $\mathrm{Y}$ & $\mathrm{Y}$ & Y & $Y$ \\
\hline Adjusted R squared & 0.214 & 0.213 & 0.215 & 0.216 \\
\hline $\mathrm{N}$ & 172 & 172 & 172 & 172 \\
\hline
\end{tabular}

$*$ indicates significance at $10 \%$ level; $* *$ significance at $5 \%$ level; $* * *$ significance at $1 \%$ level 
We review the timing of takeover announcements closely to investigate any clustering. We investigate the time of day that the takeover intent is made public, as well as the day of the week when the takeover is announced to the market. There is no apparent clustering of announcements across days of the week or time intervals during those days. This indicates that the occurrence of takeover announcements in the market appears to be random with respect to the time of day and day of the week.

\subsubsection{Discussion}

The results show that Cornelli and Li (2002) theory is supported by the empirical test findings, unveiling economically and statistically significant effects in the data. The estimates of logistic regressions show that the impact on success of the takeover is represented by the $P I$ trading, while controlling for all other company and takeover characteristics. The effect of $P I$ trading remains significant at all aggregation periods with the estimates showing consistent results. The effect is persistent at larger event windows and remains significant in all the different model specifications used. The analysis using probability and odds ratio inference shows a significantly large impact of informed traders from their participation in trading takeover target shares. These traders also participate more in takeovers that end successfully, supporting Cornelli and Li (2002) model.

\subsubsection{Impact of Probability of Informed Trading on Cumulative Abnormal} Returns

The estimates presented in Table 5.5 show that the presence of takeover traders has a positive impact on the CARs in all event windows in order to test hypothesis $H_{3}$. A $1 \%$ increase in PI trading, estimated using the 15-minute interval, is associated with a $2.76 \%$ 
increase in CARs in the $0,+1$ window. This relationship remains fundamentally the same over different event windows. The marginal effect of $P I$ trading in successful takeovers suggests that a $1 \%$ increase in the probability of informed trading in the 15 -minute interval increases the CAR in the $0-1$ day event window by $1.21 \%$ more than in the unsuccessful case.

Successful takeovers deliver a higher CAR $(2.46 \%$ higher $)$ in the announcement +1 day window, increasing for longer event windows as the takeover becomes more certain. Premium 1 Day also increases CAR, which is especially significant in the $0,+1$ day window, but is economically insignificant, as a $1 \%$ increase in premiums is linked to a $0.12 \%$ increase in CAR. This coefficient becomes insignificant outside the $0,+1$ day event window.

\subsubsection{Tests of explanatory power}

To test the model's power, we conduct an F test by removing the variables connected to the probability of informed trading and so specify the restricted model. This is also tested in relation to the unrestricted model containing the two additional variables of $P I$ and $P I$ interacted with takeover success indicator variable. We find that $F$ statistics are significant at the $5 \%$ level. 


\section{Table 5.5. Australian Sample: Impact of Probability of Informed Trading on Target Firm Cumulative Abnormal Returns}

Table 5.5 shows the estimates of linear regression results using Hansen (1982) GMM estimator of cumulative abnormal returns (CARs) of the target firm over different time windows after the takeover is announced, on the PI 15min measure and controls. The CAR of target firm shares above the Fama and French (1993) factors, the dependent variables, are calculated at daily frequency for the appropriate event window of takeover announcement. The independent variables include the natural logarithm of firm size expressed as a logarithm of the market capitalisation of the firm on the takeover announcement day. ROA is the return on assets calculated as last reported net income divided by total assets by the target company. Premium 1 Day is the percentage difference of share price one day prior to the takeover announcement and the takeover price contained in the announcement. PI is estimated using Bollen, Smith and Whaley (2004) model, aggregating trade data in 15 minute trading intervals, the results of which are reported in Table 5.2. The indicator variable on takeover method of payment equals 1 when cash is the method of payment and 0 otherwise. The toe hold variable is an indicator of the bidder ownership greater than $5 \%$ in the bidder prior to the takeover announcement equal to 1 and 0 otherwise. The indicator variable of multiple bidders is equal to 1 when there are more than one bidder during the takeover process and 0 if there is only one. The block holding variable is the control for the existence of block holders owning more than $5 \%$ of the target shares on the announcement day equals 1 and 0 otherwise. Control for the firm effects is the inverse mills ratio estimated using the 2-step Heckman (1976) procedure to account for sample selection bias using the closest firm matched on market capitalisation and industry of operation not engaged in any takeover activity. Firm year effects include indicator variables for each year equal to 1 for the year in which takeover is announced and 0 otherwise. Firm industry effects include an indicator variable equal to 1 when the takeover occurs with a specific industry based on 2-digit SIC code categorisation and 0 otherwise.

\begin{tabular}{|c|c|c|c|c|}
\hline Dependent variable & CAR $[0,+1]$ & CAR $[0,+5]$ & CAR $[0,+10]$ & CAR $[0,+30]$ \\
\hline $\begin{array}{l}\text { Independent } \\
\text { variables }\end{array}$ & (1) & $(2)$ & (3) & (4) \\
\hline \multirow[t]{2}{*}{ Intercept } & $26.702 * * *$ & $16.168 * *$ & 11.711 & $31.284^{*}$ \\
\hline & $(2.878)$ & $(2.026)$ & $(1.395)$ & $(1.858)$ \\
\hline \multirow[t]{2}{*}{ Log(Size) } & -0.6427 & -1.0318 & $-1.6388 *$ & -1.4601 \\
\hline & $(-1.031)$ & $(-1.608)$ & $(-1.832)$ & $(-1.297)$ \\
\hline \multirow[t]{2}{*}{ ROA } & $5.4617^{* *}$ & 6.4898 & 7.4093 & 12.765 \\
\hline & $(1.809)$ & $(1.382)$ & $(1.317)$ & $(1.391)$ \\
\hline \multirow[t]{2}{*}{ Premium 1 Day } & $0.1159 * *$ & -0.0187 & -0.0635 & -0.0337 \\
\hline & $(2.439)$ & $(-0.403)$ & $(-0.845)$ & $(-0.414)$ \\
\hline \multirow[t]{2}{*}{ D Pay Cash } & $1.4517^{* *}$ & $3.0288 * *$ & $1.1267 * *$ & $1.9614^{* *}$ \\
\hline & $(2.402)$ & $(2.497)$ & $(2.435)$ & $(2.565)$ \\
\hline \multirow[t]{2}{*}{ D Toe Hold } & 1.0840 & 1.9234 & 0.8349 & 3.4201 \\
\hline & $(0.391)$ & $(0.686)$ & $(0.268)$ & $(0.537)$ \\
\hline \multirow[t]{2}{*}{ D Block Holding } & -6.3224 & -0.0149 & -2.3628 & -7.4980 \\
\hline & $(-1.177)$ & $(-0.027)$ & $(-0.358)$ & $(-0.618)$ \\
\hline \multirow[t]{2}{*}{ D Success } & $2.4587 * * *$ & $6.4669 * * *$ & $9.3299 * * *$ & $16.5394 * * *$ \\
\hline & $(2.953)$ & $(2.976)$ & $(2.943)$ & $(2.920)$ \\
\hline \multirow[t]{2}{*}{ PI 15min } & $2.7568 * * *$ & $2.0149 * * *$ & $2.1811 * * *$ & $2.9217^{* * *}$ \\
\hline & $(2.861)$ & $(2.675)$ & $(2.761)$ & $(2.655)$ \\
\hline D Success $x$ & $1.2122 * *$ & $1.0125^{* *}$ & $0.7046 * *$ & $0.3095 * *$ \\
\hline PI 15min & $(1.710)$ & $(1.663)$ & $(1.865)$ & $(1.996)$ \\
\hline D Block Holding $\mathrm{x}$ & 0.8795 & 0.3539 & 0.7359 & 1.0964 \\
\hline PI 15min & $(1.365)$ & $(1.579)$ & $(0.918)$ & $(0.969)$ \\
\hline \multicolumn{5}{|l|}{ Firm Control } \\
\hline Variables & $Y$ & $\mathrm{Y}$ & $Y$ & $Y$ \\
\hline Year Effects & $\mathrm{Y}$ & $Y$ & $\mathrm{Y}$ & $\mathrm{Y}$ \\
\hline Industry Effects & $\mathrm{Y}$ & $Y$ & $\mathrm{Y}$ & $\mathrm{Y}$ \\
\hline Adjusted R squared & 0.325 & 0.334 & 0.314 & 0.290 \\
\hline $\mathrm{N}$ & 172 & 172 & 172 & 172 \\
\hline
\end{tabular}

$*$ indicates significance at $10 \%$ level; **significance at $5 \%$ level; ***significance at $1 \%$ level 


\subsubsection{Conclusions}

We tested the theoretical model of trading of takeover shares' impact on takeover outcomes, as proposed in Cornelli and Li (2002). We employed Australian takeover data between 2008 and 2013 to investigate the impact of takeover traders purchasing the shares of target firms on takeover success. Takeover announcements present an important corporate and randomly occurring event, revealing previously private information to the market. Cornelli and Li (2002) propose that active trading of target shares in the takeover period directly influences the takeover outcome, through takeover traders acting as block holders. Takeover traders purchase target firm shares after the takeover intent is announced, and then sell those shares to the bidder. Incentives for takeover traders to participate in trading takeover shares lie in the profit motive of purchasing target shares in successful takeovers. Once a takeover bid has been announced, the offer price paid by the bidder for target shares becomes known but the probability of takeover success remains less than certain. The takeover traders decide to participate in trading target shares depending on the profit available to them, the difference between the bid and market price at which they are able to purchase shares, and their assessment of takeover success likelihood. We can therefore classify trades conducted by takeover traders as informed trades, according to the Cornelli and Li (2002) sufficiency specification. This states that takeover traders derive information from knowledge of their own positions. We also tested the impact of takeover traders on takeover success by employing microstructure data and the robust estimation methodology of informed trading, as proposed in Bollen, Smith and Whaley (2004) model of bid-ask spread decomposition. We contributed to the literature by using the reliably estimated $P I$ trading using computationally intensive trade-by-trade microstructure data to obtain daily estimates. We specified a logistic model to test Cornelli and Li (2002) 
theory using the daily PI trading, takeover characteristics, firm-specific and industry characteristics, as well as year of announcements. According to estimates of the model using the sample of Australian takeover firms, the presence of informed traders increases the likelihood of success from the average rate of $41.33 \%$. The increase of $1 \%$ in informed trading increases the probability of takeover success to $48.75 \%$, while an increase of $3.45 \%$ (a one standard deviation increase) is associated with a takeover success probability of $76.86 \%$. A one standard deviation decrease in informed trading from its mean is linked to a reduced probability of takeover success, to $18.23 \%$. Using the interpretation of odds ratio analysis, a $1 \%$ increase in PI trading increases the odds of success by 3.322 times above the odds of the average takeover. A decrease of $1 \%$ in informed trading reduces the odds ratio of success by 2.382 times the odds of an average takeover.

We tested the reverse causality, as proposed in Larker and Lys (1987), by first considering the regressions estimated to capture the probabilities of informed trading. We observed that the daily PI trading estimates did not increase significantly in successful over unsuccessful takeovers until the day of announcement, remaining significant for four subsequent days. The PI trades before the announcement were not significantly different between the targets of successful and unsuccessful takeovers, suggesting that takeover traders do not trade before a takeover is formally announced. We also carried out the test of reverse causality and found that $P I$ trading increased by $2.5 \%$ when the takeover was successful, revealing a significant relationship between the $P I$ trading and takeover success. 
The impact of a $1 \%$ increase in PI trading was associated with a $2.76 \%$ increase in CAR over two days, starting on the day of the takeover announcement. The marginal effect of successful takeovers over unsuccessful takeovers of a $1 \%$ increase in PI trading was accompanied by a $1.21 \%$ higher CAR in successful takeovers.

\subsection{United States Sample Results}

\subsubsection{Inventory Holding Premium}

Estimations of models undertaken using Bollen, Smith and Whaley (2004) framework of bid-ask spread decomposition comprising three separate components-inverse trading volume, normalised Herfindahl-Hirshmann index and the inventory holding premium for informed and uninformed trading-requires a calibration stage and an estimation stage to produce the desired results. The calibration stage yields variables of the amount of time between trades $\tau_{i}$ and annualised standard deviation of firm returns $\sigma_{i}$, which are then used in the model's estimation phase. Table 5.6 shows the average of estimates for all takeover targets for both successful and unsuccessful takeovers together and separately during the event period of ten days before and ten days after takeover announcement for a United States sample of takeover targets. The estimated average inventory holding premium $I H P_{i}$ remains largely stable over all days in the estimation period. The variation of this estimate is higher in the successful takeover sub-sample than in the unsuccessful takeover sub-sample; this does not significantly differ from the average sample figure on any particular day, apart from the takeover announcement day. In the unsuccessful sub-sample, the average inventory holding premium remains largely unchanged for the duration reported. 
Table 5.6. United States Sample: Inventory Holding Premium Estimates

Table 5.6 shows the average estimates of time series linear regression results on the United States sample data using Hansen (1982) Generalised method of moments estimator of the first stage of Bollen, Smith and Whaley (2004) model of bid-ask spread decomposition for the target firm shares. The specification on the model $S P R D_{i t}=\alpha_{0}+$ $\alpha_{1} I n v T V_{i t}+\alpha_{2} N H I_{i t}+\alpha_{3} I H P_{i t}\left(T_{i}\right)+\varepsilon_{i}$ where $I H P_{i t}$, is the expected inventory holding premium for trading period and firm, $N H I_{i t}$ is the normalised Herfindahl index and $I n v T V_{i t}$ is inverse trading volume. The bid-ask spread of target firm shares, $S P R D_{i t}$, the dependent variable, is calculated according to the standard bid ask spread model as $S P R D_{i t}=$

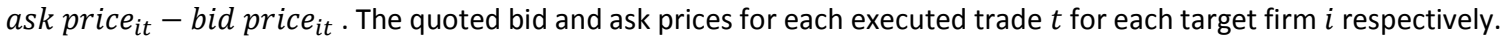
The independent variables include the inverse of trading volume, 1 divided by number of shares per trade, for each trade as well as inventory holding premium calculated as a European at-the-money call option according to Black and Scholes (1973) model $I H P_{i}=M_{i}\left(2 N\left[\frac{1}{2} \sigma_{i} E\left(\sqrt{T_{i}}\right)\right]-1\right)$ where the mid-quote $M_{i}=\left(\frac{\left(\text { ask price }_{i}+\text { bid price }_{i}\right)}{2}\right), \sigma_{i}$ is the annualised standard deviation of 15 minutes of returns, $T_{i}$ is the calculated average time until offsetting trade in share of firm $i$ can occur. The estimator of $I H P_{i}$ is employed as a scaling factor for obtaining the length between offsetting trades such that $\tau_{i}=\sqrt{\widehat{\alpha_{2}} / T_{i}}$. Trade and Quote data is obtained from Thomson Reuters Tick History. Date of takeover announcement, is captured from Thomson Reuters SDC Platinum Database.

\begin{tabular}{|c|c|c|c|c|c|c|c|c|c|}
\hline $\begin{array}{l}\text { Dependent } \\
\text { variable }\end{array}$ & \multicolumn{3}{|c|}{ Bid-Ask Spread } & & & & & & \\
\hline & \multicolumn{3}{|c|}{ All Takeovers } & \multicolumn{3}{|c|}{ Successful Takeovers } & \multicolumn{3}{|c|}{ Unsuccessful Takeovers } \\
\hline $\begin{array}{l}\text { Independent } \\
\text { variables }\end{array}$ & $I H P_{i t}$ & $\tau_{i}$ & $\sigma_{i}$ & $I H P_{i t}$ & $\tau_{i}$ & $\sigma_{i}$ & $I H P_{i t}$ & $\tau_{i}$ & $\sigma_{i}$ \\
\hline \multicolumn{10}{|l|}{$\begin{array}{l}\text { Announcement } \\
\text { Day }\end{array}$} \\
\hline-10 & 0.0175 & 0.0014 & 0.0530 & 0.0167 & 0.0017 & 0.0607 & 0.0184 & 0.0011 & 0.0437 \\
\hline-9 & 0.0161 & 0.0025 & 0.0654 & 0.0129 & 0.0018 & 0.0821 & 0.0207 & 0.0035 & 0.0419 \\
\hline-8 & 0.0199 & 0.0023 & 0.0726 & 0.0177 & 0.0017 & 0.0905 & 0.0230 & 0.0032 & 0.0475 \\
\hline-7 & 0.0188 & 0.0026 & 0.0531 & 0.0152 & 0.0028 & 0.0498 & 0.0238 & 0.0022 & 0.0577 \\
\hline-6 & 0.0210 & 0.0017 & 0.0540 & 0.0196 & 0.0016 & 0.0561 & 0.0229 & 0.0018 & 0.0511 \\
\hline-5 & 0.0211 & 0.0019 & 0.0659 & 0.0198 & 0.0019 & 0.0641 & 0.0230 & 0.0019 & 0.0685 \\
\hline-4 & 0.0190 & 0.0023 & 0.0642 & 0.0164 & 0.0027 & 0.0720 & 0.0227 & 0.0018 & 0.0532 \\
\hline-3 & 0.0199 & 0.0019 & 0.1197 & 0.0180 & 0.0017 & 0.1636 & 0.0226 & 0.0023 & 0.0810 \\
\hline-2 & 0.0187 & 0.0031 & 0.1183 & 0.0169 & 0.0036 & 0.1449 & 0.0211 & 0.0025 & 0.1747 \\
\hline-1 & 0.0175 & 0.0034 & 0.1116 & 0.0151 & 0.0052 & 0.0665 & 0.0208 & 0.0009 & 0.0746 \\
\hline 0 & 0.0207 & 0.0036 & 0.6584 & 0.0219 & 0.0022 & 0.6891 & 0.0191 & 0.0146 & 0.2184 \\
\hline+1 & 0.0155 & 0.0036 & 0.1488 & 0.0140 & 0.0045 & 0.0991 & 0.0175 & 0.0023 & 0.2155 \\
\hline+2 & 0.0184 & 0.0026 & 0.0891 & 0.0180 & 0.0030 & 0.0996 & 0.0189 & 0.0021 & 0.0556 \\
\hline+3 & 0.0209 & 0.0080 & 0.0698 & 0.0209 & 0.0114 & 0.0800 & 0.0209 & 0.0032 & 0.0537 \\
\hline+4 & 0.0204 & 0.0028 & 0.0742 & 0.0199 & 0.0027 & 0.0888 & 0.0211 & 0.0030 & 0.0495 \\
\hline+5 & 0.0203 & 0.0025 & 0.0879 & 0.0203 & 0.0025 & 0.0755 & 0.0202 & 0.0024 & 0.0500 \\
\hline+6 & 0.0192 & 0.0019 & 0.0651 & 0.0185 & 0.0021 & 0.1154 & 0.0202 & 0.0016 & 0.0495 \\
\hline $\begin{array}{l}+7 \\
\end{array}$ & 0.0213 & 0.0040 & 0.0657 & 0.0218 & 0.0016 & 0.0758 & 0.0208 & 0.0073 & 0.0762 \\
\hline+8 & 0.0190 & 0.0046 & 0.1195 & 0.0182 & 0.0055 & 0.0773 & 0.0201 & 0.0033 & 0.0707 \\
\hline+9 & 0.0193 & 0.0024 & 0.0638 & 0.0193 & 0.0027 & 0.0589 & 0.0193 & 0.0019 & 0.0391 \\
\hline+10 & 0.0145 & 0.0045 & 0.1003 & 0.0116 & 0.0032 & 0.1615 & 0.0174 & 0.0058 & 0.0284 \\
\hline
\end{tabular}




\subsubsection{Model Calibration}

Table 5.6 presents the calibration variables of interest results in event time perspective. The variable of time between trades $\tau_{i}$, does not exhibit any significant variation on the day of announcement. The average values of time between trades for successful takeovers are lower than for unsuccessful takeovers. This suggests that the shares of successful targets are traded with greater intensity on average than the shares of unsuccessful takeovers. Further, the time between trades of unsuccessful takeovers is much higher on the day of takeover announcement for unsuccessful takeovers. In contrast, it increases only slightly when compared to previous days' levels for successful takeovers for four days after the announcement. After these four days, the trading returns to pre-announcement levels. This result is consistent with the theory that the shares of successful takeover firms are traded in larger volumes after the takeover is announced, due to takeover traders' activity. Overall, the successful sub-sample appears to have a lower level of time between trades than the unsuccessful sub-sample. This indicates that takeover traders prefer firms with greater liquidity, where they find it easier to acquire shares that can then be sold to the bidder (more easily than with less liquid shares). This observation remains valid even after adjusting for overall levels of trading volume. For unsuccessful takeovers, the trading dynamics appear unchanged, due to the fact that takeover traders, on average, engage in less trading activity during unsuccessful takeover attempts.

The calibration variable of annualised standard deviation of returns $\sigma_{i}$ increases to a significantly higher level on the announcement day; five times the amount observed on ordinary days, reducing sharply to ordinary levels in the next day's trading. As this variable is obtained through standard deviations of returns, this result is consistent with the effect 
of a single large positive return of the target on takeover announcement day, as previously reported in the takeover literature. The effect does not appear to differ across successful and unsuccessful takeovers. However, the overall magnitude of the standard deviation is higher in the successful sub-sample, which may once again be linked to higher liquidity levels of average firms in the successful takeover sub-sample. From a time-series perspective, the effect of a higher overall standard deviation among the successful takeovers tends to occur only on the announcement day, after which the standard deviation reduces to ordinary pre-announcement levels.

Both calibration variables of time between trades $\tau_{i}$ representing the maturity, and the annualised standard deviation $\sigma_{i}$, representing the variance of returns, are used in the Black and Scholes (1973) option pricing model. Here, they establish the price of a synthetic call-option associated with submitting an order to trade in the market, as outlined previously in the methodology section.

\subsubsection{Model Estimation}

The control variables in this model include inverse trading volume and the normalised Herfindahl index, adjusting the decomposition for the order and the availability of trading counterparties. New York Stock Exchange (NYSE), the electronic New York Stock Exchange Arca (NYSE-Arca) and National Association of Securities Dealers Automated Quotations (NASDAQ) offer a very transparent equity trading infrastructure and allow large number of brokers to participate in trading of listed shares. Due to the high level of competition between brokers, the estimates on the normalised Herfindahl index variable are very small and statistically insignificant. This result confirms the competitive nature or provision of market making services and trading outcomes in competitive markets, as 
outlined in Dennert (1993). The relationship of the inverse volume of orders to the bidask spread is negative and small, suggesting that large orders do not reduce the size of bid-ask spread. Small trades have a more significant negative impact on the size of the bid-ask spread, decreasing the spread. This result is consistent with of Lin, Sanger and Booth (1995) theoretical model and empirical test. Finally, the intercept offers an additional form of verification of the model's appropriateness; Bollen, Smith and Whaley (2004) suggest that this value should be close to the average tick size for shares traded. After the decimalisation of share exchanges in the United States - on 1 February 2001 for NYSE and 12 March 2001 for NASDAQ, including all the dates covered in our sampleshare prices have been quoted in cents, with a tick of 1 cent offers a very simple check that the model specification is correct. Indeed, the estimated values for intercepts are very close to 1 cent, which is the tick size implemented on all three exchanges.

\subsubsection{Model Estimation Results}

The model estimates presented in event time in Table 5.7 suggest that, on average, the PI trading in target shares increase on the day of a takeover announcement but is reduced to pre-announcement levels for all reported days immediately following the announcement day.

The difference in inventory holding premium of informed trader estimates between successful and unsuccessful takeover outcomes is insignificant before the takeover is announced; however, the difference is significant on the announcement day. Over the following days, the difference remains significant but very small, suggesting a marginal presence of informed traders in the market among successfully acquired targets, compared to the unsuccessful cases. This effect is most significant two trading days after 
the takeover is announced, with the magnitude of the difference varying over the subsequent nine days. This supports the hypothesis regarding the inclusion of new information by takeover traders dealing in target firm shares. This observation-of informed trading for a few days after the takeover announcement-is consistent with the Cornelli and Li (2002) theoretical model. This indicates that takeover traders have a limited time within which to take advantage of their superior information to derive profit, as competition from other informed or uninformed traders increase the target share price closer to the bid offer price. This observation is also consistent with Kyle (1985) and Glosten and Milgrom (1985) theoretical models of gradual information incorporation in the market price through trading activities. In these models, informed traders effectively hide their trading strategies among uninformed traders in the market. 
Table 5.7. United States Sample: Probability of Informed Trading Estimates

Table 5.7 shows the average estimates of time series linear regression results on the United States sample data using Hansen (1982) Generalised method of moments estimator of the second stage of Bollen, Smith and Whaley (2004) model of bid-ask spread decomposition for the target firm shares. In the second stage, effective bid-ask spread of the target firm shares is decomposed into the expected inventory holding premium of uninformed traders $\left(I H P_{U i t}\right)$, and inventory holding premium of uninformed traders less inventory holding premium of informed traders $\left(I H P_{\text {Iit }}-I H P_{U i t}\right)$, inverse trading volume $\left(I n v T V_{i t}\right)$ and $N H I_{i t}$, the normalised Herfindahl index. The model is specified as: $E S P R D_{i t}=\alpha_{0}+\alpha_{1} I n v T V_{i t}+\alpha_{2} N H I_{i t}+\alpha_{3} I H P_{U i t}\left(\tau_{i}\right)+\alpha_{4}\left(I H P_{I i t}\left(\tau_{i}\right)-I H P_{U i t}\left(\tau_{i}\right)\right)+\varepsilon_{i}$. Where the effective bid-ask spread of target firm, the dependent variable, are calculated trade level frequency according to the standard effective spread model is $E S P R D_{i t}=2 \mid$ Trade Price $_{i t}-M_{i t} \mid / M_{i t}$ where the mid-quote $M_{i t}=$ $\left(\frac{\left(\text { ask price }_{i t}+\text { bid price }_{i t}\right)}{2}\right)$ and Trade Price $_{i t}$ is the price for each executed trade $t$ for each target firm $i$, bid price $i t$ and ask price $_{i t}$ are the quoted bid and ask prices for each executed trade $t$ for each target firm $i$ respectively. The independent variables of the model include the inverse of trading volume, 1 divided by the number of shares per trade, for each trade as well as inventory premium calculated as a the value European call option according to Black and Scholes (1973) model IHP $P_{i t}=M_{i t} N\left(\frac{\ln \left(\frac{M_{i t}}{X_{i t}}\right)}{\sigma_{i \sqrt{\tau_{i}}}}+\frac{1}{2} \sigma_{i} \sqrt{\tau_{i}}\right)-X_{i t} N\left(\frac{\ln \left(\frac{M_{i t}}{X_{i t}}\right)}{\sigma_{i \sqrt{\tau_{i}}}}-\frac{1}{2} \sigma_{i} \sqrt{\tau_{i}}\right)$ where $X_{i t}$ is the synthetic option exercise price at maturity selected according to Bollen, Smith and Whaley (2004) at $5 \%$ above the prevailing mid-quote for the $I H P_{I t}$ and at the mid-quote for $I H P_{U t}, \sigma_{i}$ is the annualised standard deviation of 15 minutes of returns, $\tau_{i}$ is the calibrated time until offsetting trade in share of firm $i$ from the first stage of estimation. Probability of informed trading $(P I 15 \mathrm{~min})$ is captured by the model $\alpha_{4}$ regression coefficient on $\left(I H P_{I i t}-I H P_{U i t}\right)$ variable. Trade and Quote data is obtained from Thomson Reuters Tick History Database. Date of takeover announcement, is captured from Thomson Reuters SDC Platinum Database.

\begin{tabular}{|c|c|c|c|}
\hline & Average & Successful- & ccessful \\
\hline Independent variable & $P I 15 \mathrm{~min}$ & PI 15min & $p$ value \\
\hline \multicolumn{4}{|l|}{ Announcement Day } \\
\hline-10 & 0.0465 & 0.0001 & 0.3491 \\
\hline-9 & 0.0449 & 0.0030 & 0.6584 \\
\hline-8 & 0.0465 & 0.0021 & 0.1039 \\
\hline-7 & 0.0460 & -0.0010 & 0.3437 \\
\hline-6 & 0.0461 & $0.0003^{*}$ & 0.0536 \\
\hline-5 & 0.0487 & -0.0076 & 0.2760 \\
\hline-4 & 0.0493 & 0.0004 & 0.3507 \\
\hline-3 & 0.0473 & -0.0005 & 0.4267 \\
\hline-2 & 0.0477 & 0.0030 & 0.3663 \\
\hline-1 & 0.0480 & $0.0001^{*}$ & 0.0895 \\
\hline 0 & 0.0603 & $0.0181 * * *$ & 0.0005 \\
\hline+1 & 0.0428 & 0.0004 & 0.5861 \\
\hline+2 & 0.0446 & $0.0019 * * *$ & 0.0061 \\
\hline+3 & 0.0490 & $-0.0056 * * *$ & 0.0000 \\
\hline+4 & 0.0452 & 0.0074 & 0.1838 \\
\hline+5 & 0.0496 & $-0.0015^{* * *}$ & 0.0000 \\
\hline+6 & 0.0467 & $0.0006 * * *$ & 0.0000 \\
\hline+7 & 0.0508 & $0.0054 * * *$ & 0.0000 \\
\hline+8 & 0.0448 & $-0.0010 * * *$ & 0.0042 \\
\hline+9 & 0.0453 & $0.0042 * * *$ & 0.0000 \\
\hline+10 & 0.0447 & $0.0065 *$ & 0.0911 \\
\hline
\end{tabular}

$*$ indicates significance at $10 \%$ level; **significance at $5 \%$ level; ***significance at $1 \%$ level 


\subsubsection{Discussion}

The results in Tables 5.6 and 5.7 are consistent with the previous literature on takeovers, market microstructure and trading behaviour. The results in Table 5.6 show that the intensity of trading in target shares on the takeover announcement day increases substantially from pre-takeover levels. The evidence for this is represented by the decrease in estimated time between trades. This is the case for successful takeovers. For unsuccessful takeover attempts, the estimate of time between trades increases on the takeover announcement day. The average annualised standard deviation estimate increases on the announcement day for both sub-samples, consistent with the abnormal increases in returns of target firms on the announcement day that are well documented in the empirical literature. In Table 5.7, the PI trading estimate increased, on average, for the whole sample on the announcement day and remained at similar levels for one day after the announcement. We report differences in informed trading between successful and unsuccessful takeover targets to initially investigate Cornelli and Li (2002) theory that more takeover traders participate in successful takeovers than in unsuccessful ones. The results in Table 5.7 suggest that the presence of informed traders is significantly higher and statistically significant on the takeover announcement day. This estimate remains significant up to nine days in successful takeovers when compared to unsuccessful takeover targets, but the difference is small.

\subsubsection{Impact of Probability of Informed Trading on Takeover Success}

Cornelli and Li (2002) predicted that takeover traders would have a direct impact on the outcome of the takeover process through increasing the likelihood of takeover success. The results from the direct tests regarding this hypothesis, $H_{1}$, are given in Table 5.8. The 
table presents the estimates of a logistic (logit) regression. The results of this model specification can be interpreted in two ways, either in terms of the effects on the probability of success (which constitutes the inference of overall model prediction), or the results can be presented in terms of the likelihood odds over unsuccessful cases (where the marginal effects of one variable may be used to show the effect of its changes on the odds of a successful outcome over an unsuccessful outcome). We report on both techniques of inference in this logistic model.

Table 5.8 presents the results of logistic estimation using the results from informed trading regressions in different time aggregation groups of 5, 10, 15 and 30 minutes separately. As the results are very close to each another, we present the inference of our model using a 15 -minute PI trading estimate. The coefficient is reported at 3.477 , and the probability of success of the average transaction is $50.59 \%$. If the $P I$ trading estimate was to increase by $1 \%$ from its mean value, the probability of success would increase to $62.80 \%$, while all other variables remain constant. Conversely, if the $P I$ trading figure was to decrease by $1 \%$, the probability of success would fall to $38.32 \%$, with other variables remaining at the original levels. If the PI trading variable was to rise by 1 standard deviation above its mean (by $4.16 \%$ ), the probability of takeover success would increase to $81.49 \%$, while the same decrease in the 15 -minute $P I$ trading measure from the mean would decrease the probability of success to $17.97 \%$, with other levels of variables held constant. 
Table 5.8. United States Sample: Impact of Probability of Informed Trading on Takeover Success

Table 5.8 shows the estimates of binary logit regression results of takeover outcome on the $(P I)$ measure and controls. The takeover outcome indicator, the dependent variable, is equal to 1 when the takeover is a success and 0 otherwise. The independent variables include the $\log ($ Size), the natural logarithm transformation of market capitalisation of the firm on the day of takeover announcement, calculated as the number of ordinary shares multiplied by the opening share price; Premium 1 Day is a calculated as the difference between the takeover target offer price per share and the closing price per one day prior to the announcement. Shares sought is the percentage of shares to be acquired under the takeover. The indicator variable on takeover method of payment equals 1 when cash is the method of payment and 0 otherwise. The toe hold variable is an indicator of the bidder ownership greater than $5 \%$ in the bidder prior to the takeover announcement equal to 1 and 0 otherwise. The indicator variable of multiple bidders is equal to 1 when there are more than one bidder during the takeover process and 0 if there is only one. The block holding variable is the control for the existence of block holders owning more than $5 \%$ of the target shares on the announcement day equals 1 and 0 otherwise. PI is estimated using Bollen, Smith and Whaley (2004) model, aggregating trade data in 5, 10, 15 and 30 minute trading intervals. The effects of individual firms are controlled by the inverse mills ratio estimated using the 2-step Heckman (1976) procedure to account for sample selection bias by using the closest propensity scored matched firm that is not engaged in any takeover activity. Matching is performed on market capitalisation and industry of operation. Firm year effects controls include a set of indicator variables for each year equal to 1 for the year in which takeover activity takes place and 0 otherwise. Firm industry effects controls include an indicator variable equal to 1 when the takeover occurs with a specific industry (based on 2-digit SIC code categorisation) and 0 otherwise.

Dependent variable

Outcome

\begin{tabular}{|c|c|c|c|c|}
\hline Independent variables & (1) & $(2)$ & (3) & (4) \\
\hline \multirow[t]{2}{*}{ Intercept } & -27.1279 & -26.9439 & -26.7959 & -27.0828 \\
\hline & $(-1.472)$ & $(-1.465)$ & $(-1.475)$ & $(-1.471)$ \\
\hline \multirow[t]{2}{*}{ Log(Size) } & $-0.1122 *$ & -0.1229 & $-0.0964^{*}$ & $-0.1159 *$ \\
\hline & $(-1.796)$ & $(-1.562)$ & $(-1.758)$ & $(-1.856)$ \\
\hline \multirow[t]{2}{*}{ Premium 1 Day } & $0.0025^{* * *}$ & $0.0081 * * *$ & $0.0048 * * *$ & $0.0047^{* * *}$ \\
\hline & $(4.748)$ & $(4.835)$ & $(4.761)$ & $(3.760)$ \\
\hline \multirow[t]{2}{*}{ Shares Sought } & $0.0047^{* * *}$ & $0.0213 * * *$ & $0.0214 * * *$ & $0.0213^{* * *}$ \\
\hline & $(4.323)$ & $(4.286)$ & $(4.288)$ & $(4.270)$ \\
\hline \multirow[t]{2}{*}{ D Pay Cash } & $0.2497 * *$ & $0.2432 * *$ & $0.2315^{* *}$ & $0.2499 * *$ \\
\hline & $(2.422)$ & $(2.392)$ & $(2.173)$ & $(1.997)$ \\
\hline \multirow[t]{2}{*}{ D Toe Hold } & 0.8022 & 0.8071 & 0.8189 & 0.8033 \\
\hline & $(1.026)$ & $(1.030)$ & $(1.045)$ & $(1.027)$ \\
\hline \multirow[t]{2}{*}{ D Multiple Bidders } & $-4.6687^{* * *}$ & $-4.6902 * * *$ & $-4.6912 * * *$ & $-4.6928 * * *$ \\
\hline & $(-5.558)$ & $(-5.591)$ & $(-5.611)$ & $(-5.587)$ \\
\hline \multirow[t]{2}{*}{ D Block Holding } & -0.2318 & -0.3986 & -0.3707 & -0.2557 \\
\hline & $(-0.419)$ & $(-0.698)$ & $(-0.675)$ & $(-0.459)$ \\
\hline \multirow[t]{2}{*}{ PI $5 \min$} & $3.5035 * * *$ & & & \\
\hline & $(3.011)$ & & & \\
\hline \multirow[t]{2}{*}{ PI 10min } & & $7.3474 * * *$ & & \\
\hline & & (3.090) & & \\
\hline \multirow[t]{2}{*}{ PI 15min } & & & $3.4770 * * *$ & \\
\hline & & & $(3.085)$ & \\
\hline \multirow[t]{2}{*}{ PI 30min } & & & & $4.2800 * * *$ \\
\hline & & & & (3.356) \\
\hline \multirow[t]{2}{*}{ PI x D Block Holding } & 1.6407 & 5.2140 & 5.4888 & 2.0758 \\
\hline & $(0.1587)$ & $(0.488)$ & $(0.528)$ & $(0.200)$ \\
\hline Firm Control Variables & $\mathrm{Y}$ & $\mathrm{Y}$ & $\mathrm{Y}$ & $\mathrm{Y}$ \\
\hline Year Effects & $\mathrm{Y}$ & $\mathrm{Y}$ & $\mathrm{Y}$ & $Y$ \\
\hline Industry Effects & $\mathrm{Y}$ & $\mathrm{Y}$ & $\mathrm{Y}$ & $\mathrm{Y}$ \\
\hline Pseudo R squared & 0.2782 & 0.2788 & 0.2782 & 0.2783 \\
\hline $\mathrm{N}$ & 491 & 491 & 491 & 491 \\
\hline
\end{tabular}

*indicates significance at $10 \%$ level; $* *$ significance at $5 \%$ level; $* * *$ significance at $1 \%$ level 
We also consider the interpretation of the results in Table 5.8, using the odds ratio analysis on the same model estimated using a 15-minute PI trading. In this case, a $1 \%$ increase in the PI trading from its average level leads to an increase in the odds success by 2.688 times the odds of the average takeover success. The same level of decrease in informed trading from the average level would lead to a decrease in the odds ratio by 1.621 times the odds of the average takeover.

The estimated coefficient on the indicator variable for block holders is statistically insignificant in United States takeovers covered by the sample, and is very small, negative or close to zero, suggesting that the present shareholders holding more than $5 \%$ have no impact on takeover success. An explanation for this finding can be found in the interests of pre-existing block holders who may oppose the takeover activity; takeover traders may still participate and cause the takeover to succeed. If the block holders do not own more than $50 \%$ of all shares of the target company ${ }^{5}$, takeover traders may still be able to acquire sufficient shares to sell to an outside bidder, thus making the takeover binding for all shareholders. Conversely, if block holders do own more than $50 \%$ of the target firm shares, they would most likely already have negotiated with the bidder prior to the announcement privately, and secured a private arrangement with the bidder firm on acquisition of their shares. In such a situation, if block holders oppose the takeover, informed traders will not have sufficient incentives to participate in the takeover process. This is because they cannot acquire a sufficient amount of shares to make the takeover offer binding to acquire the remaining shares. The decisions of block holders, coupled with their initial shareholding amounts, are exogenous to the decisions of takeover

\footnotetext{
${ }^{5}$ We also remove any firms where blockholders hold more than $60 \%$ of shares from the sample and re-estimate the model results. These results are presented in appendix tables 5A, 6A and 7A. The results presented show that there are no significant effects of blockholdings greater than $60 \%$ on the original results which include these observations.
} 
traders. This is revealed in the information gathering process immediately after a takeover announcement and is factored into the decision of takeover traders regarding participation in target share trading.

Surprisingly, the estimated coefficient on the indicator variable for toehold is insignificant, suggesting that the bidder holding more than $5 \%$ in the target company before the takeover announcement has no significant impact on the takeover outcome. This test of the theoretical model proposed in Cornelli and Li (2002) employs high frequency trade-by-trade intraday data to estimate the daily Bollen, Smith and Whaley (2004) measure of PI trading, as well as takeover target and takeover characteristics, to adjust for any effects these variables may have on the probability of takeover success. While the PI trading estimation employs very high frequency data, the remaining variables employ a takeover-specific set of variables, or target firm variables obtained primarily from the last financial statement released by the target firm. Such significantly different frequencies of these variables are very unlikely to contain any significant relationships between variables.

\subsubsection{Test of Reverse Causality}

Larcker and Lys (1987) propose that takeover traders may have superior predictive abilities regarding the likelihood of takeover success. We construct a test in relation to this by specifying a model where the $P I$ trading is the dependent variable, while the success variable is independent. This is done by testing the reverse causality of the

original model. Table 5.9 details the results of this model specification. In this case, a positive relationship exists between the $P I$ trading and a one day premium and the likelihood of success. Both effects are expected as informed traders have an incentive to 
participate more in takeovers with higher premiums and takeovers that are more likely to be successful $\mathrm{H}_{2}$ and $H_{4}$ respectively. If informed traders indeed have perfect foresight over what takeovers are ultimately successful, then the coefficient on the success variable should be very large. The coefficient is around 2.1 and is significant at the $1 \%$ level, which means that there is $2.1 \%$ increase in the $P I$ trading when the takeover is successful. The $1 \%$ increase in the one day premium is only linked to a $0.03 \%$ increase in PI trading, suggesting that higher premiums have only a marginal effect on inducing informed traders to participate in target share trading. Far more important to the informed traders' participation levels is their ability to purchase a sufficient amount of shares to conclude the takeover activity successfully.

The measures of informed trading offer indirect evidence that takeover traders react to news, rather than anticipate those takeovers. In Table 5.7, the probability of difference between informed and uninformed trading becomes significant only after the takeover is announced and remains economically and statistically significant for one day after the announcement on average. 


\section{Table 5.9. United States Sample: Impact of Takeover Success on Probability of Informed Trading}

Table 5.9 shows the estimates of linear regression results using Hansen (1982) GMM estimator of the PI measure on the indicator of takeover success and controls on United States takeovers. PI is estimated using Bollen, Smith and Whaley (2004) model, aggregating trade data in 5, 10, 15 and 30 minute intervals. The independent variables include the $\log (\mathrm{Size})$, the natural logarithm transformation of market capitalisation of the firm on the day of takeover announcement, calculated as the number of ordinary shares multiplied by the opening share price; Premium 1 Day is a calculated as the percentage difference between the takeover target offer price per share and the closing price per one day prior to the announcement. The indicator variable on takeover method of payment equals 1 when cash is the method of payment and 0 otherwise. The toe hold variable is an indicator of the bidder ownership greater than $5 \%$ in the bidder prior to the takeover announcement equal to 1 and 0 otherwise. The indicator variable of multiple bidders is equal to 1 when there are more than one bidder during the takeover process and 0 if there is only one. The block holding variable is the control for the existence of block holders owning more than $5 \%$ of the target shares on the announcement day equals 1 and 0 otherwise. The indicator variable on hostile takeovers equals 1 when the bid is accompanied by a proxy contest or tender offer and 0 otherwise. The Firm fixed effects is the inverse mills ratio estimated using the 2-step Heckman (1976) procedure to account for sample selection bias using the closest matched firm not engaged in any takeover activity based on market capitalisation and industry of operation. Firm year effects include indicator variables for each year equal to 1 for the year in which takeover is announced and 0 otherwise. Firm industry effects include an indicator variable equal to 1 when the takeover occurs within a specific industry based on 2-digit SIC code categorisation and 0 otherwise.

\begin{tabular}{|c|c|c|c|c|}
\hline Dependent variable & $P I 5 \min$ & $P I 10 \mathrm{~min}$ & $P I 15 \mathrm{~min}$ & $P I 30 \mathrm{~min}$ \\
\hline Independent variables & (1) & (2) & (3) & (4) \\
\hline \multirow[t]{2}{*}{ Intercept } & $0.1036 * * *$ & $0.1045^{* * *}$ & $0.0895 * * *$ & $0.0932 * * *$ \\
\hline & $(3.141)$ & $(3.197)$ & $(3.100)$ & $(3.203)$ \\
\hline \multirow[t]{2}{*}{ Log(Size) } & $-0.0074 * * *$ & $-0.0075^{* * *}$ & $-0.0061^{* * *}$ & $-0.0070 * * *$ \\
\hline & $(-6.715)$ & $(-6.799)$ & $(-6.071)$ & $(-9.076)$ \\
\hline \multirow[t]{2}{*}{ Premium 1 Day } & $0.0031 * * *$ & $0.0034 * * *$ & $0.0037^{* * *}$ & $0.0017 * * *$ \\
\hline & $(2.709)$ & $(2.794)$ & $(2.854)$ & $(2.805)$ \\
\hline \multirow[t]{2}{*}{ D Pay Cash } & -0.0012 & -0.0012 & -0.0013 & -0.0023 \\
\hline & $(-0.369)$ & $(-0.368)$ & $(-0.322)$ & $(-0.218)$ \\
\hline \multirow[t]{2}{*}{ D Toe Hold } & 0.0033 & 0.0031 & 0.0051 & 0.0054 \\
\hline & $(0.686)$ & $(0.651)$ & $(1.125)$ & $(1.285)$ \\
\hline \multirow[t]{2}{*}{ D Block Holding } & -0.0041 & -0.0039 & -0.0052 & -0.0047 \\
\hline & $(-1.275)$ & $(-1.230)$ & $(-1.640)$ & $(-1.489)$ \\
\hline \multirow[t]{2}{*}{ D Hostile } & -0.0013 & -0.0012 & $-0.0078^{*}$ & -0.0016 \\
\hline & $(-0.148)$ & $(-0.135)$ & $(-1.651)$ & $(-1.191)$ \\
\hline \multirow[t]{2}{*}{ D Success } & $2.4533 * * *$ & $2.4722 * * *$ & $2.1791 * * *$ & $2.1574 * * *$ \\
\hline & $(2.994)$ & $(2.647)$ & (3.409) & $(3.479)$ \\
\hline Firm Control Variables & $\mathrm{Y}$ & $Y$ & $Y$ & $\mathrm{Y}$ \\
\hline Year Effects & $\mathrm{Y}$ & $\mathrm{Y}$ & Y & $\mathrm{Y}$ \\
\hline Industry Effects & $\mathrm{Y}$ & $\mathrm{Y}$ & $Y$ & $\mathrm{Y}$ \\
\hline Adjusted R squared & 0.2071 & 0.2066 & 0.2485 & 0.2569 \\
\hline $\mathrm{N}$ & 491 & 491 & 491 & 491 \\
\hline
\end{tabular}

*indicates significance at $10 \%$ level; **significance at $5 \%$ level; ***significance at $1 \%$ level 
The remaining noteworthy days remain economically insignificant; nevertheless, the occurrence of informed trading is higher for successful takeovers on most days after the takeover is announced. This suggests that informed trading occurs only after the announcement of takeovers has been made, rather than before this day when informed agents and insiders are most likely to engage in trading of target shares, which would increase the PI trading of target shares before the announcement was made. We do not observe this behaviour in our data suggesting that insider-trading rules prevent them from doing so. We also closely review the timing of takeover announcements to investigate any clustering of their occurrence. We consider the time of day that the takeover intent is made public, as well as the day of the week when the takeover is announced to the market. There is no clustering of announcements across days of the week or time intervals during those days. This suggests that the occurrence of takeover announcements in the market appears to be random with respect to the time of day and day of the week.

\subsubsection{Test of Predictive Power}

We undertook a test of predictive power by randomly separating the full sample of 491 takeover events into two sub-samples. We then estimated the model of takeover characteristics, firm characteristics and control variables of takeover success on a subsample containing 252 takeovers. The estimation results are presented in Table 5.10. We then used the estimates to predict the takeover outcome. The model predicts the takeover outcome with $75.89 \%$ accuracy. 
Table 5.10. United States Sample: Impact of Probability of Informed Trading on Takeover Success Random Sub-sample

Table 5.10 shows the estimates of binary logit regression results of takeover outcome on the $(P I)$ measure and controls on random sub-sample of United States takeovers. The takeover outcome indicator, the dependent variable, is equal to 1 when the takeover is a success and 0 otherwise. The independent variables include the $\log (\mathrm{Size})$, the natural logarithm transformation of market capitalisation of the firm on the day of takeover announcement, calculated as the number of ordinary shares multiplied by the opening share price; Premium 1 Day is a calculated as the difference between the takeover target offer price per share and the closing price per one day prior to the announcement. Shares sought is the percentage of shares to be acquired under the takeover. The indicator variable on takeover method of payment equals 1 when cash is the method of payment and 0 otherwise. The toe hold variable is an indicator of the bidder ownership greater than $5 \%$ in the bidder prior to the takeover announcement equal to 1 and 0 otherwise. The indicator variable of multiple bidders is equal to 1 when there are more than one bidder during the takeover process and 0 if there is only one. The block holding variable is the control for the existence of block holders owning more than $5 \%$ of the target shares on the announcement day equals 1 and 0 otherwise. PI is estimated using Bollen, Smith and Whaley (2004) model, aggregating trade data in 5, 10, 15 and 30 minute trading intervals. The effects of individual firms are controlled by the inverse mills ratio estimated using the 2-step Heckman (1976) procedure to account for sample selection bias by using the closest propensity scored matched firm that is not engaged in any takeover activity. Matching is performed on market capitalisation and industry of operation. Firm year effects controls include a set of indicator variables for each year equal to 1 for the year in which takeover activity takes place and 0 otherwise. Firm industry effects controls include an indicator variable equal to 1 when the takeover occurs with a specific industry (based on 2 digit SIC code categorisation) and 0 otherwise.

\begin{tabular}{|c|c|c|c|c|}
\hline \multirow{2}{*}{$\begin{array}{l}\text { Dependent variable } \\
\text { Independent variables }\end{array}$} & \multicolumn{2}{|c|}{ Outcome } & \multirow[b]{2}{*}{ (3) } & \multirow[b]{2}{*}{$(4)$} \\
\hline & $(1)$ & $(2)$ & & \\
\hline \multirow[t]{2}{*}{ Intercept } & -19.081 & -19.822 & -18.485 & -19.218 \\
\hline & $(-1.239)$ & $(-1.234)$ & $(-1.137)$ & $(-1.243)$ \\
\hline \multirow[t]{2}{*}{$\log ($ Size) } & $-0.1578^{*}$ & $-0.1928^{*}$ & $-0.1726^{*}$ & $-0.1682^{*}$ \\
\hline & $(-1.804)$ & $(-1.736)$ & $(-1.691)$ & $(-1.765)$ \\
\hline \multirow[t]{2}{*}{ Premium 1 Day } & $0.0047^{* * *}$ & $0.0052 * * *$ & $0.0049 * * *$ & $0.0048 * * *$ \\
\hline & $(2.753)$ & $(2.819)$ & $(2.671)$ & $(2.776)$ \\
\hline \multirow[t]{2}{*}{ Shares Sought } & $0.0207^{* * *}$ & $0.0216 * * *$ & $0.0213^{* * *}$ & $0.0209 * * *$ \\
\hline & $(2.867)$ & $(2.965)$ & $(2.919)$ & $(2.889)$ \\
\hline \multirow[t]{2}{*}{ D Pay Cash } & $0.2318^{*}$ & $0.2001^{*}$ & $0.2160^{*}$ & $0.2235^{*}$ \\
\hline & $(1.674)$ & $(1.544)$ & $(1.809)$ & $(1.809)$ \\
\hline \multirow[t]{2}{*}{ D Toe Hold } & $1.9938^{*}$ & $1.9113^{*}$ & $1.9589 *$ & $1.9683^{*}$ \\
\hline & $(1.815)$ & $(1.745)$ & $(1.779)$ & $(1.794)$ \\
\hline \multirow[t]{2}{*}{ D Multiple Bidders } & $-4.4967 * * *$ & $-4.4691 * * *$ & $-4.4851 * * *$ & $-4.4893 * * *$ \\
\hline & $(-3.881)$ & $(-3.854)$ & $(-3.873)$ & $(-3.875)$ \\
\hline \multirow[t]{2}{*}{ D Block Holding } & -0.1739 & -0.1709 & -0.0548 & -0.1718 \\
\hline & $(-0.236)$ & $(-0.223)$ & $(-0.074)$ & $(-0.231)$ \\
\hline \multirow[t]{2}{*}{ PI $5 \min$} & $3.8353^{* * *}$ & & & \\
\hline & $(3.428)$ & & & \\
\hline \multirow[t]{2}{*}{ PI 10min } & & $2.7409 * * *$ & & \\
\hline & & $(3.649)$ & & \\
\hline \multirow[t]{2}{*}{ PI 15min } & & & $2.7446 * * *$ & \\
\hline & & & $(3.385)$ & \\
\hline \multirow[t]{2}{*}{ PI 30min } & & & & $5.1664^{* * *}$ \\
\hline & & & & $(3.808)$ \\
\hline \multirow[t]{2}{*}{ PI x D Block Holding } & 1.9241 & 1.6928 & 0.6953 & 1.8843 \\
\hline & $(0.143)$ & $(0.122)$ & $(0.052)$ & $(0.140)$ \\
\hline Firm Control Variables & $Y$ & $Y$ & $\mathrm{Y}$ & Y \\
\hline Year Effects & $\mathrm{Y}$ & $Y$ & $Y$ & $Y$ \\
\hline Industry Effects & $Y$ & $\mathrm{Y}$ & $\mathrm{Y}$ & $Y$ \\
\hline Pseudo R squared & 0.2839 & 0.2887 & 0.2882 & 0.2848 \\
\hline $\mathrm{N}$ & 252 & 252 & 252 & 252 \\
\hline
\end{tabular}

*indicates significance at $10 \%$ level; **significance at $5 \%$ level; $* * *$ significance at $1 \%$ level 


\subsubsection{Discussion}

The results show that Cornelli and Li (2002) theory is supported by the empirical test results, revealing economically and statistically significant estimates in the data. The estimates of logistic regressions show that the impact on takeover success is represented by the PI trading while controlling for all other company and takeover characteristics. The effect of $P I$ trading remains significant at all aggregation periods with the estimates showing consistent results. The effect is persistent at larger event windows and remains significant in all the different model specifications used. The analysis using probability and odds ratio inference shows a significantly large impact that informed traders present through their participation in trading takeover target shares. They also participate more in takeovers that turn out to be successful, supporting Cornelli and Li (2002) theoretical model

5.3.6. Impact of Probability of Informed Trading on Cumulative Abnormal Returns

\subsubsection{Model Estimation Results}

The estimates presented in Table 5.11 show that the presence of takeover traders has a positive impact on the CAR in all event windows testing our hypothesis $H_{3}$. A $1 \%$ increase in PI trading, estimated using the 15 -minute interval, is associated with a $2.59 \%$ increase in CARs in the 0,+1 window. This relationship remains fundamentally the same over different event windows. The marginal effect of $P I$ trading in successful takeovers suggests that a $1 \%$ increase in PI trading in the 15 -minute interval increases the CAR in the $0-1$ day event window by $2.63 \%$ higher than in unsuccessful cases. 
Successful takeovers deliver a higher CAR (by 2.84\%) in the announcement plus 1 day window, increasing in longer event windows as the takeover becomes more certain. Premium 1 Day also increases CAR, and is especially significant in the $0,+1$ day window but economically insignificant, as a $1 \%$ increase in premium is linked to a $0.197 \%$ increase in CAR. This coefficient becomes insignificant outside the $0,+1$ day event window.

\subsubsection{Tests of explanatory power}

To test the model's power, we conducted an $\mathrm{F}$ test by removing the variables connected to the PI trading. We specified the restricted model while testing it in relation to the unrestricted model containing the two additional variables of $P I$ and $P I$ interacted with the takeover success indicator variable. We find that $F$ statistics are significant at the $5 \%$ level. 


\section{Table 5.11. United States Sample: Impact of Probability of Informed Trading on Target Firm Cumulative Abnormal Returns}

Table 5.11 shows the estimates of linear regression results using Hansen (1982) GMM estimator of cumulative abnormal returns (CARs) of the target firm over different time windows after the takeover is announced, on the PI $15 \mathrm{~min}$ measure and controls. The CAR of target firm shares above the Fama and French (1993) factors, the dependent variables, are calculated at daily frequency for the appropriate event window of takeover announcement. The independent variables include the natural logarithm of firm size expressed as a logarithm of the market capitalisation of the firm on the takeover announcement day. ROA is the return on assets calculated as last reported net income divided by total assets by the target company. Premium 1 Day is the percentage difference of share price one day prior to the takeover announcement and the takeover price contained in the announcement. $P I$ is estimated using Bollen, Smith and Whaley (2004) model, aggregating trade data in 15 minute trading intervals, the results of which are reported in Table 5.7. The indicator variable on takeover method of payment equals 1 when cash is the method of payment and 0 otherwise. The toe hold variable is an indicator of the bidder ownership greater than $5 \%$ in the bidder prior to the takeover announcement equal to 1 and 0 otherwise. The indicator variable of multiple bidders is equal to 1 when there are more than one bidder during the takeover process and 0 if there is only one. The block holding variable is the control for the existence of block holders owning more than $5 \%$ of the target shares on the announcement day equals 1 and 0 otherwise. The takeover outcome indicator, is equal to 1 when the takeover is a success and 0 otherwise. Control for the firm effects is the inverse mills ratio estimated using the 2-step Heckman (1976) procedure to account for sample selection bias using the closest firm matched on market capitalisation and industry of operation not engaged in any takeover activity. Firm year effects include indicator variables for each year equal to 1 for the year in which takeover is announced and 0 otherwise. Firm industry effects include an indicator variable equal to 1 when the takeover occurs with a specific industry based on 2-digit SIC code categorisation and 0 otherwise.

\begin{tabular}{|c|c|c|c|c|}
\hline Dependent variable & CAR $[0,+1]$ & CAR $[0,+5]$ & CAR $[0,+10]$ & CAR $[0,+30]$ \\
\hline \multicolumn{4}{|l|}{ Independent } & $(4)$ \\
\hline \multirow[t]{2}{*}{ Intercept } & 5.7618 & 9.5147 & 14.4015 & 13.1212 \\
\hline & $(0.404)$ & $(0.629)$ & $(0.960)$ & $(0.841)$ \\
\hline \multirow[t]{2}{*}{$\log ($ Size $)$} & $-2.2304 * * *$ & $-1.9594 * * *$ & $-2.1356 * * *$ & $-1.7939 * * *$ \\
\hline & $(-4.235)$ & $(-3.454)$ & $(-3.733)$ & $(-2.798)$ \\
\hline \multirow[t]{2}{*}{ ROA } & $4.3104^{* *}$ & $3.3758 * *$ & $3.3394 * *$ & $3.0743^{* *}$ \\
\hline & $(2.421)$ & $(2.190)$ & $(2.102)$ & $(1.742)$ \\
\hline \multirow[t]{2}{*}{ Premium 1 Day } & $0.1966 * * *$ & $0.2155^{* * *}$ & $0.2205 * * *$ & $0.2240 * * *$ \\
\hline & $(3.542)$ & $(3.610)$ & $(3.669)$ & $(3.614)$ \\
\hline \multirow[t]{2}{*}{ D Pay Cash } & $6.7235 * * *$ & $7.0714^{* * *}$ & $7.2213^{* * *}$ & $7.9243^{* * *}$ \\
\hline & $(5.304)$ & $(5.189)$ & $(5.157)$ & $(5.082)$ \\
\hline \multirow[t]{2}{*}{ D Toe Hold } & 3.9452 & 4.2172 & 3.7207 & 2.4979 \\
\hline & $(0.838)$ & $(0.089)$ & $(0.731)$ & $(0.387)$ \\
\hline \multirow[t]{2}{*}{ D Block Holding } & 0.0790 & 1.3756 & 1.7891 & 0.0524 \\
\hline & $(0.035)$ & $(0.612)$ & $(0.775)$ & $(0.023)$ \\
\hline \multirow[t]{2}{*}{ D Success } & $2.8378 * * *$ & $2.0403 * *$ & $2.3071^{* * *}$ & $2.7157^{* *}$ \\
\hline & $(2.900)$ & $(2.209)$ & $(2.775)$ & $(2.426)$ \\
\hline \multirow[t]{2}{*}{ PI 15min } & $2.5873 * * *$ & $3.0409 * * *$ & $1.6159 * * *$ & $1.3132 * * *$ \\
\hline & $(2.894)$ & $(2.650)$ & $(3.052)$ & $(2.739)$ \\
\hline D Success $x$ & $2.6349 * *$ & $3.8237 * * *$ & $4.3036 * * *$ & $3.0276 * * *$ \\
\hline PI 15min & $(2.488)$ & $(2.769)$ & $(2.848)$ & $(2.657)$ \\
\hline D Block Holding $x$ & 8.9935 & 9.0665 & $12.6909 * *$ & $9.8186 *$ \\
\hline PI 15min & $(1.795)$ & $(1.791)$ & $(2.482)$ & $(1.903)$ \\
\hline \multicolumn{5}{|l|}{ Firm Control } \\
\hline Variables & $Y$ & $Y$ & $Y$ & $Y$ \\
\hline Year Effects & $\mathrm{Y}$ & $\mathrm{Y}$ & $\mathrm{Y}$ & $\mathrm{Y}$ \\
\hline Industry Effects & $\mathrm{Y}$ & $\mathrm{Y}$ & $Y$ & $\mathrm{Y}$ \\
\hline Adjusted R squared & 0.4168 & 0.3940 & 0.3955 & 0.3502 \\
\hline $\mathrm{N}$ & 491 & 491 & 491 & 491 \\
\hline
\end{tabular}

*indicates significance at $10 \%$ level; **significance at $5 \%$ level; $* * *$ significance at $1 \%$ level 


\subsubsection{Conclusions}

We tested the theoretical model of trading of takeover shares' effect on takeover outcomes, as proposed in Cornelli and Li (2002). We employed Australian and United States takeover data between 2008 and 2013 to investigate the impact on takeover success of takeover traders purchasing the target firms' shares. Takeover announcements present an important corporate and randomly occurring event revealing previously private information to the market. Cornelli and Li (2002) propose that the active trading of target shares during the takeover period directly influences the takeover outcome, by takeover traders acting as block holders. Takeover traders purchase target firm shares after the takeover intent is announced and then sell on their shares to the bidder. The incentives of takeover traders to participate in trading takeover shares are derived from the profit motive of purchasing target shares in successful takeovers. Once a takeover bid has been announced, the offer price paid by the bidder for target shares becomes known, but the probability of takeover success remains less than certain. The takeover traders decide to participate in trading target shares depending on the profit available to them, the difference between the bid price and market price at which they are able to purchase the shares, and their assessment of the takeover success likelihood. We can therefore classify trades conducted by takeover traders as informed trades according to Cornelli and Li (2002) sufficiency specification that states takeover traders derive information from knowledge of their own positions. We tested the impact of takeover traders on takeover success by employing microstructure data and the robust estimation methodology of informed trading as proposed in Bollen, Smith and Whaley (2004) model of bid-ask spread decomposition. We contributed to the literature through the reliably estimated $P I$ trading, using computationally intensive trade-by-trade microstructure data to obtain daily estimates. We specified a logistic model to test Cornelli and Li (2002) 
theory using the daily PI trading, takeover characteristics, firm-specific and industryspecific charateristics as well as year of announcements. According to estimates of the model using the sample of Australian takeover firms, the presence of informed traders increases the likelihood of success from the average rate of $50.59 \%$. The increase of $1 \%$ in informed trading increases the probability of takeover success to $62.80 \%$, while the increase by $3.45 \%$ (a one standard deviation increase) is associated with a takeover success probability of $81.49 \%$. A one standard deviation decrease in informed trading from its mean is linked to a reduction takeover success probability to $17.98 \%$. Using the interpretation of odds ratio analysis, a $1 \%$ increase to $P I$ trading increases the odds of success by 2.688 times above the odds of the average takeover. A decrease of $1 \%$ in informed trading reduces the odds ratio of success by 1.621 times the odds of an average takeover.

We tested the reverse causality, as proposed in Larker and Lys (1987), by first considering the regressions estimated to capture the probabilities of informed trading. We observed that the daily PI trading estimates did not increase significantly more in successful over unsuccessful takeovers until the day of announcement, remaining significant for two subsequent days. The PI trades before the announcement were not significantly different between the targets of successful and unsuccessful takeovers, suggesting that takeover traders do not trade before a takeover is formally announced. We also conducted the test of reverse causality and found that PI trading increases by $2.18 \%$ when the takeover is successful, showing a significant relationship between the PI trading and takeover success. The impact of a $1 \%$ increase in PI trading is associated with a $2.59 \%$ increase in CARs over two days, starting on the takeover announcement day. The marginal effect of a $1 \%$ increase in $P I$ trading in relation to successful takeovers is accompanied by $2.64 \%$ higher CAR in successful takeovers. 
CHAPTER SIX: ROBUSTNESS TESTS

\subsection{Introduction}

To confirm the validity of the results presented in Chapter Five, here we estimate the same models as presented in Chapter Two. However, instead of estimating PI trading by using Bollen, Smith and Whaley (2004) model, we employ alternative models of informed trading developed in the extant literature. Studies developing measures of probability of informed trading $(P I)$ are based on Glosten and Milgrom (1985) suggestion that informed trading can be identified by large imbalances of the order flow. The PIN models developed in formative studies, including those of Easley and O'Hara (1987), Easley, Kiefer, O'Hara and Paperman (1996) and Easley, Kiefer and O'Hara (1997), exploit the order imbalance argument to measure information asymmetry. Duarte and Young (2009) extend the PIN family of models by deconstructing the measure into trading occurring as a result of private information arrival and trading occurring as part of liquidity provision activities. Easley, Prado and O'Hara (2012) propose an alternative adjustment to the PIN family of models with a volume adjustment procedure that more closely tracks the behaviour of market liquidity providers through an alternative methodology of buy- and sell-volume classifications (this is applicable also for microstructure data). We employ all three measures of informed trading to confirm the results obtained by employing Bollen, Smith and Whaley (2004) PI measures. 


\subsection{Probability of Informed Trading Models}

\subsubsection{The Probability of Informed Trading Model}

Easley, Kiefer, O'Hara and Paperman (1996) propose a model where liquidity providers receive buy and sell orders from both informed and uninformed traders. Here, only informed traders possess private information about the future price of shares and consider the relative presence of each order being made by an informed trader to estimate a PI trading for each trading day. In this model, informed traders receive a private signal with a positive probability $\theta_{E}$ at the beginning of the trading day. If the private signal is positive, buy orders from informed and uninformed traders submitted to the market maker follow a Poisson distribution with intensity $\lambda_{1}+\delta$. Conversely, the sell orders, placed only by the uninformed traders, are submitted with $\lambda_{-1}$. If the private signal is negative, with a probability $\left(1-\theta_{E}\right)$, sell orders from informed and uninformed traders follow a Poisson distribution with intensity $\lambda_{-1}+\delta$ and buy orders placed only by uniformed traders with intensity $\lambda_{1}$. When no private signal is revealed to informed traders, they do not trade; only uninformed traders place buy orders with intensity $\lambda_{1}$ and sell orders with intensity $\lambda_{-1}$. The intuition implicit in Easley, Kiefer, O'Hara and Paperman (1996) model is that informed trader dealings on days when they receive private information disrupts the ordinary trading of uninformed traders on days when no private information is released to the informed traders. For this reason, the study claims it can identify the arrival of private information through changes in ordinary trade flow in the absolute amount of the order imbalance. This specification allows the PIN model to track the impact of private information on the variation in average trading turnover.

Easley, Kiefer, O'Hara and Paperman (1996) estimate the PIN model numerically by a maximum likelihood estimator with the function on sells and buys, each occurring 
according to independent Poisson distributions, with separate intensities for each trading day. We follow the model specifications and estimate the probability of private information endowment to the informed trader for each day, conditional on both the model parameters and the observed number of buy and sell orders. The PIN estimator therefore represents the posterior unconditional probability of a private information event occurring, given the trading data observed on that day. This assumes that the model parameters are selected appropriately by maximising the likelihood of the following model fit:

Where:

$$
\begin{aligned}
\mathcal{L}_{d}\left(\theta_{E}, \theta_{B}, \lambda_{1}, \lambda_{-1}, \delta \mid B_{d}, S_{d}\right) & \\
& =\left(1-\theta_{E}\right) \frac{\lambda_{1}^{B_{d}}}{B_{d} !} e^{-\lambda_{1}} \frac{\lambda_{-1}^{S_{d}}}{S_{d} !} e^{-\lambda_{-1}}+\theta_{E} \theta_{B} \frac{\lambda_{1}^{B_{d}}}{B_{d} !} e^{-\lambda_{1}} \frac{\left(\lambda_{-1}+\delta\right)^{S_{d}}}{S_{d} !} e^{-\left(\lambda_{-1}+\delta\right)} \\
& +\theta_{E}\left(1-\theta_{B}\right) \frac{\left(\lambda_{1}+\delta\right)^{B_{d}}}{B_{d} !} e^{-\left(\lambda_{1}+\delta\right)} \frac{\lambda_{-1}^{S_{d}}}{S_{d} !} e^{-\lambda_{-1}}
\end{aligned}
$$

$\theta_{E}$ is the probability of informed traders receiving information signal

$\theta_{B}$ is the probability of informed traders receive bad news as part of their informational signal

$\lambda_{1}$ is the ordinary aggregate number of buyer initiated orders

$\lambda_{-1}$ is the ordinary aggregate number of seller initiated orders

$\delta$ is the constant amount by which ordinary orders will be modified by informed traders due to information release

$B_{d}$ is the number buyer initiated orders for each trading period $d$

$S_{d}$ is the number of seller initiated trades for each trading period $d$.

Folowing the estimation of the Easley, Kiefer, O'Hara and Paperman (1996) model, PIN measure is calculated as relative intensity of informed trades to all trades. 


$$
\operatorname{PIN}_{i}=\frac{\theta_{E} \delta}{\lambda_{1}+\lambda_{-1}+\theta_{E} \delta}
$$

Where:

$P I N_{i}$ is the probability of informed trading for each firm $i$

$\theta_{E}$ is the probability of informed traders receiving information signal

$\delta$ is the constant amount by which ordinary orders will be modified by informed traders due to information release

$\lambda_{1}$ is the ordinary aggregate number of buyer initiated orders

$\lambda_{-1}$ is the ordinary aggregate number of seller initiated orders.

\subsubsection{The Adjusted Probability of Informed Trading Model}

Duarte and Young (2009) extend the original PIN model to address issues concerning the matching of order flow data. Easley, Kiefer, O'Hara and Paperman (1996) model relies on the expectation that buy and sell orders are negatively correlated. Duarte and Young (2009) however, note that in empirical data the correlation of buy and sell orders are positive. To correct this conflict between theory and empirical observation, Duarte and Young (2009) attempt to separate the natural variation of trade order flow from that caused by the arrival of private information. As with Easley, Kiefer, O'Hara and Paperman (1996) model, informed traders are endowed with private information with a positive probability $\theta_{E}$ at the beginning of the trading day. Similarly, a positive private signal results in informed buy orders arriving to the market maker according to a Poisson distribution with intensity $\lambda_{1}$, a negative signal results in sell orders with intensity $\lambda_{-1}$ and no private information release results in no trading by informed traders. Further, Duarte and Young (2009) model allows for symmetric order flow shocks where the occurrence of buys and sells is allowed to increase or decrease, depending on changes in share liquidity. Days 
when the level of trading increases or decreases on both buy and sell sides of the order book at the same time may be caused by various situations, including asset manager rebalancing days, derivatives maturity days, share inclusion or removal from index portfolios, or ambiguous interpretations of public news. Regardless of the cause, Duarte and Young (2009) add the probability of symmetric order flow shocks $\theta_{E}$ in the model. On days when these shocks occur, both the number of buy and sell orders increase by amounts drawn from an independent Poisson distribution with intensities $\Delta_{1}$ and $\Delta_{-1}$ respectively. The uninformed buy and sell trades arrive according to a Poisson distribution with intensities $\lambda_{1}+\Delta_{1}$ and $\lambda_{-1}+\Delta_{-1}$ respectively on shock days while the intensities return to $\lambda_{1}$ and $\lambda_{-1}$ on days where no shocks occur.

In this updated model, the increases in orders may occur due to either symmetric order flow shock or trading on private information. The number of buys and sells without symmetric order flow shocks on positive private information days is $\lambda_{1}+\lambda_{-1}+\delta_{1}$, while on negative private information days the orders sum to $\lambda_{1}+\lambda_{-1}+\delta_{-1}$. Further, as the trade flow is allowed to increase or decrease independent of the private information on days with symmetric order flow shock and without any private information, the amount of trades submitted is $\lambda_{1}+\lambda_{-1}+\Delta_{1}+\Delta_{-1}$. Finally, trades on days without either private information signal and no symmetric order flow shocks the expected number of trades is $\lambda_{1}+\lambda_{-1}$

The model specification is estimated according to the maximum likelihood methods function using numerical techniques estimating the probability of private information conditional on both the model parameters and observed buys and sells for each trading period: 


$$
\begin{aligned}
\mathcal{L}_{d}\left(\theta_{E}, \theta_{B}, \theta_{C}\right. & \left.\lambda_{1}, \lambda_{-1}, \delta_{1}, \delta_{-1} \Delta_{1}, \Delta_{-1} \mid B_{d}, S_{d}\right) \\
& =\left(1-\theta_{E}\right) \theta_{C} \frac{\left(\lambda_{1}+\Delta_{1}\right)^{B_{d}}}{B_{d} !} e^{-\left(\lambda_{1}+\Delta_{1}\right)} \frac{\left(\lambda_{-1}+\Delta_{-1}\right)^{S_{d}}}{S_{d} !} e^{-\left(\lambda_{-1} \Delta_{-1}\right)} \\
& +\left(1-\theta_{E}\right)\left(1-\theta_{C}\right) \frac{\lambda_{1}^{B_{d}}}{B_{d} !} e^{-\lambda_{1}} \frac{\lambda_{-1}^{S_{d}}}{S_{d} !} e^{-\lambda_{-1}} \\
& +\theta_{E} \theta_{B} \theta_{C} \frac{\left(\lambda_{1}+\Delta_{1}\right)^{B_{d}}}{B_{d} !} e^{-\left(\lambda_{1}+\Delta_{1}\right)} \frac{\left(\lambda_{-1}+\delta_{-1}+\Delta_{-1}\right)^{S_{d}}}{S_{d} !} e^{-\left(\lambda_{-1}+\delta_{-1}+\Delta_{-1}\right)} \\
& +\theta_{E} \theta_{B}\left(1-\theta_{C}\right) \frac{\lambda_{1}^{B_{d}}}{B_{d} !} e^{-\lambda_{1}} \frac{\left(\lambda_{-1}+\delta_{-1}\right)^{S_{d}}}{S_{d} !} e^{-\left(\lambda_{-1} \delta_{-1}\right)} \\
& +\theta_{E}(1 \\
& \left.-\theta_{B}\right) \theta_{C} \frac{\left(\lambda_{1}+\delta_{1}+\Delta_{1}\right)^{B_{d}}}{B_{d} !} e^{-\left(\lambda_{1}+\delta_{1}+\Delta_{1}\right)} \frac{\left(\lambda_{-1}+\Delta_{-1}\right)^{S_{d}}}{S_{d} !} e^{-\left(\lambda_{-1}+\Delta_{-1}\right)} \\
& +\theta_{E}\left(1-\theta_{B}\right)\left(1-\theta_{C}\right) \frac{\left(\lambda_{1}+\delta_{1}\right)^{B_{d}}}{B_{d} !} e^{-\left(\lambda_{1}+\delta_{1}\right)} \frac{\lambda_{-1}^{S_{d}}}{S_{d} !} e^{-\lambda_{-1}}
\end{aligned}
$$

Where:

$\theta_{E}$ is the probability of informed traders receiving information signal

$\theta_{B}$ is the probability of informed traders receive bad news as part of their informational signal

$\theta_{C}$ is the probability of a common shock to the ordinary order flow

$\lambda_{1}$ is the ordinary aggregate number of buyer initiated orders

$\lambda_{-1}$ is the ordinary aggregate number of seller initiated orders

$\delta_{1}$ is the constant amount by which ordinary orders will be modified by informed traders due to information release

$\delta_{-1}$ is the constant amount by which ordinary orders will be modified by informed traders due to information release

$\Delta_{1}$ is the shock to ordinary aggregate number of buyer initiated orders due to common shock to the ordinary order flow

$\Delta_{-1}$ is the ordinary aggregate number of seller initiated orders due to common shock to the ordinary order flow 
$B_{d}$ is the number buyer initiated orders for each trading period $d$

$S_{d}$ is the number of seller initiated trades for each trading period $d$.

The Duarte and Young (2009) adjusted AdjPIN model specification is obtained by maximising the likelihood function in equation (65) and calculating separate measures of probability of symmetric order flow shocks $P S O S_{i}$ and adjusted probability of informed trading $\operatorname{AdjPIN}_{i}$ for each trading day using equations:

$$
\begin{gathered}
\operatorname{PSOS}_{i}=\frac{\theta_{C}\left(\Delta_{1}+\Delta_{-1}\right)}{\lambda_{1}+\lambda_{-1}+\theta_{E}\left[\left(1-\theta_{B}\right) \delta_{1}+\theta_{B} \delta_{-1}\right]+\theta_{C}\left(\Delta_{1}+\Delta_{-1}\right)} \\
\operatorname{AdjPIN}_{i}=\frac{\theta_{E}\left[\left(1-\theta_{B}\right) \delta_{1}+\theta_{B} \delta_{-1}\right]}{\lambda_{1}+\lambda_{-1}+\theta_{E}\left[\left(1-\theta_{B}\right) \delta_{1}+\theta_{B} \delta_{-1}\right]+\theta_{C}\left(\Delta_{1}+\Delta_{-1}\right)}
\end{gathered}
$$

Where:

$\operatorname{PSOS}_{i}$ is the probability of symmetric order flow for each sequence of trades for each firm $i$

$\operatorname{AdjPIN}_{i}$ is the adjusted probability of informed trading for each firm $i$

$\theta_{E}$ is the probability of informed traders receiving information signal

$\theta_{B}$ is the probability of informed traders receive bad news as part of their informational signal

$\theta_{C}$ is the probability of a common shock to the ordinary order flow

$\lambda_{1}$ is the ordinary aggregate number of buyer initiated orders

$\lambda_{-1}$ is the ordinary aggregate number of seller initiated orders

$\delta_{1}$ is the constant amount by which ordinary orders will be modified by informed traders due to information release 
$\delta_{-1}$ is the constant amount by which ordinary orders will be modified by informed traders due to information release

$\Delta_{1}$ is the shock to ordinary aggregate number of buyer initiated orders due to common shock to the ordinary order flow

$\Delta_{-1}$ is the ordinary aggregate number of seller initiated orders due to common shock to the ordinary order flow.

\subsubsection{The Volume Synchronised Probability of Informed Trading Model}

Easley, Lopez de Prado and O'Hara (2012) propose a simplification of the estimation of informed trading process with maximum likelihood methods. This is instead of using an approximation of the PIN measure by including the buy and sale volume multiplied by a value of an option such as payoff representing the real time risk of buy and sale orders separately. The study further proposes an alternative classification of buy and sale orders to Lee and Ready (1991) algorithm: aggregating trades over short intraday intervals and using increases in price over these periods to categorise all trades as buy trades and all decreases in price as signalling sale orders. Easley, Lopez de Prado and O'Hara (2012) present this methodology as extremely useful in applications using high frequency data, suggesting that volume synchronised PIN (VPIN) can indicate market situations when liquidity provision by market makers may be at risk, allowing traders to identify their execution risks before they submit their trades. Easley, Lopez de Prado and O'Hara (2012) methodology is based on Engle and Lange (2001) work, and calculates rather than estimates a market depth measure using the order imbalance metric during share price increases and decreases. Easley, Lopez de Prado and O'Hara (2012) divide the trading day in terms of volume and not time or price, providing a more direct measure of order flow risk by studying trading in event time rather than real time. 
Easley, Lopez de Prado and O'Hara (2012) model the trading process as a game between the market maker and traders (position takers) repeated over multiple trading periods. At the start of each period, information is released with probability $\theta_{E}$. The information contains good news with the probability $(1-\gamma)$ and bad news with probability $\gamma$. Orders from informed traders arrive according to a Poisson distribution with intensity $\lambda_{1}$. A negative signal results in sell orders with intensity $\lambda_{-1}$. Informed traders buy shares, in the event that news is released, with intensity of $\Delta_{1}$ and sell shares with intensity $\Delta_{-1}$ depending on whether the news is positive or negative respectively. Uninformed traders buy and sell trades arrive according to a Poisson distribution with intensities $\lambda_{1}$ and $\lambda_{-1}$ on all trading days. The model then compares ordinary trading flow, interpreting these as uninformed orders, while extraordinary trades are categorised as orders by informed traders. The number of days in which informed trading is identified are used to estimate $\theta_{E}$ and $\gamma$. The market maker then uses these parameters to set the bid and ask prices quoted to market participants.

Easley, Lopez de Prado and O'Hara (2012) employ an alternative method of buy and sell volume classification to that established Lee and Ready (1991) by specifying a whole section of trading during the day as buy or sell, depending on the last price update in that section. If the price has decreased from the first trade in the section, the whole section of trading is classified as sells, irrespective of the actual initiation of orders. If the price increases during the trading interval, the trades are classified as buys, again without regard to actual trade initiation. The paper argues that applying the above bulk classification process overcomes the classification errors in Lee and Ready (1991) algorithm, identified in Theissen (2001). The classification of buy $\left(V_{\tau}^{B}\right)$ and sell $\left(V_{\tau}^{S}\right)$ 
trades using equal daily volume aggregation parts. The aggregation formula for classifying buy orders is specified as:

Where:

$$
V_{\tau}^{B}=\sum_{j=t(\tau-1)+1}^{t(\tau)} V_{j} N\left(\frac{P_{j}-P_{j-1}}{\sigma_{\Delta P}}\right)
$$

$V_{\tau}^{B}$ is the calculated buy volume of shares during the trading period

$t$ is the part of the trading volume during any trading period

$\tau$ is the last part of the trading volume during any trading period

$V_{j}$ is the overall volume of shares traded in each trading period

$N[$.$] is the cumulative normal density function$

$P_{j}$ is the last trading price at the end of any trading period

$P_{j-1}$ is the last trading price at the end of the previous trading period

$\sigma_{\Delta P}$ is the standard deviation of the price changes during the last trading period.

The aggregation formula for classifying sell orders is specified as:

$$
V_{\tau}^{S}=\sum_{j=t(\tau-1)+1}^{t(\tau)} V_{j}\left[1-N\left(\frac{P_{j}-P_{j-1}}{\sigma_{\Delta P}}\right)\right]
$$

Where:

$V_{\tau}^{S}$ is the calculated sell volume of shares during the trading period

$t$ is the part of the trading volume during any trading period

$\tau$ is the last part of the trading volume during any trading period

$V_{j}$ is the overall volume of shares traded in each trading period

$N[$.$] is the cumulative normal density function$

$P_{j}$ is the last trading price at the end of any trading period

$P_{j-1}$ is the last trading price at the end of the previous trading period 
$\sigma_{\Delta P}$ is the standard deviation of the price changes during the last trading period.

The above specification is then used to calculate the absolute value of trade imbalance for each trading day. According to Easley, Engle, O'Hara and Wu (2008) the total expected number of trades according to the above specification can be written as $E\left(V_{\tau}^{S}+V_{\tau}^{B}\right)=$ $\lambda_{1}+\lambda_{-1}+\theta_{E} \delta$ while the expected total trade imbalance can be written as $E\left(\mid V_{\tau}^{S}-\right.$ $\left.V_{\tau}^{B} \mid\right) \approx \theta_{E} \delta$

On this basis, Easley, Lopez de Prado and O'Hara (2012) specify an approximation to PIN measure in their volume synchronised VPIN measure calculated by:

Where:

$$
\operatorname{PIN}_{i}=\frac{\theta_{E} \delta}{\lambda_{1}+\lambda_{-1}+\theta_{E} \delta} \approx V P I N_{i}=\frac{\sum_{\tau=1}^{n}\left|V_{\tau}^{S}-V_{\tau}^{B}\right|}{n V}
$$

$V P I N_{i}$ is the volume synchronised probability of informed trading for each firm $i$

$V_{\tau}^{S}$ is the calculated sell volume of shares during the trading period

$V_{\tau}^{B}$ is the calculated buy volume of shares during the trading period

$n$ is the number of the trading periods during the day

$V$ is the total number of trades during the day.

\subsection{Robustness Model Specifications}

6.3.1. Impact of Probability of Informed Trading on Takeover Success

We perform the tests for PI trading using different measures of informed trading established in Easley, Kiefer, O'Hara and Paperman (1996), Duarte and Young (2009) and Easley, Lopez de Prado and O'Hara (2012), by applying them (each in turn) to the original test model specified in Palepu (1986) nominal logistic regression framework across all 
reliable daily estimates for all firms. We employ the original methodology and specify the logistic model as:

$$
\operatorname{Pr}_{i}=E\left(\operatorname{SUCCESS}_{i}=1 \mid Z_{i}\right)=\frac{1}{1+e^{-Z_{i}}}
$$

$$
\ln \left(\frac{P r_{i}}{1-P r_{i}}\right)=Z_{i}=\beta_{0}+\beta_{1} \ln \left(\text { SIZE }_{i}\right)+\beta_{2} P R E M I U M 1 D_{i}+\beta_{3} D_{P A Y C A S H}
$$

$+\beta_{4}$ DHOSTILE $_{i}+\beta_{5}$ DBIDDERS $+\beta_{6}$ DTOEHOLD $_{i}+\beta_{7}$ BLOCKHOLDING $_{i}+\beta_{8}$ PIX $_{i}$

$+\beta_{9} R O A_{i}+\beta_{10} R O E_{i}+\beta_{11} E P S_{i}+\beta_{12} B / M_{i}+\beta_{13} D I N D U S T R Y_{i}+\beta_{14} D Y E A R_{i}$

$$
+\beta_{15} I M R_{i}+\varepsilon_{i}
$$

Where:

$P r_{i}$ is the probability of takeover success expected in the logistic model conditional on the set of parameters $Z_{i}$

SUCCESS $_{i}$ takes value of 1 when the takeover is successful and 0 otherwise

$\ln \left(S I Z E_{i}\right)$ is the natural logarithm transformation of the market capitalisation of each firm $i$ on the announcement day

PREMIUM $1 D_{i}$ is the premium offered by the bidder compared to the last observed market price for each firm $i$ before the announcement

$\mathrm{DPAYCASH}_{i}$ is an indicator variable equal to 1 when the takeover announced is in cash and is otherwise 0 for each firm $i$ 
$D_{\text {HOSTILE }}$ is an indicator variable equal 1 when the takeover can be characterised as hostile and 0 otherwise for each firm $i$

$D B I D D E R S_{i}$ is an indicator variable equal to 1 when the takeover has more than one bidder and is otherwise 0 for each firm $i$

DTOEHOLD $D_{i}$ is an indicator variable equal to 1 when bidder owns an amount of $5 \%$ or more of the target shares when the takeover is announced and is otherwise 0 for each firm $i$

BLOCKHOLDING $G_{i}$ is the proportion of shares of each firm $i$ held by blockholders (individual holdings greater than $5 \%$ of shares of each firm $i$ )

$P I X_{i}$ is the estimated probability of informed trading measures from each of the PIN models in turn: Easley, Kiefer, O'Hara and Paperman (1996) PIN $i$, Duarte and Young (2009) $\operatorname{AdjPIN}_{i}$ and Easley, Lopez de Prado and O'Hara (2012) $V P I N_{i}$ for each firm $i$ on the announcement day for different estimation time intervals of $5,10,15$ and 30 minute aggregation windows over each trading day

$R O A_{i}$ is the most recently reported return on assets prior to the takeover announcement day for each firm $i$

$R O E_{i}$ is the most recently reported return on equity prior to the takeover announcement day for each firm $i$

$E P S_{i}$ is the earnings per share most recently reported for each firm $i$

$B / M_{i}$ is the book to market ratio for each firm $i$

$\operatorname{DINDUSTR} Y_{i}$ is an indicator variable equal to 1 when the target firm is in the primary industry of operation, the same as the defined industry for each firm $i$ $D Y E A R_{i}$ is an indicator variable equal to 1 when the takeover is announced that year 
$I M R_{i}$ is the Inverse Mills Ratio estimated in the second step of Heckman (1979) model correcting for the sample selection bias that could be present in the model estimates.

6.3.2. Impact of Probability of Informed Trading on Cumulative Abnormal Returns

To test the effects of informed trading on the abnormal returns of target firms we specify the following model using a cross sectional regression framework across all daily estimates to estimate for firms $i$ :

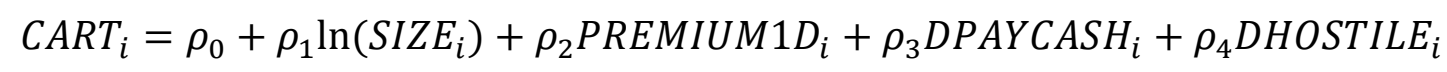

$$
\begin{aligned}
& +\rho_{5} \text { DTOEHOLD }_{i}+\rho_{6} \text { DBIDDERS }{ }_{i}+\rho_{7} \text { DBLOCKHOLDING }_{i}+\rho_{8} \text { DSUCCESS }_{i} \\
& +\rho_{9} P_{I} X_{i}+\rho_{10} D_{S U C C E S S} \times P I X_{i}+\rho_{11} R O A_{i}+\rho_{12} R O E_{i}+\rho_{13} E P S_{i}+\rho_{14} B / M_{i} \\
& +\rho_{15} \operatorname{DINDUSTR}_{i}+\rho_{16} \text { DYEAR }_{i}+\rho_{17} I M R_{i}+\varepsilon_{i}
\end{aligned}
$$

Where:

$C A R T_{i}$ is the CAR of target firm at different event windows of $1,5,10$ and 30 days from the takeover announcement day for each target firm $i$

$\ln \left(S I Z E_{i}\right)$ is the natural logarithm transformation of market capitalisation of each firm $i$ on the day of announcement

PREMIUM $1 D_{i}$ is the premium offered by the bidder compared to the last observed market price for each firm $i$ before the announcement 
$D P A Y C A S H_{i}$ is an indicator variable equal to 1 when the takeover announced is in cash and is otherwise 0 for each firm $i$

DHOSTILE $_{i}$ is an indicator variable equal to 1 when the takeover can be characterised as hostile and is otherwise 0 for each firm $i$

$D B I D D E R S_{i}$ is an indicator variable equal to 1 when the takeover has more than one bidder and is otherwise 0 for each firm $i$

DTOEHOLD $D_{i}$ is an indicator variable equal 1 when bidder owns an amount of $5 \%$ or more of the target shares when the takeover is announced and 0 otherwise for each firm $i$ before the day of announcement

$B_{L O C K H O L D I N G}$ is the proportion of shares of each firm $i$ held by blockholders (individual holdings greater than $5 \%$ of shares of each firm $i$ )

$\operatorname{DSUCCESS}_{i}$ is an indicator variable equal to 1 when the takeover is a success and is otherwise 0 for each firm $i$

$\operatorname{DSUCCESS}_{i} \times P I_{i}$ is a variable equal to $P I_{i}$ when the takeover is successful and 0 otherwise

$P I X_{i}$ is the estimated probability of the informed trading measure from each of the PIN models in turn: Easley, Kiefer, O'Hara and Paperman (1996) PIN $_{i}$, Duarte and Young (2009) $\operatorname{AdjPIN}_{i}$ and Easley, Lopez de Prado and O'Hara (2012) $V P I N_{i}$ for each firm $i$ on the announcement day for different estimation time intervals of 5, 10, 15 and 30 minute aggregation windows over each trading day 
$R O A_{i}$ is the most recently reported return on assets prior to the takeover announcement day for each firm $i$

$R O E_{i}$ is the most recent return on equity prior to the takeover announcement day for each firm $i$

$E P S_{i}$ is the recently reported earnings per share most for each firm $i$

$B / M_{i}$ is the book to market ratio for each firm $i$

$\operatorname{DINDUSTR} Y_{i}$ is an indicator variable which equal to 1 when the target firm is in the primary industry of operation, the same as the defined industry for each firm $i$

$D Y E A R_{i}$ is an indicator variable equal to 1 when the takeover is announced that year $I M R_{i}$ is the Inverse Mills Ratio estimated in the second step of Heckman (1979) model correcting for the sample selection bias that could be present in the model estimates.

\subsubsection{Impact of Takeover Success on Probability of Informed Trading}

To test the effects of takeover success on the probability of informed trading we specify the following model using a cross sectional regression framework across all daily estimates to estimate for firms $i$. We employ the same model as previously by specifying the following model: 


$$
\begin{gathered}
\text { PIX }_{i}=\gamma_{0}+\gamma_{1} \ln \left(\text { SIZE }_{i}\right)+\gamma_{2} \text { ROA }_{i}+\gamma_{3}{\text { PREMIUM } 1 D_{i}+\gamma_{4} \text { DPAYCASH }_{i}}_{+\gamma_{5} \text { DHOSTILE }_{i}+\gamma_{6} \text { DBIDDERS }_{i}+\gamma_{7} \text { DTOEHOLD }_{i}+\gamma_{8} \text { BLOCKHOLDING }_{i}} \\
+\gamma_{9} \text { DSUCCESS }_{i}+\gamma_{10} \text { ROE }_{i}+\gamma_{11} \text { EPS }_{i}+\gamma_{12} B / M_{i}+\gamma_{13} \text { DINDUSTR }_{i} \\
+\gamma_{14} \text { DYEAR }_{i}+\gamma_{15} \text { IMR }_{i}+\varepsilon_{i}
\end{gathered}
$$

Where:

$P I X_{i}$ is the estimated probability of the informed trading measure from each of the PIN models in turn: Easley, Kiefer, O'Hara and Paperman (1996) PIN Duarte and Young (2009) AdjPIN $i$ and Easley, Lopez de Prado and O'Hara (2012) VPIN $i$ for each firm $i$ on the announcement day for different estimation time intervals of $5,10,15$ and 30 minute aggregation windows over each trading day

$\ln \left(S I Z E_{i}\right)$ is the natural logarithm transformation of market capitalisation of each firm $i$ on the announcement day

PREMIUM1D $D_{i}$ is the premium offered by the bidder compared to last observed market price for each firm $i$ before the announcement

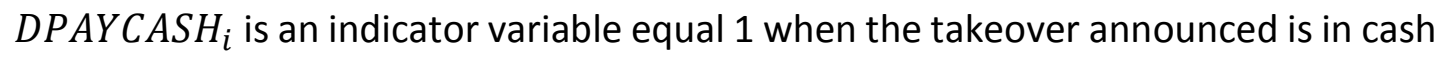
and 0 otherwise for each firm $i$

DHOSTILE $_{i}$ is an indicator variable equal 1 when the takeover can be characterised as hostile and 0 otherwise for each firm $i$

$D B I D D E R S_{i}$ is an indicator variable equal 1 when the takeover has more than one bidder and 0 otherwise for each firm $i$ 
DTOEHOLD $D_{i}$ is an indicator variable equal to 1 when the bidder owns an amount of

$5 \%$ or more of the target shares when the takeover is announced and 0 otherwise for each firm $i$

BLOCKHOLDING $G_{i}$ is the proportion of shares of each firm $i$ held by blockholders (individual holdings greater than $5 \%$ of shares of each firm $i$ )

$\operatorname{DSUCCESS}_{i}$ is an indicator variable equal to 1 when the takeover is a success and is otherwise 0 for each firm $i$

$R O A_{i}$ is the most recently reported return on assets prior to the takeover announcement day for each firm $i$

$R O E_{i}$ is the most recently reported return on equity prior to the takeover announcement day for each firm $i$

$E P S_{i}$ is the earnings per share most recently reported for each firm $i$

$B / M_{i}$ is the book to market ratio for each firm $i$

DINDUSTRY $Y_{i}$ is an indicator variable which equal to 1 when the target firm is in the primary industry of operation, the same as defined the industry for each firm $i$

$D Y E A R_{i}$ is an indicator variable equal to 1 when the takeover is announced that year $I M R_{i}$ is the Inverse Mills Ratio estimated in the second step of Heckman (1979) model correcting for the sample selection bias which could be present in the model estimates. 


\subsection{Robustness Data}

We employ the data described in Chapter 4, replacing Bollen, Smith and Whaley (2004) estimated PI with other measures of informed trading proposed in Easley, Kiefer, O'Hara and Paperman (1996), Duarte and Young (2009) and Easley, Lopez de Prado and O'Hara (2012); each in turn using both Australian and United States sub-samples. The sample selection procedure for the Australian sample is detailed in Table 6.1, while the selection for the United States sample is detailed in Table 6.2. This process results in reducing the number of testable observations, depending on the measure used, due to the limitations of the estimation procedures that are detailed next. 
Table 6.1 Australian Sample: Data Selection Australia

Table 6.1 shows the process of Australian sample data selection. It details the extraction of observations from four databases used to obtain the data: Thomson Reuters SDC Platinum Mergers and Acquisitions Database, Thomson Reuters Tick History, Thompson Financial Datastream and Annual Reports Online, via the Aspect Huntley Database. The initial sample was collected for takeover events between 1 January 2008 and 1 July 2013 in the Australian market. The Transaction data was collected from the Thomson Reuters SDC Platinum Mergers and Acquisitions Database and filtered as described in the table below. The availability of supplementary data from Thomson Reuters Tick History, Thompson Financial Datastream, Annual Reports Online via the Aspect Huntley Database, the Securities Industry Research Centre of Asia-Pacific (SIRCA), and the Corporate Governance Database resulted in only two firms being removed from the sample. Finally. One further firm was removed due to unexplained extreme values. The greatest reductions in sample occurred when alternative measures of $P I N$ used to estimate informed trading.

\begin{tabular}{lrrr} 
Thomson Reuters Security Data Corporation (SDC) Platinum Mergers and Acquisitions Database & $P I N_{i}$ & AdjPIN $_{i}$ & VPIN $_{i}$ \\
\hline \hline Total number of Mergers and Acquisitions (1 January 2008 - 1 July 2013) & 112,321 & 112,321 & 112,321 \\
\hline Target Firms domiciled in Australia & 2,778 & 2,778 & 2,778 \\
\hline Clearly identifiable parties to takeover activity & 1,856 & 2,778 & 2,778 \\
\hline Clearly stated method of payment either cash, shares or both & 566 & 566 & 566 \\
\hline The activity is not share repurchases and capital restructuring & 501 & 501 & 501 \\
\hline Activity where bidder has less than 50\% holdings in the target prior to announcement & 484 & 484 & 484 \\
\hline Activity where bidder intends to acquire more than 50\% holdings in the target & 244 & 244 & 244 \\
\hline Activity where both bidder and target are listed firms & 205 & 205 & 205 \\
\hline Target market capitalisation is above than 1 million dollars & 175 & 175 & 175 \\
\hline
\end{tabular}

\section{Thomson Reuters Tick History}

Trade and Quote data (10:10am-4pm)

175

175

175

Thompson Financial Datastream

\begin{tabular}{llll}
\hline \hline Earnings per share & 175 & 175 & 175 \\
\hline Book to market & 175 & 175 & 175 \\
\hline
\end{tabular}

Annual Reports Online via Aspect Huntley Database

\begin{tabular}{llll}
\hline \hline Return on Equity & 173 & 173 & 173 \\
\hline Return on Assets & 173 & 173 & 173 \\
\hline
\end{tabular}

Securities Industry Research Centre of Asia-Pacific (SIRCA), Corporate Governance Database

Block Holdings

173

173

173

Extreme Values

Non extreme value observations

172

172

Estimation of Probability of Informed Trading

Statistically Significant $P I X_{i}$

83

58 129

Takeover Sample

\begin{tabular}{llll}
\hline Successful Takeovers & 31 & 21 & 54 \\
\hline Unsuccessful Takeovers & 52 & 37 & 75 \\
\hline \hline
\end{tabular}


Table 6.2. United States Sample: Data Selection United States

Table 6.2 shows the process of United States sample data selection. It details the obtaining of observations from four databases used to obtain the data: Thomson Reuters Security Data Corporation (SDC) Platinum Mergers and Acquisitions Database, Thomson Reuters Tick History, Thompson Financial Datastream and Wharton Research Data Services CRSP and Compustat Databases and Bureau van Dijk Orbis Database. The initial sample was collected from takeover events between 11 January 2008 and 11 July 2013 in the United States takeover market, with data from Thomson Reuters Security Data Corporation (SDC) Platinum Mergers and Acquisitions Database and filtered as described in the table. The availability of supplementary data from Thomson Reuters Tick History, Thompson Financial Datastream, Wharton Research Data Services CRSP and Compustat Database and Bureau van Dijk Orbis Database resulted in no firms being removed from the sample. The greatest reductions in sample occurred when alternative measures of PIN used to estimate informed trading.

Thomson Reuters Security Data Corporation (SDC) Platinum Mergers and Acquisitions Database

\begin{tabular}{lrrr} 
Thomson Reuters Security Data Corporation (SDC) Platinum Mergers and Acquisitions Database & PIN & AdjPIN & VPIN \\
\hline \hline Total number of Mergers and Acquisitions (1 January 2008 - 1 July 2013) & 63,033 & 63,033 & 63,033 \\
\hline Target Firms domiciled in United States of America & 9,429 & 9,429 & 9,429 \\
\hline Clearly identifiable parties to takeover activity & 6,352 & 6,352 & 6,352 \\
\hline Clearly stated method of payment either cash, shares or both & 5,969 & 5,969 & 5,969 \\
\hline The activity is not share repurchases and capital restructuring & 1,323 & 1,323 & 1,323 \\
\hline Activity where bidder has less than 50\% holdings in the target prior to announcement & 1,283 & 1,283 & 1,283 \\
\hline Activity where bidder intends to acquire more than 50\% holdings in the target & 1,185 & 1,185 & 1,185 \\
\hline Activity where both bidder and target are listed firms & 605 & 605 & 605 \\
\hline Target market capitalisation is above than 1 million dollars & 491 & 491 & 491 \\
\hline
\end{tabular}

Thomson Reuters Tick History

Trade and Quote data (9:31am-3:59pm)

522

522

522

Thompson Financial Datastream

\begin{tabular}{llll}
\hline \hline Earnings per share & 512 & 512 & 512 \\
\hline Book to market & 512 & 512 & 512 \\
\hline
\end{tabular}

Wharton Research Data Services CRSP and Compustat

Database

\begin{tabular}{llll}
\hline \hline Return on Equity & 491 & 491 & 491 \\
\hline Return on Assets & 491 & 491 & 491 \\
\hline
\end{tabular}

Bureau van Dijk Orbis Database

Block Holdings

491

491

491

Extreme Values

Non extreme value observations

491

491

Estimation of Probability of Informed Trading

Statistically Significant $P I X_{i}$ 272

474

Takeover Sample

\begin{tabular}{lrrr}
\hline \hline Successful Takeovers & 179 & 320 & 327 \\
\hline Unsuccessful Takeovers & 93 & 154 & 159 \\
\hline \hline
\end{tabular}




\subsection{Robustness Models Estimation Procedure}

For statistical estimation of Easley, Kiefer, O'Hara and Paperman (1996) and Duarte and Young (2009) models of informed trading, we employ maximum likelihood methodologies in order to obtain PIN, and AdjPIN respectively, disregarding observations where convergence is not achieved by maximum likelihood estimator or where the estimated coefficient is not statistically different from zero at $10 \%$ significance level. The procedure significantly reduces the sample size of observations available for the test of Cornelli and Li (2002) hypotheses. The size of the Australian sample for the 15 minute time interval is reduced significantly - from 172 observations using Bollen, Smith and Whaley (2004) model in our main results to 83 observations due to estimation of PIN, and 58 under the AdjPIN model. The size of the United States sample in the same 15 minute interval measure is also reduced from 491 for the $P I$ to 228 observations for PIN, and to 265 observations for AdjPIN measures.

We follow Easley, Lopez de Prado and O'Hara (2012) and employ the calculation methodology for establishing the VPIN measure. The size of the Australian sample is also reduced due to insufficient number of trading observations during the day to 129 from 172 observations, while the United States sample is reduced to 477 from 491 for the Bollen, Smith and Whaley (2004) PI.

Each of the alternative measures established in the existing literature have their own theoretical origins and different estimation approaches. While the Bollen, Smith and Whaley (2004) model relies on the linear link of spread decomposition using Hansen (1982) GMM estimator, Easley, Kiefer, O'Hara and Paperman (1996) and Duarte and Young (2009) rely on maximising a log likelihood function, conditional on the number of 
buy and sell orders. Finally, Easley, Lopez de Prado and O'Hara (2012) rely on more simple trading volume aggregation to attempt to measure informed trading in market activity.

\subsubsection{Discussion}

The Bollen, Smith and Whaley (2004) model specification relies on the market maker's abilities to assess and react to the relative presence of informed traders by adjusting the bid-ask spread. Instead of this, Easley, Kiefer, O'Hara and Paperman (1996) and Duarte and Young (2009) rely on the observed number of buys and sells reported by the exchange. Easley, Lopez de Prado and O’Hara (2012) measure relies on a more simple trading volume aggregation methodology to measure informed trading in the market. The models used for robustness testing-in particular, Easley, Kiefer, O'Hara and Paperman (1996) and Duarte and Young (2009) - reduce the number of observations available to test Cornelli and Li (2002) hypotheses. Thus, we prefer to employ the estimates in Bollen, Smith and Whaley (2004) model to test the main hypotheses, rather than using any other model for identifying informed trading. We provide the results of using the abovedescribed measures of PIN, AdjPIN and VPIN in the next section.

\subsection{Robustness Tests Results}

We conduct the robustness tests using the same data from Australian and United States markets separately apart from substituting the three alternative measures of informed trading, PIN, AdjPIN and VPIN (referred to in results together as PIX). It is important to highlight that Easley, Lopez de Prado and O'Hara (2012) VPIN measure has many of the same features, (in particular the option form) as the Bollen, Smith and Whaley (2004) PI measure. 


\subsubsection{Australian Sample Robustness Tests Results}

The results of robustness tests for Cornelli and Li (2002) theoretical model are presented in Table 6.3 for the Australian sample.

In general, the estimates of logistic regressions, show the same relationship of informed trading to takeover outcomes as the main results presented in Table 5.3 and discussed in Chapter Five, Section 5.2.2. In particular, the estimate using the VPIN measure in Table 6.3, has a very similar estimate in size and significance to our main result.

Estimates obtained using the 15 minute PIN measure of informed trading indicate that the likelihood of success of the average takeover transaction is $51.1 \%$, which is slightly higher than our main result. A $1 \%$ increase in PIN increases the likelihood of takeover success to $55.44 \%$ with the same decrease reducing the likelihood to $34.23 \%$. A 1 standard deviation increase in the PIN of $1.49 \%$ would lead to an increase in likelihood of success to $85.52 \%$, while a similar decrease from the mean value of $0.553 \%$ is predicted to reduce the probability of takeover success to $11.63 \%$. Regarding the odds of takeover success, a $1 \%$ increase in PIN leads to an increase in odds of success by 6.145 times the average, while a similar decrease in PIN is linked to a reduction of these odds by 2.261 times the likelihood of an average takeover. 


\section{Table 6.3. Australian Sample: Impact of Probability of Informed Trading on Takeover \\ Success}

Table 6.3 shows estimates of binary logit regressions results of takeover outcome on the probability of informed trading ( $P I X 15 \mathrm{~min}$ ) measure and controls. The takeover outcome indicator, the dependent variable, is equal to 1 when the takeover is a success and 0 otherwise. The independent variables include the $\log ($ Size), the natural logarithm transformation of market capitalisation of the firm on the day of takeover announcement, calculated as the number of ordinary shares multiplied by the opening share price; Premium 1 Day is a calculated as the difference between the takeover target offer price per share and the closing price per one day prior to the announcement. Shares sought is the percentage of shares to be acquired under the takeover. The indicator variable on takeover method of payment equals 1 when cash is the method of payment and 0 otherwise. The toe hold variable is an indicator of the bidder ownership greater than $5 \%$ in the bidder prior to the takeover announcement equal to 1 and 0 otherwise. The indicator variable of multiple bidders is equal to 1 when there are more than one bidder during the takeover process and 0 if there is only one. The block holding variable is the control for the existence of block holders owning more than $5 \%$ of the target shares on the announcement day equals 1 and 0 otherwise. Probability of informed trading is estimated using Easley, Keifer, O'Hara and Paperman (1996), (AdjPIN) is estimated using the Duarte and Young (2009) and (VPIN) is estimated using the Easley, Lopez de Prado and O'Hara (2012) models aggregating trade data in 15 minute trading intervals. Control for firm effects is the inverse mills ratio estimated using the 2-step Heckman (1976) procedure to account for sample selection bias using the closest propensity scored matched firm not engaged in any takeover activity. Matching is performed on market capitalisation and industry of operation. Firm year effects controls include a set of indicator variables for each year equal to 1 for the year in which takeover activity takes place and 0 otherwise. Firm industry effects controls include an indicator variable equal to 1 when the takeover occurs with a specific industry (based on 2digit SIC code categorisation) and 0 otherwise.

\begin{tabular}{|c|c|c|c|}
\hline \multirow{2}{*}{$\begin{array}{l}\text { Dependent variable } \\
\text { Independent variables }\end{array}$} & \multicolumn{2}{|l|}{ Outcome } & \multirow[b]{2}{*}{ (3) } \\
\hline & (1) & $(2)$ & \\
\hline \multirow[t]{2}{*}{ Intercept } & $-17.5068 * * *$ & $-18.4618^{*}$ & $-16.6707^{* * *}$ \\
\hline & $(-2.947)$ & $(-1.774)$ & $(-3.849)$ \\
\hline \multirow[t]{2}{*}{ Log(Size) } & $-0.8388^{*}$ & -0.6573 & -0.5831 \\
\hline & $(-1.657)$ & $(-1.129)$ & $(-0.310)$ \\
\hline \multirow[t]{2}{*}{ Premium 1 Day } & 0.0062 & 0.0047 & $0.0623 * * *$ \\
\hline & $(1.231)$ & $(1.279)$ & $(2.787)$ \\
\hline \multirow[t]{2}{*}{ Shares Sought } & 0.0054 & 0.0016 & 0.0021 \\
\hline & $(0.374)$ & $(0.107)$ & $(0.257)$ \\
\hline \multirow[t]{2}{*}{ D Pay Cash } & $2.2981^{*}$ & $-3.2332 * * *$ & $1.1725^{*}$ \\
\hline & $(1.768)$ & $(-2.675)$ & $(1.869)$ \\
\hline \multirow[t]{2}{*}{ D Toe Hold } & $2.8517^{*}$ & -5.0010 & $1.9591^{*}$ \\
\hline & $(1.769)$ & $(-1.147)$ & $(1.802)$ \\
\hline \multirow[t]{2}{*}{ D Multiple Bidders } & -0.9736 & -1.7137 & -1.6241 \\
\hline & $(-0.755)$ & $(-0.736)$ & $(-1.619)$ \\
\hline \multirow[t]{2}{*}{ D Block Holding } & $-2.8517^{*}$ & $-6.4309 *$ & $-1.7777 * * *$ \\
\hline & $(-1.799)$ & $(-1.692)$ & $(-2.782)$ \\
\hline \multirow[t]{2}{*}{$P I N 15 \mathrm{~min}$} & $1.8156^{* * *}$ & & \\
\hline & (3.409) & & \\
\hline \multirow[t]{2}{*}{ AdjPIN $15 \mathrm{~min}$} & & $5.2009 * *$ & \\
\hline & & $(2.145)$ & \\
\hline \multirow[t]{2}{*}{ VPIN $15 \mathrm{~min}$} & & & $0.3534 * * *$ \\
\hline & & & $(3.301)$ \\
\hline \multirow[t]{2}{*}{ D Block Holding $\times$ PIX } & 1.1547 & -5.1889 & 0.0775 \\
\hline & $(0.649)$ & $(1.077)$ & $(0.498)$ \\
\hline Firm Control Variables & $Y$ & $\mathrm{Y}$ & $\mathrm{Y}$ \\
\hline Year Effects & $\mathrm{Y}$ & $Y$ & $Y$ \\
\hline Industry Effects & $Y$ & $\mathrm{Y}$ & $\mathrm{Y}$ \\
\hline Pseudo R squared & 0.3224 & 0.3623 & 0.4174 \\
\hline $\mathrm{N}$ & 83 & 58 & 129 \\
\hline
\end{tabular}

$*$ indicates significance at $10 \%$ level; $* *$ significance at $5 \%$ level; $* * *$ significance at $1 \%$ level 
When considering the 15 minute AdjPIN measure, the likelihood of average takeover is $50.13 \%$. A $1 \%$ increase in the informed trading measure is linked to an increase in this value to $53.86 \%$, while the same decrease in informed trading leads to a decrease in success to $43.85 \%$. With a 1 standard deviation increase in the AdjPIN the likelihood of takeover success is predicted to increase to $80.94 \%$, while the same decrease in the measure is linked to reduction in the likelihood of takeover success to $36.85 \%$. Regarding odds, a $1 \%$ increase in $\operatorname{AdjPIN}$ leads to an increase in odds of 8.114 times above the average, and with a $1 \%$ decrease in the measure, the odds reduce by 3.323 times the average.

The model using the 15 minute VPIN measure, the average likelihood of takeover success is $45.61 \%$. A $1 \%$ rise of VPINleads to an increase in the probability of takeover success to $64.35 \%$. The same decrease leads to a reduction in the probability of success to $24.67 \%$. A 1 standard deviation increase in the measure is linked to an increase of takeover probability to $86.26 \%$, while 1 standard deviation decrease in VPIN leads to a decrease in the likelihood of takeover to $3.34 \%$. With a $1 \%$ increase in the measure of informed trading, the odds of a successful takeover increases to 6.734 times above the average, while the same reduction in VPIN leads to a decrease of odds of success by 1.911 times the odds of the average.

Among the other regression coefficients, most importantly, the pay cash indicator variable is similar in the significance and magnitude of its effect on the likelihood of takeover success for models containing PIN and being very negative and significant for the model with AdjPIN measure. 
Table 6.4 shows the results of GMM estimations for the linear models of informed trading impact on CAR on the announcement day and the next day $(0,+1$ event window). For the model using the PIN measure in the 15 minute interval, a $1 \%$ increase in PIN is associated with $2.37 \%$ increase in CAR. A $1 \%$ increase in 15 minute $\operatorname{AdjPIN}$ measure is associated with a $1.89 \%$ increase in CAR. The issue with these estimates is the $10 \%$ significance level for those coefficients. The impact of informed trading on CAR in the $0-1$ day event window is significant at the $1 \%$ level and suggests that the 15 minute VPIN measure of informed trading is associated with $1.72 \%$ increase in CAR. In comparison, our main results reveal that the 15 minute $P I$ is associated with $2.76 \%$ increase in CAR, with the interaction term also for all measures employed. The interaction terms of success indicator variable and informed trading variables also remain significant and suggest a $1.46 \%$ and $1.03 \%$ increase in CAR for AdjPIN and VPIN models. This result supports our main result where the coefficient on the interaction term using $P I$ to measure informed trading increases CAR by $1.21 \%$ over unsuccessful takeovers.

Table 6.5 details the results of the reverse causality test conducted as detailed in the main models of reverse causality. The relationship of informed trading is significant at the $1 \%$ level and increases in successful takeovers by $0.17 \%$ and $0.09 \%$ over unsuccessful takeovers. The original results remain consistent with robustness results, where increases in probability of informed trading $P I_{i}$ are $2.5 \%$ higher in successful takeovers and significant at the $1 \%$ level. Only the model using the VPIN measure shows insignificant coefficient on the takeover success indicator variable. 
Table 6.4. Australian Sample: Impact of Probability of Informed Trading on Target Firm Cumulative Abnormal Returns

Table 6.4 shows the estimates of linear regression results using Hansen (1982) GMM estimator of cumulative abnormal returns (CARs) of the target firm over different time windows after the takeover is announced on informed trading (PIX 15 min) measure and controls. The CAR of target firm shares above the Fama and French (1993) factors, the dependent variables, are calculated at daily. The independent variables include the log(Size), the natural logarithm transformation of market capitalisation of the firm on the day of takeover announcement, calculated as the number of ordinary shares multiplied by the opening share price; ROA is the return on assets calculated as last reported net income divided by total assets by the target company. Premium 1 Day is a calculated as the difference between the takeover target offer price per share and the closing price per one day prior to the announcement. The indicator variable on takeover method of payment equals 1 when cash is the method of payment and 0 otherwise. The toe hold variable is an indicator of the bidder ownership greater than $5 \%$ in the bidder prior to the takeover announcement equal to 1 and 0 otherwise. The indicator variable of multiple bidders is equal to 1 when there are more than one bidder during the takeover process and 0 if there is only one. The block holding variable is the control for the existence of block holders owning more than $5 \%$ of the target shares on the announcement day equals 1 and 0 otherwise. Probability of informed trading (PIN) is estimated using Easley, Keifer, O'Hara and Paperman (1996), (AdjPIN) is estimated using the Duarte and Young (2009) and (VPIN) is estimated using the Easley, Lopez de Prado and O'Hara (2012) models aggregating trade data in 15 minute time intervals. Control for the firm effects is the inverse mills ratio estimated using the 2-step Heckman (1976) procedure to account for sample selection bias using the closest firm matched on market capitalisation and industry of operation not engaged in any takeover activity. Firm year effects include indicator variables for each year equal to 1 for the year in which takeover is announced and 0 otherwise. Firm industry effects include an indicator variable equal to 1 when the takeover occurs with a specific industry based on 2-digit SIC code categorisation and 0 otherwise.

\begin{tabular}{|c|c|c|c|}
\hline Dependent variable & CAR $[0,+1]$ & & \\
\hline Independent variables & $(1)$ & $(2)$ & (3) \\
\hline PIX & PIN 15min & AdjPIN $15 \mathrm{~min}$ & $V P I N 15 \mathrm{~min}$ \\
\hline \multirow[t]{2}{*}{ Intercept } & 22.7396 & 8.0658 & $32.923 * * *$ \\
\hline & $(1.331)$ & $(0.363)$ & (3.169) \\
\hline \multirow[t]{2}{*}{$\log ($ Size) } & -1.4267 & -0.1759 & -0.9267 \\
\hline & $(-1.584)$ & $(-0.182)$ & $(-1.182)$ \\
\hline \multirow[t]{2}{*}{ ROA } & $15.3059 * *$ & $23.7839 * *$ & 7.8812 \\
\hline & $(2.188)$ & $(2.647)$ & $(1.385)$ \\
\hline \multirow[t]{2}{*}{ Premium 1 Day } & 0.0053 & $0.1792 * *$ & $0.0746 * * *$ \\
\hline & $(0.078)$ & $(2.167)$ & $(3.446)$ \\
\hline \multirow[t]{2}{*}{ D Pay Cash } & $0.2128 * * *$ & $0.1811^{* * *}$ & 1.5729 \\
\hline & $(3.316)$ & $(2.761)$ & $(0.639)$ \\
\hline \multirow[t]{2}{*}{ D Toe Hold } & 1.8995 & $9.8797^{*}$ & 1.4174 \\
\hline & $(0.654)$ & $(1.961)$ & $(0.493)$ \\
\hline \multirow[t]{2}{*}{ D Block Holding } & 2.5062 & 8.5131 & 1.3777 \\
\hline & $(0.533)$ & $(1.177)$ & $(0.476)$ \\
\hline \multirow[t]{2}{*}{ D Success } & $15.7756 * * *$ & $7.7141 * * *$ & $12.413^{* * *}$ \\
\hline & $(2.804)$ & $(2.928)$ & $(4.694)$ \\
\hline \multirow[t]{2}{*}{ PIX 15min } & $2.3706^{*}$ & $1.8875^{*}$ & $1.7197 * * *$ \\
\hline & $(1.835)$ & $(1.857)$ & $(3.172)$ \\
\hline \multirow[t]{2}{*}{ D Success $\times$ PIX $15 \mathrm{~min}$} & $7.7703^{* *}$ & $1.4583^{* *}$ & $1.0321 * * *$ \\
\hline & $(2.238)$ & $(1.966)$ & $(2.490)$ \\
\hline D Block Holding $x$ & 0.1234 & $11.2838^{* *}$ & $1.3439 * *$ \\
\hline$P I X 15 \mathrm{~min}$ & $(0.243)$ & $(1.987)$ & $(1.965)$ \\
\hline Firm Control Variables & $Y$ & $\mathrm{Y}$ & Y \\
\hline Year Effects & $\mathrm{Y}$ & $\mathrm{Y}$ & $\mathrm{Y}$ \\
\hline Industry Effects & $Y$ & $\mathrm{Y}$ & $\mathrm{Y}$ \\
\hline Adjusted R squared & 0.2245 & 0.3081 & 0.2134 \\
\hline $\mathrm{N}$ & 83 & 56 & 129 \\
\hline
\end{tabular}




\section{Table 6.5. Australian Sample: Impact of Takeover Success on Probability of Informed Trading}

Table 6.5 shows the estimates of linear regression results using Hansen (1982) GMM estimator of PIX $15 \mathrm{~min}$ trading measures on indicator of success and controls. The independent variables include the log(Size), the natural logarithm transformation of market capitalisation of the firm on the day of takeover announcement, calculated as the number of ordinary shares multiplied by the opening share price; Premium 1 Day is a calculated as the difference between the takeover target offer price per share and the closing price per one day prior to the announcement. The indicator variable on takeover method of payment equals 1 when cash is the method of payment and 0 otherwise. The toe hold variable is an indicator of the bidder ownership greater than $5 \%$ in the bidder prior to the takeover announcement equal to 1 and 0 otherwise. The indicator variable of multiple bidders is equal to 1 when there are more than one bidder during the takeover process and 0 if there is only one. The block holding variable is the control for the existence of block holders owning more than $5 \%$ of the target shares on the announcement day equals 1 and 0 otherwise. The indicator variable on hostile takeovers equals 1 when the bid is accompanied by a proxy contest or tender offer and 0 otherwise. Probability of informed $(P I N)$ is estimated using Easley, Keifer, O'Hara and Paperman (1996), (AdjPIN) is estimated using the Duarte and Young (2009) and (VPIN) is estimated using the Easley, Lopez de Prado and O'Hara (2012) models aggregating trade data in 15 minute time intervals. The effects of individual firms are controlled by the inverse mills ratio estimated using the 2-step Heckman (1976) procedure to account for sample selection bias by using the closest propensity scored matched firm that is not engaged in any takeover activity. Matching is performed on market capitalisation and industry of operation. Firm year effects controls include a set of indicator variables for each year equal to 1 for the year in which takeover activity takes place and 0 otherwise. Firm industry effects controls include an indicator variable equal to 1 when the takeover occurs with a specific industry (based on 2-digit SIC code categorisation) and 0 otherwise.

\begin{tabular}{|c|c|c|c|}
\hline Dependent variable & $P I N 15 \mathrm{~min}$ & AdjPIN $15 \mathrm{~min}$ & VPIN $15 \mathrm{~min}$ \\
\hline Independent variables & (1) & $(2)$ & (3) \\
\hline \multirow[t]{2}{*}{ Intercept } & 1.0066 & 0.1124 & 4.5395 \\
\hline & $(1.076)$ & $(0.218)$ & $(1.004)$ \\
\hline \multirow[t]{2}{*}{$\log ($ Size $)$} & $-0.0321 * * *$ & $-0.0229 *$ & -0.1141 \\
\hline & $(-2.811)$ & $(-1.639)$ & $(-0.363)$ \\
\hline \multirow[t]{2}{*}{ Premium 1 Day } & 0.0006 & 0.0002 & 0.0401 \\
\hline & $(1.179)$ & $(1.086)$ & $(1.635)$ \\
\hline \multirow[t]{2}{*}{ D Pay Cash } & -0.1679 & -0.0566 & 0.2259 \\
\hline & $(-1.389)$ & $(-0.582)$ & $(0.185)$ \\
\hline \multirow[t]{2}{*}{ D Toe Hold } & 0.0078 & 0.1194 & 0.3861 \\
\hline & $(0.109)$ & $(1.079)$ & $(0.213)$ \\
\hline \multirow[t]{2}{*}{ D Block Holding } & 0.0282 & $0.0798 * *$ & -0.6551 \\
\hline & $(0.201)$ & $(2.431)$ & $(-0.485)$ \\
\hline \multirow[t]{2}{*}{ D Hostile } & 0.2597 & $0.2430^{*}$ & 0.9295 \\
\hline & $(0.200)$ & $(1.811)$ & $(0.304)$ \\
\hline \multirow[t]{2}{*}{ D Success } & $0.1661 * * *$ & $0.0872 * * *$ & 0.6503 \\
\hline & $(2.999)$ & $(2.908)$ & $(0.580)$ \\
\hline Firm Control Variables & $\mathrm{Y}$ & $\mathrm{Y}$ & $\mathrm{Y}$ \\
\hline Year Effects & $\mathrm{Y}$ & $\mathrm{Y}$ & $\mathrm{Y}$ \\
\hline Industry Effects & $\mathrm{Y}$ & $Y$ & $Y$ \\
\hline Adjusted R squared & 0.0346 & 0.1217 & 0.1309 \\
\hline $\mathrm{N}$ & 83 & 53 & 129 \\
\hline
\end{tabular}

$*$ indicates significance at $10 \%$ level; $* *$ significance at $5 \%$ level; $* * *$ significance at $1 \%$ level 


\subsubsection{Discussion}

The robustness results largely align with our main results. Regarding estimations of the likelihood of takeover success, with the alternative measures of informed trading, the results provide a slightly higher probability of the average, along with a slightly wider interval of success and in terms of odds, than that reported in our main results. This outcome can be attributed to the different observations and measurement models used in the logistic regressions when applying the alternative measures of $P I$. The different observations included when using measures of $P I$ highlight the estimation limitations of those individual measures, introducing the greater effect of small samples when used in the robustness logistic regression models.

The impact of informed trading on CAR reported in our main results is very similar to the robustness tests results at around $2 \%$ increase in CAR for every $1 \%$ increase in informed trading, a very consistent result across the different measures of informed trading reinforcing the validity of the relationship captured by our main results. Our results presented in Chapter Five are more stable than the robustness results presented in this chapter due to the linear models used our main results. In this chapter, we employ nonlinear maximum likelihood methodologies to capture effects of informed trading on takeover success. These results, however, provide less stable results due to insignificant estimates of probabilities of informed trading driving the small sample limitations of our tests.

The test of reverse causality using PIN and AdjPIN report significant but small coefficients at the $1 \%$ level suggesting that there is weak reverse relationship between takeover success and informed trading, while the VPIN shows a statistically insignificant 
coefficient. These measures all show a weaker relationship between takeover success and informed trading than $P I$ in our main results which is estimated $2.5 \%$ higher in successful takeover.

\subsubsection{United States Sample Robustness Tests Results}

Table 6.6 presents results of the Cornelli and Li (2002) model tests using a United States sample and the alternative probability measures of informed trading. The estimation results of the impact of takeover traders' participation in trading of shares under a takeover offer on takeover success show that all alternative measures (PIN, AdjPIN and VPIN) have the same relationship regarding the direction and significance level. With the relationship regarding the other variables, the coefficients remain the same, in terms of size and significance, as the main results presented in Table 5.6 and discussed in Section 5.3.2 of Chapter 5.

Estimates obtained using the 15 minute PIN measures of informed trading show that the average takeover has a likelihood of success is $51.83 \%$, very similar to our main result for the United States sample. The coefficient of the estimated model is 1.192 , which if it increases by $1 \%$, is predicted to lead to an increased rate of success to $55.89 \%$. A $1 \%$ decrease in the level of informed trading is linked to a decrease in the rate of takeover success to $34.17 \%$, while with a 1 standard deviation of $1.71 \%$, an increase in informed trading predicts an increase in takeover success to $63.31 \%$. A 1 standard deviation decrease in informed trading is associated with a decrease in the probability of success to $29.64 \%$. In terms of odds ratio, a $1 \%$ increase in informed trading increases the odds of success by 8.991 times above the average, while a similar decrease in PIN leads to a decrease in the odds of a takeover success by 1.222 times the average. 
Table 6.6. United States Sample: Impact of Probability of Informed Trading on Takeover Success

Table 6.6 shows estimates of binary logit regressions results of takeover outcome on the probability of informed trading (PIX) measure and controls. The takeover outcome, the dependent variable, is equal to 1 when the takeover is a success and zero otherwise. The independent variables include the $\log ($ Size), the natural logarithm transformation of market capitalisation of the firm on the day of takeover announcement, calculated as the number of ordinary shares multiplied by the opening share price; Premium 1 Day is a calculated as the difference between the takeover target offer price per share and the closing price per one day prior to the announcement. Shares sought is the percentage of shares to be acquired under the takeover. The indicator variable on takeover method of payment equals 1 when cash is the method of payment and 0 otherwise. The toe hold variable is an indicator of the bidder ownership greater than $5 \%$ in the bidder prior to the takeover announcement equal to 1 and 0 otherwise. The indicator variable of multiple bidders is equal to 1 when there are more than one bidder during the takeover process and 0 if there is only one. The block holding variable is the control for the existence of block holders owning more than $5 \%$ of the target shares on the announcement day equals 1 and 0 otherwise. Probability of informed (PIN) is estimated using Easley, Keifer, O'Hara and Paperman (1996), (AdjPIN) is estimated using the Duarte and Young (2009) and $(V P I N)$ is estimated using the Easley, Lopez de Prado and O'Hara (2012) models aggregating trade data in 15 minute time intervals. The effects of individual firms are controlled by the inverse mills ratio estimated using the 2-step Heckman (1976) procedure to account for sample selection bias by using the closest propensity scored matched firm that is not engaged in any takeover activity. Matching is performed on market capitalisation and industry of operation. Firm year effects controls include a set of indicator variables for each year equal to 1 for the year in which takeover activity takes place and 0 otherwise. Firm industry effects controls include an indicator variable equal to 1 when the takeover occurs with a specific industry (based on 2-digit SIC code categorisation) and 0 otherwise.

\begin{tabular}{|c|c|c|c|}
\hline \multirow{2}{*}{$\begin{array}{l}\text { Dependent variable } \\
\text { Independent variables }\end{array}$} & \multicolumn{2}{|c|}{ Outcome } & \multirow[b]{2}{*}{ (3) } \\
\hline & $(1)$ & $(2)$ & \\
\hline \multirow[t]{2}{*}{ Intercept } & $-26.952 * *$ & -23.2960 & -30.8129 \\
\hline & $(-2.185)$ & $(-1.235)$ & $(-1.539)$ \\
\hline \multirow[t]{2}{*}{ Log(Size) } & $-0.0119 *$ & -0.0894 & -0.0681 \\
\hline & $(-1.837)$ & $(-1.158)$ & $(-0.767)$ \\
\hline \multirow[t]{2}{*}{ Premium 1 Day } & $0.0179 * *$ & $0.0037 * *$ & $0.0048 * *$ \\
\hline & $(2.284)$ & $(2.219)$ & $(2.520)$ \\
\hline \multirow[t]{2}{*}{ Shares Sought } & $0.0160 * *$ & $0.0218^{* * *}$ & $0.0223 * * *$ \\
\hline & $(2.057)$ & $(4.247)$ & $(4.394)$ \\
\hline \multirow[t]{2}{*}{ D Pay Cash } & $0.3656 * *$ & $0.1543^{*}$ & $0.2055^{* *}$ \\
\hline & $(2.017)$ & $(1.652)$ & $(2.308)$ \\
\hline \multirow[t]{2}{*}{ D Toe Hold } & 1.6256 & 0.7299 & 1.0261 \\
\hline & $(1.111)$ & $(0.878)$ & $(1.249)$ \\
\hline \multirow[t]{2}{*}{ D Multiple Bidders } & $-4.6361 * * *$ & $-4.6489 * * *$ & $-4.7531 * * *$ \\
\hline & $(-3.734)$ & $(-5.529)$ & $(-5.647)$ \\
\hline \multirow[t]{2}{*}{ D Block Holding } & -0.0994 & -0.1511 & -0.6842 \\
\hline & $(-0.080)$ & $(-0.408)$ & $(-1.496)$ \\
\hline \multirow[t]{2}{*}{ PIN 15min } & $1.1962 * * *$ & & \\
\hline & $(2.783)$ & & \\
\hline \multirow[t]{2}{*}{ AdjPIN $15 \mathrm{~min}$} & & $0.1502 * * *$ & \\
\hline & & $(4.513)$ & \\
\hline \multirow[t]{2}{*}{ VPIN $15 \mathrm{~min}$} & & & $0.2222 * * *$ \\
\hline & & & $(2.786)$ \\
\hline \multirow[t]{2}{*}{ D Block Holding $\times$ PIX } & 0.2102 & 0.6618 & $0.2882 * *$ \\
\hline & $(0.144)$ & $(0.671)$ & $(2.060)$ \\
\hline Firm Control Variables & $\mathrm{Y}$ & $\mathrm{Y}$ & $\mathrm{Y}$ \\
\hline Year Effects & $\mathrm{Y}$ & $\mathrm{Y}$ & Y \\
\hline Industry Effects & $\mathrm{Y}$ & $\mathrm{Y}$ & $\mathrm{Y}$ \\
\hline Pseudo R squared & 0.3498 & 0.2787 & 0.2926 \\
\hline $\mathrm{N}$ & 228 & 265 & 477 \\
\hline
\end{tabular}

$*$ indicates significance at $10 \%$ level; $* *$ significance at $5 \%$ level; ***significance at $1 \%$ level 
Using the 15 minute $A d j P I N$ measure, the average takeover contained in the sample is successful $53.96 \%$ of the time. A $1 \%$ increase in the measure is associated with an increase in takeover success to $57.01 \%$, while the same decrease in the measure will lead to a decrease of chances of takeover success to $37.32 \%$. A 1 standard deviation increase in AdjPIN leads to an increase in probability of takeover success of $66.28 \%$ while a decrease of the same amount, $1.29 \%$ in $\operatorname{AdjPIN}$, is predicted to lead to a decrease in probability of success to $39.84 \%$. In relation to the odds ratio, a $1 \%$ increase in $\operatorname{AdjPIN}$ leads to an increase in the success odds of 3.158 times the average likelihood. The same reduction in the informed trading measure leads to a decrease of 2.339 times the likelihood of the average takeover.

The model using 15 minute VPIN, shows the average likelihood of takeover success is 45.14\%. A $1 \%$ increase in VPIN predicts an increase in the likelihood of success to $50.03 \%$, while the same decrease in the measure leads to $41.51 \%$ probability of takeover success. A 1 standard deviation, or $2.682 \%$, increase in VPINis predicted to lead to a $70.58 \%$ probability of takeover success while the same decrease in VPIN is linked to a decrease in probability of takeover success to $30.64 \%$. With the odds, a $1 \%$ increase in VPINincreases the odds of success to 3.395 times the average case while the same decrease leads to decreased odds of success at 2.177 times the average.

Among the other regression coefficients, the indicator variable on payment in cash is significant level at $1 \%$ in the model containing $\operatorname{AdjPIN}$. The 1 day premium over the last traded price before the announcement, as well as the indicator variable on block holding are significant with very similar estimates to our main result using $P I$ as presented in Table 5.6 . 
The impact of the informed trading on CAR in the 0-1 day event window is presented in Table 6.7. The estimates on measures of informed trading show a positive relationship significant at the $10 \%$ level. A $1 \%$ increase in PIN is associated with a $7.34 \%$ increase in CAR, while the AdjPIN measure leads to a $3.64 \%$ increase in CAR. Coefficient on VPIN is significant at the $1 \%$ level, and a $1 \%$ increase in informed trading leads to a $1.79 \%$ increase in CAR. These results are consistent with our main results, where a $1 \%$ increase in $P I_{i}$ leads to a $2.59 \%$ increase in CAR.

The impact of the marginal effect of informed trading on successful takeovers over unsuccessful takeovers is estimated by the interaction term of informed trading measures and the success indicator variable. The probability of informed trading is stronger in successful takeovers with the marginal effect on the interaction estimates on PIN, AdjPIN and VPIN. This suggests a $1 \%$ increase in informed trading linked to a $5.23 \%, 4.93 \%$ and $2.09 \%$ increase in the CAR of targets in successful takeovers. This relationship is significant at the $1 \%$ level for the model containing VPIN. This result is consistent with our main results using $P I_{i}$ in the interaction term, the coefficient significant at the $1 \%$ level, suggests a $2.84 \%$ increase in CAR for every $1 \%$ increase in informed trading.

Tests of reverse causality are included in Table 6.8. The estimates are lower in both economic and statistical significance than the main result. Successful takeovers are associated with higher informed trading $0.0027 \%, 0.0425 \%$ and $0.0879 \%$ for PIN, AdjPIN and VPIN respectively, significant at the $5 \%$ level. Our main results show a similar characteristic but are significant at the $1 \%$ level and a significantly higher level with a $2.18 \%$ increase in informed trading in successful takeovers. 
Table 6.7. United States Sample: Impact of Probability of Informed Trading on Target Firm Cumulative Abnormal Returns

Table 6.7 shows the estimates of linear regression results using Hansen (1982) Generalised method of moments estimator of cumulative abnormal returns of the target firm on the probability of informed trading (PIX $15 \mathrm{~min}$ ) measure and controls. The cumulative abnormal returns of target firm shares above the Fama and French (1993) factors, the dependent variables, are calculated at daily frequency. The independent variables include natural logarithm of firm size expressed as logarithm of the market capitalisation of the firm on the day of takeover announcement. ROA is the return on assets calculated as last reported net income divided by total assets by the target company. Premium 1 Day is the percentage difference of share price one day prior to the takeover announcement and the takeover price contained in the announcement. The indicator variable on takeover method of payment equals 1 when cash is the method of payment and 0 otherwise. The toe hold variable is an indicator of the bidder ownership greater than $5 \%$ in the bidder prior to the takeover announcement equal to 1 and 0 otherwise. The indicator variable of multiple bidders is equal to 1 when there are more than one bidder during the takeover process and 0 if there is only one. The block holding variable is the control for the existence of block holders owning more than $5 \%$ of the target shares on the announcement day equals 1 and 0 otherwise. Probability of informed informed $(P I N)$ is estimated using Easley, Keifer, O'Hara and Paperman (1996), (AdjPIN) is estimated using the Duarte and Young (2009) and $(V P I N)$ is estimated using the Easley, Lopez de Prado and O'Hara (2012) models aggregating trade data in 15 minute time intervals. The effects of individual firms are controlled by the inverse mills ratio estimated using the 2-step Heckman (1976) procedure to account for sample selection bias by using the closest propensity scored matched firm that is not engaged in any takeover activity. Matching is performed on market capitalisation and industry of operation. Firm year effects controls include a set of indicator variables for each year equal to 1 for the year in which takeover activity takes place and 0 otherwise. Firm industry effects controls include an indicator variable equal to 1 when the takeover occurs with a specific industry (based on 2-digit SIC code categorisation) and 0 otherwise.

\begin{tabular}{|c|c|c|c|}
\hline Dependent variable & $\operatorname{CAR}[0,+1]$ & & \\
\hline Independent variables & $(1)$ & $(2)$ & (3) \\
\hline$P I X 15 \mathrm{~min}$ & $P I N 15 \mathrm{~min}$ & AdjPIN $15 \mathrm{~min}$ & VPIN $15 \mathrm{~min}$ \\
\hline \multirow[t]{2}{*}{ Intercept } & -6.2755 & 4.3911 & -4.7238 \\
\hline & $(0.439)$ & $(0.289)$ & $(-0.333)$ \\
\hline \multirow[t]{2}{*}{ Log(Size) } & $-1.7378 * * *$ & $-2.0814^{* * *}$ & $-2.3400 * * *$ \\
\hline & $(-2.839)$ & $(-3.688)$ & $(-4.161)$ \\
\hline \multirow[t]{2}{*}{ ROA } & $18.9251 * *$ & $41.6127 * *$ & $42.302 * *$ \\
\hline & $(2.496)$ & $(2.223)$ & $(2.406)$ \\
\hline \multirow[t]{2}{*}{ Premium 1 Day } & $0.3113^{* * *}$ & $0.1886 * * *$ & $0.1938 * * *$ \\
\hline & $(3.437)$ & $(3.407)$ & $(3.596)$ \\
\hline \multirow[t]{2}{*}{ D Pay Cash } & $5.7349 * * *$ & $6.5469 * * *$ & $7.5891 * * *$ \\
\hline & $(3.636)$ & $(5.218)$ & $(5.963)$ \\
\hline \multirow[t]{2}{*}{ D Toe Hold } & 5.5743 & 7.2436 & 7.2359 \\
\hline & $(0.668)$ & $(1.444)$ & $(1.386)$ \\
\hline \multirow[t]{2}{*}{ D Block Holding } & $7.3383^{*}$ & $4.4802^{* *}$ & $3.7801^{*}$ \\
\hline & $(1.790)$ & $(2.286)$ & $(1.386)$ \\
\hline \multirow[t]{2}{*}{ D Success } & $5.2307 * * *$ & $3.1403^{* *}$ & $7.8215^{* * *}$ \\
\hline & $(2.949)$ & $(2.259)$ & $(2.857)$ \\
\hline \multirow[t]{2}{*}{ PIX $15 \mathrm{~min}$} & $7.3383^{*}$ & $3.6439 *$ & $1.7900 * * *$ \\
\hline & $(1.789)$ & $(1.913)$ & $(2.662)$ \\
\hline D Success $x$ & $5.2307^{* *}$ & $4.9297^{*}$ & $2.0857^{* * *}$ \\
\hline$P I X 15 \mathrm{~min}$ & $(2.051)$ & $(1.818)$ & $(3.034)$ \\
\hline D Block Holding $\times$ & 4.1027 & 4.1421 & 0.0851 \\
\hline$P I X 15 \min$ & $(0.766)$ & $(0.676)$ & $(0.1707)$ \\
\hline Firm Control Variables & $\mathrm{Y}$ & $\mathrm{Y}$ & $\mathrm{Y}$ \\
\hline Year Effects & $\mathrm{Y}$ & $\mathrm{Y}$ & $\mathrm{Y}$ \\
\hline Industry Effects & $\mathrm{Y}$ & $\mathrm{Y}$ & $\mathrm{Y}$ \\
\hline Adjusted R squared & 0.4889 & 0.3826 & 0.3963 \\
\hline $\mathrm{N}$ & 267 & 265 & 477 \\
\hline
\end{tabular}

$*$ indicates significance at $10 \%$ level; $* *$ significance at $5 \%$ level; $* * *$ significance at $1 \%$ level 


\section{Table 6.8. United States Sample: Impact of Takeover Success on Probability of Informed Trading}

Table 6.8 shows the estimates of linear regression results using Hansen (1982) Generalised method of moments estimator of probability of informed trading measures and controls. The independent variables include the $\log (\mathrm{Size})$, the natural logarithm transformation of market capitalisation of the firm on the day of takeover announcement, calculated as the number of ordinary shares multiplied by the opening share price; Premium 1 Day is a calculated as the difference between the takeover target offer price per share and the closing price per one day prior to the announcement. The indicator variable on takeover method of payment equals 1 when cash is the method of payment and 0 otherwise. The toe hold variable is an indicator of the bidder ownership greater than $5 \%$ in the bidder prior to the takeover announcement equal to 1 and 0 otherwise. The indicator variable of multiple bidders is equal to 1 when there are more than one bidder during the takeover process and 0 if there is only one. The block holding variable is the control for the existence of block holders owning more than $5 \%$ of the target shares on the announcement day equals 1 and 0 otherwise. The indicator variable on hostile takeovers equals 1 when the bid is accompanied by a proxy contest or tender offer and 0 otherwise Probability of informed $(P I N)$ is estimated using Easley, Keifer, O'Hara and Paperman (1996), (AdjPIN) is estimated using the Duarte and Young (2009) and (VPIN) is estimated using the Easley, Lopez de Prado and O'Hara (2012) models aggregating trade data in 15 minute time intervals. The effects of individual firms are controlled by the inverse mills ratio estimated using the 2-step Heckman (1976) procedure to account for sample selection bias by using the closest propensity scored matched firm that is not engaged in any takeover activity. Matching is performed on market capitalisation and industry of operation. Firm year effects controls include a set of indicator variables for each year equal to 1 for the year in which takeover activity takes place and 0 otherwise. Firm industry effects controls include an indicator variable equal to 1 when the takeover occurs with a specific industry (based on 2-digit SIC code categorisation) and 0 otherwise.

\begin{tabular}{|c|c|c|c|}
\hline Dependent variable & $P I N 15 \mathrm{~min}$ & AdjPIN $15 \mathrm{~min}$ & $V P I N 15 \mathrm{~min}$ \\
\hline Independent variables & $(1)$ & $(2)$ & $(3)$ \\
\hline \multirow[t]{2}{*}{ Intercept } & $0.6233 * * *$ & $0.2039 * *$ & $4.4156^{*}$ \\
\hline & $(2.548)$ & $(2.149)$ & $(1.831)$ \\
\hline \multirow[t]{2}{*}{ Log(Size) } & $-0.2151 * * *$ & $-0.0377 * * *$ & $0.7753^{* * *}$ \\
\hline & $(-11.667)$ & $(-4.839)$ & $(10.052)$ \\
\hline \multirow[t]{2}{*}{ Premium 1 Day } & 0.0008 & $-0.0006 * * *$ & 0.0016 \\
\hline & $(1.458)$ & $(-3.176)$ & $(0.806)$ \\
\hline \multirow[t]{2}{*}{ D Pay Cash } & -0.0405 & 0.0138 & -0.0405 \\
\hline & $(-0.881)$ & $(0.506)$ & $(-0.881)$ \\
\hline \multirow[t]{2}{*}{ D Toe Hold } & 0.0078 & 0.0686 & 0.1899 \\
\hline & $(0.109)$ & $(1.264)$ & $(0.875)$ \\
\hline \multirow[t]{2}{*}{ D Block Holding } & -0.0681 & -0.0063 & -0.0681 \\
\hline & $(-1.423)$ & $(-0.188)$ & $(-1.423)$ \\
\hline \multirow[t]{2}{*}{ D Hostile } & 0.0196 & -0.0465 & 0.0772 \\
\hline & $(0.294)$ & $(-0.752)$ & $(0.268)$ \\
\hline \multirow[t]{2}{*}{ D Success } & $0.0027^{*}$ & $0.0425 * *$ & $0.0879 * *$ \\
\hline & $(1.692)$ & $(1.645)$ & $(2.108)$ \\
\hline Firm Control Variables & $\mathrm{Y}$ & Y & Y \\
\hline Year Effects & $Y$ & $Y$ & Y \\
\hline Industry Effects & $Y$ & $\mathrm{Y}$ & $\mathrm{Y}$ \\
\hline Adjusted R squared & 0.1464 & 0.0871 & 0.3627 \\
\hline $\mathrm{N}$ & 267 & 265 & 477 \\
\hline
\end{tabular}

$*$ indicates significance at $10 \%$ level; $* *$ significance at $5 \%$ level; $* * *$ significance at $1 \%$ level 


\subsubsection{Discussion}

The robustness tests are carried out by using three alternative measures of informed trading: Easley, Kiefer, O'Hara and Paperman (1996) PIN, Duarte and Young (2009) AdjPIN and Easley, Lopez de Prado and O'Hara (2012) VPIN. We used them instead of the Bollen, Smith and Whaley (2004) $P I_{i}$ measure in the primary test. The primary concern of the results in the Australian sample is that the test suffers from small sample problems in models when using PIN and AdjPIN. The model employing VPIN measure does not suffer from this issue with 129 observations. The results are very close to our main results using PI measures. In the United States sample, robustness tests do not suffer from small sample issues and provide more consistent results than the robustness tests using Australian data sample.

Regarding the estimations of the likelihood of takeover success, the significance level of estimates using the alternative measures of informed trading were at the $1 \%$ level, the same as the main result. The magnitude of the coefficients was lower for all alternative measures than our main result; however, this was due to the significantly different way in which these measures were estimated and calculated. Other than that, the results of the robustness tests were consistent with all main results of the study using United States sample data.

The average of takeover success is in line with our main result of $50.59 \%$ apart from the average of the model using VPIN which is lower. The interval around the inference of impact of informed trading on the success of takeovers is very similar to our main reported results of $62.8 \%$ and $38.32 \%$ in the $1 \%$ change in $P I$. The odds ratios were slightly wider for the alternative measures of informed trading than reported in our main results. 
The impacts of informed trading on CAR in the robustness tests is similar to our main results. The coefficients are slightly larger in models using PIN and AdjPIN and lower in the model using VPIN. In terms of significance, the coefficient on VPIN is significant at the $1 \%$ level, while coefficients on the other measures are less significant, only at $5 \%$ and $10 \%$ levels respectively.

In the reverse causality tests, coefficients were smaller and less significant for all models in the robustness tests using the alternative measures than those in the main result. The significance at the $5 \%$ level was weaker than in the main result, but still shows that a relationship between the probabilities of informed trading and takeover success is indeed present, as reported in our main results. The smaller levels of coefficients in the robustness tests were due to the difference in constructing the alternative measures of informed trading compared to the PI measure used in our main results. Even though the tests no longer suffered from small-sample issues, the main tests using the PI measure still used more observations, increasing the overall power of those tests. 


\section{CHAPTER SEVEN: CONCLUSIONS}

\subsection{Introduction}

The results presented in Chapters 5 and 6 reveal that Cornelli and Li (2002) theory is supported by empirical trading data. We determine that a higher level of informed trading in a target's shares after a takeover announcement leads to higher probability of the takeover being successful. We further show that an increased presence of informed trading in target shares has a positive impact on the CAR of those shares, and that this effect is higher in successful takeovers. Our results are robust when using alternative measures of informed trading as established in the extant literature.

\subsection{Probability of Informed Trading}

Our results - presented in Tables 5.2 and 5.7, discussed in Sections 5.2.1.2 and 5.3.1.4 for Australian and United States samples, respectively-show that $P I$, estimated using Bollen, Smith and Whaley (2004) bid-ask spread decomposition model, increases significantly more on the announcement day when takeovers are successful than when they are not. The effect of increased informed trading in successful takeovers is present for up to four days in the Australian sample, while in the United States sample the effect is concentrated only on the takeover announcement day. The magnitude of the informed trading is largest on the announcement day in both samples in our tests. The out-ofsample predictions for our results are $75 \%$ accurate for identifying the outcome of a takeover, given the amount of informed trading observed in the trading data of the target shares on the takeover announcement day. 


\subsection{Impact of Informed Trading on Takeover Success}

We tested Cornelli and Li (2002) prediction that traders of takeover target shares directly influence the takeover process outcome by increasing the likelihood of takeover success through their trading activity. These results are illustrated in Tables 5.3 and 5.8 for Australian and United States sub-samples respectively, and are discussed in Sections 5.2.2 and 5.3.2 respectively. To perform this test reliably, we controlled for all takeover bid and target firm characteristics, as well as adjusting for year and industry differences specified in the takeover literature. Our results suggest that a higher level of informed trading of target firm shares leads to an increase in the takeover success rate. The effect remains significant across different aggregation periods of trading on the takeover announcement day. Takeover traders participate more in takeovers that end successfully, supporting Cornelli and Li (2002) theoretical model. The results are stronger in the United States sample than the Australian, due to the higher concentration of informed trading on the takeover announcement day.

\subsection{Impact of Informed Trading on Cumulative Abnormal Returns}

We conducted a further test for the impact of informed trading abnormal returns on takeover target shares at different day aggregation intervals following the takeover announcement. These results are presented in Section 5.2.5 and Table 5.5 for the Australian sample, and Section 5.4.1 and Table 5.11 for the United States sample. An increased occurrence of informed trading on the takeover announcement day is linked to an increase in CAR over two days, starting on the takeover announcement day in the Australian sample, with the largest return in the United States sample occurring on the day of the takeover. There is also a slight marginal effect of informed trading leading to a 
slightly higher cumulative abnormal return of target firms in successful takeovers. This effect is larger in the United States sample, where the trading is more active on the takeover announcement day.

\subsection{Impact of Informed Trading Using Alternative Measures}

We conducted our robustness tests as detailed in Chapter 6 , by replacing Bollen, Smith and Whaley (2004) PI measure of informed trading with alternative and widely accepted measures of informed trading. We reproduced our tests using estimates from Easley, Kiefer, O'Hara and Paperman (1996) PIN model, Duarte and Young (2009) AdjPIN model and Easley, Lopez de Prado and O'Hara (2012) VPIN to measure the probability of informed trading.

Overall, the results of robustness testing confirmed our main results in all respects. However, expected deviations exist due to the sometimes non-linear nature of the models used to capture informed trading, combined with the non-linear models used to estimate the relationships between informed trading and takeover success. In combination, these issues lead to the Australian sample's results suffering from smallsample effects; however, the United States sample performs much better, due to more observations being available for estimation purposes. This results in the United States sample's results of robustness tests being much closer to our main results. Regarding the impact of informed trading on CAR, the effect of small samples is mitigated somewhat due to the linear model used in the estimation process. Therefore, our robustness results-even for the Australian sample-are more aligned with our main results. All estimates for robustness tests are around the same level as in the main results, reinforcing the validity of relationships captured in our main results. 
In this chapter we repeat our original tests, in Chapter 5, of the Cornelli and Li (2002) using alternative measures of informed trading using estimates from Easley, Kiefer, O'Hara and Paperman (1996) PIN model, Duarte and Young (2009) AdjPIN model and Easley, Lopez de Prado and O'Hara (2012) VPIN. The robustness results, with regards to the tests of Cornelli and Li (2002), have similar magnitude of effects of informed trading on the outcome of takeover activity as our main results in Chapter 5 . The robustness results are, however, less significant than the main results due to small samples effects which impact the significance more than in our main results in Chapter 5. 


\section{CHAPTER EIGHT: LIMITATIONS AND FUTURE RESEARCH DIRECTIONS}

\subsection{Limitations}

First and foremost, we would like to emphasise that any research using trade and quote data requires a significant amount of data processing power to obtain estimates within a reasonable time frame. A limitation also exists with regard to the frequency of takeovers, which have decreased significantly since 2008 , after the global financial crisis. This has resulted in fewer opportunities to study takeover dynamics. We are severely limited by only being able to observe market transactions in our study. Observing over-the-counter and private transactions, in particular between different block holders, may result in much clearer specifications and testing of Cornelli and Li (2002) model.

\subsection{Future Research Opportunities}

One simple opportunity to extend the study is to increase the sample period. This would in particular benefit the robustness tests on the Australian sample suffering from smallsample issues. A more detailed study could track the level of informed trading from the announcement day to the day of takeover completion. In particular, days of interest for consideration include the day an offer is approved or rejected by the target's board of directors, the day approval or rejection of the offer is given by a regulatory body, the day when the offer becomes binding for the bidder, and finally the day the takeover offer is completed or withdrawn. Around these days, we should observe higher levels of informed trading. However, it would be interesting to study the dynamic relationship between the likelihood of takeover success and informed trading. Of particular interest is the empirical threshold for shares traded leading to takeover success and the cumulative level of informed trading associated with achieving this result. 


\subsection{Practical Applications}

The practical applications of our research are clear. The detection of increased informed trading in target shares can be used to indicate the likelihood of takeover success. A trader on an investment fund can take positions in the target shares and derivatives to profit from a more informative, market-attuned probability of takeover success. Bidder firms can also benefit from this research by using the same methodology to judge their position in relation to securing sufficient shares to acquire the target. Bidders may use this information when considering increases in future bids to game their responses to the reaction of informed traders to a takeover announcement. 


\section{REFERENCES}

Admanti, AR \& Pfleiderer, P 1988, 'A theory of intraday patterns: volume and price variability', Review of Financial Studies, vol. 1, no. 1, pp. 3-40.

Aitken, M, Buckland, C, Izan, HY, Walter TS 1996, 'Price clustering on the Australian stock exchange', Pacific-Basin Finance Journal, vol. 4, no. 2-3, pp. 297-314.

Anderson, D, Haynes A \& Heaney, R 1994, 'Company takeovers and equity returns: the target size effect', Australian Journal of Management, vol. 19, no.1, pp. 1-30.

Andrade, G, \& Stafford E 2004, 'Investigating the economic role of Mergers', Journal of Corporate Finance, vol. 25, pp.1-36.

Andrade, G, Mitchell, M \& Stafford E 2001, 'New Evidence And Perspectives On Mergers', Journal of Economic Perspectives, vol. 15, no. 2, pp.103-120.

Ascioglu, NA, Mclnish, TH \& Wood, RA 2002, 'Merger announcements and trading', Journal of Financial Research, vol. 25, no. 2, pp. 263-278.

Back, K \& Baruch, S 2004, 'Information in securities markets: Kyle meets Glosten and Milgrom', Econometrica, vol. 72, no.2, pp. 433-465.

Back, K \& Baruch, S 2007, 'Working orders in limit order markets and floor exchanges', Journal of Finance, vol. 62, no. 4, pp. 1589-1621.

Bagehot, W 1971,'The only game in town', Financial Analysts Journal, vol. 27, no.2, pp. 12-14.

Barclay, MJ \& Warner, JB 1993, 'Stealth trading and volatility', Journal of Financial Economics, vol. 34, no. 3, pp. 281-305.

Bellamy, DE \& Lewin, WM 1992, 'Corporate takeovers, method of payment, and bidding 
firms. Shareholder returns: Australian evidence', Asia Pacific Journal of Management, vol. 9, no. 2, pp. 137-149.

Betton, S, Eckbo, BE \& Thorburn KS 2008, 'Corporate Takeovers', Handbook of Empirical Corporate Finance, vol. 2, pp. 289-427.

Berkovitch, E \& Narayanan, MP 1990, 'Competition and the medium of exchange in takeovers', Review of Financial Studies, vol. 3, no. 2, pp. 153-174.

Berkovitch, E \& Narayanan, MP 1993, 'Motives for takeovers: An Empirical investigation', Journal of Financial and Quantitative Analysis, vol. 28, pp. 347-362.

Bhagat, S, Brickley, JA \& Loewenstein, U 1987, 'The Pricing Effects of Interfirm Cash Tender Offers'. The Journal of Finance, vol. 42, no. 4, pp. 965-986.

Bishop, S, Dodd, P \& Officer, RR 1987, 'Takeovers: The Australian evidence, 1972-1985'. Centre for Independent Studies Monograph 12, pp.16-58

Black, F \& Scholes, M 1973, 'The pricing of options and corporate liabilities', Journal of Political Economy, vol. 81, no. 3, p. 637-654.

Blume, ME \& Stambaugh, RF 1983, 'Biases in computed returns', Journal of Financial Economics, vol. 12 , no. 3, pp. 387-404.

Bollen, NPB, Smith, T \& Whaley, RE 2004, 'Modeling the bid/ask spread: measuring the inventory-holding premium', Journal of Financial Economics, vol. 72, no. 1, pp. 97-141.

Bradley, M 1980, 'Interfirm tender offers and the market for corporate control', The Journal of Business, vol. 53, no. 4, p. 345-376.

Bradley, MH \& Sundaram, AK 2006, 'Do acquisitions drive performance or does performance drive acquisitions?' SSRN Working Paper. 
Bradley, M, Desai, A \& Han Kim, E 1988, 'Synergistic gains from corporate acquisitions and their division between the stockholders of target and acquiring firms', Journal of Financial Economics, vol. 21, no. 1, pp. 3-40.

Brav, A \& Heaton JB 2002, 'Competing theories of financial anomalies', Review of Financial Studies, vol. 15, p. 3-40.

Brown, KC \& Raymond, MV 1986, 'Risk arbitrage and the prediction of successful corporate takeovers', Financial Management, vol. 15, no. 3, p. 54-63.

Brown, P \& Da Silva Rosa, R 1985, 'Research method and the long-run performance of acquiring firms', Australian Journal of Management, vol. 23, no. 1, pp. 23-38.

Bruner, RF 2002, 'Does M\&A Pay? A Survey of Evidence for the Decision-Maker', Journal of Applied Finance, Vol. 12, no. 1, pp. 48-68.

Bugeja, M \& Walter, T 1995, 'An empirical analysis of some determinants of the target shareholder premium in takeovers', Journal of Accounting \& Finance, vol. 35, no. 2, pp. $33-60$.

Bugeja, M \& da Silva Rosa, R 2010, 'Capital gains taxation and shareholder wealth in takeovers', Journal of Accounting \& Finance, vol. 50, no. 2, pp. 241-262.

Campa, JM \& Hernando, I 2004, 'Shareholder Value Creation in European M\&As', European Financial Management, vol. 10, no. 1, pp. 47-81.

Campbell, JY, Grossman, SJ \& Wang, J 1993, 'Trading volume and serial correlation in stock returns', The Quarterly Journal of Economics, vol. 108, no. 4, pp. 905-939.

Casey, R, Dodd, P \& Dolan, P 1987, 'Takeovers and corporate raiders: empirical evidence from extended event studies', Australian Journal of Management, vol. 12, no. 2, pp. 201-220. 
Chae, J 2005, 'Trading volume, information asymmetry, and timing information', Journal of Finance, vol. 60, no.1, pp. 413-442.

Chan, LKC, Jegadeesh, N \& Lakonishok, J 1995, 'Evaluating the performance of value versus glamour stocks the impact of selection bias', Journal of Financial Economics, vol. 38, no. 3, pp. 269-296.

Chen, L, Lesmond, DA \& Wei, J 2007, 'Corporate yield spreads and bond liquidity', Journal of Finance, vol. 62, no. 1, pp. 119-149.

Chordia, T, Roll, R \& Subrahmanyam, A 2001, 'Market liquidity and trading activity', Journal of Finance, vol. 56, no. 2, pp. 501-530.

Collin-Dufresne, P \& Fos, V 2015, 'Do prices reveal the presence of informed trading?' Journal of Finance, vol. 70, no. 4, pp.1555-1582.

Cornelli, F \& Li, DD 2002, 'Risk arbitrage in takeovers', Review of Financial Studies, vol. 15 , no. 3, pp. 837-868.

da Silva Rosa, R, Izan, H, Steinbeck, A, Walter, T 2000, 'The method of payment decision in Australian takeovers: an investigation of causes and effects', Australian Journal of Management, vol. 25, no. 1, pp. 67-94.

Dacorogna, MM, Gencay, R, Muller, UA, \& Pictet, OV 2001, 'Effective return, risk aversion and drawdowns', Physica A: Statistical Mechanics and its Applications, vol. 289, no. $1-2$, pp. $229-248$.

Davidson III, W, N \& Cheng, LTW 1997, 'Target firm returns: does the form of payment affect abnormal returns?' Journal of Business Finance \& Accounting, vol. 24, no. 3, pp. 465-479.

Diamond, DW \& Verrecchia, RE 1987, 'Constraints on short-selling and asset price 
adjustment to private information', Journal of Financial Economics, vol. 18, no. 2, pp. 277-311.

Dodd, P 1976, 'Company takeovers and the Australian equity market', Australian Journal of Management, vol. 1, no. 2, pp. 15-35.

Dodd, P \& Ruback, R 1977, 'Tender offers and stockholder returns: An empirical analysis', Journal of Financial Economics, vol. 5, no. 3, pp. 351-373.

Duarte, J \& Young, L 2009, 'Why is PIN priced?' Journal of Financial Economics, vol 91. no. 2, pp. 119-138.

Dufour, A \& Engle, RF 2000, 'Time and the price impact of a trade', Journal of Finance, vol. 55 , no. 6 , pp. $2467-2498$.

Durnev, A, Morck, R \& Yeung, B 2004, 'Value-enhancing capital budgeting and firmspecific stock return variation', Journal of Finance, vol. 59, no. 1, pp. 65-105.

Easley, D, Engle, RF, O'Hara, M \& Wu L 2007, 'Time-varying arrival rates of informed and uninformed trades', Journal of Financial Econometrics, vol. 6, no. 2, pp. 171-207.

Easley, D, Hvidkjaer, S \& O'Hara, M 2002 'Is information risk a determinant of asset returns?' Journal of Finance, vol. 57, no. 5, pp. 2185-2221.

Easley, D, Hvidkjaer, S \& O’Hara, M 2010 'Factoring Information into Returns'. Journal of Financial and Quantitative Analysis, vol. 45, no. 2 pp. 293-309.

Easley, D \& O'Hara, M 1992, 'Time and the process of security price adjustment', Journal of Finance, vol. 47, no. 2, pp. 577-605.

Easley, D \& O'Hara, M 2004, 'Information and the cost of capital', Journal of Finance, vol. 59, no. 4, pp. 1553-1583. 
Easley, D, O’Hara, M \& Saar G 2001, ‘How stock splits affect trading: a microstructure approach', Journal of Financial and Quantitative Analysis, vol. 36, no. 1, p. 25-51.

Easley, D, Kiefer, NM, O’Hara, M \& Paperman JB 1996, 'Liquidity, information, and infrequently traded stocks', Journal of Finance, vol. 51, no. 4, pp. 1405-1436.

Easley, D, Kiefer, NM \& O'Hara, M 1997, 'The information content of the trading process', Journal of Empirical Finance, vol. 4, no. 2-3, pp. 159-186.

Easley, D, Kiefer, NM, O’Hara, M \& Paperman, JB 1997, 'Liquidity, information, and infrequently traded stocks', Journal of Empirical Finance, vol. 4, no. 2-3, pp. 159-186.

Easley, D, Lopez de Prado, MM \& O’Hara, M 2012, ‘Flow toxicity and liquidity in a highfrequency world', Review of Financial Studies, vol. 25, pp. 1457-1493.

Engle, RF \& Russell, JR 1998, 'Autoregressive conditional duration: a new model for irregularly spaced transaction data', Econometrica, vol. 66, no. 5, p. 1127-1162.

Fama, EF 1970, 'Efficient capital markets: a review of theory and empirical work', Journal of Finance, vol. 25, no. 2, p. 383-417.

Fama, EF \& MacBeth, JD 1973, 'Risk, return, and equilibrium: empirical tests', Journal of Political Economy, vol. 81, no. 3, p. 607-636.

Fama, EF \& French, KR 1993, 'Common risk factors in the returns on stocks and bonds', Journal of Financial Economics, vol. 33, no. 1, pp. 3-56.

Foster, FD \& Viswanathan, S 1990, 'A theory of the interday variations in volume, variance, and trading costs in securities markets', Review of Financial Studies, vol. 3, no. 4, pp. 593-624.

Foster, FD \& Viswanathan, S 1993, 'Variations in trading volume, return volatility, and trading costs: evidence on recent price formation models', Journal of Finance, vol. 48, 
no. 1 , p. 187-211.

Franks, J, Harris, R \& Titman, S 1991, 'The postmerger share price performance of acquiring firms', Journal of Financial Economics, vol. 29, p. 81-96.

Garman, MB 1976, 'Market microstructure', Journal of Financial Economics, vol. 3, no. 3. pp. 257-275.

Glosten, LR 1987, 'Components of the bid-ask spread and the statistical properties of transaction prices', Journal of Finance, vol. 42, no. 5, p. 1293-1307.

Glosten, LR \& Milgrom, PR 1985, 'Bid, ask and transaction prices in a specialist market with heterogeneously informed traders', Journal of Financial Economics, vol. 14, no. 1 , pp. 71-100.

Glosten, LR \& Harris, LE 1988, 'Estimating the components of the bid/ask spread', Journal of Financial Economics, vol. 21, no. 1, pp. 123-142.

Gorton, LR \& Kahl, M 2008, 'Blockholder scarcity, takeovers, and ownership structures', Journal of Financial and Quantitative Analysis, vol. 43, pp. 937-974.

Gugler, K, Mueller, DC, Yurtoglu, BB \& Zulehner, C 2003, 'The effects of mergers: An international comparison', International Journal of Industrial Organization, vol. 21, pp. $625-653$.

Grossman, SJ \& Stiglitz, JE 1976, 'Information and Competitive Price Systems', The American Economic Review, vol. 66, no. 2, pp. 246-253.

McGowan, JJ 1971, 'International comparisons of merger activity', Journal of Law and Economics, vol. 14, no. 1, p. 233-250.

Graham, JR, Koski, JL \& Loewenstein, U 2006, 'Information flow and liquidity around anticipated and unanticipated dividend announcements', Journal of Business, vol. 79, 
no. 5, pp. 2301-2336.

Grossman, SJ \& Hart, OD 1980, 'Disclosure laws and takeover bids', Journal of Finance, vol. 35 , no. 2 , p. 323-334.

Handa, P, Schwartz, R \& Tiwari, A 2003, 'Quote setting and price formation in an order driven market', Journal of Financial Markets, vol. 6, no. 4, pp. 461-489.

Hansen, L, 1982, 'Large sample properties of generalized methods of moments estimators', Econometrica, vol. 50, pp. 1029-1054.

Harford, J, Jenter D \& Li, K 2011, 'Institutional cross-holdings and their effect on acquisition decisions', Journal of Financial Economics, vol. 99, pp. 27-39.

Harris, M, \& Raviv, A 1988, 'Corporate control contests and capital structure', Journal of Financial Economics, vol. 20, pp. 55-86.

Hart-Scott-Rodino Antitrust Improvements Act 1976, 15 U.S.C. § 18a. Pub. L. pp114-138.

Hasbrouck, J 1991, 'Measuring the information content of stock trades', Journal of Finance, vol. 46, no. 1, pp. 179-207.

Heckman, JJ 1976, 'The common structure of statistical models of truncation, sample selection and limited dependent variables and a simple estimator for such models', Annals of Economic and Social Measurement, vol. 5, no. 4, pp. 475-492.

Hsieh, J \& Walkling, RA 2005, 'Determinants and implications of arbitrage holdings in acquisitions', Journal of Financial Economics, vol. 77, pp. 605-648.

Jarrell, GA, Brickley, JA \& Netter, JM 1988, 'The Market for Corporate Control: The Empirical Evidence Since 1980', The Journal of Economic Perspectives, vol. 2, no. 1, p. 49-68. 
Jarrell, GA \& Poulsen, AB 1989, 'The returns to acquiring firms in tender offers: evidence from three decades', Journal of Financial Management, vol. 18, no. 3, p. 12-19.

Jegadeesh, N \& Titman, S 2001, 'Profitability of momentum strategies: an evaluation of alternative explanations', Journal of Finance, vol. 56, no. 2, pp. 699-720.

Jennings, R 1994, 'Intraday changes in target firms' share price and bid-ask quotes around takeover announcements', Journal of Financial Research, vol. 17, no. 2, pp. 255270.

Jensen, MC \& Ruback, RS 1983, 'The market for corporate control', Journal of Financial Economics, vol. 11, no. 1-4, pp. 5-50.

Jensen, MC 1986, 'Agency cost of free cash flow, corporate finance, and takeovers', American Economic Review, vol. 76, no. 2, pp. 323-329.

Kelly, GJ 1981, 'Australian social responsibility disclosure: some insights into contemporary measurement', Journal of Accounting \& Finance, vol. 21, no. 2, pp. 97107.

Kim, O \& Verrecchia, RE 1991, 'Market reaction to anticipated announcements', Journal of Financial Economics, vol. 30, no. 2, pp. 273-309.

Klein, RW \& Bawa, VS 1977, 'The effect of limited information and estimation risk on optimal portfolio diversification', Journal of Financial Economics, vol. 5, no. 1, pp. 89111.

Kreps, DM \& Wilson, R 1982, 'Sequential equilibria', Econometrica, vol. 50, no. 4, p. 863-894.

Kyle, AS 1985, 'Continuous auctions and insider trading', Econometrica, vol. 53, no. 6, p. 1315-1336. 
Lakonishok, J \& Smidt, S 1986, 'Trading bargains in small firms at year-end', Journal of Portfolio Management, vol. 12, no. 3, pp. 24-29.

Lang, LHP \& Stulz, RM 1994, 'Tobin's Q, corporate diversification, and firm performance', Journal of Political Economy, vol. 102, no. 6, p. 1248-1280.

Larker, DF \& Lys, T 1987, 'An empirical analysis of the incentives to engage in costly information acquisition', Journal of Financial Economics, vol. 18, no. 1, pp. 111-126.

Lee, CMC, \& Ready, MJ 1991, 'Inferring trade direction from intraday data', The Journal of Finance, vol. 46, no. 2, pp. 733-746.

Loughran, T \& Vijh, AM 1997, 'Do long-term shareholders benefit from corporate acquisitions?' Journal of Finance, vol. 52, no. 5, p. 1765-1790.

Mandelbrot, B \& Taylor, HM 1967, 'On the distribution of stock price differences', Operations Research, vol. 15, no. 6, pp. 1057-1062.

Manne, HG 1965, 'Mergers and the Market for Corporate Control', The Journal of Political Economy, vol. 73, no. 2, pp. 110-120.

McDougall, FM \& Round, DK 1986, 'The determinants and effects of corporate takeovers in Australia, 1970-1981', The Effects of Mergers \& Takeovers in Australia: Research reports No 3, Australian Institute of Management pp. 27-30.

Mclnish, TH \& Wood, RA 1992, 'An analysis of intraday patterns in bid/ask spreads for NYSE stocks', Journal of Finance, vol. 47, no. 2, p. 753-764.

Merton, RC 1973, 'An intertemporal capital asset pricing model', Econometrica, vol. 41, no. 5, p. $867-887$.

Mitchell, ML \& Mulherin, JH 1996, 'The impact of industry shocks on takeover and restructuring activity', Journal of Financial Economics, vol. 41, no. 2, pp. 193-229. 
Mitchell, M \& Pulvino, T 2001, 'Characteristics of risk and return in risk arbitrage', Journal of Finance, vol. 56, no. 6, pp. 2135-2175.

Mitchell, M, Pulvino, T \& Stafford, E 2004, 'Price Pressure around Mergers', Journal of Finance, vol. 59, no. 1, pp. 31-63.

Moeller, SB, Schlingemann, FP \& Stulz, RM 2005, 'Wealth destruction on a massive scale? A study of acquiring-firm returns in the recent merger wave', Journal of Finance, vol. 60. no. 2, pp. 757-782.

Morck, R, Yeung, B \& Yu, W 2000, 'The information content of stock markets: why do emerging markets have synchronous stock price movements?' Journal of Financial Economics, vol. 58, no. 1-2, pp. 215-260.

Murray, LC 1991, 'A study on the wealth effects of Irish takeovers and mergers', Managerial and Decision Economics, vol. 12, no. 1, pp. 67-72.

Mulherin, JH \& Boone, AL 2000, 'Comparing acquisitions and divestitures', Journal of Corporate Finance, vol. 6, pp. 117-139.

Noe, TH 2002, 'Investor activism and financial market structure', Review of Financial Studies, vol. 15, pp. 289-318.

Nelson, RL 1959, 'Merger Movements In American Industry, 1895-1956'. Princeton University Press

Nelson, SA 1904, 'The ABC of options and arbitrage', New York: S.A. Nelson, 1904. Print

Officer, MS 2003, 'Termination fees in mergers and acquisitions', Journal of Financial Economics, vol. 69, no. 3, pp. 431-467.

Omnibus Trade and Competitiveness Act $1988 \S 5021$, Pub. L. No. pp.100-418, 102 Stat. 
1107. Exon-Florio Amendment Executive Order 13456.

Palepu, KG 1986, 'Predicting takeover targets', Journal of Accounting and Economics, vol. 8, no. 1, pp. 3-35.

Petersen, MA 2009, 'Estimating standard errors in finance panel data sets: comparing approaches', Review of Financial Studies, vol. 22, no. 1, pp. 435-480.

Powell, Ronan G 1997, 'Modelling takeover likelihood', Journal of Business Finance \& Accounting, vol. 24, no. 7-8, pp. 1009-1030.

Ravenscraft, DJ \& Scherer, FM 1989, 'The profitability of mergers', International Journal of Industrial Organization, vol. 7, no. 1, pp. 101-116.

Rhodes-Kropf, M, Robinson, DT \& Viswanathan, S 2005, 'Valuation waves and merger activity: the empirical evidence', Journal of Financial Economics, vol. 77, no. 3, pp. 561603.

Roll, R 1988, 'The stochastic dependence of security price changes and transaction volumes: implications for the mixture of distributions hypothesis', Journal of Finance, vol. 43 , no. 3 , pp. $541-566$.

Securities Act of 1934, 15 U.S.C. §§ 77a-77aa.

Schwert, GW 1996, 'Markup pricing in mergers and acquisitions', Journal of Financial Economics, vol. 41, pp. 153-192.

Shleifer, A \& Vishny, RW 1997, 'The limits of arbitrage', Journal of Finance, vol. 52, no. 1, pp. 35-55.

Sidhu, B, Smith T, Whaley RE \& Willis RH, 2008, 'Regulation fair disclosure and the cost of adverse selection', Journal of Accounting Research, vol. 46, no. 3, pp. 697-728.

Skoulakis, G 2008, 'A recursive formula for computing central moments of a multivariate 
lognormal distribution', American Statistician, vol. 62, no. 2, pp. 147-150.

Stoll, HR 1989, 'Inferring the components of the bid-ask spread: theory and empirical tests', Journal of Finance, vol. 44, no. 1, p. 115-134.

Toke, IM 2011, Econophysics of order-driven markets. Milan: Springer. 2011.

Tenorio, R 1997, 'On strategic quantity bidding in multiple unit auctions', Journal of Industrial Economics, vol. 45, p. 207-2017.

Theissen, E 2001, 'A test of the accuracy of the Lee/ready trade classification algorithm', Journal of International Financial Institutions and Money, vol. 11, no. 2, p. 147-165.

Travlos, NG 1987, 'Corporate takeover bids, methods of payment, and bidding firms' stock returns', Journal of Finance, vol. 42, no. 4, p. 943-963.

United States Statutes at Large, 'Securities Exchange Act of 1934' 15 USCS § 78m Schedule 13D (17 CFR 240.13d-101), pp.105-110.

Walter, TS 1984, 'Australian takeovers: capital market efficiency and shareholder risk and return', Australian Journal of Management, vol. 9, no. 1, pp. 63-118.

Wyart, M, Bouchard, JP, Kockelkoren, J, Potters, M, \& Vettorazzo M 2008, 'Relation between bid\& ask spread, impact and volatility in order-driven markets', Quantitative Finance, vol. 8, no. 1, pp. 41-57.

Zeghal, D 1984, 'Firm size and the information content of financial statements', Journal of Financial and Quantitative Analysis, vol. 19, no. 3, p. 299-310.

Zhang, MY, Russell, JR \& Tsay, RS 2001, 'A nonlinear autoregressive conditional duration model with applications to financial transaction data', Journal of Econometrics, vol. 104, no. 1 , pp. 179-207. 


\section{APPENDICES}

Table A.1. Australian Sample: Impact of Probability of Informed Trading on Takeover Success (observations with block holding greater than $60 \%$ of target firms removed)

Table A.1 shows the estimates of binary logit regression results of takeover outcome on the (PI) measure and controls. The takeover outcome indicator, the dependent variable, is equal to 1 when the takeover is a success and 0 otherwise. The independent variables include the $\log ($ Size), the natural logarithm transformation of market capitalisation of the firm on the day of takeover announcement, calculated as the number of ordinary shares multiplied by the opening share price; Premium 1 Day is a calculated as the difference between the takeover target offer price per share and the closing price per one day prior to the announcement. The indicator variable on takeover method of payment equals 1 when cash is the method of payment and 0 otherwise. The toe hold variable is an indicator of the bidder ownership greater than $5 \%$ in the bidder prior to the takeover announcement equal to 1 and 0 otherwise. The indicator variable of multiple bidders is equal to 1 when there are more than one bidder during the takeover process and 0 if there is only one. The block holding variable is the control for the existence of block holders owning more than $5 \%$ of the target shares on the announcement day equals 1 and 0 otherwise. PI is estimated using Bollen, Smith and Whaley (2004) model, aggregating trade data in 5, 10, 15 and 30 minute trading intervals. The effects of individual firms are controlled by the inverse mills ratio estimated using the 2-step Heckman (1976) procedure to account for sample selection bias by using the closest propensity scored matched firm that is not engaged in any takeover activity. Matching is performed on market capitalisation and industry of operation. Firm year effects controls include a set of indicator variables for each year equal to 1 for the year in which takeover activity takes place and 0 otherwise. Firm industry effects controls include an indicator variable equal to 1 when the takeover occurs with a specific industry (based on 2-digit SIC code categorisation) and 0 otherwise..

\begin{tabular}{|c|c|c|c|c|}
\hline Dependent variable & Outcome & & & \\
\hline Independent variables & $(1)$ & $(2)$ & (3) & $(4)$ \\
\hline Intercept & $\begin{array}{l}-28.708 * * * \\
(-5.149)\end{array}$ & $\begin{array}{l}-28.733^{* * *} \\
(-5.158)\end{array}$ & $\begin{array}{l}-28.708^{* * *} \\
(-5.149)\end{array}$ & $\begin{array}{l}-28.734 * * * \\
(-5.159)\end{array}$ \\
\hline Log(Size) & $\begin{array}{l}-0.3052^{*} \\
(-1.693)\end{array}$ & $\begin{array}{l}-0.3061^{*} \\
(-1.698)\end{array}$ & $\begin{array}{l}-0.3049 * \\
(-1.691)\end{array}$ & $\begin{array}{l}-0.3063^{*} \\
(-1.698)\end{array}$ \\
\hline Premium 1 Day & $\begin{array}{l}-0.0148^{*} \\
(-1.693)\end{array}$ & $\begin{array}{l}-0.0147^{*} \\
(-1.698)\end{array}$ & $\begin{array}{l}-0.0148 * \\
(-1.644)\end{array}$ & $\begin{array}{l}-0.0149 * \\
(-1.699)\end{array}$ \\
\hline D Pay Cash & $\begin{array}{l}1.3631^{* *} \\
(2.191)\end{array}$ & $\begin{array}{l}1.3624^{* *} \\
(2.190)\end{array}$ & $\begin{array}{l}1.3628 * * \\
(2.189)\end{array}$ & $\begin{array}{l}1.3633^{* *} \\
(2.191)\end{array}$ \\
\hline D Toe Hold & $\begin{array}{l}0.0293 \\
(0.048)\end{array}$ & $\begin{array}{l}0.0274 \\
(0.046) \\
\end{array}$ & $\begin{array}{l}0.0288 \\
(0.048) \\
\end{array}$ & $\begin{array}{l}0.0277 \\
(0.460) \\
\end{array}$ \\
\hline D Multiple Bidders & $\begin{array}{l}-0.4824 \\
(-0.060) \\
\end{array}$ & $\begin{array}{l}-0.4821 \\
(-0.600) \\
\end{array}$ & $\begin{array}{l}-0.4829 \\
(-0.601) \\
\end{array}$ & $\begin{array}{l}-0.4821^{*} \\
(-0.600)\end{array}$ \\
\hline D Block Holding & $\begin{array}{l}-0.0338^{* *} \\
(-2.271) \\
\end{array}$ & $\begin{array}{l}-0.0339 * * \\
(-2.269)\end{array}$ & $\begin{array}{l}-0.0338^{* *} \\
(-2.271)\end{array}$ & $\begin{array}{l}-0.0338^{* *} \\
(-2.269) \\
\end{array}$ \\
\hline PI 5 min & $\begin{array}{l}0.3625^{* * *} \\
(3.593)\end{array}$ & & & \\
\hline$P I 10 \mathrm{~min}$ & & $\begin{array}{l}0.3624 * * * \\
(3.591)\end{array}$ & & \\
\hline PI $15 \mathrm{~min}$ & & & $\begin{array}{l}0.3627^{* * *} \\
(3.593) \\
\end{array}$ & \\
\hline$P I 30 \mathrm{~min}$ & & & & $\begin{array}{l}0.3626 * * * \\
(3.592)\end{array}$ \\
\hline PI $\times$ D Block Holding & $\begin{array}{l}-0.1287 \\
(-0.812)\end{array}$ & $\begin{array}{l}-0.1136 \\
(-0.812)\end{array}$ & $\begin{array}{l}-0.1285 \\
(-0.865)\end{array}$ & $\begin{array}{l}-0.1298 \\
(-0.813)\end{array}$ \\
\hline Firm Control Variables & $\mathrm{Y}$ & $\mathrm{Y}$ & $Y$ & $\mathrm{Y}$ \\
\hline Year Effects & $Y$ & $Y$ & $Y$ & $Y$ \\
\hline Industry Effects & $\mathrm{Y}$ & $\mathrm{Y}$ & $\mathrm{Y}$ & $\mathrm{Y}$ \\
\hline Pseudo R squared & 0.473 & 0.472 & 0.473 & 0.476 \\
\hline $\mathrm{N}$ & 161 & 161 & 161 & 161 \\
\hline
\end{tabular}

*indicates significance at $10 \%$ level; **significance at $5 \%$ level; $* * *$ significance at $1 \%$ level 
Table A.2. Australian Sample: Impact of Takeover Success on Probability of Informed Trading

(observations with block holding greater than $60 \%$ of target firms removed)

Table A.2 shows the estimates of linear regression results using Hansen (1982) GMM estimator of the PI measure on the indicator of takeover success and controls. PI is estimated using Bollen, Smith and Whaley (2004) model, aggregating trade data in 5, 10, 15 and 30 minute intervals. The independent variables include the log(Size), the natural logarithm transformation of market capitalisation of the firm on the day of takeover announcement, calculated as the number of ordinary shares multiplied by the opening share price; Premium 1 Day is a calculated as the percentage difference between the takeover target offer price per share and the closing price per one day prior to the announcement. The indicator variable on takeover method of payment equals 1 when cash is the method of payment and 0 otherwise. The toe hold variable is an indicator of the bidder ownership greater than $5 \%$ in the bidder prior to the takeover announcement equal to 1 and 0 otherwise. The indicator variable of multiple bidders is equal to 1 when there are more than one bidder during the takeover process and 0 if there is only one. The block holding variable is the control for the existence of block holders owning more than $5 \%$ of the target shares on the announcement day equals 1 and 0 otherwise. The indicator variable on hostile takeovers equals 1 when the bid is accompanied by a proxy contest or tender offer and 0 otherwise. The Firm fixed effects is the inverse mills ratio estimated using the 2-step Heckman (1976) procedure to account for sample selection bias using the closest matched firm not engaged in any takeover activity based on market capitalisation and industry of operation. Firm year effects include indicator variables for each year equal to 1 for the year in which takeover is announced and 0 otherwise. Firm industry effects include an indicator variable equal to 1 when the takeover occurs within a specific industry based on 2-digit SIC code categorisation and 0 otherwise.

\begin{tabular}{|c|c|c|c|c|}
\hline Dependent variable & $P I 5 \mathrm{~min}$ & $P I 10 \mathrm{~min}$ & $P I 15 \mathrm{~min}$ & $P I 30 \mathrm{~min}$ \\
\hline Independent variables & (1) & $(2)$ & (3) & (4) \\
\hline \multirow[t]{2}{*}{ Intercept } & 3.7816 & 3.7393 & 3.7812 & 3.8595 \\
\hline & $(1.202)$ & $(1.182)$ & $(1.202)$ & $(1.248)$ \\
\hline \multirow[t]{2}{*}{ Log(Size) } & -0.6963 & -0.0843 & -0.0699 & -0.0616 \\
\hline & $(-0.382)$ & $(-0.457)$ & $(-0.384)$ & $(-0.917)$ \\
\hline \multirow[t]{2}{*}{ Premium 1 Day } & $0.0402 * * *$ & $0.0414 * * *$ & $0.0402 * * *$ & $0.0411^{* * *}$ \\
\hline & $(6.729)$ & $(6.741)$ & $(6.732)$ & $(6.816)$ \\
\hline \multirow[t]{2}{*}{ D Pay Cash } & -0.2384 & -0.1623 & -0.2391 & -0.2140 \\
\hline & $(-0.388)$ & $(-0.265)$ & $(-0.389)$ & $(-0.349)$ \\
\hline \multirow[t]{2}{*}{ D Toe Hold } & 0.4767 & 0.4851 & 0.4724 & 0.4593 \\
\hline & $(0.889)$ & $(0.900)$ & $(0.890)$ & $(0.867)$ \\
\hline \multirow[t]{2}{*}{ D Block Holding } & $0.0241 *$ & 0.0216 & $0.0241 *$ & 0.0235 \\
\hline & $(1.675)$ & $(1.429)$ & $(1.678)$ & $(1.614)$ \\
\hline \multirow[t]{2}{*}{ D Hostile } & $-1.3819 *$ & $-1.4289 * *$ & $-1.3819 *$ & $-1.400 *$ \\
\hline & $(-1.825)$ & $(-1.994)$ & $(-1.824)$ & $(-1.844)$ \\
\hline \multirow[t]{2}{*}{ D Success } & $2.5320 * * *$ & $2.5211^{* * *}$ & $2.5322 * * *$ & $2.5236 * * *$ \\
\hline & $(4.233)$ & $(4.199)$ & $(4.234)$ & $(4.242)$ \\
\hline Firm Control Variables & $\mathrm{Y}$ & $\mathrm{Y}$ & $\mathrm{Y}$ & $\mathrm{Y}$ \\
\hline Year Effects & $\mathrm{Y}$ & $\mathrm{Y}$ & $\mathrm{Y}$ & $\mathrm{Y}$ \\
\hline Industry Effects & $\mathrm{Y}$ & $\mathrm{Y}$ & $\mathrm{Y}$ & $\mathrm{Y}$ \\
\hline Adjusted R squared & 0.328 & 0.327 & 0.328 & 0.328 \\
\hline $\mathrm{N}$ & 161 & 161 & 161 & 161 \\
\hline
\end{tabular}

$*$ indicates significance at $10 \%$ level; $* *$ significance at $5 \%$ level; $* * *$ significance at $1 \%$ level 
Table A.3. Australian Sample: Impact of Probability of Informed Trading on Target Firm

\section{Cumulative Abnormal Returns}

(observations with block holding greater than $60 \%$ of target firms removed)

Table A.3 shows the estimates of linear regression results using Hansen (1982) GMM estimator of cumulative abnormal returns (CARs) of the target firm over different time windows after the takeover is announced, on the PI 15min measure and controls. The CAR of target firm shares above the Fama and French (1993) factors, the dependent variables, are calculated at daily frequency for the appropriate event window of takeover announcement. The independent variables include the natural logarithm of firm size expressed as a logarithm of the market capitalisation of the firm on the takeover announcement day. ROA is the return on assets calculated as last reported net income divided by total assets by the target company. Premium 1 Day is the percentage difference of share price one day prior to the takeover announcement and the takeover price contained in the announcement. $P I$ is estimated using Bollen, Smith and Whaley (2004) model, aggregating trade data in 15 minute trading intervals, the results of which are reported in Table 5.2. The indicator variable on takeover method of payment equals 1 when cash is the method of payment and 0 otherwise. The toe hold variable is an indicator of the bidder ownership greater than $5 \%$ in the bidder prior to the takeover announcement equal to 1 and 0 otherwise. The indicator variable of multiple bidders is equal to 1 when there are more than one bidder during the takeover process and 0 if there is only one. The block holding variable is the control for the existence of block holders owning more than $5 \%$ of the target shares on the announcement day equals 1 and 0 otherwise. Control for the firm effects is the inverse mills ratio estimated using the 2-step Heckman (1976) procedure to account for sample selection bias using the closest firm matched on market capitalisation and industry of operation not engaged in any takeover activity. Firm year effects include indicator variables for each year equal to 1 for the year in which takeover is announced and 0 otherwise. Firm industry effects include an indicator variable equal to 1 when the takeover occurs with a specific industry based on 2-digit SIC code categorisation and 0 otherwise.

\begin{tabular}{lllll} 
Dependent variable & CAR $[0,+1]$ & CAR $[0,+5]$ & \multicolumn{1}{c}{ CAR $[0,+10]$} & CAR $[0,+30]$ \\
\hline \hline Independent variables & \multicolumn{1}{c}{$(1)$} & \multicolumn{1}{c}{$(2)$} & \multicolumn{1}{c}{$(3)$} & $(4)$ \\
\hline \hline Intercept & $30.595^{* *}$ & 20.194 & 21.317 & 39.357 \\
& $(2.674)$ & $(1.576)$ & $(1.331)$ & $(1.626)$ \\
\hline Log(Size) & -0.8533 & -0.5078 & -1.2259 & -0.3688 \\
& $(-1.139)$ & $(-0.797)$ & $(-1.754)$ & $(-0.294)$ \\
\hline ROA & $6.369^{* *}$ & 5.914 & 6.999 & 12.402 \\
& $(1.845)$ & $(1.246)$ & $(1.201)$ & $(1.312)$ \\
\hline Premium 1 Day & $0.0864^{*}$ & 0.0292 & 0.0661 & -0.0010 \\
& $(1.696)$ & $(0.637)$ & $(0.928)$ & $(-0.012)$ \\
\hline D Pay Cash & $0.5719^{* *}$ & $3.3378^{* *}$ & $1.466^{* *}$ & $3.2468^{* *}$ \\
& $(2.062)$ & $(2.327)$ & $(2.253)$ & $(2.291)$ \\
\hline D Toe Hold & 1.5409 & 1.7899 & 0.9343 & 1.6782 \\
& $(0.525)$ & $(0.718)$ & $(0.365)$ & $(0.441)$ \\
\hline D Block Holding & -0.0591 & $-0.1021^{*}$ & -0.0843 & -0.0713 \\
& $(-0.895)$ & $(-1.745)$ & $(-1.090)$ & $(-0.787)$ \\
\hline D Success & $5.8811^{* * *}$ & $7.0447^{* * *}$ & $10.5209^{* * *}$ & $15.8306^{* * *}$ \\
& $(2.782)$ & $(2.719)$ & $(2.687)$ & $(3.441)$ \\
\hline PI 15 min & $3.1411^{* * *}$ & $2.0346^{* * *}$ & $2.0961^{* * *}$ & $3.4798^{* * *}$ \\
& $(2.745)$ & $(2.698)$ & $(2.686)$ & $(2.684)$ \\
\hline D Success $\times$ & $0.8146^{* *}$ & $1.0425^{* *}$ & $0.6553^{* *}$ & $0.8829^{* *}$ \\
PI 15 min & $(1.893)$ & $(1.845)$ & $(1.853)$ & $(1.862)$ \\
\hline D Block Holding x & 0.8685 & 0.3498 & 0.7425 & 1.0651 \\
PI 15 min & $(1.354)$ & $(1.369)$ & $(0.845)$ & $(0.998)$ \\
\hline Firm Control Variables & $\mathrm{Y}$ & $\mathrm{Y}$ & $\mathrm{Y}$ & $\mathrm{Y}$ \\
\hline Year Effects & $\mathrm{Y}$ & $\mathrm{Y}$ & $\mathrm{Y}$ & $\mathrm{Y}$ \\
\hline Industry Effects & $\mathrm{Y}$ & $\mathrm{Y}$ & $\mathrm{Y}$ & $\mathrm{Y}$ \\
\hline Adjusted R squared & 0.336 & 0.359 & 0.313 & 0.316 \\
N & 161 & 161 & 161 & 161 \\
\hline \hline
\end{tabular}

$*$ indicates significance at $10 \%$ level; $* *$ significance at $5 \%$ level; $* * *$ significance at $1 \%$ level 
Table A.4. Australian Sample: Impact of Probability of Informed Trading on Takeover Success One Week Prior to Announcement

Table A.4 shows the estimates of binary logit regression results of takeover outcome on the $(P I)$ measure and controls. The takeover outcome indicator, the dependent variable, is equal to 1 when the takeover is a success and 0 otherwise. The independent variables include the $\log (\mathrm{Size})$, the natural logarithm transformation of market capitalisation of the firm on the day of takeover announcement, calculated as the number of ordinary shares multiplied by the opening share price; Premium 1 Day is a calculated as the difference between the takeover target offer price per share and the closing price per one day prior to the announcement. The indicator variable on takeover method of payment equals 1 when cash is the method of payment and 0 otherwise. The toe hold variable is an indicator of the bidder ownership greater than $5 \%$ in the bidder prior to the takeover announcement equal to 1 and 0 otherwise. The indicator variable of multiple bidders is equal to 1 when there are more than one bidder during the takeover process and 0 if there is only one. The block holding variable is the control for the existence of block holders owning more than $5 \%$ of the target shares on the announcement day equals 1 and 0 otherwise. PI is estimated using Bollen, Smith and Whaley (2004) model, aggregating trade data in 5, 10, 15 and 30 minute trading intervals. The effects of individual firms are controlled by the inverse mills ratio estimated using the 2-step Heckman (1976) procedure to account for sample selection bias by using the closest propensity scored matched firm that is not engaged in any takeover activity. Matching is performed on market capitalisation and industry of operation. Firm year effects controls include a set of indicator variables for each year equal to 1 for the year in which takeover activity takes place and 0 otherwise. Firm industry effects controls include an indicator variable equal to 1 when the takeover occurs with a specific industry (based on 2-digit SIC code categorisation) and 0 otherwise.

\begin{tabular}{|c|c|c|c|c|}
\hline \multirow{2}{*}{$\begin{array}{l}\text { Dependent variable } \\
\text { Independent variables }\end{array}$} & \multicolumn{2}{|c|}{ Outcome } & \multirow[b]{2}{*}{ (3) } & \multirow[b]{2}{*}{ (4) } \\
\hline & (1) & $(2)$ & & \\
\hline \multirow[t]{2}{*}{ Intercept } & $-18.109 * * *$ & $-18.110 * * *$ & $-18.108 * * *$ & $-18.109 * * *$ \\
\hline & $(-4.972)$ & $(-4.721)$ & $(-4.971)$ & $(-4.978)$ \\
\hline \multirow[t]{2}{*}{$\log ($ Size) } & $-0.3331 * *$ & $-0.3324 * *$ & $-0.3346 * *$ & $-0.3339 * *$ \\
\hline & $(-2.144)$ & $(-2.146)$ & $(-2.143)$ & $(-2.148)$ \\
\hline \multirow[t]{2}{*}{ Premium 1 Day } & 0.0003 & 0.0003 & 0.0004 & 0.0003 \\
\hline & $(0.043)$ & $(0.042)$ & $(0.043)$ & $(0.041)$ \\
\hline \multirow[t]{2}{*}{ D Pay Cash } & $1.8785^{* *}$ & 0.8579 & 0.8580 & 0.8578 \\
\hline & $(2.088)$ & (1.610) & $(1.611)$ & $(1.604)$ \\
\hline \multirow[t]{2}{*}{ D Toe Hold } & 1.8579 & $1.8785^{* *}$ & $1.8783^{* *}$ & $1.8783^{* *}$ \\
\hline & $(1.610)$ & $(2.089)$ & $(2.088)$ & $(2.087)$ \\
\hline \multirow[t]{2}{*}{ D Multiple Bidders } & $-1.2835^{*}$ & $-1.2835^{*}$ & $-1.2865^{*}$ & $-1.2836^{*}$ \\
\hline & $(-1.665)$ & $(-1.665)$ & $(-1.667)$ & $(-1.678)$ \\
\hline \multirow[t]{2}{*}{ D Block Holding } & $-1.3423^{*}$ & $-1.3433^{*}$ & $-1.3426^{*}$ & $-1.3428^{*}$ \\
\hline & $(-1.661)$ & $(-1.651)$ & $(-1.662)$ & $(-1.664)$ \\
\hline \multirow[t]{2}{*}{ PI $5 \mathrm{~min}$} & 0.1010 & & & \\
\hline & $(1.388)$ & & & \\
\hline \multirow[t]{2}{*}{ PI $10 \mathrm{~min}$} & & 0.1011 & & \\
\hline & & $(1.389)$ & & \\
\hline \multirow[t]{2}{*}{ PI $15 \mathrm{~min}$} & & & 0.1019 & \\
\hline & & & $(1.378)$ & \\
\hline \multirow[t]{2}{*}{ PI $30 \mathrm{~min}$} & & & & 0.1009 \\
\hline & & & & $(1.386)$ \\
\hline \multirow[t]{2}{*}{ PI $\times$ D Block Holding } & 0.0491 & 0.0481 & 0.0491 & 0.0492 \\
\hline & $(0.400)$ & $(0.401)$ & $(0.407)$ & $(0.403)$ \\
\hline Firm Control Variables & Y & $Y$ & Y & $Y$ \\
\hline Year Effects & $\mathrm{Y}$ & $\mathrm{Y}$ & $\mathrm{Y}$ & $\mathrm{Y}$ \\
\hline Industry Effects & $\mathrm{Y}$ & $Y$ & $\mathrm{Y}$ & $Y$ \\
\hline Pseudo R squared & 0.349 & 0.392 & 0.389 & 0.369 \\
\hline $\mathrm{N}$ & 172 & 172 & 172 & 172 \\
\hline
\end{tabular}

*indicates significance at $10 \%$ level; **significance at $5 \%$ level; ***significance at $1 \%$ level 


\section{Table A.5. Australian Sample: Impact of Probability of Informed Trading One Week prior}

to Announcement on Target Firm Cumulative Abnormal Returns

Table A.5 shows the estimates of linear regression results using Hansen (1982) GMM estimator of cumulative abnormal returns (CARs) of the target firm over different time windows after the takeover is announced, on the PI 15min measure and controls. The CAR of target firm shares above the Fama and French (1993) factors, the dependent variables, are calculated at daily frequency for the appropriate event window of takeover announcement. The independent variables include the natural logarithm of firm size expressed as a logarithm of the market capitalisation of the firm on the takeover announcement day. ROA is the return on assets calculated as last reported net income divided by total assets by the target company. Premium 1 Day is the percentage difference of share price one day prior to the takeover announcement and the takeover price contained in the announcement. PI is estimated using Bollen, Smith and Whaley (2004) model, aggregating trade data in 15 minute trading intervals, the results of which are reported in Table 5.2. The indicator variable on takeover method of payment equals 1 when cash is the method of payment and 0 otherwise. The toe hold variable is an indicator of the bidder ownership greater than $5 \%$ in the bidder prior to the takeover announcement equal to 1 and 0 otherwise. The indicator variable of multiple bidders is equal to 1 when there are more than one bidder during the takeover process and 0 if there is only one. The block holding variable is the control for the existence of block holders owning more than $5 \%$ of the target shares on the announcement day equals 1 and 0 otherwise. Control for the firm effects is the inverse mills ratio estimated using the 2-step Heckman (1976) procedure to account for sample selection bias using the closest firm matched on market capitalisation and industry of operation not engaged in any takeover activity. Firm year effects include indicator variables for each year equal to 1 for the year in which takeover is announced and 0 otherwise. Firm industry effects include an indicator variable equal to 1 when the takeover occurs with a specific industry based on 2-digit SIC code categorisation and 0 otherwise.

\begin{tabular}{|c|c|c|c|c|}
\hline Dependent variable & CAR $[0,+1]$ & CAR $[0,+5]$ & CAR $[0,+10]$ & CAR $[0,+30]$ \\
\hline Independent variables & $(1)$ & $(2)$ & (3) & (4) \\
\hline \multirow[t]{2}{*}{ Intercept } & $26.7021 * * *$ & $16.1683 * *$ & 11.7109 & $31.2837^{*}$ \\
\hline & $(2.878)$ & $(2.206)$ & $(1.395)$ & $(1.858)$ \\
\hline \multirow[t]{2}{*}{$\log ($ Size) } & -0.6427 & -1.0318 & $-1.6388^{*}$ & $-1.460 *$ \\
\hline & $(-1.001)$ & $(-1.608)$ & $(-1.833)$ & $(-1.831)$ \\
\hline \multirow[t]{2}{*}{ ROA } & $5.4617^{*}$ & 6.4894 & 7.4093 & 12.765 \\
\hline & $(1.767)$ & $(1.382)$ & $(1.318)$ & $(1.415)$ \\
\hline \multirow[t]{2}{*}{ Premium 1 Day } & $0.1159 * *$ & 0.0189 & 0.0636 & 0.0813 \\
\hline & $(2.438)$ & $(0.403)$ & $(0.845)$ & $(0.414)$ \\
\hline \multirow[t]{2}{*}{ D Pay Cash } & $1.4518^{* *}$ & 3.0288 & 1.1267 & 1.9614 \\
\hline & $(2.260)$ & $(1.260)$ & $(0.435)$ & $(0.565)$ \\
\hline \multirow[t]{2}{*}{ D Toe Hold } & 1.0840 & 1.9234 & 0.8349 & 3.4201 \\
\hline & $(0.391)$ & $(0.686)$ & $(0.268)$ & $(0.618)$ \\
\hline \multirow[t]{2}{*}{ D Block Holding } & -6.3224 & -0.0149 & -0.0236 & -0.0225 \\
\hline & $(-1.177)$ & $(-0.273)$ & $(-0.358)$ & $(-0.261)$ \\
\hline \multirow[t]{2}{*}{ D Success } & $2.4587^{* *}$ & $6.4669 * * *$ & $9.3299 * * *$ & $16.539 * * *$ \\
\hline & $(2.423)$ & (3.757) & $(3.106)$ & (3.444) \\
\hline \multirow[t]{2}{*}{ PI 15 min } & 0.7568 & 0.0175 & 0.1811 & 0.9218 \\
\hline & $(1.186)$ & $(1.030)$ & $(1.029)$ & $(1.563)$ \\
\hline D Success $x$ & 1.2122 & 1.0125 & 0.7359 & 0.3095 \\
\hline$P I 15 \mathrm{~min}$ & $(1.610)$ & & $(0.689)$ & $(0.271)$ \\
\hline D Block Holding $\mathrm{x}$ & 0.8794 & 0.3539 & 0.7359 & 0.0963 \\
\hline$P I 15 \mathrm{~min}$ & $(1.347)$ & $(0.524)$ & $(0.689)$ & $(0.699)$ \\
\hline Firm Control Variables & $\mathrm{Y}$ & $\mathrm{Y}$ & $\mathrm{Y}$ & $\mathrm{Y}$ \\
\hline Year Effects & $\mathrm{Y}$ & $\mathrm{Y}$ & $\mathrm{Y}$ & $\mathrm{Y}$ \\
\hline Industry Effects & $\mathrm{Y}$ & $\mathrm{Y}$ & $Y$ & $\mathrm{Y}$ \\
\hline Adjusted R squared & 0.215 & 0.227 & 0.203 & 0.186 \\
\hline $\mathrm{N}$ & 172 & 172 & 172 & 172 \\
\hline
\end{tabular}

$*$ indicates significance at $10 \%$ level; $* *$ significance at $5 \%$ level; $* * *$ significance at $1 \%$ level 


\section{Table A.6. Australian Sample: Impact of Takeover Success on Probability of Informed Trading One Week Prior to Announcement}

Table A.6 shows the estimates of linear regression results using Hansen (1982) GMM estimator of the PI measure on the indicator of takeover success and controls. PI is estimated using Bollen, Smith and Whaley (2004) model, aggregating trade data in 5, 10, 15 and 30 minute intervals. The independent variables include the $\log (\mathrm{Size})$, the natural logarithm transformation of market capitalisation of the firm on the day of takeover announcement, calculated as the number of ordinary shares multiplied by the opening share price; Premium 1 Day is a calculated as the percentage difference between the takeover target offer price per share and the closing price per one day prior to the announcement. The indicator variable on takeover method of payment equals 1 when cash is the method of payment and 0 otherwise. The toe hold variable is an indicator of the bidder ownership greater than $5 \%$ in the bidder prior to the takeover announcement equal to 1 and 0 otherwise. The indicator variable of multiple bidders is equal to 1 when there are more than one bidder during the takeover process and 0 if there is only one. The block holding variable is the control for the existence of block holders owning more than $5 \%$ of the target shares on the announcement day equals 1 and 0 otherwise. ROA is the return on assets calculated as last reported net income divided by total assets by the target company. The indicator variable on hostile takeovers equals 1 when the bid is accompanied by a proxy contest or tender offer and 0 otherwise. The Firm fixed effects is the inverse mills ratio estimated using the 2-step Heckman (1976) procedure to account for sample selection bias using the closest matched firm not engaged in any takeover activity based on market capitalisation and industry of operation. Firm year effects include indicator variables for each year equal to 1 for the year in which takeover is announced and 0 otherwise. Firm industry effects include an indicator variable equal to 1 when the takeover occurs within a specific industry based on 2-digit SIC code categorisation and 0 otherwise.

\begin{tabular}{|c|c|c|c|c|}
\hline Dependent variable & $P I 5 \mathrm{~min}$ & $P I 10 \mathrm{~min}$ & $P I 15 \mathrm{~min}$ & $P I 30 \mathrm{~min}$ \\
\hline Independent variables & (1) & $(2)$ & (3) & (4) \\
\hline \multirow[t]{2}{*}{ Intercept } & 4.5375 & 4.5374 & 4.5401 & 4.5528 \\
\hline & $(1.165)$ & $(1.164)$ & $(1.165)$ & $(1.168)$ \\
\hline \multirow[t]{2}{*}{ Log(Size) } & $0.5037^{* *}$ & $0.5037^{* *}$ & $0.5028 * *$ & $0.5044 * *$ \\
\hline & $(2.415)$ & $(2.415)$ & $(2.409)$ & $(2.421)$ \\
\hline \multirow[t]{2}{*}{ Premium 1 Day } & 0.0025 & 0.0025 & 0.0025 & 0.0025 \\
\hline & $(0.204)$ & $(0.204)$ & $(0.206)$ & $(0.209)$ \\
\hline \multirow[t]{2}{*}{ D Pay Cash } & -0.1156 & -0.1156 & -0.1134 & -0.1172 \\
\hline & $(-0.165)$ & $(-0.165)$ & $(-0.162)$ & $(-0.167)$ \\
\hline \multirow[t]{2}{*}{ D Toe Hold } & -0.1431 & -0.1431 & -0.1411 & -0.1434 \\
\hline & $(-0.240)$ & $(-0.240)$ & $(-0.237)$ & $(-0.241)$ \\
\hline \multirow[t]{2}{*}{ D Block Holding } & 0.0043 & 0.0043 & 0.0042 & 0.0043 \\
\hline & $(0.297)$ & $(0.296)$ & $(0.293)$ & $(0.298)$ \\
\hline \multirow[t]{2}{*}{ ROA } & $2.6339 * * *$ & $2.6339 * * *$ & $2.6336 * * *$ & $2.6315^{* * *}$ \\
\hline & $(3.468)$ & (3.468) & $(3.465)$ & $(3.468)$ \\
\hline \multirow[t]{2}{*}{ D Hostile } & $-2.0536 * *$ & $-2.0536 * *$ & $-2.0520 * *$ & $-2.0519 * *$ \\
\hline & $(-2.594)$ & $(-2.594)$ & $(-2.590)$ & $(-2.593)$ \\
\hline \multirow[t]{2}{*}{ D Success } & 0.9573 & 0.9574 & 0.9586 & 0.9554 \\
\hline & $(1.470)$ & $(1.471)$ & $(1.472)$ & $(1.467)$ \\
\hline Firm Control Variables & $\mathrm{Y}$ & $Y$ & $\mathrm{Y}$ & $Y$ \\
\hline Year Effects & $\mathrm{Y}$ & Y & $Y$ & Y \\
\hline Industry Effects & $\mathrm{Y}$ & $Y$ & $Y$ & Y \\
\hline Adjusted R squared & 0.084 & 0.084 & 0.083 & 0.079 \\
\hline $\mathrm{N}$ & 172 & 172 & 172 & 172 \\
\hline
\end{tabular}

*indicates significance at $10 \%$ level; $* *$ significance at $5 \%$ level; $* * *$ significance at $1 \%$ level 